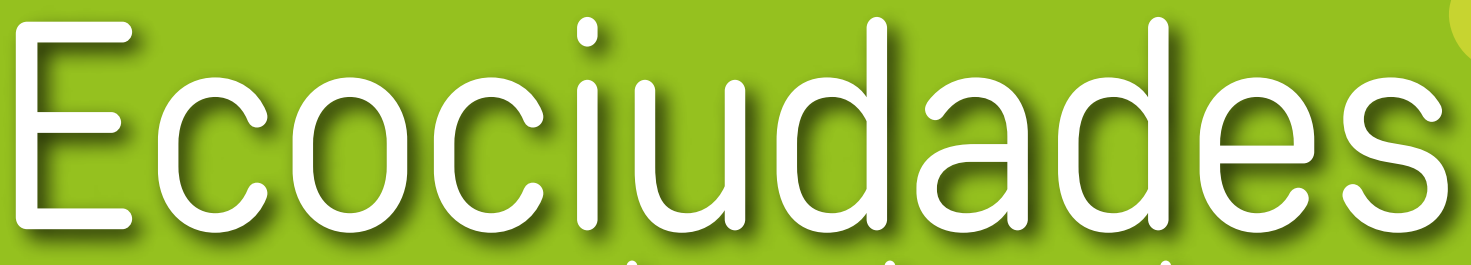

\title{
una experiencia urbana
}

Compilador

Carlos Alberto Lopera Quiroz
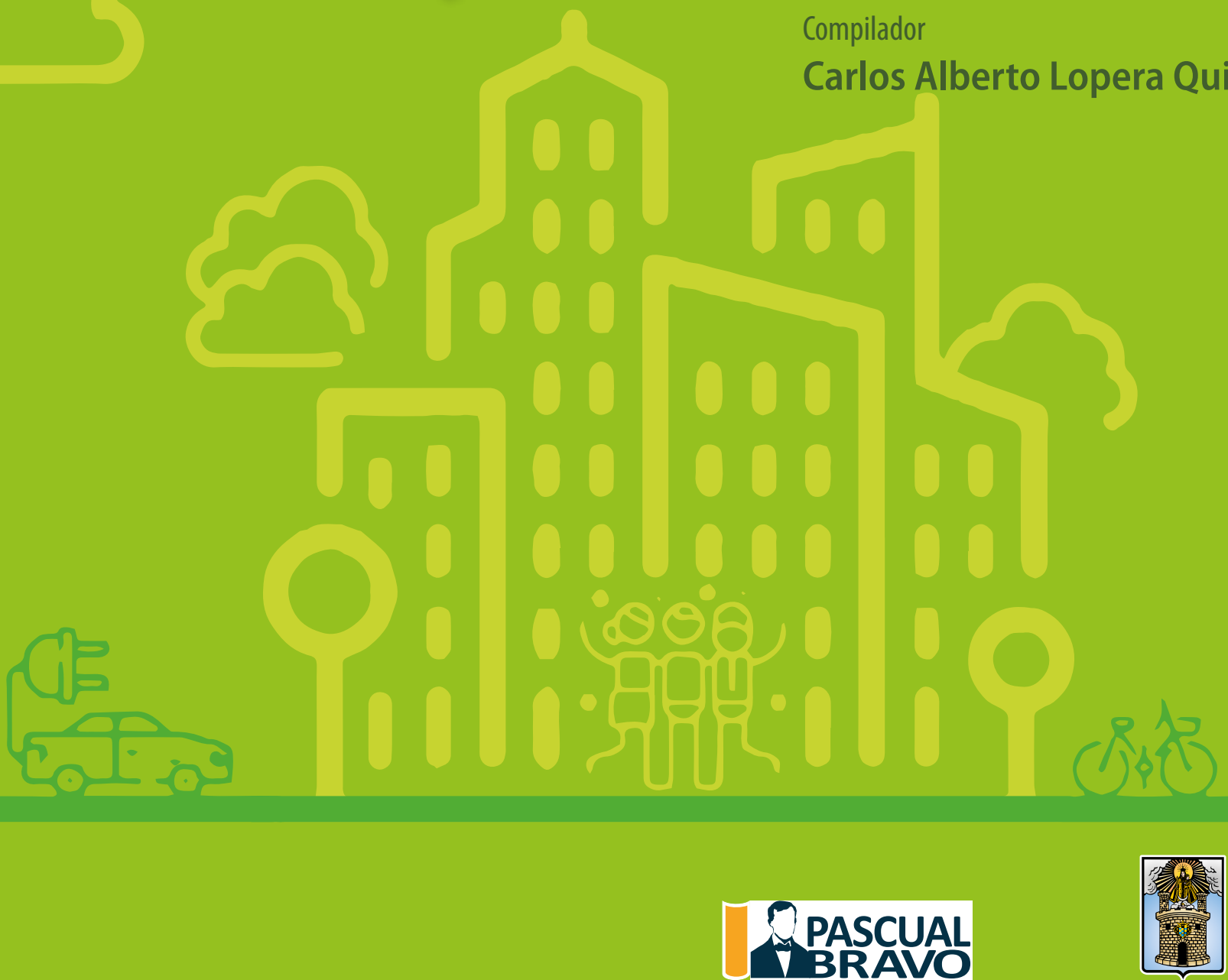

Alcaldía de Medellín 


\section{Ecociudades \\ una experiencia urbana}

Compilador

Carlos Alberto Lopera Quiroz 
333.7

E26 Ecociudadaes. Una experiencia urbana. / Compilado por Carlos Alberto Lopera Quiroz . -Medellín : IUPB, 2020

183 Páginas 19 x 23 Cms. (Serie Investigación)

ISBN: 978-958-52963-2-9

1. DESARROLLO SOSTENIBLE-INVESTIGACION -2. SOSTENIBILIDAD AMBIENTAL-INVESTIGACION

Ecociudades

Serie Investigación

Primera edición: diciembre de 2020

ISBNe: 978-958-52963-2-9

Compilador Carlos Alberto Lopera Quiroz

Rector

Juan Pablo Arboleda Gaviria

Vicerrectora de Investigación y Extensión

Carmen Elena Úsuga Osorio

Diagramación: Leonardo Sánchez Perea Corrección de texto: María Edilia Montoya Loaiza Coordinación editorial: Johana Martínez Ramírez

Editado en Medellín, Colombia Fondo Editorial Pascual Bravo Institución Universitaria Pascual Bravo Calle 73 No. 73 A - 226 - Tel. $(57+4) 4480520$ fondoeditorial@pascualbravo.edu.co www.pascualbravo.edu.co Medellín - Colombia

Las ideas expresadas en la obra aquí contenida son manifestaciones del pensamiento individual de sus autores, en esa medida, no representan el pensamiento de la Institución Universitaria Pascual Bravo, siendo ellos los únicos responsables por los eventuales daños o perjuicios que pudieran causar con lo expresado o por la vulneración de los derechos de autor de terceros en los que hubiesen podido incurrir en su creación.

Está prohibido todo uso de la obra que atente contra los derechos de autor y el acceso abierto. Esta obra está protegida a través de la licencia Creative Commons: Reconocimiento-No comercial 4.0 Internacional.

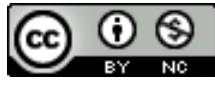




\section{Contenido}

La sostenibilidad, clave principal del campus inteligente

Carlos Alberto Lopera Quiroz

Bicicletas de carga: una mirada al futuro, retomando el pasado. Caso: LOLA Te Mueve

Economía del comportamiento, circular y colaborativa, tríptico virtuoso para Medellín como ecociudad

Fernando De Jesús Franco Cuartas

Economía circular: retos para la academia y el sector productivo

desde la investigación científica

Jorge Amado Rentería Vera, Luisa Fernanda López Gómez, Yesit Jovan Rodríguez Caro

y Chárol Kátherin Vélez Castañeda

Advertcaring: hibridación publicitaria para el bienestar

Juan-Diego López-Medina y Sofía Rojas Quintero

El traje: valores poéticos de la creación en un performance de ciudad

Juan Sebastián Hernández Olave y Andrés Mauricio López Galeano

Industria 4.0 para la competitividad en el sector textil, confección, diseño y moda de Medellín: aplicación del escaneo 3D para estudios antropométricos 


\section{La sostenibilidad, clave principal del campus inteligente}

Carlos Alberto Lopera Quiroz ${ }^{1}$

Como parte del proceso de construcción del modelo de Campus Verde, Inteligente e Inclusivo de la Institución Universitaria Pascual Bravo, en el marco del Plan de desarrollo 2019-2022 «La Transformación Continúa», se realizó este estudio con el fin de dar respuesta a la pregunta de investigación que busca encontrar las tendencias en programas, planes o estrategias que en torno a la sostenibilidad se desarrollan en los campus inteligentes y poder así reunir elementos para el modelo que consientan emprender acciones que desde el campus universitario impacten la ciudad de Medellín e incidan en la consecución de los objetivos de desarrollo sostenible, en especial, aquellos que aluden a la educación con calidad, las ciudades sostenibles e inteligentes, el medio ambiente y la energía asequible y no contaminante.

En este sentido, se plantean en este capítulo cinco apartados; en el primero se aborda el concepto de campus inteligente como una organización con una infraestructura y unas herramientas inteligentes, que a través de la obtención de datos gestiona y asume decisiones eficientes para mejorar sus servicios, sus recursos y su sostenibilidad; en el segundo apartado se hace una presentación de la bibliometría y como esta ayuda a descubrir tendencias de investigación. Aquí se detalla la metodología implementada con la extracción de información en la base de datos Web of Science y su tratamiento en el software de uso libre para análisis bibliométrico VOSViewer; en el tercer apartado se muestran los resultados obtenidos mediante tres figuras y una tabla: en la figura 1 muestra la red de visualización de coocurrencia de palabras inicial; en la figura 2 muestra la red de visualización de coocurrencia de palabras, posterior a la eliminación de las duplicidades a los resultados; en la

Maestrando Gestión Estratégica de la Información y el Conocimiento, especialista en Alta Gerencia, administrador de empresas; docente, director Grupo de Investigación Icono, de la Institución Universitaria Pascual Bravo. Correo electrónico: c.lopera@pascualbravo.edu.co 
figura 3 muestra la red de visualización de densidad de clúster. En la tabla 1 se fortalecen los hallazgos mostrados en la figura 2 y se detallan los cinco clústeres encontrados con sus palabras claves y con el porcentaje de fuerza de cada palabra y clúster. En este apartado se aprecia la estrecha relación que existe entre el campus inteligente, la sostenibilidad y la ciudad inteligente. Con base en los resultados, en el apartado cuatro se realiza una exploración de investigaciones que han abordado los hallazgos del estudio y la visión y relevancia de la sostenibilidad dentro de los mismos. Finalmente, el apartado cinco presenta las conclusiones del análisis, soportadas en el análisis bibliométrico y las fuerzas del enlace y de clúster de la tabla 1.

\section{El campus inteligente}

Una de las definiciones que más tráfico de red presenta el concepto de campus inteligente, en Google, remite al tercer libro de la colección Ideas de educación virtual, titulado Bimodalidad: artículación y convergencia en la educación superior, de la Universidad Nacional de Quilmes (Argentina). En este se define el término de la siguiente manera:

El concepto de Universidad Inteligente se sustenta sobre la idea de las Universidades como «organizaciones que aprenden», ya que se conciben como organizaciones flexibles y creativas, con capacidad de adaptación a un entorno donde el aprendizaje organizativo se vuelve el instrumento esencial que garantiza la supervivencia de las organizaciones, en general, y de las universidades, en particular, en el siglo XXI. (Tkachuk, 2016)

Para abordar de una forma más holística el concepto, se realizó una exploración que nos permitiera entender y dimensionar los elementos que giran alrededor de este. Algunos estudios han incluido - dentro de los aspectos más relevantes de los campus inteligentes- la convergencia entre recursos físicos y tecnológicos, la gestión del conocimiento, la utilización dentro del campus de las tecnologías de la información y la comunicación, el internet de las cosas, el big data, la computación en la nube y su implicación en la gestión sostenible (Popoola et al. (2018); Galeano y otros (2018); Wu et al. (2020)). Por su parte, Min-Allah $\mathcal{E}$ Alrashed (2020) asocian la impor- 
tancia de conjugar la infraestructura física con tecnologías inteligentes con el ánimo de mejorar los servicios que se ofrecen, la obtención de datos para la toma de decisiones y la sostenibilidad. Estas tecnologías giran en torno al internet de las cosas (interacción de dispositivos y objetos a través de una red) y a todas las soluciones que a través de la conexión de dispositivos se podrían ofrecer para mejorar la calidad de vida de la comunidad académica, las condiciones medioambientales de los campus y para alentar procesos de innovación y mejoramiento continuo. Así, al integrar los espacios físicos con dispositivos y herramientas digitales inteligentes, se obtendrán datos e información para hacer del campus un entorno productivo, creativo y sostenible (Chiu et al. (2020); Fernández E Fraga, 2019).

Una de las herramientas principales de los campus son los sensores - como receptores de datos - procesados y convertidos en información para alimentar los procesos administrativos, desde varias perspectivas: estratégica, funcional, financiera, física y de gestión (Valks, Arkesteijn et al., 2019). Estratégicamente, se mejoraría la calidad de vida de la comunidad académica en el campus, se estimularía la colaboración y la innovación. Funcionalmente, al tener información se podrían flexibilizar procesos y desarrollar servicios inteligentes avanzados (Jurva et al., 2020). En el aspecto financiero, le permitiría al campus aumentar ingresos y disminuir costos. Físicamente, se impactaría el medio ambiente a través de la optimización de la infraestructura, por cuanto elementos como la calefacción, la ventilación y la iluminación favorecerían un ahorro de energía. En el proceso de gestión, admitiría optimizar recursos educativos, financieros, energéticos y humanos (Valks, Arkesteijn, Koutamanis et al., 2020).

\section{La bibliometría aplicada a la investigación científica}

Es una técnica que aplica las matemáticas y la estadística para analizar la información relacionada con la producción científica que es difundida a través de diferentes medios, entre ellos, los libros, capítulos de libro, revistas y artículos de investigación. Permite identificar tendencias, temas y clúster de conocimiento de diferentes redes y comunidades científicas (Arbeláez y Onrubia, 2014). Su análisis arroja datos estadísticos como resultado del estudio cuantitativo de material bibliográfico (Leyva y otros 2019). Se considera una 
poderosa herramienta de investigación que puede representar la naturaleza y especificidad de diferentes disciplinas (Zhang et al. 2016) a partir de la utilización de diferentes softwares desarrollados para equipos de cómputo e internet (Merigó y Yang, 2017).

En este estudio se realizó un análisis bibliométrico en la base de datos Web of Science (en adelante, WOS). WOS es una plataforma digital que desde el año 1900 recoge citas y revistas de las principales publicaciones del conocimiento científico, tecnológico y humanístico del mundo (Delgado y otros, 2019); así mismo, es reconocida por los investigadores por sus altos estándares de calidad, por tanto, provee a sus usuarios metadatos que facilitan realizar análisis de resúmenes, referencias, número de citaciones, autores, países, instituciones financiadoras y factores de impacto. Incluye más de quince mil revistas, cincuenta millones de documentos, clasificados en doscientos cincuenta y un categorías y ciento cincuenta y un áreas temáticas de investigación (Gaviria y otros, 2019).

El análisis de la base de datos se realizó durante los meses de junio y julio de 2020 a través del acceso que brinda a WOS el gobierno de España, el Ministerio de Ciencia, Innovación y Universidades, y la Fundación Española para la Ciencia y la Tecnología (Fecyt), a través de la Universitat Oberta de Catalunya. El criterio de búsqueda utilizó palabras claves y operadores boleanos con la ecuación Smart camp * AND Sustainability.

El resultado de la ecuación de búsqueda fue analizado en el software de uso libre VOSviewer, versión 1.6.15. Este software, desarrollado por el Centro de Estudios en Ciencia y Tecnología de la Universidad de Leiden, ofrece la funcionalidad de minería de texto que se puede utilizar para construir y visualizar redes de coincidencia de términos importantes extraídos de un cuerpo de literatura científica (Guo et al., 2019).

En el caso de VOSviewer, este arroja mapas bibliométricos a partir de diferentes tipos de análisis: coautoría, coocurrencia de palabras, citaciones, cocitaciones. Este estudio específico realizó un análisis de coocurrencia de palabras claves. Este análisis indica la relación de proximidad entre dos o más palabras claves dentro de un documento y las representa en diferentes mapas en los que se visualizan enlaces entre los términos -Network visualization, overlay visualization, density visualization- (Martínez y otros, 2019). 
Los mapas bibliométricos resultantes muestran círculos en diferentes tamaños que representan la aparición de las palabras claves y su importancia dentro de la tendencia de investigación. Los círculos, también denominados nodos, forman clústeres o conglomerados; no son más que nodos de palabra con afinidades y que son vecinos entre sí (Lopera, 2019). La técnica de investigación se considera confiable (Yu et al., 2014; citado por Akhtar et al., 2019).

El criterio de búsqueda Smart Camp * AND Sustainabitity arrojó un resultado inicial de quinientos treinta y dos documentos en la colección principal de WOS, en los índices SCI-EXPANDED, SSCI, AEHCI, CPCI-S, CPCISSH, BKCI-S, BKCI-SSH, ESCI, CCR-EXPANDED, IC. Estos documentos fueron revisados uno a uno, con el objetivo de desechar aquellos que no incluyeran el criterio de búsqueda en el título, resumen o palabras claves. Dicho refinamiento permitió reducir los resultados a setenta y cuatro documentos con la siguiente temporalidad: seis del año 2020, doce del 2019, diecisiete del 2018, diez del 2017, diez del 2016, cinco del 2015, siete del 2014, uno del 2012, uno del 2011, dos del 2010, dos del 2009 y, finalmente, un documento del año 2008. De los 64 documentos seleccionados, 55 (74,3\%) se publicaron en los últimos cinco años (2020-2016). Este refinamiento aseguró la actualidad de los documentos, objeto de la investigación.

\section{Los mapas bibliométricos}

Los 64 documentos fueron seleccionados y llevados al listado de registros marcados, una útil herramienta de WOS que permite exportar los archivos a otros formatos y realizar diferentes análisis, entre ellos el bibliométrico. El tratamiento realizado en VOSviewer, con el archivo originado por WOS fue el siguiente: se ejecutó el software y se señaló crear mapas basados en datos bibliográficos -esta opción permite realizar un análisis de coocurrencia de palabras clave-, se seleccionó la opción leer datos de archivos con bases de datos bibliográficas, se seleccionó el archivo generado por WOS, el tipo de análisis y método de conteo seleccionado fue la coocurrencia con conteo total con un mínimo de dos palabras. Con este tratamiento, VOSviewer encontró 431 palabras claves, de las cuales cuarenta cumplen el umbral y las condiciones para ser representadas en un mapa bibliométrico. 
La figura 1 muestra la primera red de visualización de coocurrencia de palabras.

\section{Figura 1}

Red de visualización de coocurrencia de palabras inicial

\section{A. vosviewer}

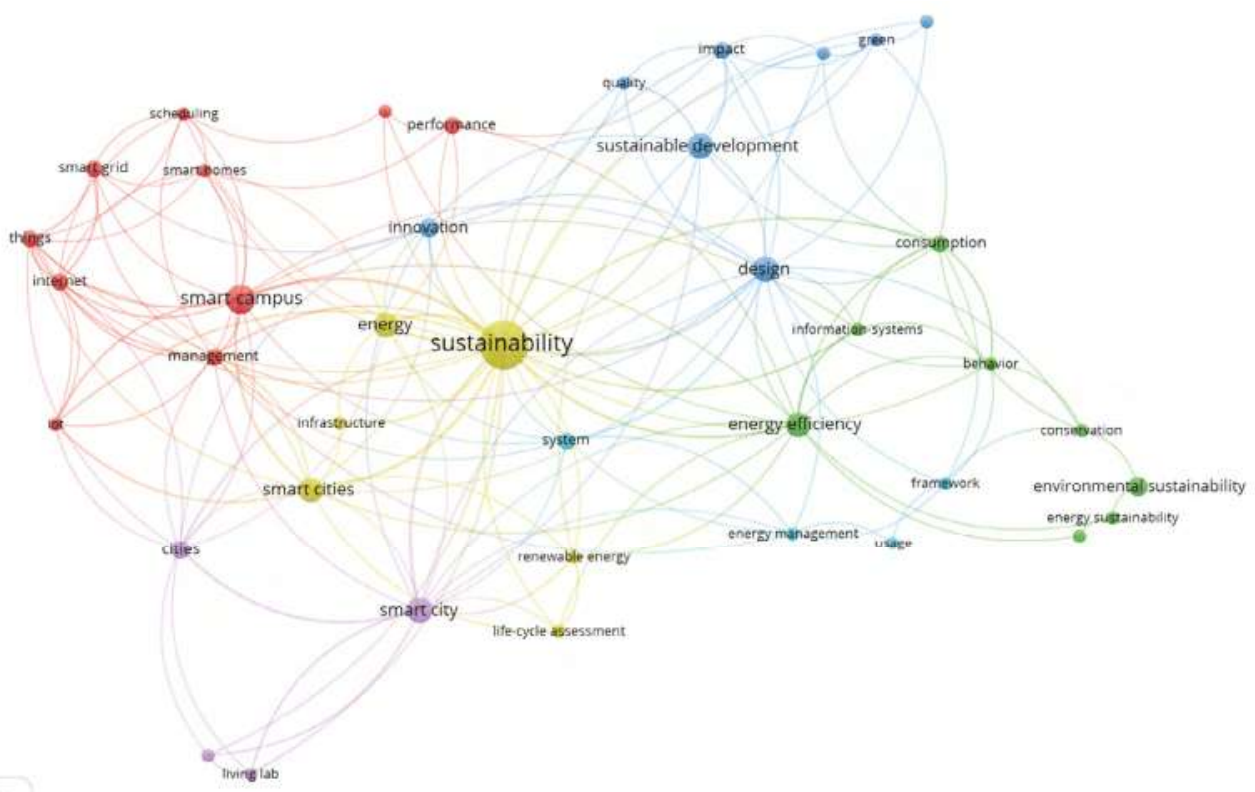

Nota: esta red presenta la sostenibilidad como nodo central en el primer análisis bibliométrico de coocurrencia de palabras, enlazado con cinco clústeres. Fuente: Elaboración propia con el software VOSviewer 1.6.15.

En este primer hallazgo se observa la importancia y la fortaleza del concepto de sostenibilidad en el objeto de estudio, al posicionarse como nodo central. Sin embargo, existen nodos duplicados que requieren ser depurados para eliminar ruido en la red. Conceptos como smart cities y smart city, smart home y smart homes, energy sustainability y sustainability energy son procesados en el software, previa construcción de tesauros, con el fin de eliminar ruidos y generar redes que agreguen mayor valor.

En la figura 2 se observa la red de visualización de coocurrencia de palabras sin duplicidades. 


\section{Figura 2}

Red de visualización de coocurrencia de palabras sin duplicidades

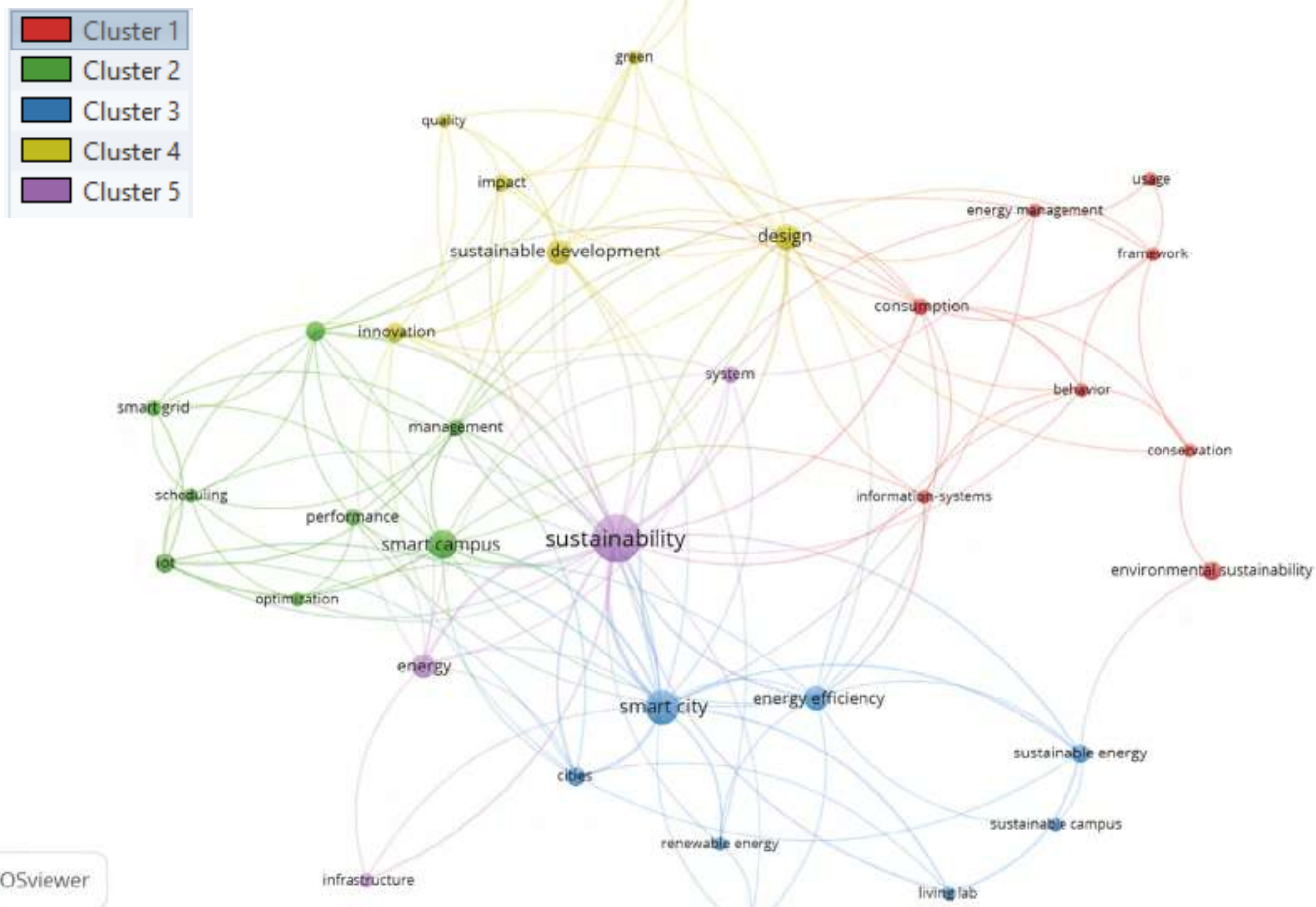

Nota: esta red presenta el resultado del análisis bibliométrico luego de eliminar las duplicidades de manera manual, obteniendo una red más limpia. Fuente: Elaboración propia con el software VOSviewer 1.6.15

Esta figura permite obtener un gráfico mucho más limpio en el que se observa la sostenibilidad como nodo central y tres grandes nodos próximos correspondientes a la ciudad inteligente (smart city), el campus inteligente (smart campus) y al desarrollo sostenible (sustainable development). Los colores representan cada uno de los cinco clústeres de la red.

En la tabla 1 se detallan los cinco clústeres que arrojó la red de visualización de coocurrencia de palabras. 


\section{Tabla 1}

Clústeres de la red de visualización de coocurrencia de palabras

\begin{tabular}{|c|c|c|c|c|c|}
\hline Clúster & Keyword & Ocurrences & $\begin{array}{l}\text { Total Link } \\
\text { Strength }\end{array}$ & \% Strength & $\begin{array}{l}\text { \% Strength } \\
\text { Clúster }\end{array}$ \\
\hline \multirow{8}{*}{1} & Behavior & 2 & 8 & $2,04 \%$ & \multirow{8}{*}{$13,01 \%$} \\
\hline & Conservation & 2 & 5 & $1,28 \%$ & \\
\hline & Consumption & 3 & 13 & $3,32 \%$ & \\
\hline & Energy Management & 2 & 7 & $1,79 \%$ & \\
\hline & Enviromental sustainability & 4 & 2 & $0,51 \%$ & \\
\hline & Framework & 2 & 6 & $1,53 \%$ & \\
\hline & Information - systems & 2 & 8 & $2,04 \%$ & \\
\hline & Usage & 2 & 2 & $0,51 \%$ & \\
\hline \multirow{8}{*}{2} & IoT & 4 & 14 & $3,57 \%$ & \multirow{8}{*}{$22,19 \%$} \\
\hline & Management & 3 & 15 & $3,83 \%$ & \\
\hline & Optimization & 2 & 4 & $1,02 \%$ & \\
\hline & Performance & 3 & 6 & $1,53 \%$ & \\
\hline & Scheduling & 2 & 7 & $1,79 \%$ & \\
\hline & Smart Campus & 9 & 21 & $5,36 \%$ & \\
\hline & Smart Grid & 3 & 7 & $1,79 \%$ & \\
\hline & Smart Home & 4 & 13 & $3,32 \%$ & \\
\hline \multirow{8}{*}{3} & Cities & 4 & 14 & $3,57 \%$ & \multirow{8}{*}{$24,49 \%$} \\
\hline & Energy efficiency & 6 & 16 & $4,08 \%$ & \\
\hline & Life-cycle assessment & 2 & 4 & $1,02 \%$ & \\
\hline & Living lab & 2 & 7 & $1,79 \%$ & \\
\hline & Renewable energy & 2 & 6 & $1,53 \%$ & \\
\hline & Smart city & 12 & 37 & $9,44 \%$ & \\
\hline & Sustainable campus & 2 & 2 & $0,51 \%$ & \\
\hline & Sustainable energy & 4 & 10 & $2,55 \%$ & \\
\hline \multirow{7}{*}{4} & Desing & 7 & 24 & $6,12 \%$ & \multirow{7}{*}{$18,62 \%$} \\
\hline & Green & 2 & 7 & $1,79 \%$ & \\
\hline & Impact & 3 & 10 & $2,55 \%$ & \\
\hline & Innovation & 4 & 10 & $2,55 \%$ & \\
\hline & Management - systems & 2 & 3 & $0,77 \%$ & \\
\hline & Quality & 2 & 6 & $1,53 \%$ & \\
\hline & Sustainable development & 7 & 13 & $3,32 \%$ & \\
\hline \multirow{4}{*}{5} & Energy & 6 & 12 & $3,06 \%$ & \multirow{4}{*}{$21,68 \%$} \\
\hline & Infraestructure & 2 & 4 & $1,02 \%$ & \\
\hline & Sustainability & 24 & 61 & $15,56 \%$ & \\
\hline & System & 3 & 8 & $2,04 \%$ & \\
\hline
\end{tabular}

Nota: esta tabla detalla la composición de cada uno de los cinco clústeres arrojados por el software y el peso de cada una de las palabras coocurrentes. Fuente: Elaboración propia a partir de datos extractados del software VOSviewer 1.6.15

Tras la eliminación de duplicidades se encontraron 35 palabras distribuidas de la siguiente forma: 
El clúster 1, con un peso total del 13,01\% de la red, comprende ocho conceptos. En este clúster la palabra más coocurrente es environment sustainability (cuatro veces); sin embargo, la mayor fuerza de enlace total está representada en la palabra consumption con un porcentaje de fuerza del $3,32 \%$, seguido de behavior e information-systems con un 2,04\%.

El clúster 2, con un peso total del 22,19\% de la red, comprende ocho conceptos. En este la palabra más coocurrente y la que posee una mayor fuerza de enlace es smart campus (nuevo veces). Esta palabra también es la que tiene una mayor fuerza de enlace total, con un porcentaje del 5,36\%; por último, management con un 3,83\% e I o T (Internet de las cosas) con un 3,57\%.

El clúster 3, con un peso total del $24,49 \%$ de la red, comprende ocho conceptos. En este clúster la palabra más coocurrente y la que posee una mayor fuerza de enlace es smart city (doce veces), representa también la mayor fuerza de enlace total con un porcentaje del $9,44 \%$; posteriormente, la palabra energy efficiency con un 4,05\% y cities con un 3,57\%.

El clúster 4, con un peso total del $18,62 \%$ de la red, comprende siete conceptos. En este la palabra más coocurrente y la que posee una mayor fuerza de enlace es desing (siete veces), además de obtener también la mayor fuerza de enlace total con un porcentaje del 6,12\%; seguidamente, la palabra sustainable development con un 3,32\%.

El clúster 5, con un peso total del $21,68 \%$ de la red comprende cuatro conceptos. En este clúster la palabra más coocurrente y la que posee una mayor fuerza de enlace es la palabra sustainability (veinticuatro veces), obtiene también la mayor fuerza de enlace total con un 15,56\%; por último, la palabra energía con un 3,06\%. Este clúster representa el nodo central del mapa bibliométrico.

Los cinco clústeres se pueden observar de una forma más clara en la figura 3. En este mapa, la fuerza del color está determinada por el número de elementos que pertenecen a ese grupo en la vecindad del nodo, tal como se presentó en la tabla 1. 


\section{Figura 3}

Red de visualización de densidad de clúster

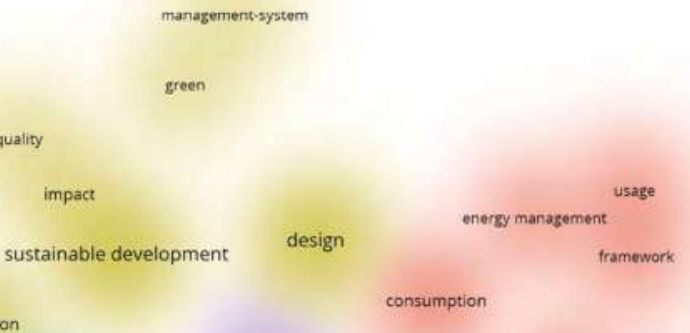

innovation

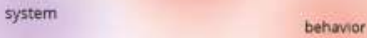

smart grid

management

system

behavior

smant gid

(n)

scheduling

smart campus sustainability

consorvation

iot

information-systems

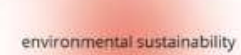

optimization

energy

smart city energy efficiency

cities

sustainable energy

renewable energy

sustainable campus

infrastructure

renewe

living lab

life-cycle assessment

\& vosviewer

Nota: esta figura presenta los cinco clústeres de acuerdo a la densidad de cada una de las palabras coocurrentes. Fuente: Elaboración propia con el software VOSviewer 1.6.15

Un análisis detallado de las redes de visualización presentadas en las figura 1, 2 y 3 permiten entender la estrecha relación entre el campus inteligente y la sostenibilidad.

Sin ninguna exclusión, los cinco clústeres del análisis incluyen por lo menos un concepto o palabra que articula la relación. En el clúster uno, se presentan las palabras conservación, consumo, gestión de la energía, ambiente sostenible, uso; en el clúster dos, donde se encuentra el nodo central del campus inteligente, se aborda el concepto de optimización; en el clúster tres, el de mayor peso dentro del sistema, se incluye la eficiencia en la energía, los ciclos de vida, la energía renovable, los campus y la energía sustentable; en el 
clúster 4 se aborda el desarrollo sostenible, lo verde, el impacto y la innovación; finalmente, en el clúster 5 se presenta el concepto de sostenibilidad, energía, sistemas e infraestructura.

\section{La sostenibilidad en las universidades inteligentes. Otros estudios.}

La relación entre campus inteligente y sostenibilidad es moderna. Este estudio encontró la primera publicación con el criterio de búsqueda en el año 2008. Desde entonces, muchos estudios se han centrado en conceptualizar el campus inteligente y en asociar como clave principal dentro del mismo el componente de sostenibilidad. Algunos autores fortalecen estos hallazgos en investigaciones previas similares al objeto de este estudio.

Cerdeira y Mendes (2018) realizaron una revisión sistemática de literatura en la que encontraron una asociación entre los conceptos de ciudad inteligente y campus inteligentes, resaltando cinco conceptos principales: la economía, las personas, el medio ambiente, la energía y la movilidad. Estos hallazgos se pueden considerar alimentadores de las tres dimensiones del desarrollo sostenible: la dimensión económica, la ambiental y la social.

Coccoli et al. (2014), en su estudio relacionado con los rápidos cambios que suceden en los campus inteligentes en la era digital, propusieron que las universidades deberían explotar las tecnologías disponibles para mejorar la sostenibilidad, el respeto por el medio ambiente y la movilidad a partir del desarrollo de sistemas y soluciones inteligentes que impacten los objetivos de desarrollo sostenible.

Algunas universidades han trabajado estratégicamente en la relación campus inteligente - sostenibilidad. La Universidad de Malagá plantea el concepto de SmartUMA. En este se aplican los conceptos de smart city al campus universitario y lo dirige a hacer de la universidad un referente mundial en sostenibilidad medioambiental, abordando tres áreas principales: conservación y construcción, sostenibilidad y aplicación, y utilización de tecnologías innovadoras. Fortes et al. (2019) definen estas tres bases como los pilares para el establecimiento de un campus sostenible, inteligente, cómodo, y social. Asocian el concepto de inteligente con la capacidad que tiene la 
universidad a través de la instalación de sensores, el internet de las cosas y la computación en la nube; de recopilar y transformar datos relacionados con la calidad del aire, los consumos de energía y el manejo de residuos sólidos, y hacer así un mejor control de su medio ambiente.

En esta misma línea, la Universidad de Alicante denominó su plan estratégico del período 2014-2019 como UA40. En él contempla el uso de las tecnologías de la información para su desarrollo en todos los ámbitos, entre ellos, el aspecto económico, el medio ambiente, la movilidad sostenible, el gobierno y la comunidad.

Diseña, además, un modelo de objetivos básicos para lograr lo que consideran la «sostenibilidad inteligente», en el que se incluye la eficiencia, la innovación y la interoperabilidad como pilares fundamentales, sin olvidar los ejes que para Macía y otros (2017) articulan el concepto smart environment de las ciudades inteligentes: la importancia de centrar los esfuerzos en las tecnologías de la información y la comunicación para optimizar, gestionar y racionalizar de manera correcta los recursos naturales y la reducción de la contaminación y el gasto.

Galeano y otros (2018) derivan del concepto de ciudad inteligente, la definición de campus inteligente, con cinco dimensiones: 1. Personas y hábitat; 2. Economía; 3. Energía; 4. Medio Ambiente y 5. Movilidad. Esta última dimensión comprende el impacto en términos de contaminación, promoción y protección de zonas verdes, gestión de aguas residuales, uso de recursos y microclima de interiores y exteriores y calidad del aire; además, recalca la importancia del uso de las fuentes de energía renovables.

Kwok (2015) en su trabajo denominado Una visión para el desarrollo de un campus inteligente plantea la importancia de la proyección de inversiones en infraestructuras con tecnologías de la información y la comunicación desde la planeación presupuestal en las instituciones, para apoyar el desarrollo económico sostenible. Esto implica la instalación de sistemas de sensores inteligentes que monitoreen las condiciones ambientales, ayuden a fortalecer la sostenibilidad ecológica e impacten la calidad de vida de la comunidad académica.

Por último, Parra y otros (2017) asocian el campus inteligente con el concepto de sostenibilidad inteligente. Igualmente, proponen en sus estudios 
que para aplicarlos y desarrollarlos de forma eficiente es necesario construir y desarrollar una infraestructura completa que gire alrededor del internet de las cosas y que generen información para el mejoramiento de las condiciones medio ambientales de los campus.

\section{Conclusiones}

En este estudio se realizó un análisis de documentación en la base de datos Web of Science con el criterio de búsqueda smart camp * AND Sustainability, con el objetivo de encontrar las tendencias en programas, planes o estrategias, que en torno a la sostenibilidad se desarrollan en los campus inteligentes. La búsqueda realizada durante los meses de junio y julio de 2020 arrojó un resultado final de setenta y cuatro documentos analizados en el software VOSviewer con mapas bibliométricos.

Con VOSviewer se concluye que existe una fuerte relación entre el concepto de sostenibilidad y el concepto de campus inteligente (smart campus); incluso se pudo apreciar en las figuras 2 y 3 que para la investigación científica es más relevante el concepto de sostenibilidad que el de campus inteligente.

Los mapas bibliométricos arrojaron cinco clústeres, en los cuales se destacaron tres nodos particulares: el nodo sostenibilidad con un peso del 15,56\%; el nodo campus inteligente con un peso del 5,36\%; y el nodo ciudad inteligente con un peso del 9,44\% (tabla 1). La fuerza de estos enlaces y el gráfico de visualización de densidad de clúster confirman la afinidad y relevancia de estos conceptos en los estudios recientes (2016-2020).

Es viable concluir que dentro de los programas, planes o estrategias que se desarrollan en torno a la sostenibilidad en los campus inteligentes se encuentran programas de conservación y consumo, uso y gestión eficiente de la energía, energía renovable, procesos de automatización, fortalecimiento de la conexión de aparatos a través del internet de las cosas, la gestión y la automatización, el uso eficiente de la energía, el respeto por los ciclos de vida, el uso de energías renovables, los espacios verdes, el desarrollo sostenible, la infraestructura y el uso de sistemas. 


\section{Referencias bibliográficas}

Arbeláez Gómez, M. y Onrubia Goñi, J. (2014). Análisis bibliométrico y de contenido. Dos metodologías complementarias para el análisis de la revista colombiana Educación y Cultura. Revista de Investigaciones UCM, 14 (23), 14-31. http://dx.doi.org/10.22383/ri.v14i1.5

Akhtar, N.et al. (2019). A bibliometric analysis of contemporary research regarding industrial symbiosos: a path towards urban environmental resilience. Applied ecology and environmental research, 17(1), 1159-1221. http://dx.doi.org/10.15666/aeer/1701_11591221

Cerdeira, F. $\mathcal{3}$ Mendes, R. (2018). Campus Inteligentes: Conceitos, aplicações, tecnologias e desafios. Relatórios Técnicos Do DIA/UNIRIO, 3. http:/www.seer.unirio.br/index.php/ monografiasppgi/article/view/7147

Chiu, P. S. et al. (2020). Enabling Intelligent Environment by the Design of Emotionally Aware Virtual Assistant: A Case of Smart Campus. IEEE Access, 8, 62032-62041. https:// ieeexplore.ieee.org/abstract/document/9050793

Coccoli, M. et al. (2014). Smarter universities: A vision for the fast changing digital era. Journal of Visual Languages and Computing, 25(6), 1003-1011. https://doi.org/10.1016/j. jvlc.2014.09.007

Delgado, Á. M. y otros. (2019). Análisis bibliométrico del impacto de la investigación educativa en diversidad funcional y competencia digital: Web of Science y Scopus. Aula abierta, 48 (2), 147-156. https://doi.org/10.17811/rifie.48.2.2019.147-156

Fernández, T. M., y Fraga-Lamas, P. (2019). Towards next generation teaching, learning, and context-aware applications for higher education: A review on blockchain, IoT, fog and edge computing enabled smart campuses and universities. Applied Sciences, 9 (21), 4479. https://doi.org/10.3390/app9214479

Fortes, S., Santoyo, J., Palacios, D., Baena, E., Mora, R., Medina, M., Mora, P., y Barco, R. (2019). The Campus as a Smart City: University of Málaga Environmental, Learning, and Research Approaches. Sensors, 19(6), 1349. https://doi.org/10.3390/s19061349

Galeano, C. J., Bellón, D., Zabala, S. A., Romero, E., y Duro, V. (2018). Identificación de los pilares que direccionan a una institución universitaria hacia un smart-campus. Revista de Investigación, Desarrollo e Innovación, 9(1), 127-145. https://doi.org/10.19053/20278306. v9.n1.2018.8511

Gaviria, M., Merigó, J. M., E Baier, H. (2019). Knowledge management: A global examination based on bibliometric analysis. Technological Forecasting and Social Change, 140, 194220. https://doi.org/10.1016/j.techfore.2018.07.006

Guo, Y. M., Huang, Z. L., Guo, J., Li, H., Guo, X. R., E Nkeli, M. J. (2019). Bibliometric analysis on smart cities research. Sustainability, 11(13), 3606. https://doi.org/10.3390/su11133606

Jurva, R., Matinmikko, Niemelä, V., y Nenonen, S. (2020). Architecture and Operational Model for Smart Campus Digital Infrastructure. Wireless Personal Communications, 113, 1437 - 1454. https://doi.org/10.1007/s11277-020-07221-5 
Kwok, L. (2015). A vision for the development of i-campus. Smart Learning Environments, 2(2), 1-12. https://doi.org/10.1186/s40561-015-0009-8

Leyva Duarte, J. E., Chávez Martínez, J. D. J., Pinedo de Anda, F. J., E Niebla Zatarain, J. C. (2019). Análisis bibliométrico sobre Cultura organizacional en Economía de negocios de Web of Science, 1980-2018. Nova scientia, 11 (22), 478-500. https://doi.org/10.21640/ ns.v11i22.1810

Lopera, C.A. (2019). Ciudad inteligente y sostenibilidad: un análisis bibliométrico. En: Lopera, CA. (Ed.), Sostenibilidad, cultura y sociedad (pp. 212 - 230). Medellín, Colombia : Fondo Editorial Pascual Bravo.

Martínez, G., Rico, D., Romero, E., Galeano, C., Guerrero, C. y Parra, J. (2019). Análisis de la estructura intelectual y la evolución de la investigación en la interacción humano - computador: un análisis bibliométrico. Revista Ibérica de Sistemas y Tecnologías de Información, s.i., 363-378. Recuperado de: https://search.proquest.com/openview/c83d 025ba536d994653457eb865e9417/1?pq-origsite=gscholarE3cbl=1006393

Maciá, F. y otros (2017). Smart University. Hacia una universidad más abierta. Alfaomega $\mathcal{G}$ Marcombo, Eds.

Merigó, J. M. y Yang, J. B. (2017). Un análisis bibliométrico de la investigación de operaciones y la ciencia de gestión. Omega , 73 , 37-48. https://doi.org/10.1016/j.omega.2016.12.004

Parra, J., Guerrero, C., E Rico, D. (2017). IOT: Una aproximación desde ciudad inteligente a universidad inteligente. Revista Ingenio UFPSO, 13, 9-20. Retrieved from http://revistas. ufpso.edu.co/index.php/ringenio/article/view/398

Popoola, S. I., Atayero, A. A., Arausi, O. D., E Matthews, V. O. (2018). Path loss dataset for modeling radio wave propagation in smart campus environment. Data in brief, 17, 10621073. https://doi.org/10.1016/j.dib.2018.02.026

Min-Allah, N. y Alrashed, S. (2020). Smart campus - A sketch. Sustainable Cities and Society, 59. https://doi.org/10.1016/j.scs.2020.102231

Tkachuk, C. (2016). La Universidad inteligente: un nuevo paradigma de gestión institucional. En: Villar, A. (Ed). Bimodalidad: Articulación y Convergencia en la Educación Superior. Buenos Aire, Argentina : Universidad Nacional de Quilmes. Disponible en: http://libros. uvq.edu.ar/assets/libro3/la_universidad_inteligente_un_nuevo_paradigma_de_gestin_ institucional.html\#

Valks, B., Arkesteijn, M., E Den Heijer, A. (2019). Smart campus tools 2.0 exploring the use of real-time space use measurement at universities and organizations. Facilities. https:// doi.org/10.1108/F-11-2018-0136

Valks, B., Arkesteijn, M. H., Koutamanis, A., y Den Heijer, A. C. (2020). Towards a smart campus: supporting campus decisions with Internet of Things applications. Building Research 8 Information, 1-20. https://doi.org/10.1080/09613218.2020.1784702

Wu, F., Zheng, Q., Tian, F., Suo, Z., Zhou, Y., Chao, K., Xu, M., Shah, N., Liu, J. E Li, F. (2020). Supporting poverty-stricken college students in smart campus. Future Generation Computer Systems, 111, 599-616. https://doi.org/10.1016/j.future.2019.09.017 
Yu, C., Davis, C., and Dijkema, G. (2014). Understanding the evolution of industrial symbiosis research: A bibliometric and network analysis (1997-2012). Journal of Industrial Ecology, 18(2), 280-293. https://doi.org/10.1111/jiec.12073

Zhang, J., Yu, Q., Zheng, FS, Long, C., Lu, ZX y Duan, ZG. (2016). Comparing keywords plus of WOS and Author Keywords: A case study of patient adherence research. Journal of the Association for Information Science and Technology, 67 (4), 967-972. Recuperado de https://doi.org/10.1002/asi.23437 


\title{
Bicicletas de carga: una mirada al futuro, retomando el pasado
}

\section{Caso: LOLA Te Mueve}

\author{
Sandra Milena Álvarez Gallo ${ }^{1}$ \\ Jacobo Hernán Echavarría Cuervo² \\ Farley Albeiro Restrepo Loaiza ${ }^{3}$
}

\section{Introducción}

La necesidad de optimización e innovación en los procesos de los diferentes actores que intervienen en la distribución de mercancías, ha aumentado en los últimos años en razón al incremento de la población, al crecimiento económico, al desarrollo industrial, a la cantidad de vehículos; incluso, se ha acrecentado la necesidad de desarrollar nuevas soluciones como resultado de los episodios posteriores a estados de emergencia por contaminación ambiental en la ciudad de Medellín.

Planteado de esta manera, los procesos de distribución urbana de mercancía, no solo en la ciudad de Medellín, sino, en general, en todas las grandes ciudades del mundo, se han visto obstaculizados por el aumento de

\footnotetext{
Magister en Dirección Logística. Especialista en Logística Empresarial. Ingeniera industrial. Docente tiempo completo, Institución Universitaria Pascual Bravo, Grupo de investigación QUALIPRO. Correo electrónico: sandra.alvarezga@pascualbravo.edu.co

2 Magister en Desarrollo Sostenible y Medio Ambiente. Ingeniero Industrial. Docente tiempo completo, Institución Universitaria Pascual Bravo, Grupo de investigación QUALIPRO. Correo electrónico: jacobo. echavarria@pascualbravo.edu.co

3 Magister en Logística Integral. Ingeniero en Producción. Docente tiempo completo, Institución Universitaria Pascual Bravo, Grupo de investigación QUALIPRO. Correo electrónico: f.restrepolo@ pascualbravo.edu.co

Agradecimientos por su colaboración y aportes en la escritura de este capítulo a Simón Machado Pérez, CCO-Director Comercial LOLA Te mueve.
} 
la congestión vehicular que, así mismo, afecta no solo la productividad de las empresas, sino la calidad de vida de la población en cuanto a movilidad, accidentalidad, contaminación ambiental y auditiva. Dicha situación se torna más apremiante en Colombia, si se tiene en cuenta que tenemos el parque automotor más antiguo de América Latina, según lo registra el Consejo Privado de Competitividad (CPC) en 2018.

En concreto, todos estos factores que han incidido para que cada día existan más restricciones en los procesos de distribución urbana de mercancía -como ya se expuso-, por la compleja circulación de vehículos, franjas de horarios cada vez más estrechas, mayores restricciones en zonas para cargue y descargue de mercancías conlleva a que las empresas deban innovar para cumplir con las regulaciones y, al mismo tiempo, responder a un mercado que exige cada día mayor responsabilidad ambiental y mayor frecuencia en las entregas de mercancías. Como respuesta a estas demandas en algunos países se ha iniciado la implementación de un nuevo modelo de distribución urbana de mercancías, como son las bicicletas de carga, modelo que ya se está adoptando en la ciudad de Medellín.

\section{Metodología}

De acuerdo con las características específicas de la ciudad de Medellín (Colombia), el propósito de esta investigación fue determinar cuáles son las principales necesidades, problemas y retos para el sector logístico en la ciudad, el enfoque fue de tipo mixto realizando recolección de información cualitativa como cuantitativa para lo cual se realizaron veinte entrevistas a las más importantes empresas relacionadas con el sector logístico. En el proceso de investigación se destaca un caso encontrado en la ciudad de Medellín que puede servir de modelo en el ámbito nacional sino también en el global; se trata de una estrategia que mejora la productividad en la distribución urbana de mercancía y, al mismo tiempo, ayuda a mitigar el impacto ambiental, haciendo aportes significativos a lo que se visiona de ciudades sostenibles.

Para realizar la documentación del caso, se realizó una investigación documental como soporte para encontrar modelos de Distribución Urbana de Mercancías-DUM- en el contexto global, y de este modo poder sustentar que 
este es un caso innovador y pertinente; tal como lo menciona Maes (2017), pues la distribución urbana de mercancías en ciclas de carga no es un tema nuevo, pero sí poco explorado.

\section{Situación actual del problema}

La distribución urbana de mercancías cada vez reviste mayor importancia dentro de las políticas estatales alrededor del mundo; lo anterior, en virtud a su creciente influencia en los costos de la mercancía, la competitividad de las regiones, sumado al impacto social, ambiental y económico que puede causar.

Uno de los componentes principales del Plan Nacional de Desarrollo 2018-2022: Pacto por Colombia (DNP, 2018), es el transporte y logística para la competitividad y la integración regional en el que se destaca la movilidad urbana y regional de carga y pasajeros, como uno de los focos a trabajar durante los cuatro años de gobierno: «la reducción de costos de transporte es condición para exportar e integrar a millones de ciudadanos a mercados y servicios» (p. 573).

Adicionalmente, según la nueva visión de la Política Nacional Logística, el Gobierno nacional implementó la Misión de Logística y Comercio Exterior con la participación de los sectores público y el privado de diferentes regiones del país, en la cual se definieron las estrategias encaminadas a reducir los costos y los tiempos logísticos para mejorar la competitividad del país. Igualmente, para el caso específico de Antioquia, en el año 2017 se creó la Alianza Regional Logística que tiene como propósito que la logística del transporte regional alcance mayores estándares de productividad, mejore su eficiencia, desempeño y competitividad, teniendo en cuenta la mitigación del impacto ambiental. Esta alianza se encuentra conformada por gremios del sector privado, el sector público, entre los que se encuentra el Ministerio de Transporte y el sector académico, alianza que manifiesta dentro de las problemáticas de amplia discusión el tema de distribución urbana de mercancías y la problemática ambiental asociada a esta (DNP, 2018).

En cuanto al transporte de carga, actualmente la ciudad de Medellín y la región no cuentan con una infraestructura adecuada, así como tampoco con una regulación eficaz de cargue y descargue de mercancías, sus impactos en la movilidad y las posibles alternativas de solución (Alcaldía de Medellín, 2016). 
A lo dicho se agrega que no se tienen indicadores ni cifras relacionadas con el sector transporte de carga urbana de mercancías. Solo hasta años recientes ha tomado importancia, y para el caso de Medellín es muy poco lo que en términos de esta temática se ha investigado y publicado.

Otro aspecto que afecta la distribución urbana en Colombia es el problema de informalidad, a lo que se suman la afectación a la calidad de la carga transportada, y los daños irreversibles al medio ambiente, producto del parque automotor con una vida útil muy alta. Según el Consejo Privado de Competitividad (CPC, 2018) es el país de América Latina con la flota de vehículos con más años en el sector - un promedio de veintiún años . Un agravante más es tiene que ver con los serios problemas en su red vial en lo que refiere a su mantenimiento, la congestión en los accesos a las ciudades y la falta de plataformas logísticas, así como la baja calidad en las redes viales secundarias y terciarias (CPC, 2018).

De acuerdo con el CPC (2017) debe alcanzar estándares de competitividad logística con visión de futuro; en este sentido, recomienda a las empresas de transporte adoptar soluciones tecnológicas para la operación logística, permitiendo el monitoreo constante de la carga y de cada una de las variables de control. Los retos tecnológicos incluyen adaptar los procesos a la industria 4.0, además de incursionar en asuntos como el big data (corto plazo) e invertir en el uso de drones y vehículos que funcionan de manera autónoma (a futuro).

Otro de los desafíos a futuro será atender de manera rápida y eficiente el comercio electrónico. En esta línea, el XIV del Congreso Expologística (2018), el presidente de la Asociación Nacional de Comercio Exterior, Javier Díaz Molina, resaltó la importancia que tiene para el país «fomentar el desarrollo de la logística de última milla» situación grave «por el problema de movilidad que tienen las ciudades» (Colprensa, 2018).

\section{Impacto ambiental del problema}

De acuerdo con el DNP (2018) en la Conferencia de las Partes sobre Cambio Climático (COP21), «el Gobierno Nacional se comprometió en reducir el $20 \%$ [sic] de las emisiones para el año 2030. Dado que casi el 60\% del parque 
automotor de Colombia tiene más de diez años y que la emisión de dióxido de carbono (CO2) de estos vehículos es 1,4 veces más alta que la de los vehículos con menor edad» (Consejo Privado de Competitividad, 2017, p.265).

Para ello el CPC (2017) plantea realizar ajustes a las normas que permitan reducir el impacto ambiental, entre otras, adecuar restricciones para el acceso a los corredores estratégicos y a las principales ciudades, y regularlos tiempos y zonas de cargue y descargue.

A este tipo de iniciativas medioambientales se le ha sumado el sector privado; es el caso de DHL Latinoamérica Supply Chain, firma con presencia en once países: «Tenemos un objetivo muy ambicioso hasta el 2050 de reducir a cero el impacto medioambiental que tienen las actividades logísticas, y dentro de ese ámbito será vital la utilización de vehículos eléctricos, trenes y medios fluviales, entre otros» (Portafolio, 2018).

En Colombia, los consumidores se fijan menos en precio y calidad de los productos y servicios pues están cada vez más preocupados en aspectos como la salud y el medioambiente (Euromonitor International, 2019). Por ello, en el mundo, las empresas se han visto en la necesidad de implementar prácticas más sostenibles y sistemas de transporte de menores emisiones, no solo por sus consumidores sino por normas cada vez más rigurosas en cuanto a impactos ambientales se refiere (Logyca, s.f).

En Medellín, el tema ambiental y el incremento de la contaminación del aire, en algunas ocasiones, provocó que el Gobierno local hubiera declarado estado de alerta roja y estado de prevención con el propósito de tomar medidas y afrontar la situación. Según reporte del Área Metropolitana del Valle de Aburrá «el 81\% de las emisiones de partículas proviene de los vehículos que, sumado a las características geográficas y del clima, ocasionan episodios críticos de contaminación del aire, principalmente en marzo y octubre, épocas de alta nubosidad y transición entre la temporada seca y de lluvias, limitando la dispersión de los contaminantes» (Área Metropolitana del Valle del Aburrá, 2015; citado por Conpes, 2018, p. 3).

Planteado de esta manera, y debido a la creciente preocupación por el medio ambiente, las empresas tendrán que responder a mayores exigencias de la sociedad, de los consumidores, de los clientes y de los organismos gubernamentales, de una parte; de otra, tendrán que establecer mayores 
normativas para mejorar la movilidad y la calidad del aire en las ciudades, además de atender las restricciones horarias, lo que, sin lugar a dudas, hace necesario desarrollar nuevas soluciones en cuanto a logística urbana y DUM.

\section{Desafíos en la logística urbana}

Según Zona Logística (2016) el e-commerce ha transformado las condiciones de la logística; ahora la venta es omnicanal, tendencia que modifica la cadena de suministro, pues debe estar en capacidad de abastecer tanto grandes cantidades en empresas, como la demanda de personas en cantidades menores y con mayor frecuencia. Tener la flexibilidad y la capacidad para satisfacer esta demanda es la necesidad para los próximos años, manifiesta Zona Logística (2016).

Este entorno demanda de la logística transformarse en multisolución (diversificación de servicios); multicanal (con distintos canales de comercialización y distribución); multimodal (que abarque diferentes modos de transporte); multihorario (que permita flexibilidad en horarios no habituales); multidestino (con alcance en diferentes coberturas geográficas), entre otros (Mora, 2016).

Toma vigencia global el término logística verde, entendido este como la tendencia de las actividades de la logística y el transporte hacia la sostenibilidad, que busca reducir la huella de carbono. Para lograrlo, se requiere del transporte multimodal, la reducción de viajes vacíos y la aplicación de tecnologías como seguimiento satelital, vehículos eléctricos; incluso, se ha empezado a hablar de ciclologística y bicicargos para la entrega de paquetes, como solución para mejorar la movilidad en las ciudades (Subdepartamento de Inteligencia Comercial de Chile, 2014).

Según informe de PricewaterhouseCoopers (2011), el abastecimiento de productos en las grandes ciudades será uno de los principales desafíos para los proveedores de servicios logísticos, debido a que el suministro en las ciudades es cada vez más complicado, por una mayor saturación de las infraestructuras de transporte y por los crecientes volúmenes de tráfico. En consecuencia, al momento de planificar y desarrollar las infraestructuras de transporte se debe pensar de una manera diferente para integrar nuevos sistemas y modos de transporte. Ahora, las exigencias de los clientes para recibir sus compras en 
un menor tiempo, continuará demandando la reducción en los tiempos de tránsito y exigiendo la reacción de cadenas logísticas flexibles y adaptables a cambios, para citar, solicitudes de los clientes de lotes más pequeños y adaptados a los gustos (Cánovas, 2014). En suma, al estar más conectados, los procesos logísticos demandarán entregas más puntuales, aumentará la frecuencia de las entregas, lo que exigirá una mejor planificación y un menor margen de error en la cadena de suministros (Zona Logística, 2016).

\section{Antecedentes y estado actual del tema}

Entre los autores más destacados que aluden el nivel de transporte urbano de mercancías se encuentran Shu, Shin, He, y Chen (2015). Cabe advertir que se trata de los autores más citados por los planteamientos que realizan en torno al uso de la telefonía móvil, como herramienta de navegación aplicada en la logística de última milla mediante el uso de GPS, y de aplicaciones como FolowME que muestra rutas eficientes utilizadas por otros usuarios. Por su parte, Hübner, Kuhn, y Wollenburg (2016) analizan las ventajas y desventajas de los diferentes conceptos de diseño de distribución de última milla; así mismo, elaboran una revisión de la literatura clave relativa al cumplimiento de pedidos de última milla y la gestión de la cadena de suministro minorista para complementar el marco integrado de planificación de operaciones en omnicanalidad.

Actualmente, la última milla en un entorno B2C se considera como una de las secciones más caras, menos eficientes y más contaminantes de toda la cadena logística. Teniendo en cuenta estos "problemas de la última milla», los autores desarrollaron una tipología de última milla y un instrumento para simular los costos totales mediante los cuales las características específicas de esta se utilizan como variables independientes (Gevaers, Van de Voord, y Vanelslander, 2014).

Brown y Guiffrida (2014) realizan una comparación de las emisiones de carbono, resultantes de las compras convencionales que involucran la recolección del producto por parte del cliente, directamente en el negocio, versus la entrega de última milla que involucra el comercio electrónico, hasta la entrega en los hogares de los clientes. El número de equilibrio de clientes para la equivalencia de emisiones de carbono se analiza para determinar la 
viabilidad de la entrega de la última milla, en función del radio de la región de demanda y el tiempo de entrega.

De otro lado, Iwan, Kijewska, y Lemke (2016) analizan la eficiencia y los resultados de los lockers de entrega (Reception Box) de paquetes, como posible solución a la distribución urbana, y de última milla en función del mercado B2C en Polonia. Otros autores como Deutsch y Golany (2018), Vakulenko, Hellström y Hjort (2018) analizan los modelos de lockers de entrega de paquetes.

Adicionalmente, Wang, Zhan, Ruan y Zhang (2014) plantean tres diferentes modelos de distribución de última milla: attended home delivery, reception box, $y$ collection-and-delivery points. Estos autores analizan sus ventajas y desventajas en escenarios de alta densidad de población mediante modelos de ruteo de vehículos y algoritmos genéticos.

Acorde a los hallazgos bibliográficos se evidencia una correlación entre los modelos de investigación de operaciones y la logística de última milla. En beneficio de la discusión, autores como Aized y Singh (2014) exponen modelos de optimización de última milla mediante modelos de ruteo (Petri net method) y modelos estocásticos (Noyan, Balcik, y Atakan, 2016). Según Rivera y Velasco (2014) se plantea el desarrollo de un modelo matemático de distribución y asignación basado en plataformas logísticas; con base en el problema de ruteo de vehículo utilizando un algoritmo Greedy que ayude a tener un transporte de mercancía lo más eficiente posible en la ciudad.

Un modelo de multitarea móvil (crowd-tasking model) a gran escala es el que proponen Wang, Zhang, Liu, Shen y Lee (2016), modelo en el que se utiliza un grupo numeroso de trabajadores ciudadanos (crowdsourcing) para realizar la entrega de última milla. Para resolver eficientemente el modelo, lo formulan como un problema de flujo de costo mínimo de la red.

También Devari, Nikolaev y He (2017) proponen modelos de crowdsourcing aprovechando las redes sociales de los clientes de las tiendas de retail. Por su parte, autores como Castillo, Bell, Rose y Rodrigues (2017), y Frehe, Mehmann y Teuteberg (2017), también analizan dichos modelos y las futuras direcciones de investigación.

Otro enfoque, también relativo a logística de última milla, es tratado por autores como De Souza, Goh, Lau, Ng y Tan (2014), a los que se suman 
Muñoz-Villamizar, Montoya-Torres y Vega-Mejía (2015). Se trata de estrategias de logística colaborativa para distribución urbana.

Según el informe técnico denominado Distribución urbana de mercancías: estrategias con centros logísticos (Antún, 2013) se define el concepto de distribución urbana de mercancías y se detalla su problemática y las tendencias actuales, según las prácticas de diferentes compañías, y trata sobre la estrategia de centros logísticos urbanos para gestionar el transporte de mercancía. Igualmente, Antún, Lozano, Herández y Hernández 2005), en su libro Logística de distribución física a minoristas plantean la distribución física de mercancías centralizada y no centralizada; adicionalmente, proponen estrategias innovadoras para el diseño de rutas de distribución de mercancías en áreas urbanas, basadas en algoritmos y solución de problemas con modelos cuantitativos.

Sanz, Pastor y Benedito (2013) describen y clasifican las soluciones existentes para la distribución urbana de mercancías (DUM) y proponen dos soluciones; la primera de ellas consiste en cuadrantes de horarios en zonas descarga y carga, es decir, establecer unos horarios concretos para cada recepción de mercancías de cada uno de los proveedores de suministro directo; la segunda solución propuesta consiste en compartir entre diversas empresas y en diferentes horarios, una zona común para cargue y descargue. También, muestra los resultados de las pruebas piloto realizadas para evaluar las soluciones propuestas.

Otros autores como Handoko, Nguyen y Lau (2014) proponen los centros de distribución urbanas como modelo de solución para la logística de última milla.

Visto y expuesto de esta manera, es evidente que, en cuanto a literatura se refiere, los resultados se centran más en modelación, zonificación horaria y geográfica, centros de distribución urbana y logística colaborativa. Relativo a pilotos, se tienen crowdsourcing, puntos de recogida y entrega - como lockers-.

\section{Análisis bibliométrico en logística 2018}

En la IU Pascual Bravo se desarrolló un proyecto para definir el eje temático de la línea de investigación en logística para lo cual se efectuó una vigilancia 
tecnológica. En una primera etapa se realizó la búsqueda de tendencias en investigación, acordes con las publicaciones de mayor impacto de citación, relacionados con la temática de logística que, de acuerdo con los hallazgos en el estado del arte del estudio bibliométrico, se pudo mostrar que existe un vacío en el nivel de conocimiento alcanzado en la distribución de última milla. Lo anterior, debido a que con el análisis no se hallaron índices significativos de producción científica ni se encontraron modelos desarrollados para la ciudad de Medellín en este tema (Monsalve, Echavarría y Álvarez, 2020).

\section{Estado del arte de la distribución de mercancías, en ciclas, como solución a la DUM}

Al investigar específicamente acerca de la distribución urbana de mercancías en ciclas de carga, es manifiesto que se trata de una posible alternativa ya considerada viable por otros autores, entre ellos, Dablanc (2011), (Leonardi, Browne y Allen (2012), Lenz y Riehle (2012), Gruber et al. (2013), HolguínVeras et al. (2014, Gruber et al. (2014); por último, Melo et al. (2014; citado por Maes, 2017). Valga advertir que aún este servicio de entregas en bicicleta es un sector susceptible de estudios y evaluaciones más profundas, y puede considerarse un tema nuevo en investigación; además, las investigaciones y publicaciones se focalizan, sobre todo, en proyectos pilotos originados en la Unión Europea (Maes, 2017).

Al hacer una revisión de estos conceptos, se encuentran numerosas experiencias en Europa que muestran la viabilidad y eficiencia de este sistema de distribución, Aunque se basan más en el paqueteo (mensajería), son muy escasos los casos de distribución de mercancías más voluminosas y pesadas, como lo requiere gran parte de los servicios de última milla o DUM. A la luz de lo dicho, es válido mencionar publicaciones como la de Ørving, Fossheim, y Andersen (2019), con un caso de estudio de Oslo Noruega acerca de las cargobikes para las operaciones logísticas en el centro de la ciudad donde destacan que las autoridades deben apoyar la ubicación de centros de distribución multiusuarios para facilitar este tipo de iniciativas. Al caso expuesto se une la publicación de Melo y Baptista (2017), en la que destacan la introducción de cargo-bikes eléctricas en la DUM en diferentes escenarios; 
en todos ellos se han tenido múltiples efectos positivos destacando reducciones del 25\% en costos de distribución.

Los autores Maes y Vanelslander (2012) hacen una revisión de los conceptos bike couriers y cargobikes, donde hallan varios artículos que hacen estudios relacionados con estos conceptos, pero se refieren básicamente a courriers de bajo volumen pero no mencionan hallazgos de DUM para mercancías voluminosas o pesadas.

Así mismo, Conway, Cheng, Kamga y Wan (2017) analizan el caso de la ciudad de Nueva York donde las cargo cycles son usadas en las entregas de paqueteo y mensajería, pero para mercancías de bajo peso y volumen.

Nocerino, Colorni, Lia y Luè (2016) muestran los resultados del proyecto Pro-E-Bike, originado en el programa europeo de inteligencia energética que inició en el 2013 y terminó en el 2016. Este proyecto fomentó otros de uso de energía limpia - en vehículos como bicicletas y scooters - para la entrega de mercancías en zonas urbanas, en siete países europeos y treinta y nueve empresas que los han usado, mostrando que estos vehículos eléctricos pueden remplazar eficientemente los vehículos de combustión.

Este tipo de vehículos hacen menos costosa la operación, desde los costos de compra, mantenimiento y operación - que incluyen combustible, impuestos, seguros, parqueo, almacenamiento y depreciación- (Hagen, Lobo, y Mendoça, 2013). De ahí que autores como Pearce (2016) la consideran una nueva (vieja) tecnología para distribución de mercancía, vieja en el sentido de que la bicicleta es un medio más antiguo que los vehículos a motor y nueva pues está resurgiendo, sobre todo en Europa donde ha sido foco de varios estudios para evaluar su viabilidad, particularmente en la DUM. Esto ha hecho que existan bastantes emprendimientos con este enfoque, aunque no con disponibilidad en muchas ciudades y países.

De esta misma manera, Maes (2017) refiere que, aunque parezca un concepto nuevo ha estado durante décadas como una alternativa viable y sostenible en la logística urbana, siendo mayormente aplicada en Europa, favorecido por políticas de apoyo a emprendimientos, en este sentido, y surgimiento de nuevos modelos de negocio, integrando cargo bikes con asistencia eléctrica (ejemplos: Deliveroo, Foodora y Bubble Post). Adicionalmente, algunas empresas de transporte globales ya están iniciando 
su réplica (UPS, DHL y FedEx), todo esto ha llevado inclusive a fundar la European Cycle Logistics Federation.

En el caso particular de América Latina, en el proceso de entrega de paquetes ya se están empezando a utilizar las bicicargo, bicicletas adaptadas para llevar una carga. Con estas se logra que los costos de envío sean más económicos y, a su vez, más amigables con el medio ambiente; en cambio, en Europa la distribución urbana de mercancías en bicicleta (B-DUM) es una innovación en la que se viene trabajando hace más tiempo en el campo de la logística urbana, mayormente utilizado en países como Holanda, Alemania, Suecia, España, Francia y algunos casos en Estados Unidos (Peña y Pérez, 2019).

De estos proyectos, muchos continúan en operación (algunos muy conocidos; para citar, La Petit Reine en París); otros desarrollados fueron suspendidos o comprados por grandes operadores logísticos y grandes empresas que han desarrollado sus propias soluciones de entrega en cicla (como TNT Express, UPS y DHL). Igualmente, están floreciendo nuevos modelos de negocios para entrega de mercancía tipo courier, con asistencia eléctrica y tecnologías de información; para el caso, Bubble Post (Maes, 2017).

En beneficio de la exposición, la empresa DHL implementó tres iniciativas: DHL Parcycle en la cual la bicicleta lleva incorporada una caja de transporte que se puede sellar. Tiene una capacidad de ciento cuarenta litros; b) DHL Touring Bike, iniciativa más maniobrable y adecuada para su uso: con una mochila de mensajero y City hub las bicicletas pueden transportar hasta trescientos kilos de paquetes. Además de las bicicletas, DHL también usa coches eléctricos. (Peña y Pérez, 2019).

En concreto, la mayoría de estos proyectos, resultados y publicaciones se centran más en las ventajas de movilidad, generación de empleos, bajas emisiones, pero aún falta mucho estudio en cuanto a volúmenes diarios, frecuencias de entrega y relaciones costo/beneficio (Maes, 2017).

Desde otra perspectiva, Hagen, Lobo, y Mendoça (2013) destacan que en los países desarrollados de Europa y en Estados Unidos existe una tendencia al uso de la bicicleta de carga, basada en la preocupación de las personas por el medio ambiente, además de la percepción de ser un medio competitivo, mientras en Latinoamérica algunas experiencias se basan en la eficiencia del transporte en grandes ciudades, pero se dificulta por la falta de estímulos por 
parte del Gobierno para incentivar las empresas, la infraestructura y conseguir facilidades de movilidad para el ciclista. Por ejemplo, en España, la idea de distribución urbana en bicicleta ya lleva varios años funcionando en ciudades como: Valencia, con el proyecto Pro-E-Bike, desde finales del 2014; en Sevilla y otras ciudades ya están realizando pruebas piloto articuladas al proyecto europeo Cycle Logisics Ahead (Jiménez, 2017.)

En Barcelona, con la implementación de un mini muelle de carga y descarga, con triciclos eléctricos capaces de transportar hasta ciento ochenta kilogramos de carga, la empresa Vanapedal efectúa por las calles del casco antiguo de la ciudad, el reparto de las mercancías (Barcelona centre logistic, 2016).

En Madrid, la startup Mensos ha creado un centro de distribución urbana sostenible, con bicicletas que pueden transportar hasta cien kilos de carga; lleva domicilios de paquetes procedentes de los e-commerce desde su centro de distribución, donde los almacena y prepara para su reparto en sus bicicletas, equipadas con un motor de 250 w. (Esmartcity, 2019). También se tiene el caso de Mares el cual aborda el reto del sector de la ciclologística, pero a modo paqueteo en Madrid (El Mundo Ecológico, 2018)

En Bogotá, en el año 2016 se realizó el primer festival de bicicletas de carga, "Bogotá Cargo Bike Festival”, espacio con el cual se buscó visibilizar el transporte de carga en bicicleta que hay en la capital, tradicionalmente usado para llevar domicilios o surtir de productos los minimercados, mostrando que ha comenzado a tomar fuerza la bicimensajería, de paqueteo, pero con restricciones de peso. Lo anterior, para decir que ya en Colombia se ha iniciado la implementación de las bicicargo; por ejemplo, Servientrega está implementando este proceso en sus servicios de paqueteo (Área Metropolitana del Valle de Aburrá [AMVA], 2019).

En el país se han venido comercializando y utilizando los triciclos o bicicletas de carga, sin asistencia eléctrica, pero igual que en otras partes del mundo no son adecuadas para cargas pesadas. A raíz de la baja capacidad de carga de las bicicletas comunes (menor a $25 \mathrm{~kg}$ ), se han diseñado triciclos de mayor capacidad de carga que la de una bicicleta o moto común, con lo que a nivel mundial se ha empezado a generar la necesidad de legalizar estos modos transporte de carga (Jallow y Johansson, 2015; citados por Caballero 
y Ramos, 2017). En la misma línea, en Europa realizaron entrevistas con actores clave del sector público y privado, y en Colombia realizaron quince entrevistas con actores clave. El principal hallazgo fue que la transferencia de estas nuevas ideas es un asunto complejo, pues los contextos son muy diferentes; igualmente, identificó que la falta de información en esta modalidad de transporte en Colombia constituye una dificultad para su implementación. No obstante, la importancia y necesidad de la participación de las entidades gubernamentales nacionales y locales, el actor fundamental en la implementación de esta modalidad son las compañías de transporte. Finalmente, el estudio concluye que deben existir políticas encaminadas a estimular las bicicletas de carga como parte de sus planes de desarrollo, de infraestructura urbana y de apoyo a este tipo de proyectos.

A diferencia de esta falta de políticas en Latinoamérica, en el 2011 la Comisión Europea incluyó en el Libro Blanco del Transporte la necesidad de implementar vehículos no contaminantes en la DUM; de ahí, el crecimiento en Europa de las bicicletas de carga o cargobikes, consideradas como una alternativa innovadora, viable y eficiente al uso de vehículos contaminantes en la última fase de distribución de última milla (Carrillo, 2017).

Cabe anotar que en Colombia ya se ha comenzado a avanzar en cuanto a políticas relacionadas con el asunto en cuestión, pues el Ministerio de Transporte mediante resolución 3258 del 3 de agosto del 2018, «Por la cual se adopta la Guía de Ciclo-Infraestructura para Ciudades Colombianas», define que en el diseño de infraestructuras y en las políticas urbanas se deben incluir las bicicletas para facilitar un desplazamiento seguro y eficiente en este medio de transporte (Ministro de Transporte, 2018).

En general, los modelos de distribución en bicicletas se hacen a nivel courier con paqueteo, sobres, mensajería y domicilios: sin embargo, se hace necesario el desarrollo de otros modelos para suplir las necesidades de la DUM, con mercancías de mayor peso y volumen. 


\section{Caso de DUM sostenible: empresa LOLA TE MUEVE}

En las entrevistas con expertos acerca de experiencias exitosas en DUM, se encontró el caso de la empresa LOLA Te Mueve, que actualmente contribuye a las metas de ciudad sostenible mediante un nuevo modelo de DUM.

LOLA Te Mueve se fundamenta en desarrollar soluciones integrales y sostenibles que mejoran la logística de entrega de productos, disminuyendo las emisiones de $\mathrm{CO} 2$, tiempos de entrega en zonas de difícil circulación y costos asociados a la operación, contribuyendo al planeta mediante una movilidad inteligente, divertida y sostenible, que utiliza un modelo de bicicletas de carga con el que se quiere llevar felicidad, a través del trasporte de personas, bienes y servicios en bicicletas convencionales o de carga en la última milla, integrando a las personas con las ciudades.

En este sentido, a través de procesos logísticos disruptivos - como la implementación de vehículos de carga eléctricos ligeros y las bicicletas de carga para la DUM, LOLA Te Mueve- busca construir una comunidad fuerte y sólida como eje dinamizador, ayudando a forjar relaciones entre las personas y ciudades, de manera que se logre impactar los flujos de bienes dentro de las ciudades, y dinamizando el movimiento de carga urbana para que mitigue las diferentes problemáticas en movilidad como son el transporte, el tráfico, los espacios flexibles de carga y descarga, la responsabilidad ambiental, la seguridad en las ciudades, entre otros.

Es así como a través del acompañamiento y de la implementación de soluciones amigables con el medio ambiente, la empresa contribuye a generar eficiencias, mejoras en el servicio al cliente y a optimizar la gestión logística para el logro de los objetivos de sus clientes, aportando a su vez al logro de los objetivos de desarrollo sostenible (ODS) establecidos por el Programa de las Naciones Unidas para el Desarrollo (PNUD) en el 2015:

8. Trabajo decente y crecimiento económico;

9. Industrias, Innovación e Infraestructura;

11. Ciudades y comunidades sostenibles, y

13. Acción por el clima. 


\section{Figura 1}

Vehículo de carga eléctrico ligero (bicicleta de carga) LOLA Te Mueve

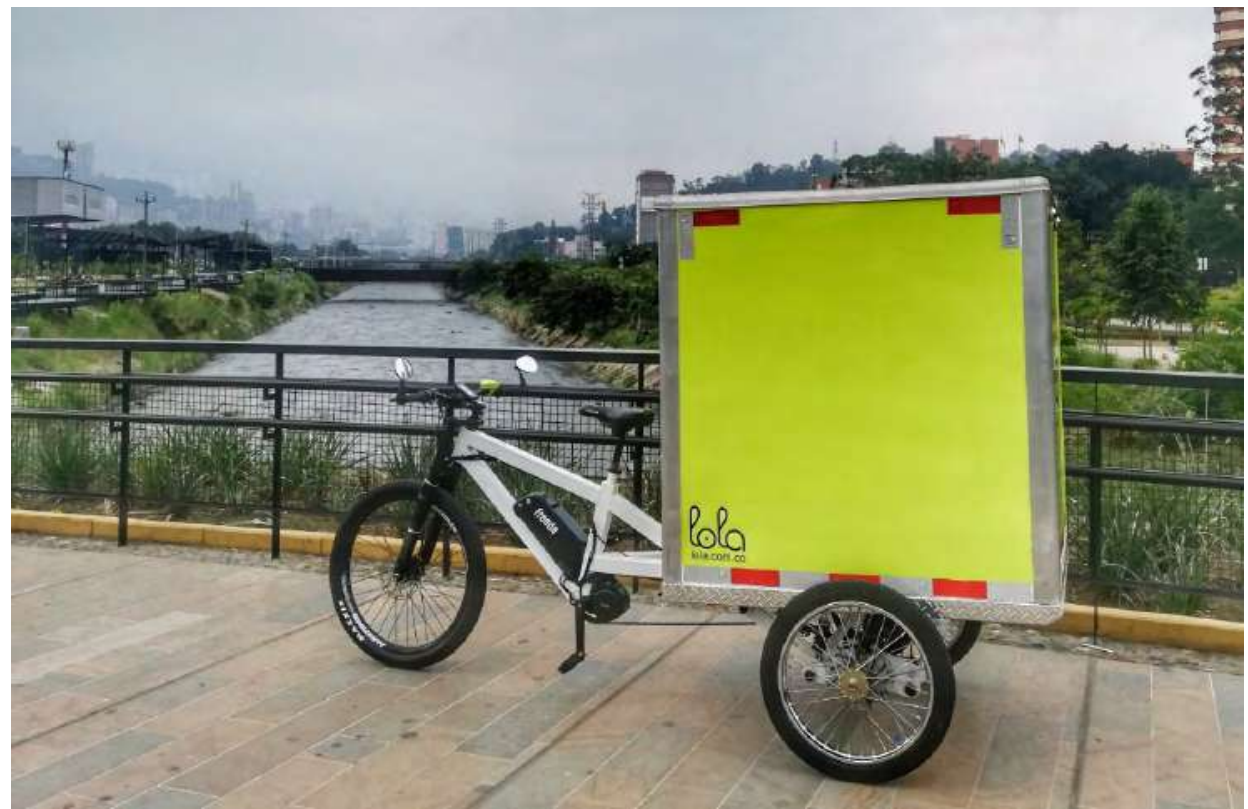

Cicla de carga con batería para asistencia eléctrica en el pedaleo. Fuente: Archivo LOLA Te mueve

LOLA Te Mueve nace de un reto de ciudad del cual hicieron parte empresas de diferentes industrias locales y nacionales, quienes, pensando en las necesidades y problemáticas sobre la logística urbana de mercancías, plantearon un proyecto futuro que buscaba, a través del trabajo colaborativo, identificar las zonas dentro de las ciudades con mayor dificultad para el transporte de mercancías. Una de las zonas identificadas fue el centro de la ciudad de Medellín, por cuanto en esta zona, hasta el día de hoy, existen grandes problemáticas para la distribución de mercancías; por ejemplo: restricciones para el cargue y descargue, vías congestionadas, estacionamiento de los vehículos, restricciones de circulación y de horarios, infracciones de tránsito, sumando a lo anterior el riesgo de robo de mercancía. Igualmente, se identificó que las dinámicas de ciudad vienen creciendo al igual que su población, lo que va incrementando cada vez más las cantidades de pedidos, frecuencia de entrega, y el crecimiento del paqueteo liviano que incluye el comercio electrónico. 
Otro factor que se viene dando en la ciudad son las contingencias ambientales generadas por las fuentes fijas y móviles, que acentúan los graves problemas ambientales, en términos de calidad del aire, generando restricciones de horarios de circulación; los días sin carro son un ejemplo de ello. Así mismo, se cuenta con las zonas urbanas de aire protegido (ZUAP) contempladas dentro del Plan de Desarrollo Metropolitano 2018-2020, las cuales tienen como objetivo implementar acciones dirigidas a gestionar la movilidad de manera más eficiente, limpia y accesible, para reducir las emisiones generadas por los automotores y la congestión vehicular, además de reducir la accidentalidad y promover el uso de energías limpias; todo esto, en zonas delimitadas por sus antecedentes en el no cumplimiento de las normas en calidad del aire (Área Metropolitana del Valle de Aburrá [AMVA], 2018).

Esta problemática, en conjunto, se debatió; se buscó desarrollar proyectos realizados en Europa, y se encontró que el modelo operaba solo en ciertas zonas de Europa, con diferentes condiciones geográficas y sociales, y para pequeños paquetes como sobres de mensajería. El mayor desafío en Colombia consistió en implementar la distribución de paquetes más grandes, más pesados y de mayor volumen. Es allí donde nace LOLA Te Mueve, asumiendo este reto de ciudad.

\section{Modelo actual de LOLA Te Mueve}

La empresa cuenta con siete triciclos eléctricos de carga de tracción humana con pedaleo asistido. Los triciclos son diseñados por la empresa y cuentan con diferentes modelos, dentro de los cuales se tiene el triciclo eléctrico de carga seca.

El triciclo eléctrico de carga seca cuenta con carrocería en perfilería de aluminio liviana para DUM, con una capacidad para llevar hasta doscientos cincuenta kilos de carga, su motor es de $750 \mathrm{w}$, batería de 48 voltios, frenos hidráulicos en las tres ruedas, freno de parqueo y otras adaptaciones para el transportar carga; todo esto focalizado para las entregas de mercancías en zonas céntricas urbanas con restricciones para vehículos grandes. 


\section{Figura 2}

DUM en el centro de la ciudad

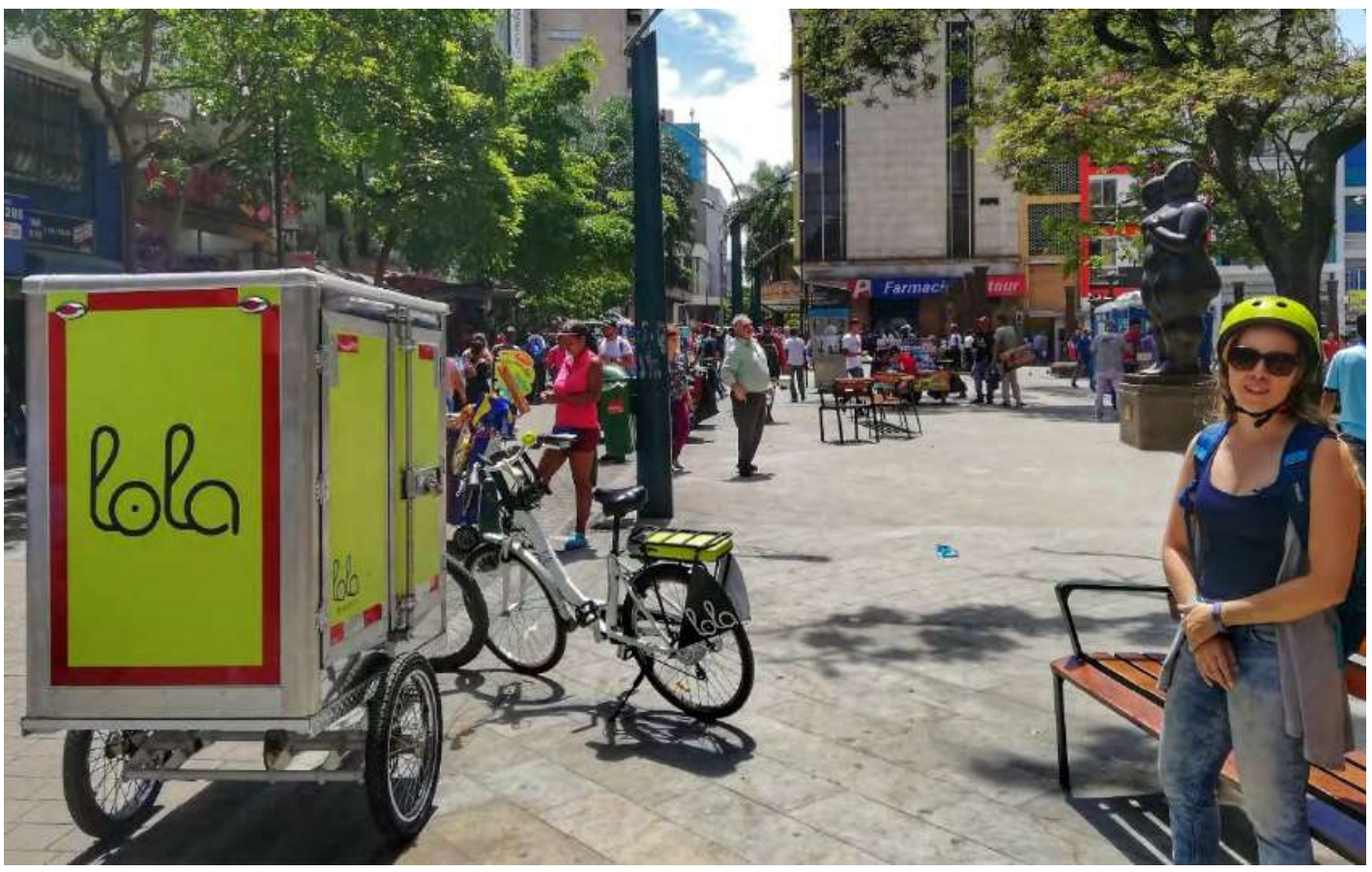

Bicicletas de carga acondicionadas para DUM en el centro de la ciudad de Medellín. Fuente: Archivo LOLA Te mueve

En la actualidad, se realizan operaciones en diferentes sectores, tales como alimentos, construcción y consumo masivo. Dentro de estas operaciones se han desarrollado esquemas con grandes empresas de consumo masivo, a través de un distribuidor en la zona céntrica, con empresas de distribución de alimentos y se han realizado pruebas piloto con una empresa cementera y otra de paquetería, entre otras. Un caso para resaltar hace alusión a una compañía que trasportaba productos al centro de Medellín, a través de un vehículo a gasolina tipo furgoneta (Van) con una media de sesenta y cinco entregas por día; en la actualidad se cubren en un $100 \%$ con la bicicleta de carga. A través del modelo LOLA; con apoyo en la gestión logística, optimización operativa y con dos vehículos sostenibles LOLA se ha logrado duplicar el número de pedidos, generando menores costos en la operación, 
mayor eficiencia en la entrega, disminución en los reprocesos de entrega y menor contaminación ambiental. A lo dicho se sumó la implementación de un HUB (lugar donde se concentran cargas para distribuir) urbano que permitió superar restricciones de cargue y descargue, de acceso vehicular, de horarios restringidos y operaciones muy largas en tiempos de trabajo y restricciones.

Con sus resultados, la empresa muestra que existe una serie de ventajas frente al modelo tradicional (tabla 1), permitiendo generar nuevas estrategias de crecimiento junto con los generadores de carga, donde se ha incluido este tipo de distribución para atender ciertos canales, como el tienda a tienda -en determinadas zonas de la ciudad-con retos en términos de transporte de mercancías.

\section{Tabla 1}

Ventajas técnicas de la distribución en bicicletas de carga

\begin{tabular}{|c|c|c|}
\hline Concepto & Media & Observación \\
\hline Distancia & $20 \mathrm{Km}$. & $\begin{array}{l}\text { En promedio, cada bicicleta de carga recorre } 20 \mathrm{~km} \text { por día, en una zona } \\
\text { georreferenciada y con pedaleo asistido con motor eléctrico }\end{array}$ \\
\hline Peso & $200 \mathrm{~kg}$. & $\begin{array}{l}\text { En promedio, cada bicicleta de carga transporta } 200 \text { kg por día y un máximo } \\
\text { de } 250 \mathrm{~kg} \text {. }\end{array}$ \\
\hline Pedidos & 50 & El promedio de entregas es de 50 pedidos al día, llegando hasta 65 al día. \\
\hline Costos & $\begin{array}{l}\text { ahorro } \\
20 \%\end{array}$ & $\begin{array}{l}\text { Se pueden tener ahorros en promedio de un } 20 \% \text { en costos de operación } \\
\text { vs vehículos tradicionales por conceptos de combustible, seguros y } \\
\text { mantenimiento. Factor costo que depende del tipo de producto a entregar; } \\
\text { por ejemplo, se tienen productos cuya entrega tenía un costo de } \$ 2450 \\
\text { COP/pedido para rebajar a un costo de } \$ 1970 \mathrm{COP} / \text { pedido en el modelo } \\
\text { LOLA te mueve. } \\
\text { El modelo no solo se basa en el ahorro de costos sino en la calidad del servicio } \\
\text { y en los demás beneficios expresados en cuanto a movilidad, sostenibilidad } \\
\text { y flexibilidad. }\end{array}$ \\
\hline $\begin{array}{l}\text { Rendimiento } \\
\text { batería }\end{array}$ & $\begin{array}{l}100 \% \\
\text { para la } \\
\text { ruta }\end{array}$ & $\begin{array}{l}\text { En las operaciones que se han realizado, ninguna presenta problemas en } \\
\text { rendimiento para culminar todo el recorrido. En algunas rutas se han utilizado } \\
\text { dos baterías, debido a la cantidad de peso y volumen de la carga. El costo } \\
\text { de carga es de aproximadamente } \$ 50 \text { COP para la batería, que equivale al } \\
1 \% \text { del costo de un galón de diesel. }\end{array}$ \\
\hline
\end{tabular}

Fuente: Elaboración propia 
Esto ha llevado a que otras compañías, con retos en términos de DUM, se interesen en el modelo Lola, gracias a la integración de equipos (bicicletas eléctricas de carga), modelos (análisis de distribución y logística), esquemas (micro HUB urbanos), y acompañamiento, que aportan al modelo de microdistribución, con el fin de solucionar las problemáticas y restricciones actuales.

LOLA Te mueve se proyecta no solo en el servicio de vehículos sostenibles para la DUM, sino también en levantamiento, procesamiento y análisis de datos, ya que se ha identificado que muy pocas empresas tienen información o no la analizan para la acertada implementación de soluciones o para proponer nuevos modelos logísticos para la DUM. De esta manera es como los procesos que se vienen realizando son efectivos, apoyados por la georreferenciación y localización de los clientes en la zona de trabajo, en radios de acción no mayores a cinco kilómetros en donde se puede impactar un gran número de clientes generando una mejor atención al cliente, más personalizada en canales como el tienda a tienda con zonas en las que se han logrado incrementar las ventas en un $38 \%$, bajando las devoluciones en los pedidos de $7 \%$ a $0,7 \%$.

La estrategia para el 2020 es seguir «pedaleando por el planeta» y poner a rodar más de cuarenta triciclos eléctricos para diferentes procesos de microdistribución y DUM; además, que empresas de diferentes sectores se comuniquen y generen procesos logísticos más amigables con el ambiente, llegando a brindar una analítica de estos datos a las empresas con el propósito de ser más eficientes.

\section{Retos en el desarrollo del modelo de DUM}

Lola Te mueve ha encontrado barreras en la implementación de modelos sostenibles basados en bicicletas eléctricas, barreras que abarcan desde las políticas públicas hasta la toma de decisiones por parte de las empresas. Por ejemplo, aún existe un paradigma frente al uso de este tipo de equipos, en razón a que es visto como una solución solo para microempresarios o empresas informales. A lo anterior se suma el desconocimiento acerca de las pólizas o seguros para la mercancía y conductores, y las pólizas obligatorias de accidentes de tránsito. Un claro ejemplo de cómo superar estas barreras 
es el apoyo de una empresa aseguradora que desarrolló pólizas de seguro para las bicicletas de carga, y seguros para los conductores, permitiendo, así, tener una operación cubierta en riesgos profesionales. La vinculación de esta compañía al modelo de negocio marcó un hito importante en el desarrollo del modelo de negocio y un cambio en la visión de la bicicleta de carga como una solución a los retos actuales de ciudad que se tienen.

Otra dificultad residió en la adecuación de un vehículo que operara de forma óptima no solo para el transporte de mercancías, sino también para la comodidad y seguridad de los conductores; A esto se suma el estado de las vías como factor fundamental en el diseño de los triciclos, ya que son necesarios equipos robustos que puedan soportar el trabajo diario logrando la disponibilidad necesaria para cumplir con los estándares de servicio y extender la vida útil del equipo. Es por ello que el diseño del vehículo está en constante evolución para soportar las cargas y los kilómetros diariamente recorridos.

Una de las principales barreras se da al interior de las mismas organizaciones, puesto que es difícil convencerlas de cambiar sus sistemas tradicionales para utilizar este tipo vehículos. De igual modo, en principio los conductores son reacios a utilizar la bicicleta como medio de distribución, pero una vez se logra iniciar con un proyecto piloto en la empresa se evidencian las ventajas del modelo y disminuye la resistencia.

Como ya se planteó, otra de las dificultades está representada en las condiciones geográficas de la ciudad de Medellín, pues existen numerosos barrios de las periferias que están ubicados en las laderas de la ciudad y el vehículo aún no tiene fuerza suficiente para subir altas pendientes y bajar de forma segura con grandes pesos, situación en la que hoy se está trabajando para desarrollar mejoras en el diseño del vehículo.

En suma, las barreras identificadas y aludidas, tanto las geográficas como las técnicas son más sencillas de superar que las barreras políticas y culturales como se evidencia en las experiencias internacionales documentadas. Por lo tanto, la aplicación de este modelo en las ciudades se podría facilitar mediante un decidido apoyo de las entidades gubernamentales, materializadas en campañas de sensibilización, capacitación y políticas públicas que incentiven el uso de medios de transporte sin motores de combustión, y mediante beneficios 
tributarios, infraestructura, seguridad para la movilidad en ciclas y apoyo a los proyectos de emprendimiento enfocados en la movilidad sostenible. Es así como los planes de desarrollo deben integrar las bicicletas como solución viable a las problemáticas de movilidad tanto como medio de transporte y de distribución de carga e igualmente la gestión de la movilidad y tránsito debe priorizar a estos medios de transporte dentro de las ciudades.

\section{Conclusiones}

La bicicleta de carga se puede convertir en un caso de estudio a nivel nacional e internacional. Se trata de un modelo que puede ser fundamental para generar soluciones en el DUM. Cabe decir que el desarrollo de este tipo de pilotos debe integrar no solo a los emprendedores, sino, además, la triada Universidad-Empresa-Estado, en virtud de que es una problemática compleja que requiere acciones conjuntas para dar una solución que apunte a un futuro de ciudad sostenible, todo con el apoyo de políticas públicas.

La implementación de las bicicletas de carga para la DUM viene de la mano de nuevas tecnologías para el análisis de la operación logística y el monitoreo de los vehículos. En esta, los distribuidores, los 3PL y los generadores de carga tienen la posibilidad de obtener mejores rendimientos. Modelos como el de LOLA Te Mueve pueden ayudar a en la eficiencia de la operación.

Para todo ello es necesario desarrollar políticas de apoyo para las empresas que estén buscando aportar a un nuevo orden logístico urbano, con menores emisiones que afecten la muy deteriorada calidad del aire en las ciudades. El modelo de distribución de LOLA Te Mueve puede ser un referente al integrar las bicicletas eléctricas de carga para la DUM con los micro HUB urbanos.

Este tipo de modelos DUM tienen gran potencial en el apoyo a las pymes que buscan implementar sistemas de distribución a escala de sus volúmenes y con menores costos de distribución. Así mismo, empresas que atienden un segmento de mercado que día a día es más consciente con la sostenibilidad, que se fija cada vez más en los productos sostenibles y con sistemas de distribución de menor impacto en el medio ambiente. Valga advertir que es un modelo que aún puede tener restricciones en zonas geográficas con 
pronunciadas inclinaciones, pero junto con los HUB logísticos urbanos, ciertamente son un modelo de distribución ideal para muchas empresas y para zonas céntricas de grandes ciudades.

Finalmente, hay que decir que de acuerdo con los hallazgos en la investigación documental y en las entrevistas con los empresarios, se identificó la necesidad de divulgar más casos de estudio acordes con los retos actuales en la distribución urbana y la logística de última milla, ya que existe poca información documentada para estos temas; en otras palabras, se recomienda investigar aún más en casos, modelos y experiencias relacionadas con las bicicletas de carga como solución viable a la DUM, por cuanto se puede considerar como un tema relativamente reciente y en evolución.

\section{Referencias bibliográficas}

Aized, T., y Singh, J. (2014). Hierarchical modelling of Last Mile logistic distribution system. The International Journal of Advanced Manufacturing Technology, 70(5-8), 1053-1061. https://link.springer.com/article/10.1007/s00170-013-5349-3

Alcaldía de Medellín. (2016). Plan de Desarrollo: Medellín cuenta con vos 2016-2019. http://bibliotecasmedellin.gov.co/content/uploads/2016/08/Plan_de-Desarrollo_ Medell\%C3\%ADn_2016_2019.pdf

Álvarez, J., y Eslava, A. (2016). La logística urbana, la ciudad logística y el ordenamiento territorial logístico. Revista RETO, 4(4), 21-40

Analdex-Asociación Nacional de Comercio. (2018). La apuesta logística de Colombia en los próximos 5 años. En XIV Congreso Expologística. http://expologisticacolombia.com/ expologistica/wp-content/uploads/2018/05/2018-05-Congreso-Supply-Chain-DR.pdf

Antún, J. P. (2013). Distribución urbana de mercancías: Estrategias con centros logísticos. Banco Interamericano de Desarrollo. https://publications.iadb.org/en/publication/15329/ distribucion-urbana-de-mercancias-estrategias-con-centros-logisticos

Antún, J., Lozano, A., Herández, J. y Hernández, R. (2005). Logística de distribución física a minoristas. Universidad Autónoma de México.

Área Metropolitana del Valle del Aburrá AMVA (2018). Resolución metropolitana 2231 de agosto 31 del 2018. https://www.metropol.gov.co/ambiental/calidad-del-aire/Documents/ Normatividad/Resolucion-metropolitana-2231-2018-ZUAP.pdf

Área Metropolitana del Valle del Aburrá AMVA (9 de julio del 2019). Paqueteo en bicicleta ayuda a mejorar la calidad del aire. https:/www.metropol.gov.co/Paginas/Noticias/ elmetropolitano-ambiental/paqueteo-en-bicicleta-ayuda-a-mejorar-la-calidad-delaire.aspx). 
Barcelona centre logistic (29 agosto 2016). Vanapedal, eco-logística para la distribución urbana de mercancías en Barcelona. https://bcncl.es/vanapedal-eco-logistica-para-ladistribucion-urbana-de-mercancias-en-barcelona/

Brown, J. y Guiffrida, A. (2014). Carbon emissions comparison of last mile delivery versus customer pickup. International Journal of Logistics Research and Applications, 17(6), 503-521. https://www.tandfonline.com/doi/abs/10.1080/13675567.2014.907397

Caballero, L. y Ramos, C. (2017). La bicicleta y el triciclo como modos de transporte de carga y domicilios en el centro histórico de Bogotá. https://ciencia.lasalle.edu.co/ing_civil/112

Cánovas, A. C. (2014). Logística internacional: una herramienta para la competitividad. ICEX España.

Carrillo, K. (2017). Bici-Distribución urbana de mercancías. Zonalogística. https:// zonalogistica.com/bici-distribucion-urbana-de-mercancias/

Castillo, V., Bell, J., Rose, W. y Rodrigues, A. (2017). Crowdsourcing Last Mile Delivery: Strategic Implications and Future Research Directions. Journal of business logistics, 39(1), 7-25. https:/onlinelibrary.wiley.com/doi/full/10.1111/jbl.12173

Colprensa (20 de agosto del 2018). Logística, tarea por hacer en el comercio electrónico. El Colombiano. https://www.elcolombiano.com/negocios/economia/logistica-tarea-porhacer-en-comercio-electronico-NY9188791

Consejo Nacional de Política Económica y Social (Conpes). (2018). Política para el mejoramiento de la calidad del aire. http://www.andi.com.co/Uploads/CONPES\%20 3943\%20Calidad\%20del\%20Aire.pdf

Consejo Privado de Competitividad (CPC). (2017) Informe Nacional de Competitividad 2017-2018. Bogotá. https://compite.com.co/wp-content/uploads/2017/10/CPC_INC_20172018-web.pdf

Consejo Privado de Competitividad (CPC). (2018) Informe Nacional de Competitividad 2018-2019. Bogotá. https://compite.com.co/wp-content/uploads/2018/10/CPC_INC_20182019_Web.pdf

Conway, A., Cheng, J., Kamga, C., y Wan, D. (2017). Cargo cycles for local delivery in New York City: Performance and impacts. New York.

De Souza, R., Goh, M., Lau, H., Ng, W. y Tan, P. (2014). Collaborative Urban Logistics Synchronizing the Last Mile a Singapore Research Perspective. Procedia-Social and Behavioral Sciences. https://doi.org/10.1016/j.sbspro.2014.01.1485

Departamento Nacional de Planeación (2018). Bases del Plan Nacional de Desarrollo 20182022. https://colaboracion.dnp.gov.co/CDT/Prensa/BasesPND2018-2022n.pdf.

. BID (2018). Nueva Visión de la Política Nacional Logística. https://onl.dnp.gov.co/es/ Publicaciones/Documents

Deutsch, Y., $\mathcal{E}$ Golany, B. (2018). A parcel locker network as a solution to the logistics last mile problem. International Journal of Production Research, 56, 251-261. https://www. tandfonline.com/doi/abs/10.1080/00207543.2017.1395490

Devari, A., Nikolaev, A. $\mathcal{E}$ He, Q. (2017). Crowdsourcing the last mile delivery of online orders by exploiting the social networks of retail store customers. Transportation Research Part 
E: Logistics and Transportation Review, 105, pp.105-122. https://www.sciencedirect.com/ science/article/pii/S1366554516308341\#!

El Mundo Ecológico (19 de febrero del 2018). Reparto urbano de mercancías a golpe de pedal. https:/www.elmundoecologico.es/entrevista-podcast/ciclologistica-bicicletascarga-mares-madrid/).

Esmartcity (14 de marzo del 2019). Un centro de distribución urbana de última milla que reparte con bicicletas eléctricas. https:/www.esmartcity.es/2019/03/14/centrodistribucion-urbana-de-ultima-milla-reparte-bicicletas-electricas).

Euromonitor International. (2019). Las 10 principales tendencias globales de consumo para 2019. https://www.fedexpor.com/wp-content/uploads/2019/02/10-tendencias-deconsumo-2019.pdf

Frehe, V., Mehmann, J. E Teuteberg, F. (2017). Understanding and assessing crowd logistics business models - using everyday people for last mile delivery. Journal of Business $\mathcal{E}$ Industrial Marketing, 32(1), 75-97. https:/www.emerald.com/insight/content/doi/10.1108/ JBIM-10-2015-0182/full/html

Gevaers, R., Van de Voord, E., y Vanelslander, T. (2014). Cost Modelling and Simulation of Lastmile Characteristics in an Innovative B2C Supply Chain Environment with Implications on Urban Areas and Cities. Procedia - Social and Behavioral Sciences, 125(20), 398-411. https://www.sciencedirect.com/science/article/pii/S1877042814015213

Hagen, J. Lobo, Z. E Mendoça, C. (2013). The benefits of cargo bikes in Rio de Janeiro: An exploratory case study. En 13th WCTR, July 15-18, 2013 - Rio de Janeiro, Brazil.

Handoko, S., Nguyen, D., y Lau, H. (2014). An auction mechanism for the last-mile deliveries via urban consolidation centre. IEEE International Conference on Automation Science and Engineering, 607-612. https://ieeexplore.ieee.org/abstract/document/6899390

Hübner, A., Kuhn, H., y Wollenburg, J. (2016). Last mile fulfilment and distribution in omnichannel grocery retailing: a strategic planning framework. International Journal of Retail $\mathcal{E}$ Distribution Management, 44(3), 228-247. https://www.emerald.com/insight/content/ doi/10.1108/IJRDM-11-2014-0154/full/html

Iwan, S., Kijewska, K., y Lemke, J. (2016). Analysis of parcel lockers' efficiency as the last mile delivery solution -the results of the research in Poland. Transportation Research Procedia, 12, 644 - 655 https://www.sciencedirect.com/science/article/pii/S2352146516000193

Jimenez, M. (marzo del 2017). San Sebastián hará pruebas piloto de entrega urbana en bicicletas. LogiNews. http://noticiaslogisticaytransporte.com/logistica/09/03/2017/sansebastian-hara-pruebas-piloto-de-entrega-urbana-en-bicicletas/98429.html

Logyca. (s/f) Oportunidades Logísticas en Colombia. Investigación Consultoría Analítica. https:// www.logyca.com/Portals/0/Documentos/Oportunidades_logisticas_en_colombia.pdf

Maes, J. y Vanelslander, T. (2012). The Use of Bicycle Messengers in the Logistics Chain, Concepts Further Revised. Procedia - Social and Behavioral Sciences. 39, 409-423. https:// www.sciencedirect.com/science/article/pii/S187704281200585X

Maes, J (2017). The potential of cargo bicycle transport as a sustainable solution for urban logistics. Doctoral tesis University of Antwerp. 
Melo, S. \& Baptista, P. (2017). Evaluating the impacts of using cargo cycles on urban logistics: integrating traffic, environmental and operational boundaries. European Transport Research Review. 9, 30. https://link.springer.com/article/10.1007/s12544-017-0246-8

Ministerio de Transporte. (2017). Transporte en cifras. https:/www.mintransporte.gov.co/ documentos/15/estadisticas/

. (2018). Resolución 3258 del 3 de agosto del 2018. https://www.mintransporte.gov. $\mathrm{co} /$ publicaciones/5800/mintransporte-da-soporte-legal-para-adoptar-guia-de-cicloinfraestructura-para-ciudades-colombianas/

Monsalve, G., Echavarria, J. y Álvarez, S. (2020). Estudio cienciométrico y bibliométrico como instrumento de análisis de tendencias en educación superior. Caso ingeniería industrial y programas afines. Revista Espacios, 41 (28), 85-99. https://www.revistaespacios.com/ a20v41n28/a20v41n28p07.pdf

Mora, L. (2016). Gestión logística integral: Las mejores prácticas en la cadena de abastecimiento. Segunda edición. Ecoe ediciones.

Muñoz-Villamizar, A., Montoya-Torres, J. R., y Vega-Mejía, C. A. (2015). Non-collaborative versus collaborative last-mile delivery in urban systems with stochastic demands. Procedia CIRP. 30, 263-268. https://doi.org/10.1016/j.procir.2015.02.147

Nocerino, R. Colorni, A. Lia, F. y Luè, A. (2016). E-bikes and E-scooters for Smart Logistics: Environmental and Economic Sustainability in Pro-E-bike Italian Pilots. Transportation Research Procedia, 14, pp. 2362-2371. https://www.sciencedirect.com/science/article/ pii/S2352146516302733

Noyan, N., Balcik, B., y Atakan, S. (2016). A stochastic optimization model for designing last mile relief networks. Transportation Science, 50(3), 1092-1113. https://pubsonline.informs. org/doi/abs/10.1287/trsc.2015.0621

Ørving, T. Fossheim, K. y Andersen, J (2019). Public sector facilitation of cargo bike operations to improve city logistics. En Autonomous Vehicles and Future Mobility, Pages 141-154. https://www.sciencedirect.com/science/article/pii/B9780128176962000111

Pearce, J. (2016). Carrying cargo and affording decarbonised urban mobility - the integration of cargo bikes into urban load-carrying practices. Thesis submitted for the Degree of Doctor of Philosophy in Geography at the University of Canterbury. https://ir.canterbury. ac.nz/handle/10092/12915

Peña, A. y Pérez, J. (2019). Diagnóstico actual logística urbana de la ciudad de Bogotá y posibles alternativas de mejora. Universidad Militar Nueva Granada.

Portafolio. (2018). Panorama logístico en el país es mucho más favorables ahora. http:// www.portafolio.co/negocios/panorama-logistico-en-el-pais-es-mucho-mas-favorableahora-517341

PricewaterhouseCoopers. (2011). Transporte y Logística 2030. Infraestructuras de transporte; ¿Motor o freno de mano para las cadenas de suministro globales?

Rivera Arroyave, M., y Velasco Naranjo, V. (2014). Desarrollo de un modelo de distribución urbana de mercancías con plataformas logísticas aplicado a la ciudad. Ingeniería USB Medellin, 5(1), 67-76. 
Sanz, G., Pastor, R., y Benedito, E. (2013). Distribución urbana de mercancías: descripción y clasificación de soluciones existentes e implementación de dos soluciones novedosas. Dyna, 179, 6-13.

Shu, Y., Shin, K., He y Chen, J. (2015). Last-Mile Navigation Using Smartphones. Proceedings of the 21st Annual International Conference on Mobile Computing and Networking, Paris, 512-524.

Subdepartamento de Inteligencia Comercial de Chile (2014). Boletín TENDENCIAS. https:// www.prochile.gob.cl/wp-content/uploads/2014/05/tendencia_logistica_mayo_2014.pdf

Vakulenko, Y., Hellström, D., y Hjort, K. (2018). What's in the parcel locker? Exploring customer value in e-commerce last mile delivery. Journal of Business Research, 88, 421427. https:/www.sciencedirect.com/journal/journal-of-business-research/vol/88/suppl/C

Wang, X., Zhan, L., Ruan, J., y Zhang, J. (2014). How to choose "last mile" delivery modes for E-fulfillment. Mathematical Problems in Engineering, 2014(1). https://doi. org/10.1155/2014/417129

Wang, Y., Zhang, D., Liu, Q., Shen, F., y Lee, L. H. (2016). Towards enhancing the last-mile delivery: An effective crowd-tasking model with scalable solutions. Transportation Research Part E: Logistics and Transportation Review, 93, 279-293. https://www. sciencedirect.com/science/article/pii/S1366554516300783

Zona Logística (14 de enero del 2016). Tendencias logísticas para 2016. https://www. zonalogistica.com/tendencias-logisticas-para-2016/ 


\section{Economía del comportamiento, circular y colaborativa, tríptico virtuoso para Medellín como ecociudad}

Fernando De Jesús Franco Cuartas ${ }^{1}$

\section{Introducción}

Mediante el análisis de las tres economías de la trilogía económica, en este estudio se busca encontrar las relaciones causales y virtuosas, entre la economía del comportamiento, la circular y la colaborativa, en el contexto de los ODS, como requisito para que la ciudad de Medellín transite, de manera organizada, creciente, diligente y consiliente, hacia la configuración de un territorio bajo los términos de referencia que dan vida a las ecociudades. Este viaje implica reconocer que los axiomas planteados por Adam Smith, en su libro cumbre sobre la economía, La riqueza de las Naciones (Mitani, 2017) y que en el devenir de la economía de mercado actual se han tornado obsoletos, y estamos hablando de las preguntas clásicas en cualquier sistema económico, como: ¿qué producir?, ¿cuándo producir?, ¿dónde producir?, ¿cómo fijar precios?, ¿cómo distribuir?, ¿qué consumir?. Incluso hoy por hoy, a parte de los interrogantes anteriores, está en entredicho el poder de la «mano invisible» desde las economías del comportamiento, circular y colaborativa, como se describen más adelante en los resultados de esta investigación.

Las políticas públicas y el liderazgo de las autoridades son determinantes en el comportamiento de los ciudadanos para hacer digna la vida en el territorio; en esta dirección, la mayoría de los argumentos para allanar el camino hacia las ecociudades, descansan en la profecía de Thomas Robert Malthus (1766-1834) quien sostenía que la desproporción del crecimiento poblacional, geométrico y desordenado, frente al crecimiento aritmético de

Especialista en Finanzas, instructor de planta del SENA. Correo electrónico: fdjfranco@sena.edu.co 
los alimentos, sería el detonador de la civilización, pero el profesor noruego Jorgen Randers afirma que «La población mundial no llegará nunca a los nueve mil millones de personas. Atribuye la inesperada disminución a que las mujeres de los países en desarrollo están mudándose a suburbios urbanos, y en un arrabal urbano no tiene sentido formar una familia numerosa» (Ibbitson $\mathcal{B}$ Bricker, 2019).

El modelo ortodoxo de extracción, consumo, compra y desechos, está agotado; en general, la obsolescencia programada o final anticipado e imprevisto para el consumidor de la vida útil de un producto, aunado a la explosión demográfica de antaño, planteó hacia los años 70 del siglo XX, el dilema entre crecimiento y sostenibilidad en todos los frentes científicos y académicos del planeta, lo que permitió el punto de inflexión en el sistema lineal de la economía, dando paso a las teorías del comportamiento, vale decir, adquirir consciencia de dos de las preguntas claves en la ciencia económica, ¿por qué producir y qué consumir? Los primeros acercamientos a estos interrogantes dan vida a la economía circular, entendida esta como un modelo cíclico que imita la naturaleza y se conecta con ella (Peláez $\mathcal{B}$ Del Granado, 2019); además, en concepto de algunos analistas, de darle respiro a la Pachamama, en su inmensa capacidad de absorber los desechos del capitalismo de expansión en la era global.

\section{Marco teórico}

La consulta sobre la literatura disponible permitió encontrar la relación directa entre crecimiento del producto nacional bruto (PNB) y la creación de empleos; e indirecta, con los desechos de la economía tradicional en el informe del Foro Económico Mundial el cual estima que el cambio hacia una economía circular podría agregar US $\$ 1$ billón a la economía global para 2025, evitar cien millones de toneladas de desechos y generar cien mil empleos en cinco años (weforum, 2014). En cuanto a América Latina y el Caribe, la Comisión Económica para América Latina (Cepal, 2018) proyecta

que la transición hacia la sostenibilidad energética genere más de un millón de empleos en América Latina y el Caribe hacia 2030. De igual manera, la transición a una economía circular, en la que se mejora la eficiencia y 
la vida útil, escapando a la obsolescencia programada (sic) de los materiales, al promover la durabilidad y la capacidad de reparación, remanufactura, reutilización y reciclaje, conllevaría ganancias de empleo en la región. Esta transición generaría 4,8 millones de puestos de trabajo netos en 2030. (p.6)

La comunidad científica y, en particular, la disciplina de ingeniería ambiental elevó las alarmas por el calentamiento global asociado por la generación de treinta y ocho mil millones de material particulado cada año, vertido a la atmósfera por la actividad humana y animal:

La tierra, nuestro hogar, está comenzando a parecerse cada vez más a un inmenso montón de basura. Es de anotar que cuando las personas utilizan energía para crear una zona estructurada en sus cuerpos y en sus hogares, han de incrementar la entropía en otras partes del entorno en forma de residuos, contaminación y otras formas de desorden, segunda ley de la termodinámica. (Pinker, 2019, pág. 161)

El caso del programa de Gobierno de la Alcaldía de Medellín, Un Salto al Futuro, se relaciona con el hecho de que «al empezar a desarrollarse, los países priorizan el crecimiento sobre la pureza ambiental, pero conforme se van enriqueciendo, sus pensamientos se dirigen al medio ambiente» (Pinker, 2019, pág. 164). Por otro lado, El Plan Nacional de Desarrollo 2018-2022, Pacto por Colombia, Pacto por la Equidad, del Gobierno del presidente Iván Duque Márquez introduce con la estrategia nacional de economía circular nuevos elementos para fortalecer el modelo de desarrollo económico, ambiental y social del país, a partir de la lógica de «producir conservando y conservar produciendo» (República de Colombia, 2019, pág. 118). Lo anterior implica un cambio cultural frente a los deshechos de la economía lineal, cambio cultural que exige compromiso ético y moral de todos los colombianos para entender el accionar y responsabilidad consigo mismo, con los demás y con la naturaleza, iniciando el camino hacia la sostenibilidad para producir y consumir sin comprometer las expectativas de las generaciones futuras en cuanto a la satisfacción de sus necesidades.

La economía circular con peso de ley inicia en Japón en el 2000, a través de la Ley de promoción de la utilización efectiva de los recursos; 
luego se promulgan normas en la misma dirección en Corea, China, Escocia, Comunidad Europea, Holanda y Canadá 2017; Estrategia para un Ontario sin desperdicios (Strategy for a Waste-Free Ontario) se cita en el documento de la República de Colombia. Cuando los Estados legislan a favor del desarrollo y sostenibilidad, sus estrategias tienen trazabilidad sobre la conducta de los individuos, sentando las bases para el constructo de la economía del comportamiento, pues el legislador es fundamental en la motivación, a través de campañas pedagógicas, hacia el cambio de actitud de las personas, tanto naturales como jurídicas, para que migren de un modelo lineal a un modelo de ecociudad con estadios intermedios en la circularidad y la economía colaborativa. En la dirección anterior, el Gobierno central de Colombia expresa que el concepto de economía circular «surge como una respuesta a la explosiva demanda de materias primas y recursos naturales para sustentar el crecimiento poblacional en el mundo, la dependencia entre países para abastecerse y la relación con la eficiencia en el uso de recursos y el cambio climático, el gran desperdicio de materiales como basura y la contaminación que estos producen en los ecosistemas (Presidencia de la República de Colombia, 2019, pág. 19).

Los beneficios esperados, de acuerdo con cálculos de la Fundación (Ellen MacArthur, 2017), al implementar modelos de circularidad en la cadena de valor, en sectores de mercancías de alta rotación (alimentos en empaques desechables, elementos de cuidado personal, entre otros), podría tener un ahorro en el rendimiento de costos de materiales entre 595 y 705 miles de millones de dólares por año a nivel global.

Parafraseando el dilema entre explosión demográfica, demanda de alimentos y agotamiento de recursos, en el contexto apocalíptico de Malthus como una de las fuentes de inspiración para el origen de la economía circular en el documento de estudios económicos sectoriales de la Superintendencia de Industria y Comercio, resultado de la investigación realizada por Rodríguez $\mathcal{E}$ Lozano, se argumenta como uno de los inductores de valor que dan vida a la economía colaborativa a las recientes crisis financieras han ayudado al surgimiento de la economía colaborativa, en la medida en que han sido un escenario clave para el desarrollo de nuevos modelos de mercado que las 
personas han aprovechado ya sea para obtener ingresos a partir de los bienes que poseen, como para acceder más fácilmente a determinados servicios.

De nuevo, por el lado de la economía conductual, los resultados nos ubican en la conclusión que plantea Thaler (2018) en su trabajo Economía del comportamiento, pasado, presente y futuro, cuando afirma:

es hora de acoger plenamente lo que yo llamaría economía basada en la evidencia. La economía se ha convertido en una disciplina cada vez más empírica. Hamermesh (2013) encuentra que el porcentaje de artículos "teóricos" en las principales revistas de economía se redujo del 50,7 \% en 1963 al 19,1 \% en 2011. Es indudable que somos una disciplina empírica; así que aceptémoslo. (p.39)

Precisamente, la economía de las evidencias muestra que el dilema entre recursos y crecimiento económico está más vigente que nunca, por cuanto llevó a diferentes pensadores a plantear alternativas que mitigaran esa brecha -. Es así como desde los años 80, psicólogos vienen planteando hipótesis alternativas al modelo económico tradicional en toda la cadena de valor, para frenar la producción, distribución y consumo compulsivo y desbordado. En esta línea, desde el año 2014 el Foro Económico Mundial WEF estima que «para el año 2030 se calcula un aumento de tres billones de consumidores en el mundo que generarán una importante demanda de energía; por ello, es esencial revertir la lógica de descartar los desperdicios, por un modelo donde estos se reutilicen y valoricen» (WEF, 2014, pág. 3). El gran reto planteado por el Foro Económico Mundial desde el 2014 le ha dado trazabilidad a las hipótesis de incorporar ideas del campo de la psicología, a la ciencia económica tradicional, las cuales tienen que ver como es el funcionamiento del cerebro del Homo sapiens a diferencia del Homo economicus, término utilizado para caracterizar el comportamiento del hombre en el modelo económico estándar. De acuerdo con los planteamientos de Facundo Manes (Manes $\mathcal{Z}$ Niro , 2019), recuerda que somos una especie, social capaz de imaginar, lo que nos hace únicos frente a los demás seres vivos, y es esta capacidad mental la que se puede entrenar y motivar hacia determinados fines a la hora de interactuar en un sistema determinado, en particular, en el económico. La premisa anterior, en el contexto social de las creencias, el procesamiento de la información y el conjunto de preferencias de los individuos 
matiza el corpus cognitivo para el estudio teórico-conceptual del campo de la economía del comportamiento, donde

el modelo económico estándar asume que los seres humanos toman decisiones con el fin de maximizar su propio bienestar (sin importarnos los demás), usando toda la información disponible y procesando esta información adecuadamente, teoría de las expectativas racionales (sic). Nuestras preferencias se asumen constantes en el tiempo y nuestras decisiones no dan importancia al contexto, creencias, emociones o a la forma cómo diferentes opciones son presentadas. (BID-INDES, 2020, pág. 5)

Puesto en estos términos, un primer hallazgo tiene que ver con que el Homo economicus del modelo económico estándar o tradicional toma decisiones sin tener en cuenta los factores «comportamentales», como sí los tiene en cuenta el Homo sapiens. Este último, en la economía conductual, otra acepción de la economía del comportamiento, en su libro 21 lecciones para el siglo XXI (Noah Harari, Trabajo, 2019) plantea la siguiente hipótesis:

Se ha descubierto que todas las elecciones que hacemos, escoger desde la comida hasta la pareja, son resultado no de algún misterioso libre albedrío, sino del trabajo de miles de millones de neuronas que calculan probabilidades en una fracción de segundo. La tan cacareada "intuición humana" es en realidad. "reconocimiento de patrones (p.39)

El modelo económico tradicional, hoy en día, es cuestionado desde todas las disciplinas humanas, en particular en los cursos de posgrado; tal es el caso de los programas de maestría en administración de negocios MBA «cuando se emplean modelos mentales para representar nuestra manera de entender "cómo funcionan las cosas", pero estos modelos mentales no son exactos: somos personas y como individuos, muestras experiencias y nuestro conocimientos son limitados concluye Josh en su obra MBA Personal lo que se aprende en un MBA por el precio de un libro. (Kaufman, 2017)

La economía colaborativa, soportada en las TIC y las tecnologías de aprendizaje de conocimiento (TAC), denominado ecosistema digital, es definido como el conjunto de infraestructuras y prestaciones (plataformas, dispositivos de acceso) asociadas a la provisión de contenidos y servicios a 
través de Internet (Katz, 2017), que están generando cambios tectónicos en la sociedad, pues los emprendedores de la tercera ola de internet (Case, Prólogo, 2017a) tienen el reto de transformar, a partir de plataformas de uso masivo, sectores clave de la humanidad como la salud, la educación, las finanzas, el conocimiento, el uso intensivo del open acces, la administración, la mitigación del cambio climático y la amenaza latente de la confrontación biológica, nuclear y atómica. Un punto a favor de la economía colaborativa consiste en que el progreso tecnológico nos permite hacer más con menos; además, la tecnología digital, subyacente a la economía de Silicon Valley, está desmaterializando el mundo al posibilitar el consumo colaborativo.

El advenimiento teórico-conceptual de la economía, al ser una ciencia es normatizada y, en este campo, el legislador viene actuando en diferentes escenarios para regular el uso de las plataformas como instrumentos de producción, consumo y distribución de productos bienes y servicios como lo plantea la sección de asuntos legales del periódico La República, en la medida en que estas mediaciones digitales rompen con el esquema de las relaciones sociales de producción, dando paso a escenarios colaborativos dentro y fuera de la cadena económica, e impulsando la competencia entre mercados abiertos y masificados, donde las utilidades son el producto de altos volúmenes y precios más favorables para el consumidor, que los ofertados en el modelo estándar, o economía clásica, agobiado de elevados costos fijos, tanto de producción como de operación en función de estructuras organizacionales burocráticas.

Buscando trazabilidad con las líneas precedentes, es fundamental la regulación y control de parte del Estado en las plataformas colaborativas. Es de resaltar en este punto, la génesis de dichas mediaciones de parte de América Online AOL. América Online en formato, «todo en uno», en la década de los 90 del siglo XX (Case, Nace America Online, 2017b), con presencia en sectores tales como transporte, hospedaje; servicios relacionados con la comida, las finanzas, las actividades de hogar, la búsqueda de empleo; así mismo, entrenamiento físico, salud y educación, entre otros. Existen algunos ejemplos de regulación como el Decreto 2119 de 2018 del Mincomercio que reglamentó la prestación de servicios de alojamiento turístico y la Resolución 2163 de 2016 del Mintransporte, concluye Rodríguez. 
El reto para el ecosistema digital de la región es revertir la tendencia en los beneficios económicos asociados al uso de plataformas, dado que América Latina, lejos de crear una industria de contenidos, servicios y aplicaciones innovadoras, más allá de algunos casos aislados de éxito, está transfiriendo riqueza al primer mundo a través de la utilización de plataformas foráneas: Despegar, Airbnb, Uber, LinkedIn, Skype, WhatsApp, Google, Bing; y a redes sociales: Facebook, Twitter, Instagram, Taringa; plataformas de alojamiento: app store; plataformas de agregación: YouTube, Netflix, Google play, amazon, Apple tv; plataformas educativas: Massive Online Open Courses MOOC, como afirma Katz.

La economía colaborativa es el reflejo de las transformaciones que vienen adelantando los jóvenes emprendedores como respuesta al nuevo orden social, económico y político, al migrar contenidos a las TIC y las TAC. Cabe destacar el uso pionero que Barack Obama hizo de Twitter para su exitosa campaña presidencial en los Estados Unidos de Norteamérica.

Los campos de acción de la economía digital tienen que ver con el consumo colaborativo, a partir de intercambio y comercialización, segundo "Hazlo tú mismo" (Do ityourself en inglés); reviviendo la teoría del prosumo o economía invisible (Toffler, 2006) como actividad transaccional no monetizada a la hora de medir el PNB mundial, y tiene que ver con la producción contributiva; el sector financiero es el tercer campo de impacto de la economía colaborativa, y es así como se habla de finanzas participativas con el norte de financiar proyectos a través del mecanismo crowdfunding, vehículo para obtener recursos en masa del público potencial. En este campo se habla incluso de la idea de Open Bank (Repositorio Banrep, 2020), siguiendo la realidad de la portabilidad numérica y de información en el sector de la telefonía móvil. Por último, está el campo del open acces (Elsevier.com, 2020), conocimiento abierto por parte de la comunidad científica y académica en el entendido de obtener realimentación cognitiva y poder potencializar el open acces para beneficio del progreso y bienestar humano.

Para analizar la hipótesis de Investigación del Centro de Innovación Universidad La Gran Colombia, planteada por Fernando Franco (Franco, 2019) quien considera que el gobierno colombiano les ha declarado la guerra a las innovaciones tecnológicas, en particular en las aplicaciones del 
sector transporte. Para ello, es importante considerar el contexto que hace Rodríguez (2019):

El derecho positivo se ha quedado corto con la aparición de este tipo de modalidades de interacción económica entre oferentes y consumidores. Su aparición ha traído inquietudes legales interesantes como la necesidad de regularlas, la inclusión de requisitos para su acceso al mercado frente a demás oferentes ya regulados, una eventual competencia desleal, la responsabilidad, la protección de usuarios, las relaciones laborales, el régimen tributario o la protección de datos personales.

A pesar de la disrupción teórico-conceptual que conlleva el tríptico económico, debemos considerar los cimientos entregados por la economía clásica, el cual le enseñó a la gente a pensar en la economía como una «situación en la que siempre se gana», en la que mis beneficios son también tus beneficios (Noah Harari, 2018), enseñanza que está presente en el espíritu de la economía del comportamiento, la economía circular y la economía colaborativa, como bien lo acota el nobel de economía 2017, Richard Thaler.

Es prometedor encontrar que el objetivo general de la estrategia nacional de economía circular, incorporado en el Plan Nacional de Desarrollo del Presidente Duque, sintetiza el objetivo de este estudio, como punto de partida para seguir profundizando en las relaciones de causalidad y no de casualidad entre el tríptico económico, cuando se redacta en los siguientes términos: promover la transformación productiva para maximizar el valor agregado de los sistemas industriales y agropecuarios y las ciudades sostenibles en términos económicos, ambientales y sociales, a partir de la circularidad, innovación tecnológica, colaboración en nuevos modelos de negocio» (Presidencia República de Colombia, 2019, pág. 37).

De acuerdo con Jhon Rawls (citado por Navajas, 2019), el padre del experimento mental: el velo de la ignorancia, los individuos toman las decisiones para intentar maximizar no solo la renta sino las características y los privilegios sociales que les favorecen (Navajas, 2019), lo cual sirve de preámbulo al tríptico económico, más allá de modelo económico estándar. El velo de la ignorancia, según el autor citado, allana el sendero hacia la objetividad, pues tomar decisiones implica tener una mente imparcial. 
El concepto de ecociudad, en palabras del alcalde de Medellín Quintero, significa que la capital antioqueña, con visión futurista le apuesta a aumentar el espacio público por habitante, el número de árboles en zonas urbanas, al manejo eficiente e inteligente de los residuos sólidos, la masificación de los vehículos eléctricos y de gas, así como la protección de la biodiversidad ( $E l$ Tiempo, 2020) y soportado en el plan de gobierno, Medellín Agenda 20202023 (Quintero, 2019).

El acercamiento a las características que identifican a una ecociudad devela la agricultura a pequeña escala: fuentes de energías renovables, incremento de áreas verdes, las cuales deben ser, al menos, el 20\% del total de la superficie urbana; así mismo, asegurar la calidad de vida; amigable con el medio ambiente: disminuir la contaminación y optimización del transporte público. De otro lado, los elementos esenciales hablan del bienestar de las personas, renovación del espacio público, reducción del monóxido de carbono (CO2), incentivar el comercio justo, economía circular —reducir, reutilizar, reciclar- (iCuidemos el planeta!, 2020).

\section{Metodología}

El primer paso consiste en la revisión de la literatura existente sobre el tema de economía del comportamiento; en segundo lugar, la literatura sobre la economía circular y, por último, se revisa la literatura sobre la economía colaborativa y la ecociudad. El orden obedece a la sintaxis que impone la psicología sobre la conducta de las personas, como insumo motivacional hacia las demás tipologías de economía; es decir, cuando los individuos se apropian del valor de reciprocidad, actúan de manera proactiva en la cadena de la economía circular, al percibir beneficios y, de manera general, como se plantea en la investigación Economía del comportamiento: pasado, presente y futuro (Thaler, 2018) El interés en la psicología del comportamiento humano es un retorno de la economía a sus orígenes. Adam Smith aludió conceptos clave como la aversión a la pérdida, el exceso de confianza y el autocontrol.

El Banco Interamericano de Desarrollo (BID) en alianza con el Instituto del Desarrollo Económico y Social (INDES) en su plataforma virtual (BIDINDES, 2020) realiza pedagogía a través de cursos online sobre la economía 
del comportamiento, el cual sirvió de referente para la elaboración teórico-conceptual. Los elementos allegados para el tríptico económico se complementan y se profundizan con el rastreo en repositorios académicos y de investigación como Elsevier, Researchgate, Econpapers y la biblioteca electrónica SSRN, todos ellos de fuentes primarias.

Para el caso de la economía colaborativa, se realiza vigilancia tecnológica en Google Scholar, en gremios económicos como la Asociación Nacional de Industriales (ANDI), asociaciones como Colombia Fintech, Ministerio de las TIC, presidencia de la República de Colombia, Apps.co; además, en plataformas de trabajo colaborativo a nivel de producción, consumo, financiación y desarrollo sostenible. En el tema de los ODS, la referencia inicial para la conceptualización de las ecociudades es el plan de gobierno de la Alcaldía de Medellín para el periodo 2020-2023, denominado un Salto al Futuro, el cual se redactó bajo los lineamientos globales de la ONU.

Los datos e información obtenidos se procesan en ofimática para establecer las relaciones teórico-conceptuales entre las tres economías, hasta determinar su trazabilidad y capacidad técnica funcional para la toma de decisiones emocionales, que permitan optimizar los recursos escasos y devengan en equipos colaborativos, virtuosidad, que conduzca hacia la conceptualización de ecociudades y, de forma paralela, a la búsqueda de información cualitativa, se elaboró y aplicó en la última semana de junio de 2020, un cuestionario de siete preguntas a una muestra aleatoria simple, por conveniencia y no probabilística, de doscientas trece personas pertenecientes a la base de datos propia, a través de WhatsApp con diseño y graficación en Google.

\section{Resultados}

Como trabajo de campo, para explorar la apropiación teórico-conceptual de esta investigación, el diseño metodológico incluyó un cuestionario de siete preguntas dirigidas a una muestra aleatoria simple por conveniencia en la ciudad de Medellín a los habitantes de Medellín, el cual fue respondido a través de la red social WhatsApp por doscientas trece personas (figura 1), de las cuales el 54 \% fueron mujeres y el $46 \%$ hombres. El 45,1\% de los encuestados manifestaron tener formación universitaria, el 32,9\% posgrado, 
el 8,5 \% educación media. Frente a la pregunta: Selecciona la opción que caracteriza a la economía del comportamiento, el 33,3 \% contestó N/R, el 25,8 \% respondió que todas las opciones planteadas son correctas y el 24,4 \% escogió: avalancha de información.

Para el 37,1 \%, materia prima, producir, consumir, reciclar es la opción u opciones correctas al hablar de economía circular; para el 31,5\% los ODS es lo correcto; el 20,2 \% de los encuestados respondió N/R. A la pregunta: Selecciona la opción u opciones correctas al hablar de economía colaborativa, el 36,6\% seleccionó la opción optimización de recursos, 22,5 \% respondieron $\mathrm{N} / \mathrm{R}$, el 24,4 \% seleccionaron la opción plataformas digitales; la opción: todas las opciones son correctas, fue seleccionada por el 25,4 \% de las doscientas trece personas de la muestra.

El diseño y las condiciones ambientales fue la opción señalada por el 57,7 \% de los encuestados como la opción correcta a la hora de hablar de ecociudad; el 21,1 \% eligió N/R, y el 17,7 \% escogió: todas las opciones son correctas. Por último, a la pregunta: Conoces cuáles son los Objetivos del Desarrollo Sostenible, el 59,6 \% respondió si, y el 40,4 \% no.

\section{Figura 1}

Resultados de la encuesta a doscientas trece personas de Medellín
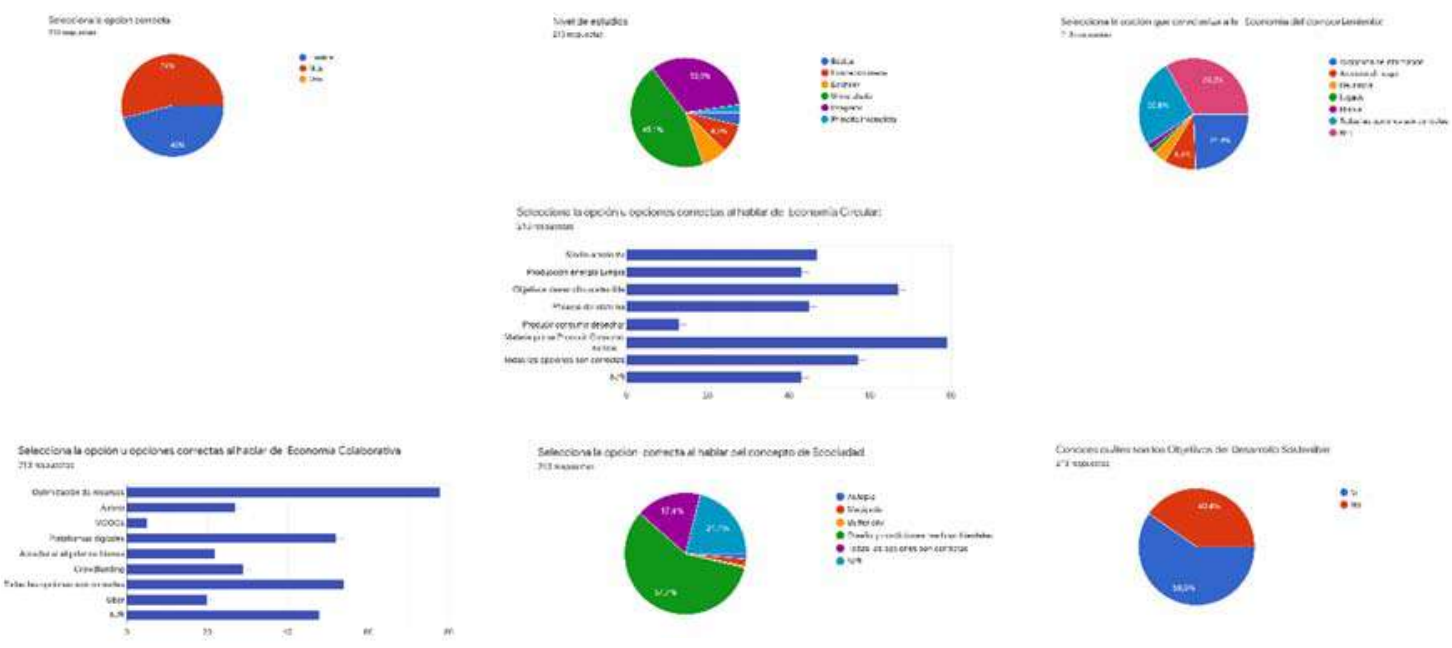

Respuestas al cuestionario realizado en Medellín. Fuente: Elaboración propia 
En la tabla 1 se enfatiza el poder para generar nuevos empleos en la economía circular y colaborativa y su relación inversa con la menor extracción de materias primas, la conservación del agua y la mayor generación energética, desde fuentes alternativas — como la eólica, la térmica, la calórica y nuclear - a favor del medio ambiente, al disminuir las emisiones de $\mathrm{CO} 2$, dada la implementación de procesos tecnológicos digitales. La transición hacia las ecociudades implica más y mayor apoyo a los procesos de CTEI que apalancan la economía digital, en función de la ciencia de datos, la inteligencia artificial y el internet de las cosas, al servicio de la nueva economía digital, que deviene en el diseño de ciudades ecológicas donde los asentamientos humanos disfruten de los espacios de ciudad, en términos de desplazamientos, calidad de vida y optimización de zonas verdes, incluida la movilidad en bicicleta; en fin: el punto de llegada de la virtuosidad del tríptico económico.

El tránsito hacia ecociudades, desde el punto de vista del ecosistema digital, plantea la retirada de la obsolescencia tecnológica programada o finalización anticipada de la vida útil de los productos, y así frenar el desangre de recursos, que a lo largo de la economía estándar ha sufrido la naturaleza. El reto de la Alcaldía actual, más allá de estar alineada con los ODS, es la implementación de políticas públicas que alineen a los ciudadanos, a través de campañas pedagógicas en el contexto de la economía del comportamiento para generar un cambio de actitud frente a la producción extractiva, consumo innecesario, compulsivo y egoísta para conservar el equilibrio de nuestro hogar en el planeta tierra.

\section{Tabla 1}

Relaciones entre las economías del tríptico y las ecociudades

\begin{tabular}{llll}
\hline $\begin{array}{c}\text { Economía } \\
\text { tradicional }\end{array}$ & \multicolumn{1}{c}{$\begin{array}{c}\text { Economía del } \\
\text { comportamiento }\end{array}$} & Economia circular & Economía colaborativa \\
\hline Homo Economicus & Homo Sapiens & Homo Sapiens & Homo Sapiens \\
\hline Racional & No siempre Racional & No siempre racional & No siempre racional \\
\hline Egoísta & Altruista & Altruista & Altruista \\
\hline \multirow{2}{*}{ Maximiza riqueza } & $\begin{array}{l}\text { Maximiza } \\
\text { competencias } \\
\text { actitudinales }\end{array}$ & $\begin{array}{l}\text { Maximiza habilidades } \\
\text { y destrezas }\end{array}$ & $\begin{array}{l}\text { Maximiza los procesos de } \\
\text { CTEI }\end{array}$ \\
\hline
\end{tabular}




\begin{tabular}{llll}
\hline \multicolumn{1}{c}{$\begin{array}{c}\text { Economía } \\
\text { tradicional }\end{array}$} & \multicolumn{1}{c}{$\begin{array}{c}\text { Economía del } \\
\text { comportamiento }\end{array}$} & Economía circular & Economía colaborativa \\
\hline $\begin{array}{l}\text { Agotamiento de } \\
\text { recursos }\end{array}$ & $\begin{array}{l}\text { Optimiza } \\
\text { potencialidades }\end{array}$ & Optimiza vida útil & $\begin{array}{l}\text { Optimiza curva de } \\
\text { aprendizaje }\end{array}$ \\
\hline $\begin{array}{l}\text { Escasez motiva la } \\
\text { acción. }\end{array}$ & Sesgos cognitivos & Poca Cultura RRR. & Cultura emprendimiento \\
\hline Individualismo & Comunidad & Comunidad & Comunidad \\
\hline Empirismo & Modelos mentales & Modelos mentales & Modelos mentales \\
\hline Desconfianzas & Confianza & Confianza & Confianza y reputación \\
\hline Lineal & Integral & Ciclo vital & P2P \\
\hline $\begin{array}{l}\text { Obsolescencia } \\
\text { programada }\end{array}$ & Vida útil infinita & Prolongar vida útil & Vida útil infinita \\
\hline Costos elevados & Consumo vital & Bajos costos & Economía de Escala \\
\hline PIB aritmético & PNB geométrico & PNB geométrico & PNB exponencial \\
\hline $\begin{array}{l}\text { Tasas desempleo } \\
\text { persistente }\end{array}$ & $\begin{array}{l}\text { Cualificación para el } \\
\text { empleo }\end{array}$ & $\begin{array}{l}\text { Generación de } \\
\text { empleos }\end{array}$ & $\begin{array}{l}\text { Generación de nuevos } \\
\text { empleos }\end{array}$ \\
\hline Datos & Datos e información & Datos e información & Nuevo conocimiento \\
\hline $\begin{array}{l}\text { Crecimiento del } \\
\text { comercio }\end{array}$ & $\begin{array}{l}\text { Interfaz entre las } \\
\text { diferentes cadenas }\end{array}$ & $\begin{array}{l}\text { Conflicto entre } \\
\text { crecimiento y recursos }\end{array}$ & $\begin{array}{l}\text { Resultado de crisis } \\
\text { financieras. Aceleración e } \\
\text { incubación APPs. }\end{array}$ \\
\hline
\end{tabular}

Síntesis de la trazabilidad entre las economías del comportamiento, circular y colaborativa. Elaboración propia con base en la literatura existente sobre el tríptico económico.

\section{Conclusión}

El objetivo general de la investigación se alcanza y se sintetiza en la tabla 1 , donde se presentan las características y las relaciones más relevantes obtenidas, entre la economía del comportamiento - como estadio inicial para implementar la economía circular y la economía colaborativa- enfatizando que estas dos últimas se matizan de acuerdo con el grado de desarrollo del modelo económico; es decir, en las economías desarrolladas tiene primacía la economía colaborativa sobre la circular y, al contrario, en países con desarrollo inferior se está en la fase de regular la economía circular en su fase incipiente con asomos tímidos, al menos en el desarrollo de contenidos en plataformas, en la economía digital. 
La toma de conciencia de los ciudadanos, en el marco de la economía del comportamiento es la cuota inicial para un tríptico económico con una ciudad limpia que optimiza sus recursos físicos ambientales, replicando la circularidad de la madre naturaleza; de igual modo, fomenta la economía colaborativa en el contexto de los términos para hacer de Medellín un territorio para la vida digna: ecociudad.

\section{Referentes bibliográficos}

iCuidemos el planeta! (23 de mayo de 2020). cuidemoselplaneta.org. Obtenido de https:// cuidemoselplaneta.org/que-es-una-ecociudad/

BID-INDES. (15 de junio de 2020). indesvirtual.iadb.org/course/. Obtenido de https:// indesvirtual.iadb.org/course/view.php?id=1856Esection=2

Case, S. (2017a). Prólogo. En S. Case, La tercera OLA (págs. 1 -13). Barcelona: Empresa Activa.

Case, S. (2017b). Nace America Online. En S. Case, La tercera OLA (págs. 49 -64). Barcelona: Empresa Activa.

CEPAL. (19 de noviembre de 2018). repositorio.cepal.org/. Obtenido de https://repositorio. cepal.org/bitstream/handle/11362/44185/1/S1800886_es.pdf

El Tiempo. (17 de mayo de 2020). eltiempo.com/. Obtenido de https:/www.eltiempo.com/ colombia/medellin/que-significa-que-medellin-se-convierta-en-una-ecociudad-496218

Ellen-MacArthur-Foundation-Towards-. (15 de agosto de 2017). Ellen MacArthur. Obtenido de https://www.ellenmacarthurfoundation.org/assets/downloads/publications/EllenMacArthur-Foundation-Towards-the-Circular-Economy-vol.1.pdf

Elsevier.com. (29 de Junio de 2020). elsevier.com. Obtenido de https:/www.elsevier.com/ about/open-science/open-access

Franco, J. (3 de Diciembre de 2019). https://www.asuntoslegales.com.co/. Obtenido de Asuntos legales: https://www.asuntoslegales.com.co/analisis/javier-francisco-franco-2939866/ guerra-del-estado-contra-la-economia-colaborativa-2939858

Grupo de Estudios Económicos. (1 de mayo de 2020). https://www.sic.gov.co/. Obtenido de Superintendencia de industria y comercio: https://www.sic.gov.co/sites/default/files/ files/Proteccion_Competencia/Estudios_Economicos/Documentos_elaborados_Grupo_ Estudios_Economicos/Economias_Colaborativas_GEE_final.pdf

Ibbitson, J., $\mathcal{E}$ Bricker, D. (2019). Malthus e hijos. En D. B. Ibbitson, El planeta vacio (págs. 41 - 66). Bogotá: Random Houese.

Katz, R. (15 de agosto de 2017). repositorio.cepal.org/. Obtenido de https://repositorio.cepal. org/bitstream/handle/11362/38916/1/ecosistema_digital_AL.pdf

Kaufman, J. (2017). Modelos mentales, no métodos. En J. Kaufman, MBA Personal (págs. 23 - 42). Barcelona: Concecta.

Manes, F., E Niro , M. (2019). El cerebro del futuro. Bogotá: Planera. 
Minambiente, $\mathcal{Z}$ Minagricultura. (2019). Presidencia de la República de Colombia. En P. R. Colombia, Estrategia nacional de economía circular.Cierre de ciclos de materiales innovación tecnológica, colaboración y nuevos modelos de negocio (págs. 18 - 21). Bogotá: Documentos Presidencia de Colombia.

Mitani, A. (19 de mayo de 2017). Laboratorio de análisis económico y social. Obtenido de https:// www.laes.org.mx/debate-economico-no-17/adam-smith-y-la-riqueza-de-las-naciones/

Navajas, S. (2019). El velo de Ignorancia de Rawls. En S. Navajas, Historia de la Filosofía (págs. 384 -394). Madrid: Almuzara.

Noah Harari, Y. (2018). El credo capitalista. En Y. N. Harari, De animales a Dioses (págs. 336 -366). Bogotá: DEBATE.

Noah Harari, Y. (2019). Trabajo. En Y. N. Harari, 21 lecciones para el siglo XXI (págs. 38 -64). Bogotá: DEBATE.

Peláez, P., \& Del Granado, S. (23 de diciembre de 2019). https://blogs.iadb.org/. Obtenido de BID: https://blogs.iadb.org/bidinvest/es/liberando-la-economia-circular-en-americalatina-y-el-caribe/

Pinker, S. (2019). Medio ambiente. En S. Pinker, En defensa de la ilustración (págs. 161 -200). Bogotá: PAIDÓS.

Quintero, D. (5 de octubre de 2019). Un salto al futuro Alcaldía de Medellín 2020 -2023. Medellín, Antioquia, Colombia.

Repositorio Banrep. (27 de Junio de 2020). repositorio.banrep.gov.co/. Obtenido de https:// repositorio.banrep.gov.co/bitstream/handle/20.500.12134/9536/Recuadro\%206.\%20 Open\%20Banking.pdf?sequence=18\&isAllowed=y

República de Colombia. (2019). Presidencia República de Colombia. Bogotá: Presidencia de la República de Colombia.

Rodriguez, L. (20 de Diciembre de 2019). https://www.asuntoslegales.com.co. Obtenido de LR: https://www.asuntoslegales.com.co/analisis/laura-rodriguez-402115/reflexionessobre-las-plataformas-colaborativas-2946268

Rodriguez, M., $\mathcal{Z}$ Lozano, S. (21 de abril de 2018). sic.gou.co. Obtenido de https://www.sic.gov. $\mathrm{co} /$ sites/default/files/files/Proteccion_Competencia/Estudios_Economicos/Documentos _ elaborados_Grupo_Estudios_Economicos/Economias_Colaborativas_GEE_final.pdf

Thaler, R. (2018). Economía del comportamiento: Pasado, presente y futuro. Revista de Economía Institucional, 9 - 43.

Toffler, A. (2006). Los gestores de la verdad. En A. y. Toffler, La revolución de la riqueza (págs. 204 - 208). Bogotá: DEBATE.

WEF. (17 de enero de 2014). https://es.weforum.org/. Obtenido de https://es.weforum.org/: https://es.weforum.org/

weforum. (15 de enero de 2014). Obtenido de http://www3.weforum.org/docs/: http://www3. weforum.org/docs/WEF_ENV_TowardsCircularEconomy_Report_2014.pdf 


\title{
Economía circular: retos para la academia y el sector productivo desde la investigación científica
}

\author{
Jorge Amado Rentería Vera ${ }^{1}$ \\ Luisa Fernanda López Gómez ${ }^{2}$ \\ Yesit Jovan Rodríguez Caro ${ }^{3}$ \\ Chárol Kátherin Vélez Castañeda ${ }^{4}$
}

\section{Introducción}

La Agenda mundial de desarrollo sostenible (ONU, 2014) ha incorporado en uno de sus pilares el concepto de economía circular como una apuesta hacia el desarrollo sostenible para la generación de un mayor nivel de conciencia por parte de la ciudadanía, el gobierno y la empresa, mediante la valorización continua de los recursos, el cierre de los ciclos de materiales y la creación de nuevos modelos económicos con enfoque sostenible; por ejemplo, un modelo que utiliza de forma eficiente los recursos naturales y los residuos, eliminando el concepto de desecho para convertirlo en materia prima. Los Objetivos de Desarrollo Sostenible (ONU, 2014) y el Plan de Acción de la Economía Circular de la Unión Europea, citado en la Estrategia Nacional de Economía Circular (Gobierno de la República de Colombia, 2019) incentivan

\footnotetext{
Doctor en Ciencias de la Educación, docente ocasional Institución Universitaria Pascual Bravo; Grupo de Investigación QUALIPRO. Correo electrónico: j.renteriave@pascualbravo.edu.co

2 Doctorando en Ingeniería de Sistemas (Universidad Nacional de Colombia), docente ocasional Institución Universitaria Pascual Bravo; Grupo de Investigación QUALIPRO. Correo electrónico: luisa. lopez@pascualbravo.edu.co

3 Magíster en Logística Integral, docente ocasional Institución Universitaria Pascual Bravo; Grupo de Investigación QUALIPRO. Correo electrónico: y.rodriguezca@pascualbravo.edu.co

4 Magíster en Logística Integral, docente ocasional Institución Universitaria Pascual Bravo; Grupo de Investigación QUALIPRO. Correo electrónico: charol.velez@pascualbravo.edu.co
} 
para Colombia la investigación, la innovación y la generación de valor en la cadena productiva, a partir del intercambio, reciclaje y optimización de energía, agua y materiales.

La transformación productiva desde la innovación, que maximice el valor agregado de los sistemas industriales contribuye al establecimiento de ciudades y comunidades sostenibles generando impactos positivos en términos ambientales, sociales y económicos. Es así como trabajos orientados al aprovechamiento de la materia prima, el uso eficiente de las fuentes de energía renovables, la reducción de los residuos y emisiones, además de la conservación por el uso eficiente de los recursos hídricos, son temas de vanguardia en el mundo y han motivado esta revisión. Es por esto que las organizaciones con enfoque en economía circular requieren de procesos empresariales eficientes y sostenibles, soportados en los fundamentos y pilares de la economía circular para la creación de modelos de producción y consumo.

El Gobierno colombiano, a través de la Estrategia Nacional de Economía Circular, prioriza varios vehículos para su operacionalización, tales como los modelos de negocio, las cadenas de valor, las ciudades sostenibles, los parques industriales ecoeficientes y la responsabilidad extendida de los actores de la cadena (Gobierno de la República de Colombia, 2019) hecho que reconoce posturas orientadas a la sostenibilidad y su relación con la empresa, así como la consideración del rol gubernamental y de la universidad en los procesos de investigación e innovación en esa materia.

En primer lugar, se expone la metodología de revisión abordada, así como las categorías y fuentes de información empleadas, que en el caso se cimentaron en las palabras claves: economía circular, logística inversa, reciclaje y organización-sostenibilidad rastreados en las bases de datos SCOPUS, Dialnet, Google Académico, Scielo y Redalyc. En segundo lugar, se presentan los resultados segmentados en tres categorías de base, a saber: los artículos de reflexión, los de revisión y los de investigación. Finalmente, se resalta que del grueso del proceso es evidente que el caso colombiano es poco explorado desde la academia y su interacción con los demás actores, dado que el número de publicaciones identificadas son muy pocas, sustentando además que, para el entorno nacional, regional y local, aún hay mucho por explorar y desarrollar en esa materia. 
A lo anterior, como posibilidad de trabajo futuro, se debe agregar que en Colombia el Plan Nacional de Desarrollo 2018-2022 (Gobierno de la República de Colombia, 2018) define una ruta para la economía dinámica, incluyente y sostenible en el capítulo denominado «Pacto por el Emprendimiento y la Productividad», cuyas premisas resaltan la frase "producir conservando y conservar produciendo». Sin embargo, para los años 2019 y 2020 son pocas las publicaciones en materia, lo cual puede deberse a la premura del proceso de indagación, la brecha existente en la política pública, su adopción por parte de todos los actores y el bajo interés de investigación relacionada.

Por ello, una de las principales conclusiones se centra en motivar a todos los entes sociales a efectuar y trabajar en el desarrollo de mejores prácticas de sostenibilidad en las organizaciones, pues, entre otras cosas, ello abre nuevas oportunidades en el mercado, en la academia y, en general, para que la ciudadanía incorpore cambios en los estilos de vida y nuevos hábitos de consumo a partir de prácticas responsables -como estímulo a la demanda y también como tendencia para la creación de ventajas competitivas-. En materia local, el departamento de Antioquia, como parte del pacto por la economía circular, se compromete a mejorar la competitividad a 2030 superando desafíos en materia ambiental y aportando a la gran meta nacional de reciclar y reutilizar los residuos (Gobierno de la República de Colombia, 2019).

De acuerdo con los intereses de la investigación, el propósito es indagar acerca de cuáles son las tendencias de investigación académica relacionadas con economía circular, logística inversa, reciclaje y organizaciónsostenibilidad, además de conocer cuáles son los aportes en la investigación científica sobre economía circular a los sectores productivos, y cómo han impactado las prácticas de economía circular a la generación de valor en el sector productivo.

\section{Metodología de análisis}

La revisión bibliográfica se efectúa desde un enfoque cualitativo como lo señala Esterberg (como se citó en Hernández, Fernández y Baptista, 2015). En este sentido, con esta revisión documental se busca identificar las tendencias investigativas alrededor del concepto de economía circular para estimular a 
productores, proveedores y demás actores de los sistemas productivos, para el desarrollo e implementación de nuevos modelos de negocio que integren la administración de residuos y manejo eficiente de los materiales; alcance definido en el marco de las nuevas políticas públicas del gobierno colombiano. Para ello, se establecieron categorías y subcategoría de análisis.

De este modo, el proceso de revisión surge de la interpretación de los hallazgos desde la fase heurística y hermenéutica aplicada en las bases de datos SCOPUS, Dialnet, Google Académico, Scielo y Redalyc, mediante la búsqueda de las palabras claves: economía circular, logística inversa, reciclaje y organización-sostenibilidad.

En la fase heurística no se aplican filtros en la búsqueda de las palabras claves con el fin de permitir mayor cobertura de artículos para el análisis.

En la fase hermenéutica, la interpretación se desarrolló bajo el sentido sintáctico, semántico y pragmático (Beuchot, 1999). En el sentido sintáctico, se identificó la coherencia entre el título y los intereses de investigación. En el sentido semántico se analizó el abordaje general de los artículos; y en el sentido pragmático, fue viable inferir sobre el impacto en los hallazgos de las propuestas de investigación. De ahí que se haya diseñado una matriz de análisis de los escritos para identificar, entre otros, el año de publicación, los autores, los temas tratados, el país de origen y las conclusiones.

La interpretación de los resultados permitió la clasificación de los artículos en tres categorías: reflexión, revisión e investigación. Los artículos de reflexión corresponden a aquellos cuya finalidad consiste en divulgar resultados e invitan al lector a profundizar en el tema; los artículos de revisión tienen por objetivo realizar una exploración de la literatura científica publicada hasta el momento y, los artículos de investigación, como aquellos en los cuales se plantea un problema específico y se describe la estrategia experimental para encontrar y comprobar los resultados obtenidos.

De este modo, el proceso de revisión bibliográfica posibilitó identificar sesenta y ocho artículos e informes en el que se soportaron los respectivos análisis, sintetizados como se indica en la figura 1 . 


\section{Figura 1}

Proceso de revisión bibliográfica

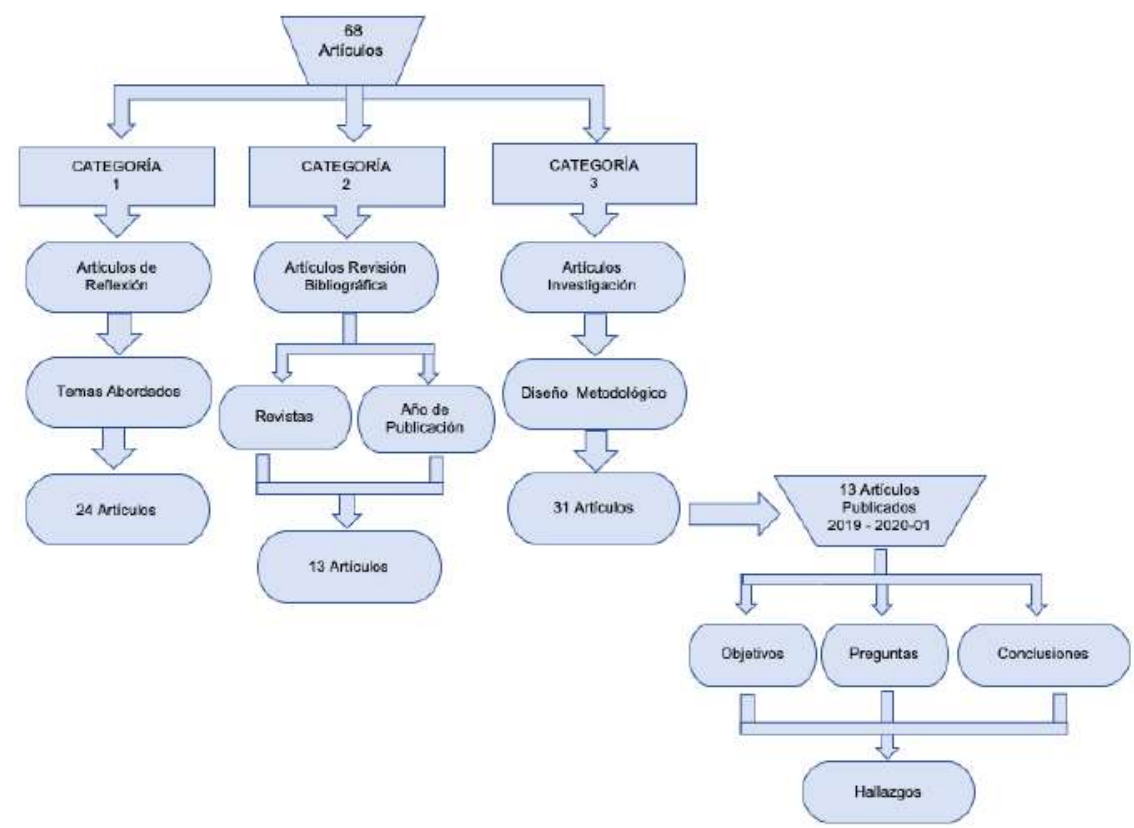

Nota: clasificación de los artículos de acuerdo con tres categorías de análisis entre reflexión, revisión e investigación. Fuente: Elaboración propia.

Como se observa, la información obtenida permite conocer el estado de la cuestión para retomar los aspectos relevantes en términos teóricometodológicos y establecer futuras líneas de investigación.

\section{Resultados}

Los principales resultados por categoría se desarrollan a continuación y muestran hallazgos que, en general, permitieron establecer que en Colombia se trata de un campo aún con posibilidad de investigación, que por los bajos niveles de participación de la academia y la empresa, favorecen el desarrollo de procesos conjuntos. 


\section{Categoría 1: artículos reflexivos}

En el análisis documental se identifican veinticuatro artículos que corresponden al 35,3 \% del total. En ellos se observa una postura cohesiva, unificada y coherente como lo muestra la tabla 1 .

\section{Tabla 1}

Artículos reflexivos

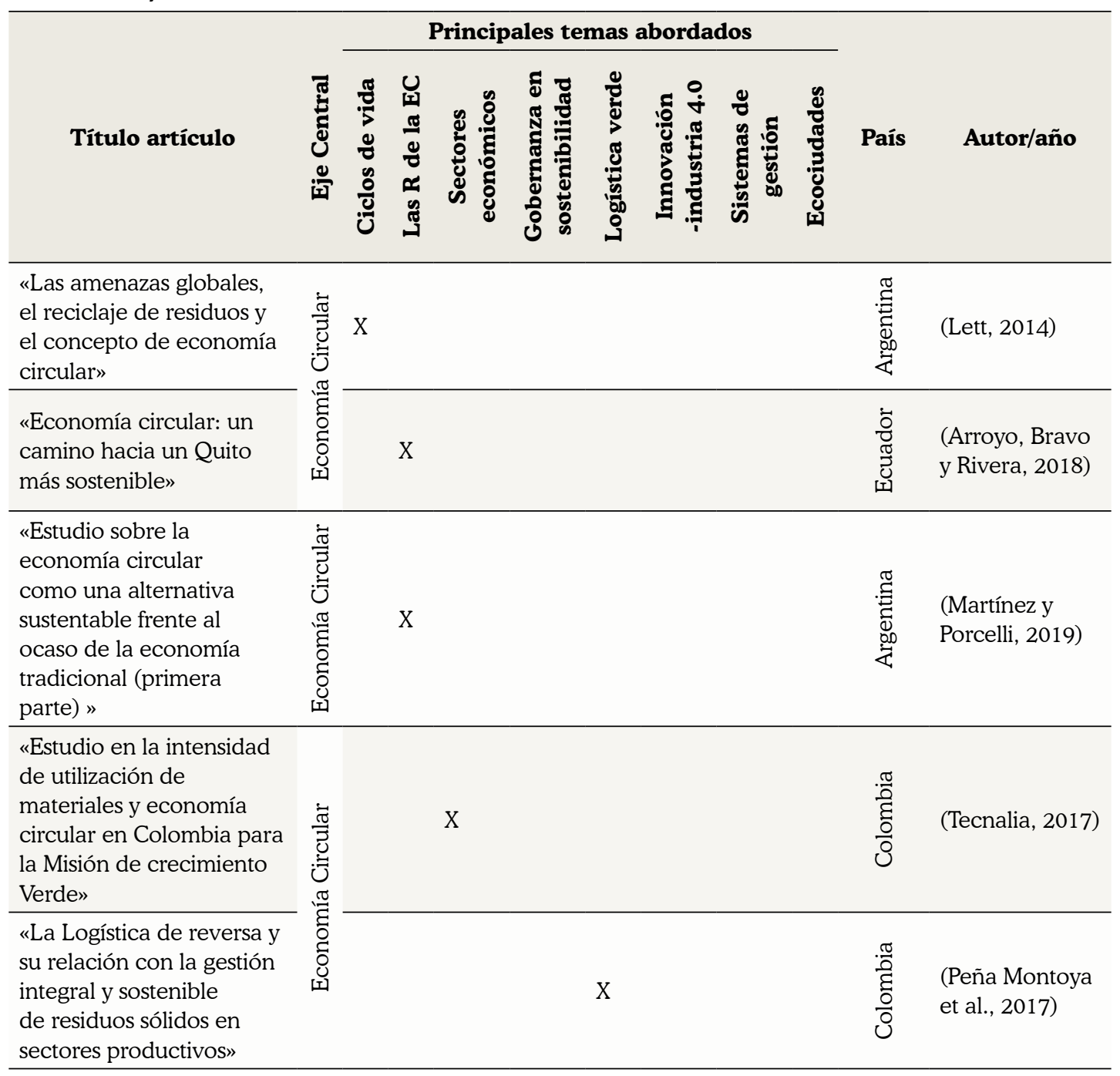




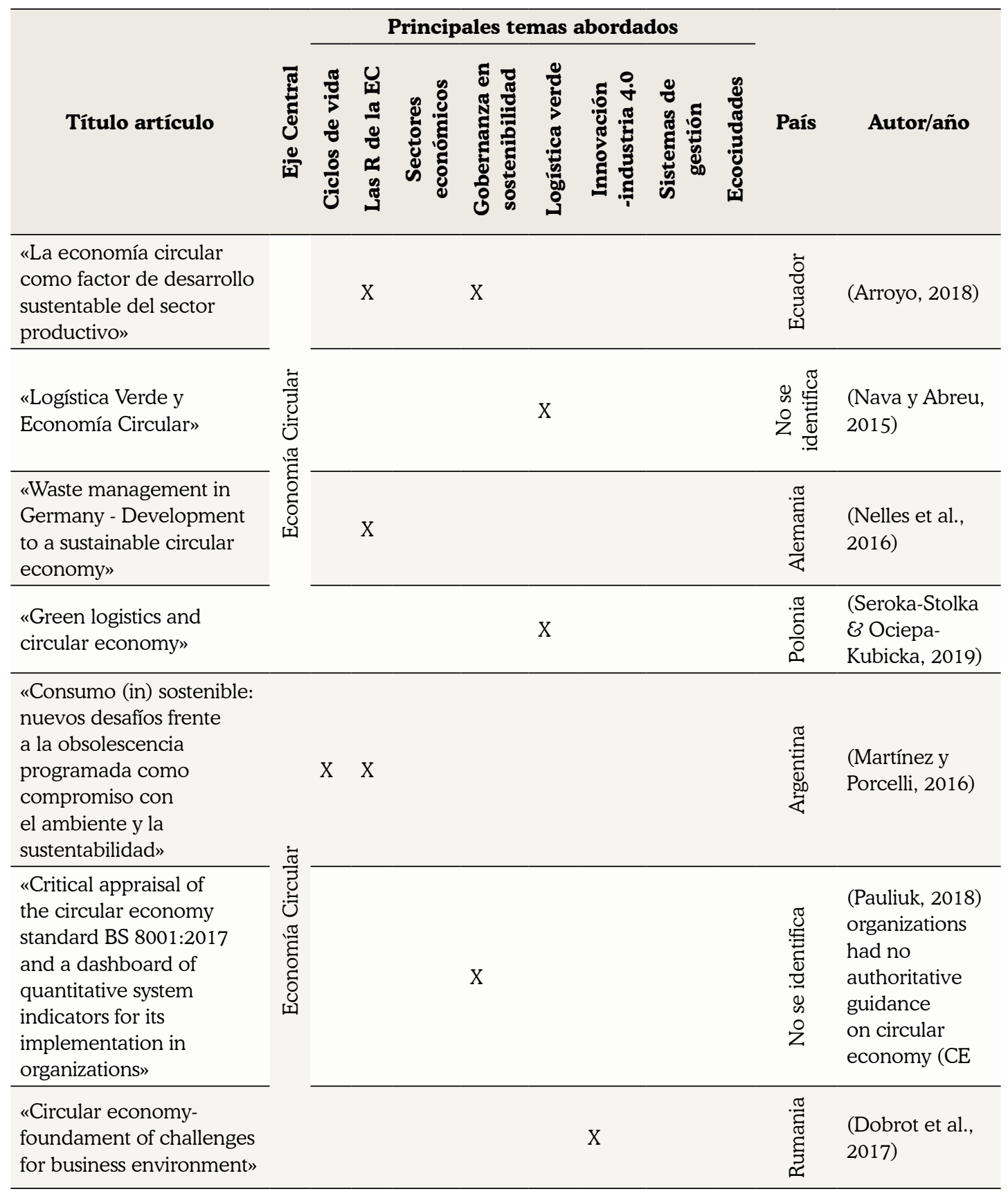




\begin{tabular}{|c|c|c|c|c|c|c|c|c|c|c|c|}
\hline \multirow[b]{2}{*}{ Título artículo } & \multirow[b]{2}{*}{ 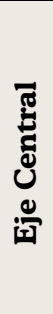 } & \multicolumn{8}{|c|}{ Principales temas abordados } & \multirow[b]{2}{*}{ País } & \multirow[b]{2}{*}{ Autor/año } \\
\hline & & $\begin{array}{l}\frac{\pi}{0} \\
\vdots \\
0 \\
0 \\
0 \\
0 \\
0 \\
0\end{array}$ & 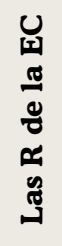 & 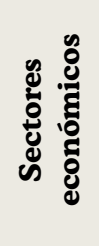 & 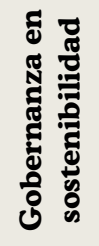 & 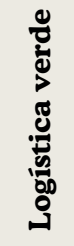 & 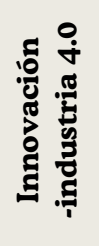 & 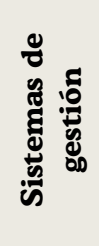 & 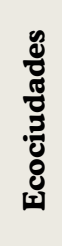 & & \\
\hline $\begin{array}{l}\text { «Gestión de residuos } \\
\text { industriales y } \\
\text { sostenibilidad. Necesidad } \\
\text { de un enfoque de } \\
\text { economía ecológica» }\end{array}$ & \multirow{4}{*}{ 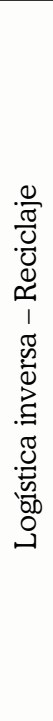 } & & & $\mathrm{X}$ & & $\mathrm{X}$ & & $\mathrm{X}$ & & $\frac{\pi}{3}$ & $\begin{array}{l}\text { (Valdés et al., } \\
\text { 2019) }\end{array}$ \\
\hline $\begin{array}{l}\text { «Producción Más Limpia: } \\
\text { una revisión de aspectos } \\
\text { generales» }\end{array}$ & & & & & & & & $\mathrm{X}$ & & $\begin{array}{l}\frac{\pi}{0} \\
\text { है } \\
\frac{0}{0}\end{array}$ & $\begin{array}{l}\text { (Bernal } \\
\text { Figueroa et al., } \\
2017 \text { ) }\end{array}$ \\
\hline $\begin{array}{l}\text { «La logística inversa y el } \\
\text { cambio climático» }\end{array}$ & & & & $\mathrm{X}$ & $\mathrm{X}$ & & & & & 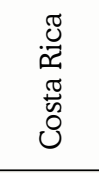 & $\begin{array}{l}\text { (Rojas Conejo, } \\
\text { 2016) }\end{array}$ \\
\hline $\begin{array}{l}\text { «Manejo de residuos } \\
\text { sólidos en América Latina } \\
\text { y el Caribe» }\end{array}$ & & & $\mathrm{X}$ & & & & & & & 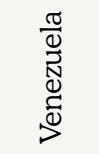 & $\begin{array}{l}\text { (Zulia et al., } \\
\text { 2006) }\end{array}$ \\
\hline $\begin{array}{l}\text { «The Stakeholders' } \\
\text { perspective within the B } \\
\text { corp certification for a } \\
\text { circular approach» }\end{array}$ & \multirow{3}{*}{ 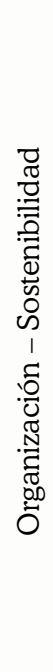 } & & & & & & & $\mathrm{X}$ & & $\stackrel{\stackrel{0}{\pi}}{\stackrel{\Xi}{\Xi}}$ & $\begin{array}{l}\text { (Poponi et al. } \\
\text { 2019) }\end{array}$ \\
\hline $\begin{array}{l}\text { "Green business } \\
\text { operations for building } \\
\text { eco-cities: Identifying } \\
\text { the role of business and } \\
\text { critical success factors for } \\
\text { sustainability» }\end{array}$ & & & & $\mathrm{X}$ & $\mathrm{X}$ & & & & $\mathrm{X}$ & 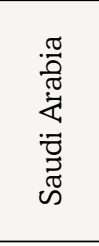 & $\begin{array}{l}\text { (Alreshidi, } \\
\text { 2018) }\end{array}$ \\
\hline $\begin{array}{l}\text { «Business models for } \\
\text { social innovation of } \\
\text { municipal solid waste } \\
\text { recycling companies: } \\
\text { Comparison of two } \\
\text { business cases in Thailand } \\
\text { and Taiwan» }\end{array}$ & & & & $\mathrm{X}$ & $\mathrm{X}$ & & & & & 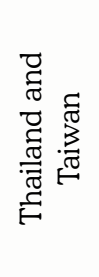 & $\begin{array}{l}\text { (Chen et al., } \\
\text { 2018) }\end{array}$ \\
\hline
\end{tabular}




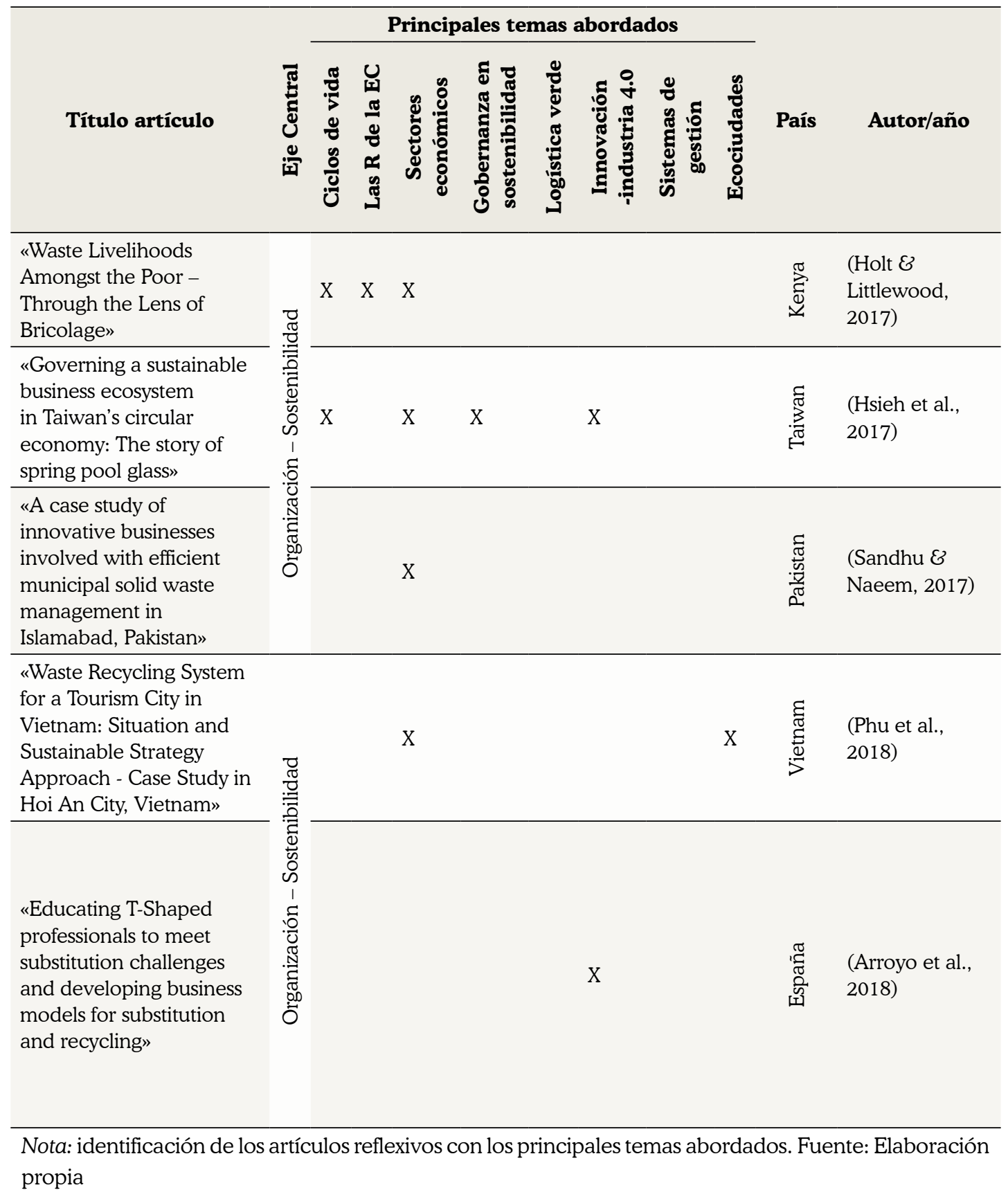


Como se observa en la tabla anterior, el propósito reflexivo gira en torno a temas relacionados con la economía circular (en adelante, EC), la logística verde, el reciclaje y la organización sostenible. Desde esta perspectiva solo se identifican dos artículos con origen en Colombia, lo que posibilita análisis hacia distintas posturas reflexivas.

Con relación a los artículos nacionales, Bernal, Beltrán y Márquez (2017) señalan que la producción más limpia impacta de manera directa a las organizaciones, debido a que se logran procesos más amigables con el medio ambiente y se generan actividades encaminadas a lograr una eficiencia ambiental. Si bien para lograr un desarrollo sostenible es necesaria una cooperación de diferentes actores, se deben adoptar prácticas de producción y consumo sostenible para mitigar efectos adversos al planeta.

Por su parte, el Centro de Desarrollo Tecnológico en su estudio sobre la intensidad de utilización de materiales y economía circular en Colombia, para la Misión de Crecimiento Verde, compara cinco naciones europeas de lo cual se concluye que en la mayoría de las experiencias internacionales se encuentran tasas de recuperación y reciclaje de hasta un $50 \%$ en los residuos manufactureros y de construcción, lo que determina un gran campo por explorar para el país (Tecnalia, 2017).

En cuanto a estudios Latinoamericanos, Arroyo (2018) analiza las cifras de reutilización del material de recuperación en Ecuador, señalando la importancia que tiene para el impulso de iniciativas basadas en diseño sin residuos, aumento de resiliencia, utilización de energías limpias y optimización de recursos, entre otros, evidenciando una baja tasa de recuperación de materiales. Así mismo, Nava y Abreu (2015) reflexionan sobre el concepto de responsabilidad social empresarial (en adelante, RSE) y la gran importancia que ha tomado en los últimos años en la región, con relación a dichas medidas, en donde se han abierto espacios para el debate entre representantes del gobierno, la sociedad civil y los empresarios; lo anterior deja indicada la necesidad de mayores acciones por parte de cada uno de los eslabones de la cadena productiva.

Lett (2014) en su artículo titulado «Las amenazas globales, el reciclaje de residuos y el concepto de economía circular», devela la necesidad de un cambio significativo en los métodos actuales de producción. Para ello se 
fomenta la responsabilidad social de las personas y de las empresas, mediante el reciclaje, la reutilización, el aprovechamiento de los residuos, la capacitación y la innovación de estrategias que permitan el logro de prácticas ambientales.

A su vez, Martínez y Porcelli (2019) analizan el impacto ambiental de la obsolescencia programada y la economía verde. En este sentido, establecen la confiabilidad de la EC como alternativa económica para el desarrollo de una cultura de sostenibilidad organizacional en la industria argentina.

Entre tanto, Rojas (2016) analiza cómo la logística inversa en el ciclo de mejora continua de la cadena de suministro, permite aportar a la reducción y mitigación de los efectos secundarios al medio ambiente, dejando de lado al consumidor, en razón a que actúa de manera individual con esfuerzos mínimos para lograr una eficiencia ambiental. Así, la mayor responsabilidad se delega a las organizaciones.

Para Bernal Figueroa et al. (2017) la producción más limpia impacta de manera directa las organizaciones, ya que con esta se logran procesos más amigables con el medio ambiente y se generan actividades encaminadas a la eficiencia ambiental. Si bien para un desarrollo sostenible es necesaria la cooperación de diferentes actores, también lo es adoptar prácticas de producción y consumo sostenible, mitigando efectos adversos al planeta.

En el ámbito global, se destacan las reflexiones de Nelles et al. (2016) sobre la gestión de residuos en Alemania y su funcionamiento en los últimos cuarenta años. Entre sus hallazgos prevalece la gran oferta de carácter industrial para el aprovechamiento, lo que ha generado caída de los precios locales; además, hacen énfasis en la necesidad de reutilizar los desechos orgánicos, adicional al reciclaje de materiales de la construcción. En sintonía con ese estudio, los investigadores Seroka-Stolka $\mathcal{E}$ Ociepa-Kubicka (2019) proponen para el tratamiento de lodos una nueva forma de gestionar los residuos, mediante la utilización térmica, indicando que se trata de un tratamiento viable y que contribuye con la logística verde contemporánea.

En otro sentido, Pauliuk (2018) analiza la evaluación critica del Estándar de la Economía Circular BS8001:2017, emitida por la British Standards Institution. En el análisis incluye una propuesta de indicadores cuantitativos para la evaluación de la estrategia de EC en las organizaciones, indicando que la norma de estandarización no es clara en la evaluación del seguimiento; 
además, señala que las organizaciones deben contribuir con el crecimiento de las existencias de uso de los materiales.

Por su parte, Poponi et al. (2019) proponen un modelo basado en la sostenibilidad, en nuevos productos y en estrategias diferenciadoras de producción e intercambio, poniendo de manifiesto la necesidad de mejorar y comprender la relevancia de las partes interesadas ${ }^{5}$ como un factor crítico en la creación de un nuevo valor en la gestión empresarial. El análisis surge a partir de un sistema de certificación denominada B-Corp (Benefit Corporation) en el marco de los principios de la EC.

A su vez, Alreshidi (2018) presenta un modelo de investigación que define los roles que juegan las empresas en la construcción de ciudades sostenibles (también llamadas ciudades inteligentes o ciudades ecológicas), incluyendo variables como las alianzas privadas y públicas efectivas, estrategias y prácticas de sostenibilidad, táctica y operación de las empresas, y los roles que vinculan las empresas con el gobierno, entidades y residentes de la ciudad. Igualmente, desarrollaron en la investigación una herramienta para examinar los roles de las empresas para hacer que los proyectos en las ciudades sean sostenibles y eficientes.

Por su parte Chen et al. (2018) reflexionan en cuanto a los cinco desafíos en los modelos sociales de innovación basados en economías del aprovechamiento: i) Las diferentes economías pueden necesitar planificar y diseñar de manera diferente sus sistemas de reciclaje institucionales para que puedan incorporar diferentes grados de diversidad y escalas para satisfacer las necesidades de reciclaje; ii) Algunas economías son más adecuadas para el gobierno del sistema de reciclaje por parte de entes públicos y otros para organizaciones privadas. Esta diferencia en el modo de gobernanza institucional también puede afectar el grado de la competencia entre recicladores; iii) Los sistemas de recompensas diferentes deben estar diseñados para estimular diferentes intenciones de los propietarios de negocios de reciclaje a que adopten modelos de negocio intencionalmente diferentes; iv) Las reglas de las empresas de reciclaje deben establecerse con suficiente comunicación y en cocreación con todos los interesados; y v) Algunas economías tienen negocios de menos edad en promedio.

Denominadas por algunos actores como stakeholders. 
La educación en emprendimiento ecológico afecta significativamente la prosperidad y la motivación de las nuevas generaciones para participar en negocios en un ambiente tan ecológico.

Holt $\mathcal{E}$ Littlewood (2017) examinaron dos empresas sociales y más de veinticinco microempresarios de la economía informal en Kenia. Los hallazgos más relevantes indicaron: i) El papel de las ONG y las empresas sociales es fundamental para generar acceso a nuevos mercados y capturar un mayor valor, ofreciendo a los empresarios oportunidades que les proporcionen un flujo de efectivo mínimo garantizado que ayude a suavizar los ingresos; ii) El capital social y las redes pueden afectar los tipos de desperdicio recolectados, los modelos de operación y los medios de vida resultantes; de manera que iniciativas que ayuden a conectar a los empresarios marginados con las redes, los recursos y la capacitación son importantes; y iii) Existen modelos de comercialización para aquellos sin habilidades o conocimientos especializados para que se ven favorecidos por el acceso a recursos adicionales, como capacitación o incluso capital.

En otro sentido, la investigación de Hsieh et al (2017) en la empresa de reciclaje de vidrio más grande de Taiwán destacó como factores claves para los mecanismos de gobernanza i) Captura continua de valor; ii) Creación de una red para el desarrollo del negocio a lo largo del ciclo de vida del ecosistema; iii) Imagen de marca y la RSE como una fuerza invisible que une las conexiones de la empresa con sus grupos de interés; iv) Capacidades de la empresa en el proceso de reciclaje; y v) La política del gobierno por su impacto en la reformulación de las relaciones entre los distintos interesados.

Por último, Sandhu $\mathcal{J}$ Naeem (2017) analizan en Islamabad la viabilidad del compostaje de residuos indicando su rentabilidad y favorabilidad para el medio ambiente en cuanto a la gestión sostenible de residuos sólidos. Los investigadores analizan el Centro Integrado de Recuperación de Recursos (IRRC) en un asentamiento donde no existe un acuerdo efectivo, eficiente y sostenible con el sector público para una gestión de los residuos sólidos municipales. Los autores creen en la replicabilidad del modelo teniendo en cuenta los arreglos institucionales para la provisión de servicios municipales, la disponibilidad de fondos, el monitoreo institucional y la voluntad de innovaciones. 
Los aportes reflexivos de carácter regional y global aportan hacia la búsqueda de alternativas de carácter local, como lo indican las conclusiones de Avraamidou et al. (2020) identificando como común denominador la necesidad de que el entorno empresarial cambie la mentalidad con relación al desarrollo socioeconómico sustentable y se desarrollen acciones concretas, además de reafirmar la importancia de las prácticas responsables de producción y la necesidad de formalizar el sector del aprovechamiento. De este modo, un elemento clave son las múltiples ventajas en materia social, económica y ambiental que traen consigo el uso eficiente de los recursos.

\section{Categoría 2: artículos de revisión bibliográfica}

En cuanto a la revisión bibliográfica (19,1\% de los artículos analizados), los artículos se relacionan en la tabla 2.

\section{Tabla 2}

Artículos de revisión bibliográfica

\begin{tabular}{|c|c|c|c|c|c|}
\hline 穿密 & Título artículo & Revista & $\begin{array}{l}\quad \mathbf{N}^{\circ} \\
\text { Artículos } \\
\text { revisados }\end{array}$ & $\begin{array}{l}\text { Rango de } \\
\text { análisis }\end{array}$ & $\begin{array}{c}\text { Autor } \\
\text { (es) /año } \\
\text { publicación }\end{array}$ \\
\hline \multirow{5}{*}{ 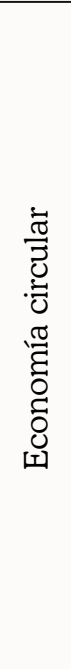 } & $\begin{array}{l}\text { «How do scholars approach the } \\
\text { Circular Economy? A systematic } \\
\text { literature review» }\end{array}$ & $\begin{array}{l}\text { Journal } \\
\text { of Cleaner } \\
\text { Production }\end{array}$ & 565 & $2004-2017$ & $\begin{array}{l}\text { (Merli et al., } \\
\text { 2018) }\end{array}$ \\
\hline & $\begin{array}{l}\text { «Circular economy performance } \\
\text { assessment methods: A systematic } \\
\text { literature review» }\end{array}$ & $\begin{array}{l}\text { Journal } \\
\text { of Cleaner } \\
\text { Production }\end{array}$ & 45 & $2009-2018$ & $\begin{array}{l}\text { (Sassanelli et } \\
\text { al., 2019) }\end{array}$ \\
\hline & $\begin{array}{l}\text { «Supply Chain Configurations in the } \\
\text { Circular Economy: A Systematic } \\
\text { Literature Review» }\end{array}$ & Sustainability & 77 & $2005-2017$ & $\begin{array}{l}\text { (Masi et al., } \\
\text { 2017) }\end{array}$ \\
\hline & $\begin{array}{l}\text { "Circular economy in cities: Reviewing } \\
\text { how environmental research aligns } \\
\text { with local practices» }\end{array}$ & $\begin{array}{l}\text { Journal } \\
\text { of Cleaner } \\
\text { Production }\end{array}$ & 101 & $1975-2017$ & $\begin{array}{l}\text { (Petit-Boix } \\
\text { E Leipold, } \\
\text { 2018) }\end{array}$ \\
\hline & $\begin{array}{l}\text { «Eco-innovation in the transition to } \\
\text { a circular economy: An analytical } \\
\text { literature review» }\end{array}$ & $\begin{array}{l}\text { Journal } \\
\text { of Cleaner } \\
\text { Production }\end{array}$ & 141 & $1992-2015$ & $\begin{array}{l}\text { (De Jesús et } \\
\text { al., 2018) }\end{array}$ \\
\hline
\end{tabular}




\begin{tabular}{|c|c|c|c|c|c|}
\hline 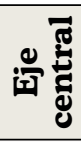 & Título artículo & Revista & $\begin{array}{l}\quad \mathbf{N}^{\circ} \\
\text { Artículos } \\
\text { revisados }\end{array}$ & $\begin{array}{l}\text { Rango de } \\
\text { análisis }\end{array}$ & $\begin{array}{c}\text { Autor } \\
\text { (es) /año } \\
\text { publicación }\end{array}$ \\
\hline \multirow{3}{*}{ 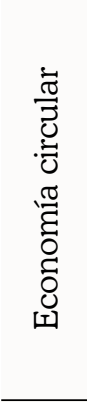 } & «Targets for a circular economy» & $\begin{array}{l}\text { Resources, } \\
\text { Conservation } \mathcal{E} \\
\text { Recycling }\end{array}$ & 72 & $2003-2018$ & $\begin{array}{l}\text { (Morseletto, } \\
\text { 2020) }\end{array}$ \\
\hline & $\begin{array}{l}\text { «Circular Economy - A challenge and } \\
\text { an opportunity for Process Systems } \\
\text { Engineering» }\end{array}$ & $\begin{array}{l}\text { Computers } \\
\mathcal{J} \text { Chemical } \\
\text { Engineering }\end{array}$ & 327 & $1997-2019^{6}$ & $\begin{array}{l}\text { (Avraamidou } \\
\text { et al., 2020) }\end{array}$ \\
\hline & $\begin{array}{l}\text { "A review of micro level indicators for a } \\
\text { circular economy e moving away from } \\
\text { the three dimensions of sustainability?" }\end{array}$ & $\begin{array}{l}\text { Journal } \\
\text { of Cleaner } \\
\text { Production }\end{array}$ & 30 & $2000-2019^{7}$ & $\begin{array}{l}\text { (Kristensen } \\
\text { E Mosgaard, } \\
\text { 2020) }\end{array}$ \\
\hline \multirow{2}{*}{ 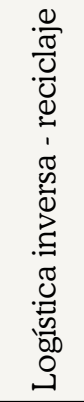 } & $\begin{array}{l}\text { «Gestión de la cadena de suministro: } \\
\text { una revisión desde la logística y el } \\
\text { medio ambiente.» }\end{array}$ & $\begin{array}{l}\text { Entre Ciencia e } \\
\text { Ingeniería }\end{array}$ & 50 & $2005-2015$ & $\begin{array}{l}\text { (Silva } \\
\text { Rodríguez, } \\
\text { 2017) }\end{array}$ \\
\hline & $\begin{array}{l}\text { «ogística inversa y sustentabilidad: } \\
\text { revisión de literatura» }\end{array}$ & $\begin{array}{l}\text { CULCyT: Cultura } \\
\text { Científica y } \\
\text { Tecnológica }\end{array}$ & 80 & $1995-2015$ & $\begin{array}{l}\text { (Jerez et al., } \\
\text { 2015) }\end{array}$ \\
\hline \multirow{3}{*}{ 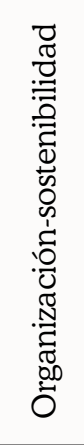 } & $\begin{array}{l}\text { «A Review on Strategic, Tactical and } \\
\text { Operational Decision Planning in } \\
\text { Reverse Logistics of Green Supply } \\
\text { Chain Network Design» }\end{array}$ & $\begin{array}{c}\text { Journal of } \\
\text { Computer and } \\
\text { Communications }\end{array}$ & 62 & $1992-2017$ & $\begin{array}{l}\text { (Misni } \mathcal{E} \\
\text { Lee, 2017) }\end{array}$ \\
\hline & $\begin{array}{l}\text { «Nuevas estrategias administrativas en } \\
\text { negocios de gestión ambiental» }\end{array}$ & $\begin{array}{c}\text { Revista } \\
\text { Publicando }\end{array}$ & 20 & $1990-2016$ & $\begin{array}{l}\text { (Fiallos } \\
\text { Tapia, 2017) }\end{array}$ \\
\hline & $\begin{array}{l}\text { «Circular, Green, and Bio Economy: } \\
\text { How Do Companies in Land- } \\
\text { Use Intensive Sectors Align with } \\
\text { Sustainability Concepts?» }\end{array}$ & $\begin{array}{l}\text { Ecological } \\
\text { economics }\end{array}$ & 123 & $2017-2016$ & $\begin{array}{l}\text { (D'Amato et } \\
\text { al., 2019) }\end{array}$ \\
\hline
\end{tabular}

Nota: clasificación de los artículos analizados en la revisión bibliográfica a partir de la revista, $\mathrm{N}^{\mathrm{O}}$ de artículos y el periodo de tiempo. Fuente: Elaboración propia

6 El análisis bibliográfico cubre un artículo de investigación titulado A food-energy-water nexus approach for land use optimization, con fecha de 2019, de los investigadores: Nie, Y. , Avraamidou, S. , Xiao, X. , Pistikopoulos, E.N. , Li, J. , Zeng, Y. , Song, F. , Yu, J. , Zhu, M.

7 Se incluyen los artículos de 1) Cong et al. (2019); 2) Niero and Kalbar (2019); 3) Ameli et al. (2019), y 4) Lacovidou et al. (2019). 
En este análisis vale destacar los aportes sobre economía circular. De acuerdo con Merli et al. (2018) en su análisis de quinientos sesenta y cinco artículos, resaltan que los principales aporte se ubican en China y Europa, para lo cual identifican tres líneas de acción: i) Cambiar la dinámica social y económica a nivel macro y administrativo; ii) Apoyar las empresas para la aplicación de procesos circulares y difusión de nuevas formas de consumo; y iii) Analizar las experiencias de la simbiosis industrial.

Los resultados del estudio indican que la economía circular es un concepto en evolución, tanto en su definición, límites y principios como en las prácticas relacionadas. En este sentido, no existe un consenso general sobre la EC y sus principios rectores.

Con relación a Masi et al., (2017) la economía circular ha ganado un gran terreno en diferentes ámbitos, en especial, en el académico. Los autores analizaron setenta y siete artículos de economía circular, logrando evidenciar que aún existen diferencias en la definición de $\mathrm{EC}$, por lo que aún no es posible unificar una definición de la misma. Así mismo, explicaron aspectos en las cadenas de suministro que se ajustan al concepto: ambiental, sostenible, verde, y cadenas de suministro de circuito cerrado. Finalmente, señalaron una limitante en su investigación la cual consiste en que muchas prácticas no evidencian el diseño del producto, la estrategia comercial y la perspectiva del modelo del negocio.

De Jesús et al. (2018), por su parte, exponen que el concepto de ecoinnovación al interior de los procesos, se ha convertido en un factor clave para lograr un cambio significativo de un sistema de producción lineal a un sistema circular. Sin embargo, revelaron que existe poca documentación sobre la ecoinnovación asociada a cómo facilitar un cambio a una economía circular y la forma de hacerlo. Si bien se cuenta con una vasta literatura acerca de estos dos conceptos, no se logra delimitar una comprensión integral en torno a los mismos. Su investigación aborda tres componentes fundamentales; en primer lugar, reconocer definiciones sobre ecoinnovación y economía circular; en segundo lugar, analizar el proceso de la ecoinnovación desde perspectivas micro, macro y meso de la economía circular; por último, identificar cómo la ecoinnovación está alineada con la economía circular mediante objetivos, mecanismos e impactos. 
En beneficio de la exposición, hay que decir que el estudio de Kristensen $\mathcal{E}$ Mosgaard (2020) abordan un análisis bibliográfico en torno al enfoque de los indicadores de EC publicados a partir de los niveles macro (global, nacional, regional y local), meso (simbiosis industrial, parques ecoindustriales) y micro (empresa único producto) para lo cual analizan treinta indicadores de una economía circular a nivel micro, señalando que dicho nivel presenta mayores inconsistencias relativas a su medición. Esto permite identificar que los indicadores se centran en reciclaje, vida útil y remanufactura, mientras que indicadores de desmontaje, extensión de la vida útil, gestión de residuos, eficiencia de los recursos o reutilización requieren de una estandarización para su medición, por lo que se dificulta realizar un mayor seguimiento y control sobre los niveles de cumplimiento de la economía circular. De acuerdo con lo anterior, el mayor enfoque de la economía circular se basa en lo económico, dejando de lado lo ambiental y, en menor medida, la dimensión social.

En síntesis, y como lo indica Sassanelli et al. (2019), luego de la revisión de cuarenta y cinco artículos, desde el año 2015 se ha evidenciado un gran interés por el tema de la EC y se han implementado diferentes modelos circulares. Estos modelos se abordan desde dos aspectos fundamentales: i) Design for $\mathrm{X}$ (DfX): Diseño de caso es de directrices: permite fortalecer un producto desde su etapa de diseño hasta su desarrollo, alineado con una orientación estratégica para realizar cambios en su modelo de producción, pasando de un modelo lineal a uno circular; ii) Los enfoques Life Cycle Assessment (LCA): Evaluación del ciclo de vida, Material Flow Analysis (MFA): Análisis de flujo de material, Data Envelopment Analysis (DEA/IeO): análisis envolvente de datos, Multi Criteria Decision Methods (MCDM): Métodos de decisión de criterios múltiples y Discrete Event Simulation (DES): Simulación discreta de eventos, los cuales permiten contemplar no solo la etapa de producción, sino también el uso del producto y su eliminación.

Así mismo, resaltan la importancia de aplicar y probar los diferentes métodos -no solo los expuestos, sino, además, los más comunes en el contexto circular- a sectores como la cadena de suministro, los parques industriales, los territorios urbanos, los desechos sólidos municipales, entre otros.

Con relación a los artículos con las palabras claves logística inversa y reciclaje se destacan: 
- La investigación de Silva Rodríguez efectuada en Colombia (2017). En esta se analizaron cincuenta artículos de los cuales el 55,5\% trataban temáticas relacionadas con el Supply Chain Management (SCM) y el 44,5\% con la cadena de suministro verde (SV). En el 56,3\% de las investigaciones relacionadas con SCM utilizan un enfoque cuantitativo, mientras que, para el caso de la cadena de SV, la colaboración y el conocimiento de los proveedores y clientes es fundamental para aprovechar los recursos.

- El análisis de Jerez et al. (2015) contempla la revisión de literatura sobre logística inversa, indicando su importancia desde diferentes enfoques industriales y sostenibles, en los que se deben trabajar sistemas de ciclos para la correcta recuperación y retorno de los recursos, todo ello de la mano de un desarrollo sustentable y la disminución del impacto ambiental. En cuanto a los artículos con las palabras claves organización y sostenibilidad, los aportes expresan que para Misni $\mathcal{E}$ Lee (2017) la mayoría de la literatura analizada se focaliza en la planificación de decisiones estratégicas y tácticas y solo unos pocos escritos están basados en las operaciones. En este sentido, señalan: i) En lugar de concentrarse solo en un flujo inverso, la red debe integrarse con el flujo directo para formar un circuito cerrado; ii) Muchos estudios se centran en la incertidumbre de la demanda y la oferta, pero muy pocos en la incertidumbre de la devolución de productos, lo cual es el problema principal en logística inversa; iii) Deben considerarse múltiples objetivos que combinen el factor económico con el impacto ambiental y social (reducción de costos, maximización de ganancias, maximización de la satisfacción y capacidad de respuesta al consumidor, y la minimización del impacto ambiental causado por la contaminación del transporte y el proceso de limpieza, entre otros); iv) Deberían considerarse también varios períodos, problemas con múltiples productos y múltiples instalaciones y operaciones de recuperación; además, v) Para el caso específico del transporte, falta modelar diferentes variables de decisión de transporte, como el modo de transporte, el consumo de combustible del transporte y la capacidad de transporte de carga.

Agregando a lo anterior, y para la misma categoría, D’Amato et al. (2019) analizan la brecha de investigación existente con el uso de tres conceptos de sostenibilidad integrados a nivel global: economía circular, economía verde (EV) y Bioeconomía (BE), a partir de un análisis de contenido a ciento 
veintitrés informes de compañías en cinco sectores intensivos en uso de la tierra (bosque, alimentos, bebidas, minería y energía), identificando:

- La EC es omnipresente y homogénea en todas las empresas y sectores. La EV fue el segundo concepto más frecuente, especialmente en bosques y minería; y la BE estuvo subrepresentada en todos los informes, con excepción del sector forestal.

- El análisis de los conceptos de sostenibilidad global, desde la perspectiva de divulgación corporativa, permite una discusión oportuna sobre el papel y los límites de las empresas como participantes de la transformación sostenible a nivel mundial.

- Siendo el sector privado, central para el desarrollo de todas las estrategias de EC, EV y BE a nivel nacional y regional, y viceversa, debe hacerse un trabajo importante en las estrategias de comunicación para alinear las estrategias de sostenibilidad de la empresa, con ideas de sostenibilidad emergentes, que se están incorporando en la formulación de políticas y la academia y por lo tanto, garantizan la legitimación con múltiples partes interesadas.

- Existe una tensión entre las ideas de sostenibilidad, legitimadas por la sociedad (por tanto, internalizadas por las empresas) y las adelantadas por académicos o activistas.

- Debe trabajarse más en la calidad, veracidad y efectividad de la información divulgada y cómo se percibe dicha divulgación entre el grupo de usuarios externos; la relación entre el desempeño financiero y los niveles de divulgación de sostenibilidad de la compañía; y la alineación de estrategias de la empresa y la industria con objetivos establecidos a nivel nacional y regional para las políticas EC, EV y BE.

En síntesis, y como se expresa en la Agenda 2030 de la ONU (como se citó en D'Amato et al., 2019), el sector privado es fundamental en la gestión conjunta de los problemas de sostenibilidad, a pesar de la intensa investigación sobre sostenibilidad corporativa no hay un análisis explícito que dé conceptos impulsados por políticas de uso para las empresas en cuanto a reenviar sus visiones y prácticas de sostenibilidad. Esto es relevante, porque la comunicación de la empresa contribuye a legitimar o deslegitimar sus 
acciones, al tiempo que retroalimenta el pensamiento público y las políticas hacia transformaciones de sostenibilidad.

Desde otra óptica, de los trece artículos de revisión bibliográfica la cobertura de análisis fue del periodo comprendido entre 1975 y 2019; valga aclarar que solo cinco artículos fueron de 2019. A su vez Journal of Cleaner Production es la revista con mayor frecuencia de publicaciones con 5 artículos.

En la figura 2 se describe el rango de análisis de los artículos de revisión, indicando en el eje $\mathrm{Y}$ el periodo de tiempo analizado, y en el eje $\mathrm{X}$ el número de artículos sometidos a revisión.

\section{Figura 2}

Rango de análisis en artículos de revisión

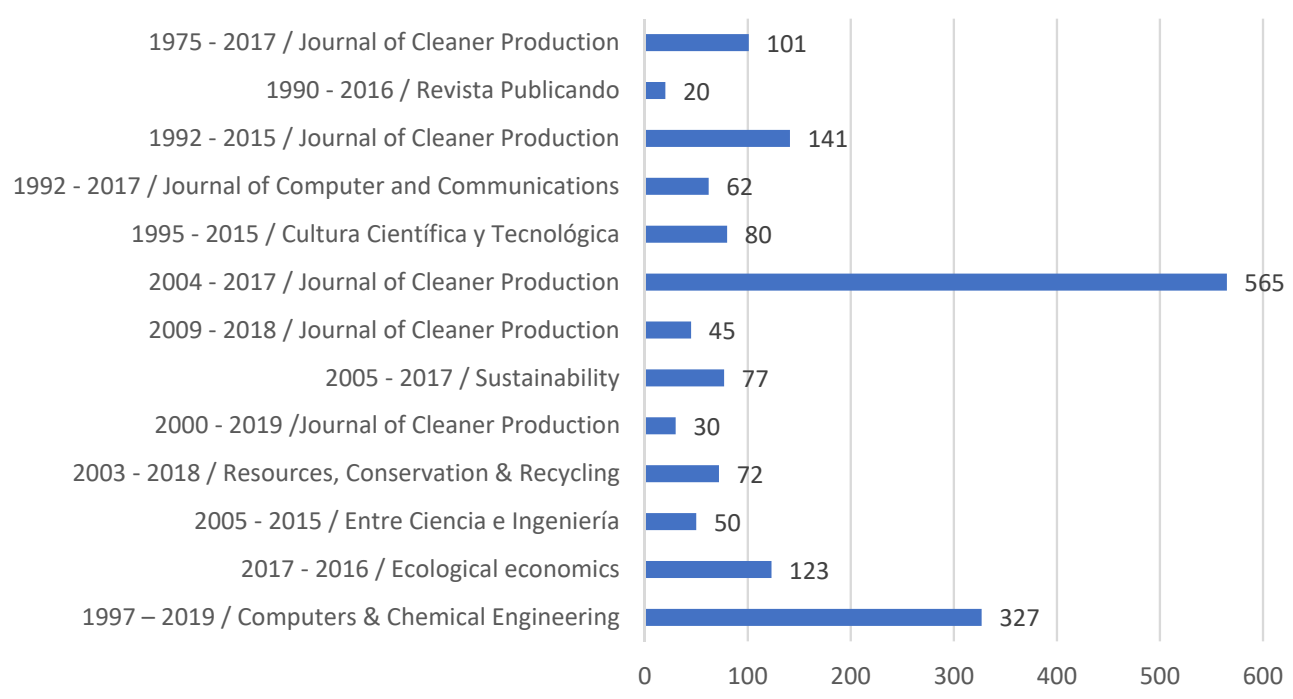

Nota: frecuencia y rango de los artículos analizados en la revisión. Fuente: Elaboración propia

De acuerdo con la figura anterior, se identifican oportunidades investigativas para 2019 y 2020, en lo que respecta a procesos de intervención empresarial para la circularidad. 


\section{Categoría 3: artículos de investigación}

En cuanto a los artículos de divulgación científica, a continuación, se detallan el enfoque metodológico seguido por los investigadores para sustentar los hallazgos, los cuales son factores claves para el éxito de intervenciones empresariales. Los artículos de investigación corresponden al 45,7\% de las publicaciones analizadas.

\section{Tabla 3}

Artículos de investigación

\begin{tabular}{|c|c|c|c|c|c|c|c|}
\hline \multirow[b]{2}{*}{ 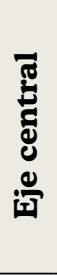 } & \multirow[b]{2}{*}{ Título artículo } & \multirow[b]{2}{*}{ Revistas } & \multicolumn{4}{|c|}{ Diseño metodológico } & \multirow[b]{2}{*}{ Autor/año } \\
\hline & & & 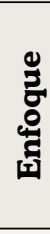 & $\frac{\mathscr{U}}{8}$ & 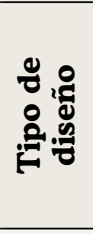 & 㟒㟒 & \\
\hline \multirow{4}{*}{ 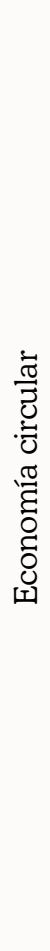 } & $\begin{array}{l}\text { «Resource efficient eco- } \\
\text { innovations for a circular } \\
\text { economy: Evidence from EU } \\
\text { firms» }\end{array}$ & $\begin{array}{c}\text { Research } \\
\text { Policy }\end{array}$ & 苞 & 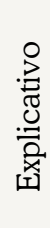 & 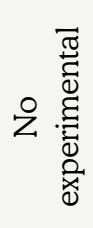 & 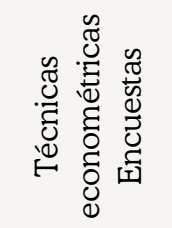 & $\begin{array}{l}\text { (Cainelli et al., } \\
\text { 2020) }\end{array}$ \\
\hline & $\begin{array}{l}\text { «Circular economy in Italian } \\
\text { SMEs: A multi-method study» }\end{array}$ & $\begin{array}{l}\text { Journal } \\
\text { of Cleaner } \\
\text { Production }\end{array}$ & 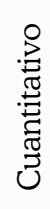 & 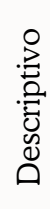 & 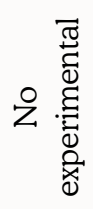 & 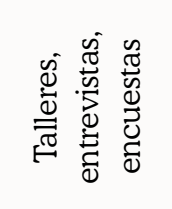 & $\begin{array}{l}\text { (Mura et al., } \\
2020 \text { ) }\end{array}$ \\
\hline & $\begin{array}{l}\text { «Transition to circular } \\
\text { economy on firm level: } \\
\text { Barrier identification and } \\
\text { prioritization along the value } \\
\text { chain» }\end{array}$ & $\begin{array}{l}\text { Journal } \\
\text { of Cleaner } \\
\text { Production }\end{array}$ & 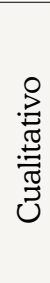 & 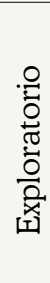 & 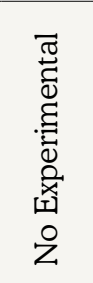 & 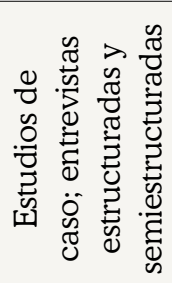 & $\begin{array}{l}\text { (Werning } \mathcal{E} \\
\text { Spinler, 2020) }\end{array}$ \\
\hline & $\begin{array}{l}\text { «Industry } 4.0 \text { and circular } \\
\text { economy: Operational } \\
\text { excellence for sustainable } \\
\text { reverse supply chain } \\
\text { performance» }\end{array}$ & $\begin{array}{l}\text { Resources, } \\
\text { Conservation } \\
\mathcal{E} \text { Recycling }\end{array}$ & 总 & 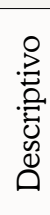 & 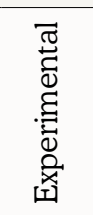 & 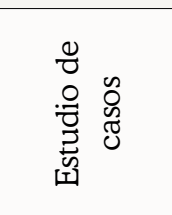 & $\begin{array}{l}\text { (Dev et al., } \\
\text { 2020) }\end{array}$ \\
\hline
\end{tabular}




\begin{tabular}{|c|c|c|c|c|c|c|c|}
\hline \multirow[b]{2}{*}{ 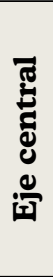 } & \multirow[b]{2}{*}{ Título artículo } & \multirow[b]{2}{*}{ Revistas } & \multicolumn{4}{|c|}{ Diseño metodológico } & \multirow[b]{2}{*}{ Autor/año } \\
\hline & & & 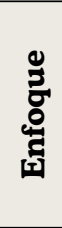 & 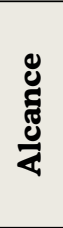 & 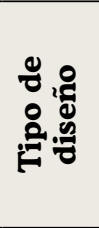 & 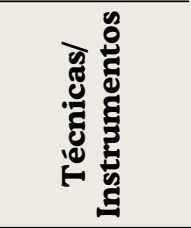 & \\
\hline \multirow{6}{*}{ 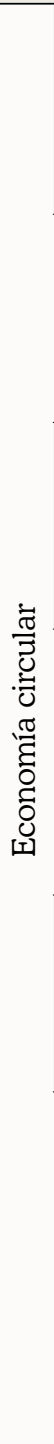 } & $\begin{array}{l}\text { «Reverse logistics and the } \\
\text { sectoral agreement of } \\
\text { packaging industry in Brazil T } \\
\text { towards a transition to circular } \\
\text { economy» }\end{array}$ & $\begin{array}{l}\text { Resources, } \\
\text { Conservation } \\
\mathcal{E} \text { Recycling }\end{array}$ & $\stackrel{\circ}{\stackrel{ }{x}}$ & : & 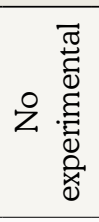 & 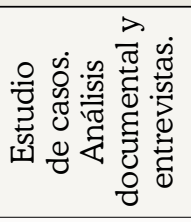 & $\begin{array}{l}\text { (Guarnieri et } \\
\text { al., 2020) }\end{array}$ \\
\hline & $\begin{array}{l}\text { «A circular economy } \\
\text { approach to green energy: } \\
\text { Wind turbine, waste, and } \\
\text { material recovery» }\end{array}$ & $\begin{array}{l}\text { Science of } \\
\text { the Total } \\
\text { Environment }\end{array}$ & 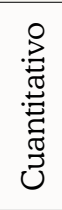 & 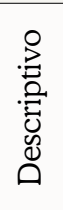 & 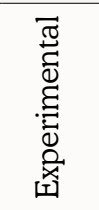 & 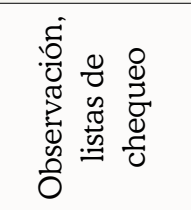 & $\begin{array}{l}\text { (Hao et al., } \\
2020)\end{array}$ \\
\hline & $\begin{array}{l}\text { «Investigation into circular } \\
\text { economy of plastics: The } \\
\text { case of the UK fast moving } \\
\text { consumer goods industry» }\end{array}$ & $\begin{array}{l}\text { Journal } \\
\text { of Cleaner } \\
\text { Production }\end{array}$ & 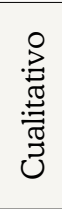 & 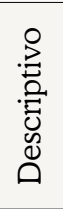 & 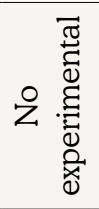 & 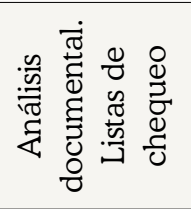 & $\begin{array}{l}\text { (Gong et al., } \\
2020 \text { ) }\end{array}$ \\
\hline & $\begin{array}{l}\text { «Implementing Circular } \\
\text { Economy in municipal solid } \\
\text { waste treatment system using } \\
\text { P-graph» }\end{array}$ & $\begin{array}{l}\text { Science of } \\
\text { the Total } \\
\text { Environment }\end{array}$ & 룰 & 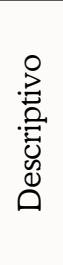 & 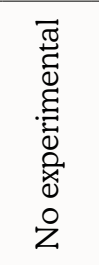 & 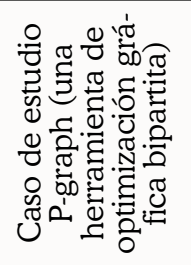 & $\begin{array}{l}\text { (Fan et al., } \\
\text { 2020) }\end{array}$ \\
\hline & $\begin{array}{l}\text { «Circular economy transition } \\
\text { in Italy. Achievements, } \\
\text { perspectives and constraints» }\end{array}$ & $\begin{array}{l}\text { Journal } \\
\text { of Cleaner } \\
\text { Production }\end{array}$ & 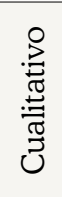 & 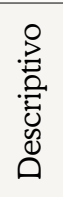 & 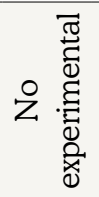 & 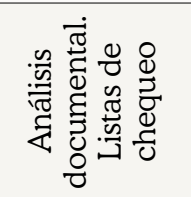 & $\begin{array}{l}\text { (Ghisellini } \mathcal{E} \\
\text { Ulgiati, 2020) }\end{array}$ \\
\hline & $\begin{array}{l}\text { «Moving towards a circular } \\
\text { economy: economic impacts } \\
\text { of higher material recycling } \\
\text { targets» }\end{array}$ & $\begin{array}{l}\text { Materials } \\
\text { Today: } \\
\text { Proceedings }\end{array}$ & i. & 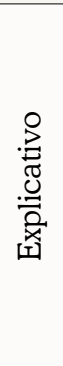 & 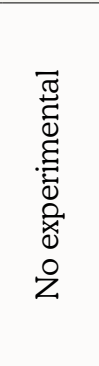 & 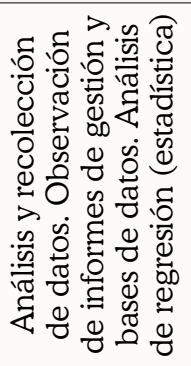 & $\begin{array}{l}\text { (Beccarello } \\
\text { E Di Foggia, } \\
\text { 2018) }\end{array}$ \\
\hline
\end{tabular}




\begin{tabular}{|c|c|c|c|c|c|c|c|}
\hline \multirow[b]{2}{*}{ 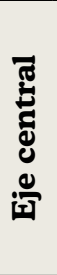 } & \multirow[b]{2}{*}{ Título artículo } & \multirow[b]{2}{*}{ Revistas } & \multicolumn{4}{|c|}{ Diseño metodológico } & \multirow[b]{2}{*}{ Autor/año } \\
\hline & & & 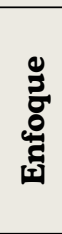 & 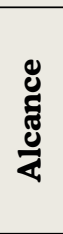 & 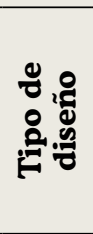 & 㟒莺 & \\
\hline \multirow{2}{*}{ 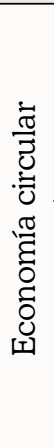 } & $\begin{array}{l}\text { «Closing the loop for } \\
\text { packaging: finding a } \\
\text { framework to operationalize } \\
\text { Circular Economy strategies» }\end{array}$ & Procedia Cirp & : & 叧 & 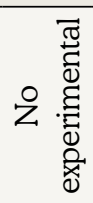 & 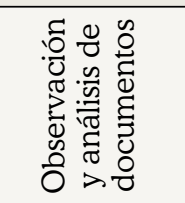 & $\begin{array}{l}\text { (Niero E } \\
\text { Hauschild, } \\
\text { 2017) }\end{array}$ \\
\hline & $\begin{array}{l}\text { «owards circular economy } \\
\text { implementation in } \\
\text { manufacturing systems using } \\
\text { a multi-method simulation } \\
\text { approach to link design and } \\
\text { business strategy» }\end{array}$ & $\begin{array}{l}\text { Journal } \\
\text { of Cleaner } \\
\text { Production }\end{array}$ & 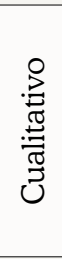 & 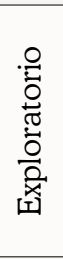 & 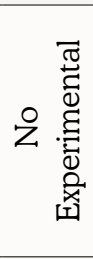 & 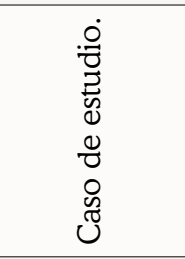 & $\begin{array}{l}\text { (Lieder et al., } \\
\text { 2017) }\end{array}$ \\
\hline \multirow{4}{*}{ 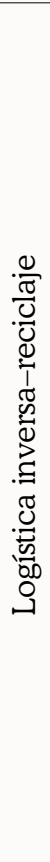 } & $\begin{array}{l}\text { «Multi-criteria decision analysis } \\
\text { (MCDA) method for assessing } \\
\text { the sustainability of end-of-life } \\
\text { alternatives for waste plastics: } \\
\text { A case study of Norway» }\end{array}$ & $\begin{array}{c}\text { Science of } \\
\text { the Total } \\
\text { Environment }\end{array}$ & 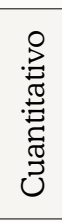 & 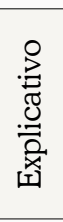 & 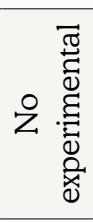 & 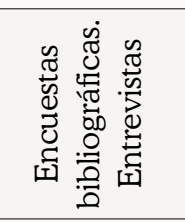 & $\begin{array}{l}\text { (Deshpande et } \\
\text { al., 2020) }\end{array}$ \\
\hline & $\begin{array}{l}\text { «Sustaining WEEE collection } \\
\text { business in China: The case } \\
\text { of online to offline (O2O) } \\
\text { development strategies» }\end{array}$ & $\begin{array}{c}\text { Science of } \\
\text { the Total } \\
\text { Environment }\end{array}$ & 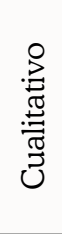 & : & 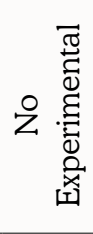 & 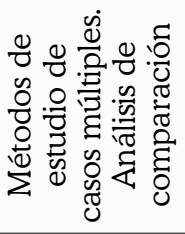 & $\begin{array}{l}\text { (Zuo et al., } \\
\text { 2020) }\end{array}$ \\
\hline & $\begin{array}{l}\text { «Evaluación de la } \\
\text { sostenibilidad de una cadena } \\
\text { de suministro inversa en } \\
\text { Ecuador» }\end{array}$ & $\begin{array}{l}\text { Ciencias } \\
\text { Holguín }\end{array}$ & 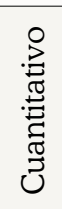 & 叧 & 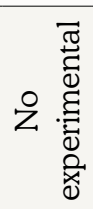 & 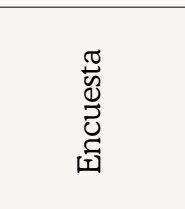 & $\begin{array}{l}\text { (Cevallos-Muóz } \\
\text { E Abreu- } \\
\text { Ledón, 2017) }\end{array}$ \\
\hline & $\begin{array}{l}\text { «Contribución a la } \\
\text { logística inversa mediante } \\
\text { la implantación de la } \\
\text { reutilización por medio de las } \\
\text { redes de Petri» }\end{array}$ & $\begin{array}{l}\text { Revista } \\
\text { chilena de } \\
\text { ingeniería }\end{array}$ & 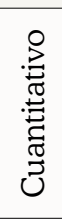 & 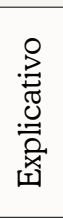 & 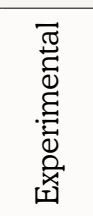 & 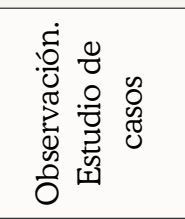 & $\begin{array}{l}\text { (De La Cruz et } \\
\text { al., 2017) }\end{array}$ \\
\hline
\end{tabular}




\begin{tabular}{|c|c|c|c|c|c|c|c|}
\hline \multirow[b]{2}{*}{ 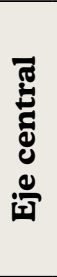 } & \multirow[b]{2}{*}{ Título artículo } & \multirow[b]{2}{*}{ Revistas } & \multicolumn{4}{|c|}{ Diseño metodológico } & \multirow[b]{2}{*}{ Autor/año } \\
\hline & & & 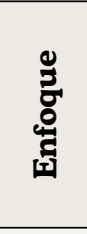 & 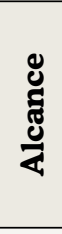 & 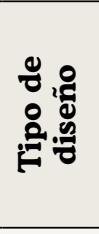 & 胥 & \\
\hline \multirow{5}{*}{ 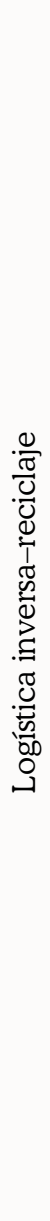 } & $\begin{array}{l}\text { «a gestión de los residuos } \\
\text { sólidos: un reto para los } \\
\text { gobiernos locales» }\end{array}$ & $\begin{array}{l}\text { Sociedad y } \\
\text { Ambiente }\end{array}$ & 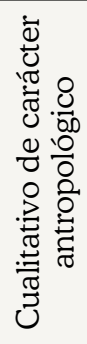 & 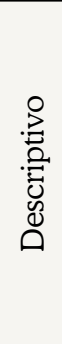 & 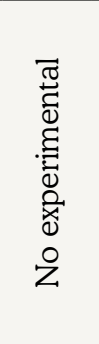 & 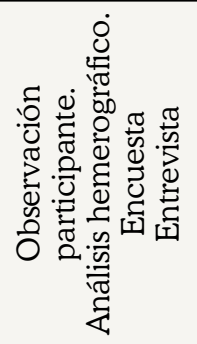 & $\begin{array}{l}\text { (Bernache } \\
\text { Pérez, 2015) }\end{array}$ \\
\hline & $\begin{array}{l}\text { «Modelos de optimización } \\
\text { para el diseño sostenible } \\
\text { de cadenas de suministros } \\
\text { de reciclaje de múltiples } \\
\text { productos» }\end{array}$ & $\begin{array}{l}\text { Revista } \\
\text { chilena de } \\
\text { ingeniería }\end{array}$ & 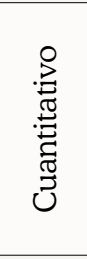 & 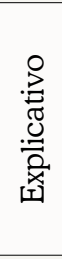 & 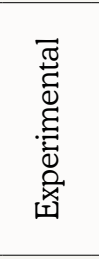 & 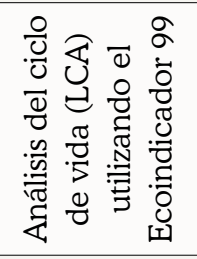 & $\begin{array}{l}\text { (Feitó Cespón } \\
\text { et al., 2016) }\end{array}$ \\
\hline & $\begin{array}{l}\text { «Bio-Waste Recycling } \\
\text { in Germany - Further } \\
\text { Challenges» }\end{array}$ & $\begin{array}{l}\text { Procedia } \\
\text { Environmental } \\
\text { Sciences }\end{array}$ & 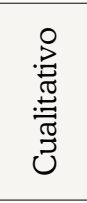 & 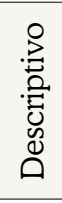 & 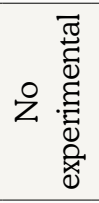 & 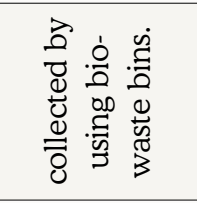 & $\begin{array}{l}\text { (Schüch et al., } \\
\text { 2016) }\end{array}$ \\
\hline & $\begin{array}{l}\text { «Waste and pollution } \\
\text { management by german } \\
\text { companies» }\end{array}$ & $\begin{array}{c}\text { IFAC- } \\
\text { PapersOnLine }\end{array}$ & 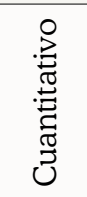 & 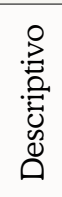 & 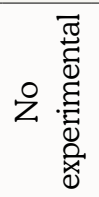 & 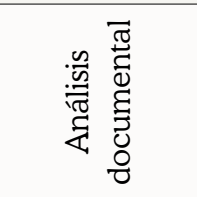 & $\begin{array}{l}\text { (Ullwer et al., } \\
\text { 2016) }\end{array}$ \\
\hline & $\begin{array}{l}\text { «Implementing coordinative } \\
\text { contracts between } \\
\text { manufacturer and retailer in a } \\
\text { reverse supply chain» }\end{array}$ & Sustainability & 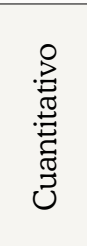 & 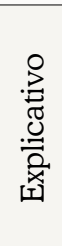 & 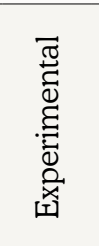 & 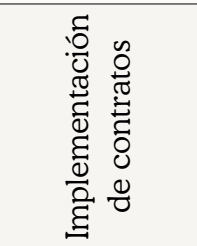 & $\begin{array}{l}\text { (Yoon E Jeong, } \\
\text { 2016) }\end{array}$ \\
\hline
\end{tabular}




\begin{tabular}{|c|c|c|c|c|c|c|c|}
\hline \multirow[b]{2}{*}{ 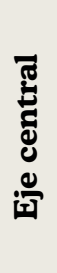 } & \multirow[b]{2}{*}{ Título artículo } & \multirow[b]{2}{*}{ Revistas } & \multicolumn{4}{|c|}{ Diseño metodológico } & \multirow[b]{2}{*}{ Autor/año } \\
\hline & & & 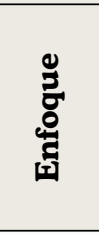 & $\frac{8}{\mathbb{Z}}$ & 。ำ & 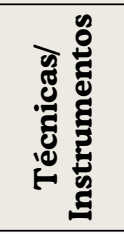 & \\
\hline \multirow{5}{*}{ 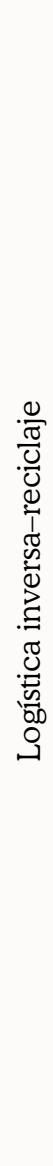 } & $\begin{array}{l}\text { «Relación entre logística } \\
\text { inversa y desempeño. } \\
\text { Estudio de casos en Córdoba, } \\
\text { Argentina» }\end{array}$ & $\begin{array}{l}\text { Cuadernos de } \\
\text { Administración }\end{array}$ & 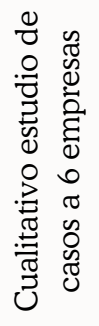 & 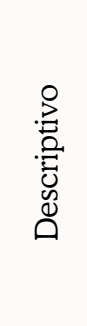 & 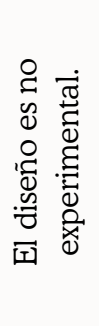 & 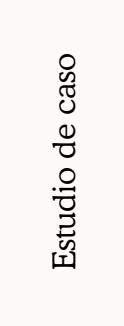 & (Amato, 2015) \\
\hline & $\begin{array}{l}\text { «La logística inversa como } \\
\text { fuente de producción } \\
\text { sostenible» }\end{array}$ & $\begin{array}{l}\text { Actualidad } \\
\text { Contable } \\
\text { Faces }\end{array}$ & 怘 & 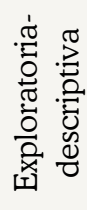 & 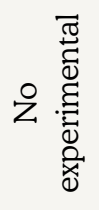 & 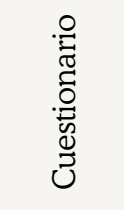 & $\begin{array}{l}\text { (Bustos } \mathcal{E} \\
\text { Carlos, 2015) }\end{array}$ \\
\hline & $\begin{array}{l}\text { «Aplicación de un modelo } \\
\text { para la implementación de } \\
\text { logística inversa en la etapa } \\
\text { productiva» }\end{array}$ & Industrial data & 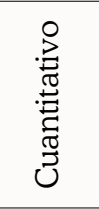 & 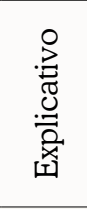 & 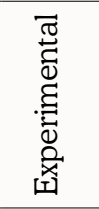 & 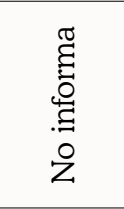 & $\begin{array}{l}\text { (Santos } \mathcal{E} \\
\text { Eulogio, 2010) }\end{array}$ \\
\hline & $\begin{array}{l}\text { «Objetivo de Desarrollo } \\
\text { Sostenible no 12: Consumo } \\
\text { y Producción Sostenible. } \\
\text { Estudio sobre hábitos de } \\
\text { consumo de los estudiantes» }\end{array}$ & $\begin{array}{l}\text { Revista de } \\
\text { Educación } \\
\text { Ambiental y } \\
\text { Sostenibilidad }\end{array}$ & 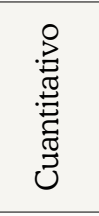 & 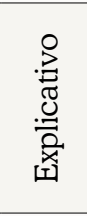 & 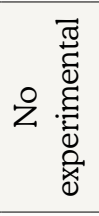 & 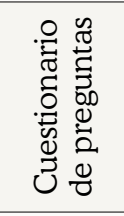 & $\begin{array}{l}\text { (Fernández et } \\
\text { al., 2019) }\end{array}$ \\
\hline & $\begin{array}{l}\text { «No Waste by 2010: Leading } \\
\text { the way» }\end{array}$ & $\begin{array}{c}\text { WIT } \\
\text { Transactions } \\
\text { on Ecology } \\
\text { and the } \\
\text { Environment }\end{array}$ & 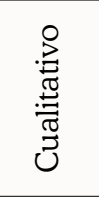 & 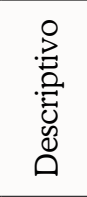 & 乙 & 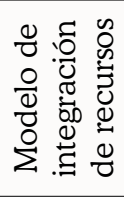 & (Horsey, 2006) \\
\hline
\end{tabular}




\begin{tabular}{|c|c|c|c|c|c|c|c|}
\hline \multirow[b]{2}{*}{ 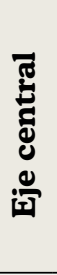 } & \multirow[b]{2}{*}{ Título artículo } & \multirow[b]{2}{*}{ Revistas } & \multicolumn{4}{|c|}{ Diseño metodológico } & \multirow[b]{2}{*}{ Autor/año } \\
\hline & & & 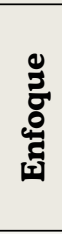 & $\frac{8}{\mathbb{Z}}$ & 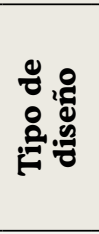 & 㟒葛 & \\
\hline \multirow{4}{*}{ 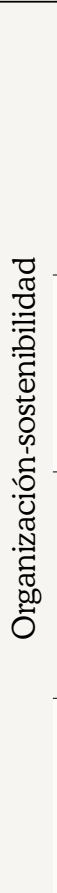 } & $\begin{array}{l}\text { «A new circular business } \\
\text { model typology for creating } \\
\text { value from agro-waste» }\end{array}$ & $\begin{array}{c}\text { Science of } \\
\text { The Total } \\
\text { Environment }\end{array}$ & 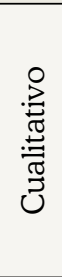 & 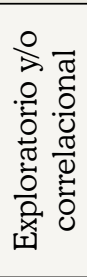 & 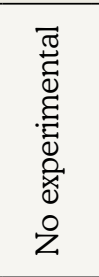 & 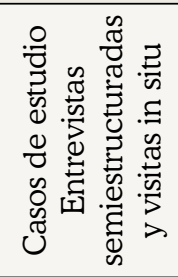 & $\begin{array}{l}\text { (Donner et al., } \\
\text { 2020) }\end{array}$ \\
\hline & $\begin{array}{l}\text { "Sustainability evaluation } \\
\text { of municipal solid waste } \\
\text { management system for hanoi } \\
\text { (Vietnam)-why to choose the } \\
\text { 'waste-to-energy' concept» }\end{array}$ & Sustainability & 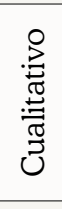 & 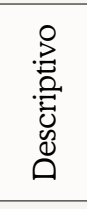 & 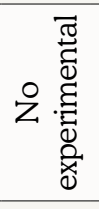 & 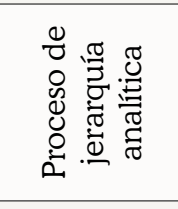 & $\begin{array}{l}\text { (Hoang } \mathcal{E} \\
\text { Fogarassy, } \\
\text { 2020) }\end{array}$ \\
\hline & $\begin{array}{l}\text { "Green initiatives for logistics } \\
\text { service providers: An } \\
\text { investigation of antecedent } \\
\text { factors and the contributions } \\
\text { to corporate goals» }\end{array}$ & $\begin{array}{l}\text { Journal } \\
\text { of Cleaner } \\
\text { Production }\end{array}$ & i & 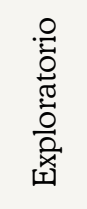 & 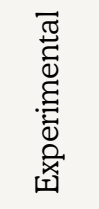 & 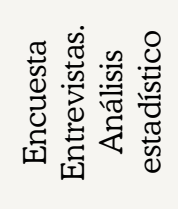 & $\begin{array}{l}\text { (Sureeyatanapas } \\
\text { et al., 2018) }\end{array}$ \\
\hline & $\begin{array}{l}\text { "Contribución de la ética } \\
\text { ambiental y empresarial a las } \\
\text { organizaciones» }\end{array}$ & Mundo FESC & 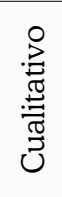 & 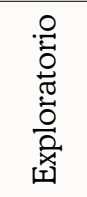 & 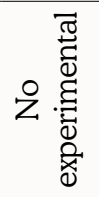 & 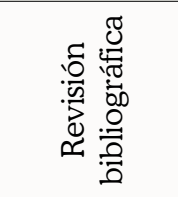 & $\begin{array}{l}\text { (Ovalles Pabón } \\
\text { et al., 2018) }\end{array}$ \\
\hline 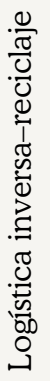 & $\begin{array}{l}\text { «Studies and investigation } \\
\text { about the attitude towards } \\
\text { sustainable production, } \\
\text { consumption and waste } \\
\text { generation in line with } \\
\text { circular economy in Romania» }\end{array}$ & Sustainability & 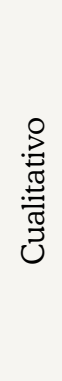 & 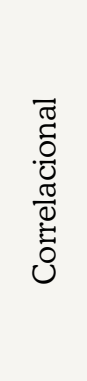 & 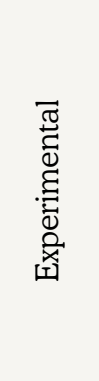 & 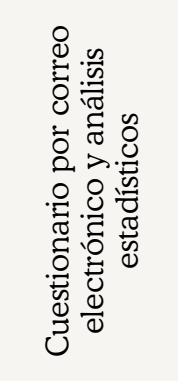 & $\begin{array}{l}\text { (Lakatos et al., } \\
\text { 2018) }\end{array}$ \\
\hline
\end{tabular}

Nota: Análisis del diseño metodológico de los artículos de investigación. Fuente: Elaboración propia

De acuerdo con la tabla anterior, y siguiendo las posturas teóricas de Hernández, Fernández y Baptista (2015), el 12,9 \% de los artículos corres- 
ponden a estudios mixtos, el 41,9\% a estudios cuantitativos y el 45,2 \% a estudios cualitativos, lo que indica en cuanto a posturas metodológicas equilibrio en los enfoques para abordar el tema. Diferente es el hecho referente al alcance, el 51,7 \% de los investigadores prefiere abordan la investigación de forma descriptiva, el 25,8 \% explicativa, el 19,3\% exploratoria y el 3,2\% correlacional.

A continuación, se profundiza en aquellos artículos de la categoría investigación, de los años 2019 y 2020, que amplían el rango de análisis con respecto a las investigaciones publicadas.

\section{Caracterización publicaciones de 2019 y 2020-1}

En cuanto a las publicaciones con la palabra clave economía circular, las conclusiones a las que se llega son las siguientes:

- Gong et al. (2020) señalan la importancia de realizar estudios exhaustivos sobre la economía circular en la industria plástica. En esta línea, proponen en su investigación, en la industria de bienes de consumo de rápido movimiento (FMGC) del Reino Unido, hallazgos significativos en cuanto a avances en aplicaciones de estrategias en plásticos, señalados como no reciclables; innovación de envases y modificaciones de etiquetas. Del mismo modo, abordan la necesidad de fortalecer la infraestructura para incluir el plástico en la economía circular, aclarando en su estudio la gran motivación de los actores en cuanto a los compromisos establecidos por el pacto del plástico.

- Ghisellini E Ulgiati, (2020) analizan la transición de la economía circular en Italia a una muestra de doscientos noventa y dos empresas; esto, luego de definir los principios que fundamentan la economía circular en la organización a partir de la reducción, separación, reutilización, recuperación, refabricación y reciclaje, definen como elemento clave la cooperación entre empresas, al igual que la generación de una cultura de sostenibilidad, los eventos culturales, acciones y prácticas para evitar el abuso del plástico. De acuerdo con lo anterior, la economía circular genera nuevas dimensiones de carácter político y social.

- En su investigación, Cainelli et al. (2020) analizaron las diferentes estrategias que la Unión Europea ha diseñado para tener al interior de 
los procesos una eficiencia en el manejo y disposición de los recursos para lograr un desarrollo en la economía circular, acciones de demanda verde y adopción de ecoinnovaciones a través de técnicas econométricas, evidenciando que las innovaciones en el reciclaje de productos y su uso posterior, se ven afectadas directamente por la política, mientras que la $\mathrm{I}+\mathrm{D}$ y los factores asociados al mercado se relacionan negativamente con las ecoinnovaciones.

- Mura et al. (2020) analizan las acciones tomadas por las pequeñas y medianas empresas para enfrentar la economía circular. Para ello, identificaron doscientos cincuenta y cuatro pequeñas y medianas empresas (pymes) italianas, cuyos hallazgos resaltan que estas aplican diferentes enfoques de $\mathrm{EC}$, lo que indica que se requiere de un enfoque sistémico para la generación de valor en las organizaciones, puesto que solo el 84\% de las empresas realizan recolección separada de los desechos, indicando percepciones confusas de sostenibilidad. Por su parte, aquellas organizaciones que aplican la EC presentan correlación positiva en el rendimiento empresarial, principalmente en la innovación empresarial.

- Werning $\mathcal{E}$ Spinler (2020) investigan las barreras en la transición de un modelo de negocio de EC a nivel de empresa, mediante un estudio de caso de una industria dedicada a la fabricación de productos electrónicos. En este sentido, se identificaron como hallazgos claves: i) La necesidad de adecuar un sistema servicio producto y logística inversa; ii) Realizar una clasificación de prioridades para la transición; iii) Transferencia de la matriz de EC a todo tipo de industria; y iv) La visión sistémica de la economía circular permite mayor eficiencia y efectividad.

- Dev et al. (2020) desarrollaron un modelo de decisión en tiempo real para el sistema de logística inversa y sostenible, integrando conceptos de la industria 4.0 (I4.0) y el modelo ReSOLVE de EC. Entre los hallazgos se resalta la importancia del intercambio de información y reglas de despacho por familia de productos, además de analizar el costo social (inversión en cobranza y tamaño del mercado) para el retorno de los productos.

- Hao et al. (2020) analizaron el impacto ambiental de la energía eólica en lo que refiere al uso de materiales antropogénicos. Para ello proponen 
usar dichos materiales en la EC, analizando posibles usos mediante la extracción del polímero reforzado con fibra de carbono como elemento viable para su uso.

- Guarnieri et al. (2020) describen la primera fase del Acuerdo Sectorial de Logística Inversa de Empaque en Brasil desde la perspectiva de la transición a la EC. En esta óptica, identificaron que en materia de política pública y su aplicación en el sector productivo para la recuperación de materiales, el reciclador es un actor clave.

- Fan et al. (2020) proponen un diseño integrado de sistemas de gestión de residuos apoyado de la EC mediante P-graph (optimización gráfica bipartita), logrando definir una combinación entre separación en la fuente, reciclaje, incineración, digestión anaeróbica y vertedero.

Con relación a la palabra clave logística inversa, las conclusiones son:

- Deshpande et al. (2020) analiza el plástico y sus efectos e impactos de manera directa en la vida submarina. De ahí que en su propuesta expongan un plan de acción para garantizar, mediante la EC, diferentes estrategias para obtener una gestión sostenible de los recursos desde lo ambiental, lo económico y lo social. En Noruega, las prácticas de reciclaje son incipientes, no solo por su desconocimiento y manejo, sino por la infraestructura. Si bien se contemplan prácticas de exportación al interior de sus procesos, no se genera valor a los residuos.

- En el estudio de Zuo et al. (2020) los investigadores contemplaron los residuos de aparatos eléctricos y electrónicos, los cuales han impactado de manera significativa no solo el ambiente, sino que, además, se han convertido en un riesgo para las personas. En China, se diseñaron estrategias y prácticas innovadoras mediante la plataforma de integración en línea y recolección fuera de línea. La propuesta de modelos corresponde a Internet corporativo, reciclaje corporativo y plataforma de terceros. Estos modelos, con su gran acogida y participación, lograron reducir los costos de transacción de diferentes personas y empresas, ampliar el alcance y la escala de la recolección y contribución, a un reciclaje de manera eficiente y efectivo. 
En cuanto a las palabras claves organización y sostenibilidad para Donner et al. (2020) la tipología dinámica envolvente favorece generar conclusiones como: i) El uso de biomasa juega un papel clave en el desarrollo de una EC, especialmente en los niveles territoriales donde grupos de pymes y nuevas empresas buscan ventajas competitivas y cooperan localmente; ii) Los modelos circulares son importantes para comprender los mecanismos de creación de valor y para facilitar las decisiones sobre modelos económicos apropiados y estrategias de entrada al mercado; iii) El carácter dinámico inherente de las tipologías permite a los actores adaptar su estrategia en el tiempo y en contextos cambiantes, incluso puede servir para explorar posibles innovaciones y problemas $\mathrm{I}+\mathrm{D}$, ya sea como parte interesada individual o como miembro de un grupo; y iv) En los modelos de negocio circulares, las relaciones típicas de cliente-proveedor se reemplazan por relaciones de múltiples actores, las responsabilidades se comparten y la evolución de los esquemas de gestión implica cocreación de valor y copropiedad.

En otro sentido, la investigación de Hoang $\mathcal{J}$ Fogarassy (2020) reveló que el escenario en el que las instalaciones de tratamiento mecánico-biológico para la separación de los desechos domésticos, hace que la energía sea la mejor alternativa para el actual sistema municipal de gestión de residuos sólidos de Hanoi hasta 2030.

Las anteriores investigaciones permiten identificar análisis desde diferentes sectores económicos; a su vez, se observan impactos significativos en términos sociales, económicos y ambientales que sirven de base para procesos de intervención. Las metodologías seguidas por los autores constituyen ejes de experimentación con significativos aportes para posteriores investigaciones.

\section{Análisis de objetivos y preguntas de investigación}

Los objetivos y preguntas de investigación permiten identificar el interés de los autores para concretar la incógnita que se desea descubrir. En esta revisión, la tabla 4 los integra de la siguiente manera: 


\section{Tabla 4}

Palabras claves, preguntas y objetivos de los artículos de investigación 2019/2020-1

\begin{tabular}{|c|c|c|c|c|c|c|}
\hline 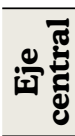 & Título artículo & Palabras claves & $\begin{array}{c}\text { Pregunta(s) de } \\
\text { investigación - objetivo }\end{array}$ & Revistas & $\begin{array}{c}\text { Sector } \\
\text { económico / } \\
\text { industria }\end{array}$ & 常 \\
\hline \multirow{4}{*}{ 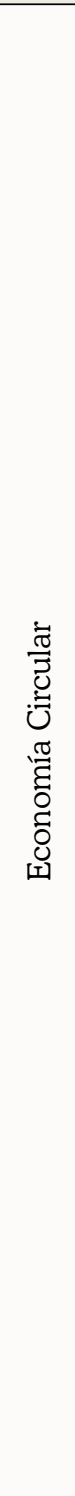 } & $\begin{array}{l}\text { «Resource } \\
\text { efficient eco- } \\
\text { innovations } \\
\text { for a circular } \\
\text { economy: } \\
\text { Evidence from } \\
\text { EU firms» }\end{array}$ & $\begin{array}{l}\text { Eco-innovations } \\
\text { Circular economy } \\
\text { Firms } \\
\text { Policy } \\
\text { Market demand }\end{array}$ & $\begin{array}{l}\text { Evaluar el papel } \\
\text { desempeñado por dos } \\
\text { impulsores clave de la } \\
\text { adopción de tecnología } \\
\text { limpia en relación con la CE: } \\
\text { políticas/regulaciones y } \\
\text { demanda del mercado. }\end{array}$ & $\begin{array}{l}\text { Research } \\
\text { Policy }\end{array}$ & $\begin{array}{l}\text { Servicios } \\
\text { Manufactura }\end{array}$ & 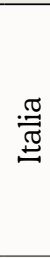 \\
\hline & $\begin{array}{l}\text { "Circular } \\
\text { economy in } \\
\text { Italian SMEs: A } \\
\text { multi-method } \\
\text { study» }\end{array}$ & $\begin{array}{l}\text { Circular economy } \\
\text { Business } \\
\text { sustainability } \\
\text { SMEs } \\
\text { Survey } \\
\text { Focus groups } \\
\text { Interviews }\end{array}$ & $\begin{array}{l}\text { Comprender qué acciones } \\
\text { tienen las pymes para } \\
\text { enfrentar los desafíos } \\
\text { y oportunidades de la } \\
\text { economía circular (CE), } \\
\text { analizando acciones, } \\
\text { barreras, facilitadores } \\
\text { y la conexión entre CE, } \\
\text { estrategia comercial y } \\
\text { desempeño. }\end{array}$ & $\begin{array}{l}\text { Journal } \\
\text { of Cleaner } \\
\text { Production }\end{array}$ & $\begin{array}{l}\text { Mecánica } \\
\text { Manufactura } \\
\text { Turismo } \\
\text { Servicios de } \\
\text { salud. }\end{array}$ & $\stackrel{\widetilde{\pi}}{\stackrel{\widetilde{\sigma}}{ \pm}}$ \\
\hline & $\begin{array}{l}\text { «Transition } \\
\text { to circular } \\
\text { economy on firm } \\
\text { level: Barrier } \\
\text { identification } \\
\text { and prioritization } \\
\text { along the value } \\
\text { chain» }\end{array}$ & $\begin{array}{l}\text { Economía circular } \\
\text { Barreras } \\
\text { Cambio } \\
\text { organizacional } \\
\text { Matriz CE } \\
\text { Conjuntos de } \\
\text { barreras } \\
\text { Nivel de empresa }\end{array}$ & $\begin{array}{l}\text { Identificar y analizar las } \\
\text { barreras en términos de } \\
\text { su impacto a lo largo de la } \\
\text { cadena de valor (VC), así } \\
\text { como el nivel de dificultad } \\
\text { requerida para superarlos. }\end{array}$ & $\begin{array}{l}\text { Journal } \\
\text { of Cleaner } \\
\text { Production }\end{array}$ & $\begin{array}{l}\text { Fabricación } \\
\text { de productos } \\
\text { electrónicos }\end{array}$ & 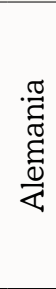 \\
\hline & $\begin{array}{l}\text { «Industry } 4.0 \\
\text { and circular } \\
\text { economy: } \\
\text { Operational } \\
\text { excellence for } \\
\text { sustainable } \\
\text { reverse } \\
\text { supply chain } \\
\text { performance» }\end{array}$ & $\begin{array}{l}\text { Excelencia en } \\
\text { operaciones } \\
\text { Cadena de } \\
\text { suministro inversa } \\
\text { sostenible } \\
\text { Industria } 4.0 \\
\text { Economía circular } \\
\text { Modelo ReSOLVE } \\
\text { Programación } \\
\text { familiar }\end{array}$ & $\begin{array}{l}\text { ¿Cómo las sinergias de I4.0 } \\
\text { y CE tienen un impacto } \\
\text { en el medio ambiente y } \\
\text { actuaciones económicas?, } \\
\text { ¿cómo la integración de las } \\
\text { innovaciones en términos } \\
\text { de difusión del verde los } \\
\text { productos y la política de } \\
\text { IEPPP afectan un sistema de } \\
\text { logística inversa en términos } \\
\text { de su rendimiento? y icómo } \\
\text { las diferentes reglas FBD } \\
\text { afectan la velocidad con } \\
\text { la que los productos se } \\
\text { alimentan a la terminal de } \\
\text { envío y, por lo tanto, afectan } \\
\text { el rendimiento? }\end{array}$ & $\begin{array}{l}\text { Resources, } \\
\text { Conservation } \\
\mathcal{E} \text { Recycling }\end{array}$ & $\begin{array}{l}\text { Logística de } \\
\text { transporte } \\
\text { en empresas } \\
\text { manufactureras }\end{array}$ & 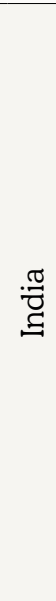 \\
\hline
\end{tabular}




\begin{tabular}{|c|c|c|c|c|c|c|}
\hline 䆑莺 & Título artículo & Palabras claves & $\begin{array}{c}\text { Pregunta(s) de } \\
\text { investigación - objetivo }\end{array}$ & Revistas & $\begin{array}{c}\text { Sector } \\
\text { económico / } \\
\text { industria }\end{array}$ & 急 \\
\hline \multirow{3}{*}{ 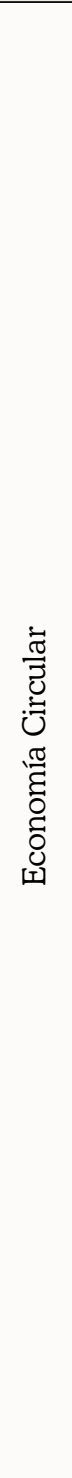 } & $\begin{array}{l}\text { «Reverse } \\
\text { logistics and } \\
\text { the sectoral } \\
\text { agreement } \\
\text { of packaging } \\
\text { industry in } \\
\text { Brazil T towards } \\
\text { a transition } \\
\text { to circular } \\
\text { economy» }\end{array}$ & $\begin{array}{l}\text { Política brasileña } \\
\text { de residuos } \\
\text { sólidos } \\
\text { Economía circular } \\
\text { Reciclaje de } \\
\text { residuos de } \\
\text { envases } \\
\text { Logística inversa } \\
\text { Acuerdo sectorial } \\
\text { de logística } \\
\text { inversa de } \\
\text { embalaje } \\
\text { Responsabilidad } \\
\text { compartida }\end{array}$ & $\begin{array}{l}\text { Describir la primera fase } \\
\text { de la implementación } \\
\text { del Acuerdo Sectorial } \\
\text { de Logística inversa de } \\
\text { envases en Brasil, desde la } \\
\text { perspectiva de la transición } \\
\text { a la economía circular. }\end{array}$ & $\begin{array}{l}\text { Resources, } \\
\text { Conservation } \\
\text { E Recycling }\end{array}$ & $\begin{array}{l}\text { Logística de } \\
\text { reversa en la } \\
\text { industria }\end{array}$ & 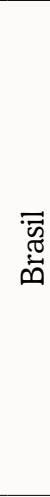 \\
\hline & $\begin{array}{l}\text { «A circular } \\
\text { economy } \\
\text { approach to } \\
\text { green energy: } \\
\text { Wind turbine, } \\
\text { waste, and } \\
\text { material } \\
\text { recovery» }\end{array}$ & $\begin{array}{l}\text { Economía circular } \\
\text { Turbina eólica } \\
\text { Fibra de carbon } \\
\text { Pirólisis } \\
\text { Recuperación } \\
\text { Reciclaje }\end{array}$ & $\begin{array}{l}\text { Viabilidad de una extracción } \\
\text { de polímero reforzado con } \\
\text { fibra de carbono, proceso } \\
\text { mediante pirólisis térmica } \\
\text { para recalibrar el valor } \\
\text { máximo de fibra de carbono } \\
\text { mediante el examen de } \\
\text { efecto de (a) velocidad } \\
\text { de calentamiento, (b) } \\
\text { temperatura y (c) velocidad } \\
\text { de flujo de gas inerte sobre } \\
\text { el rendimiento de carbón. }\end{array}$ & $\begin{array}{c}\text { Science of } \\
\text { the Total } \\
\text { Environment }\end{array}$ & Energía Eólica & 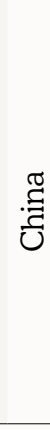 \\
\hline & $\begin{array}{l}\text { «Investigation } \\
\text { into circular } \\
\text { economy of } \\
\text { plastics: The } \\
\text { case of the UK } \\
\text { fast moving } \\
\text { consumer goods } \\
\text { industry» }\end{array}$ & $\begin{array}{l}\text { Economía circular } \\
\text { Industria de } \\
\text { bienes de } \\
\text { consumo } \\
\text { Reciclaje de } \\
\text { plástico } \\
\text { Embalaje de } \\
\text { plástico } \\
\text { Barreras y } \\
\text { restricciones } \\
\text { Pacto de plástico } \\
\text { del Reino Unido }\end{array}$ & $\begin{array}{l}\text { ¿Cuáles son las iniciativas } \\
\text { de reciclaje de plástico que } \\
\text { se están implementando } \\
\text { actualmente en las empresas } \\
\text { de bienes de consumo? ¿Por } \\
\text { qué las empresas de bienes } \\
\text { de consumo se unen a las } \\
\text { iniciativas de reciclaje de } \\
\text { plástico dirigidas por ONG? } \\
\text { ¿Cómo se centraron las } \\
\text { barreras y los facilitadores } \\
\text { de la CE en el plástico en } \\
\text { el Reino Unido? ¿Cuál es } \\
\text { impacto por la industria de } \\
\text { bienes de consumo? }\end{array}$ & $\begin{array}{l}\text { Journal } \\
\text { of Cleaner } \\
\text { Production }\end{array}$ & $\begin{array}{l}\text { Industrial del } \\
\text { Plástico }\end{array}$ & 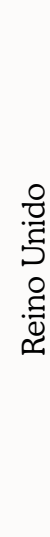 \\
\hline
\end{tabular}




\begin{tabular}{|c|c|c|c|c|c|c|}
\hline 穿菏 & Título artículo & Palabras claves & $\begin{array}{c}\text { Pregunta(s) de } \\
\text { investigación - objetivo }\end{array}$ & Revistas & $\begin{array}{c}\text { Sector } \\
\text { económico / } \\
\text { industria }\end{array}$ & 常 \\
\hline \multirow{2}{*}{ 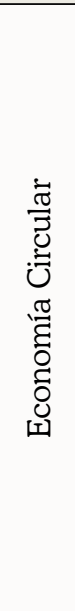 } & $\begin{array}{l}\text { «Implementing } \\
\text { Circular } \\
\text { Economy in } \\
\text { municipal solid } \\
\text { waste treatment } \\
\text { system using } \\
\text { P-graph» }\end{array}$ & $\begin{array}{l}\text { Desperdicio de } \\
\text { recursos } \\
\text { Economía circular } \\
\text { Emisión de GEI } \\
\text { Gráfico P }\end{array}$ & $\begin{array}{l}\text { El objetivo de este estudio } \\
\text { es desarrollar un diseño } \\
\text { integrado de sistemas de } \\
\text { gestión de residuos en } \\
\text { apoyo de una economía } \\
\text { circular por P-graph (una } \\
\text { herramienta de optimización } \\
\text { gráfica bipartita) como un } \\
\text { soporte de decisión eficaz. }\end{array}$ & $\begin{array}{c}\text { Science of } \\
\text { the Total } \\
\text { Environment }\end{array}$ & $\begin{array}{l}\text { Residuos } \\
\text { Sólidos } \\
\text { Municipales }\end{array}$ & 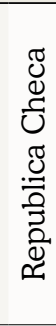 \\
\hline & $\begin{array}{l}\text { «Circular } \\
\text { economy } \\
\text { transition in Italy. } \\
\text { Achievements, } \\
\text { perspectives and } \\
\text { constraints» }\end{array}$ & $\begin{array}{l}\text { Economía circular } \\
\text { Diseño circular } \\
\text { Reducción } \\
\text { Reparar } \\
\text { Reutilizar } \\
\text { Recuperar } \\
\text { Remanufactura } \\
\text { Reciclaje }\end{array}$ & $\begin{array}{l}\text { ¿Cómo está Italia llevando } \\
\text { a cabo la transición a través } \\
\text { del análisis de la CE? }\end{array}$ & $\begin{array}{l}\text { Journal } \\
\text { of Cleaner } \\
\text { Production }\end{array}$ & $\begin{array}{l}\text { Manufacturera, } \\
\text { Centros de } \\
\text { investigación y } \\
\text { universidades }\end{array}$ & 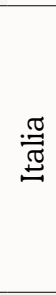 \\
\hline \multirow{2}{*}{ 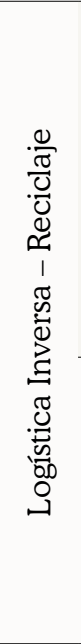 } & $\begin{array}{l}\text { «Multi-criteria } \\
\text { decision analysis } \\
\text { (MCDA) method } \\
\text { for assessing the } \\
\text { sustainability } \\
\text { of end-of-life } \\
\text { alternatives for } \\
\text { waste plastics: } \\
\text { A case study of } \\
\text { Norway» }\end{array}$ & $\begin{array}{l}\text { Plástico } \\
\text { Ecosistemas } \\
\text { marinos } \\
\text { Industria } \\
\text { pesquera } \\
\text { Economía circular }\end{array}$ & $\begin{array}{l}\text { Evaluamos los impactos } \\
\text { ambientales, económicos y } \\
\text { sociales de los vertederos, la } \\
\text { incineración y el reciclaje de } \\
\text { residuos de artes de pesca } \\
\text { en Noruega. }\end{array}$ & $\begin{array}{c}\text { Science of } \\
\text { the Total } \\
\text { Environment }\end{array}$ & Pesca reciclaje & 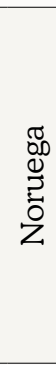 \\
\hline & $\begin{array}{l}\text { "Sustaining } \\
\text { WEEE collection } \\
\text { business in } \\
\text { China: The case } \\
\text { of online to } \\
\text { offline }(\mathrm{O} 2 \mathrm{O}) \\
\text { development } \\
\text { strategies» }\end{array}$ & $\begin{array}{l}\text { WEEE Collection } \\
\text { Business } \\
\text { modelO2O } \\
\text { China }\end{array}$ & $\begin{array}{l}\text { Investigar el nuevo modelo } \\
\text { y experiencias de recogida } \\
\text { de Residuos de aparatos } \\
\text { eléctricos y electrónicos } \\
\text { (RAEE) en China para } \\
\text { proporcionar lecciones al } \\
\text { resto del mundo. }\end{array}$ & $\begin{array}{c}\text { Science of } \\
\text { the Total } \\
\text { Environment }\end{array}$ & $\begin{array}{l}\text { Eléctrico } \\
\text { Electrónico }\end{array}$ & $\stackrel{\pi}{\Xi}$ \\
\hline 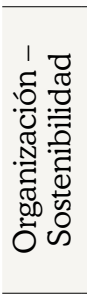 & $\begin{array}{l}\text { "A new circular } \\
\text { business model } \\
\text { typology for } \\
\text { creating value } \\
\text { from agro- } \\
\text { waste» }\end{array}$ & $\begin{array}{l}\text { Economía circular } \\
\text { Bioeconomía } \\
\text { Modelos de } \\
\text { negocio } \\
\text { Valorización } \\
\text { de los residuos } \\
\text { agrícolas } \\
\text { Redes }\end{array}$ & $\begin{array}{l}\text { Identificar y caracterizar } \\
\text { diferentes tipos de modelos } \\
\text { de negocio que crean } \\
\text { valor a partir de desechos } \\
\text { agrícolas y subproductos. }\end{array}$ & $\begin{array}{c}\text { Science of } \\
\text { The Total } \\
\text { Environment }\end{array}$ & $\begin{array}{l}\text { Sector: Primario } \\
\text { Subsector: } \\
\text { Agrícola }\end{array}$ & 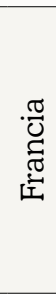 \\
\hline
\end{tabular}




\begin{tabular}{|c|c|c|c|c|c|c|}
\hline 这莺 & Título artículo & Palabras claves & $\begin{array}{c}\text { Pregunta(s) de } \\
\text { investigación - objetivo }\end{array}$ & Revistas & $\begin{array}{c}\text { Sector } \\
\text { económico / } \\
\text { industria }\end{array}$ & 莺 \\
\hline 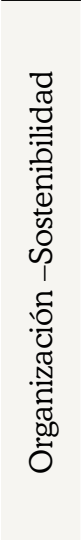 & $\begin{array}{l}\text { «Sustainability } \\
\text { evaluation } \\
\text { of municipal } \\
\text { solid waste } \\
\text { management } \\
\text { system for Hanoi } \\
\text { (Vietnam)-why } \\
\text { to choose the } \\
\text { 'waste-to- } \\
\text { energy' concept» }\end{array}$ & $\begin{array}{l}\text { Manejo de } \\
\text { residuos sólidos } \\
\text { Evaluación de } \\
\text { sostenibilidad } \\
\text { MBT MSW } \\
\text { AHP (Proceso } \\
\text { de jerarquía } \\
\text { analítica) } \\
\text { Procesos de } \\
\text { jerarquía analítica } \\
\text { Modelo de } \\
\text { negocio de } \\
\text { innovación; } \\
\text { Perdida de } \\
\text { energía } \\
\text { Innovación } \\
\text { circular }\end{array}$ & $\begin{array}{l}\text { Determinar cuál es el } \\
\text { sistema más sostenible } \\
\text { de gestión de residuos } \\
\text { sólidos de los que han sido } \\
\text { formulados por expertos del } \\
\text { Banco Mundial para Hanoi } \\
\text { hasta 2030, con el fin de } \\
\text { implementar la estrategia } \\
\text { del programa nacional de la } \\
\text { gestión general de residuos } \\
\text { sólidos hasta } 2025, \text { con } \\
\text { una visión hacia } 2050 \text { en } \\
\text { Vietnam. }\end{array}$ & Sustainability & $\begin{array}{l}\text { Sector } \\
\text { Manufactura y } \\
\text { servicios }\end{array}$ & 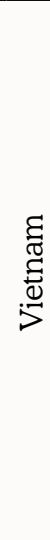 \\
\hline
\end{tabular}

Nota: consolidación de artículos de investigación 2019/2020-1. Fuente: Elaboración propia

Los resultados anteriores muestran una marcada tendencia de investigación hacia la generación de valor de la industria, mediante prácticas de economía circular y su impacto, no solo en el medio ambiente, sino desde lo económico y lo social. Así mismo, de acuerdo con la figura 3, se muestran los países y las revistas que divulgaron dichos resultados de investigación.

\section{Figura 3}

Publicaciones por revista y país de origen

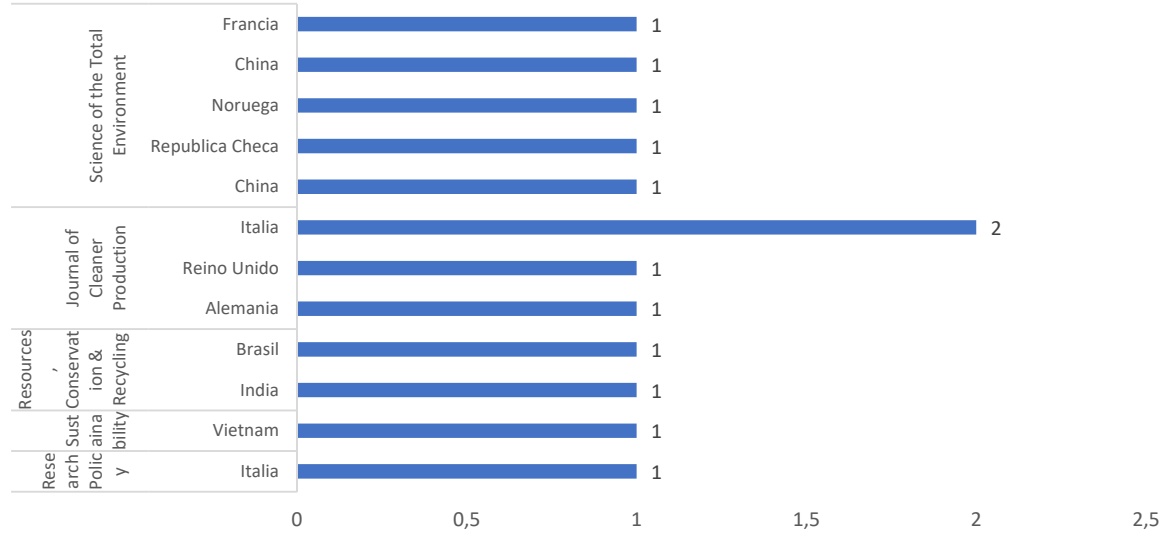

Nota: consolidado de país de origen y frecuencia de publicaciones entre 2019 y 2020-1. Fuente: Elaboración propia 
Como se observa en la figura anterior, la revista Science of the Total Environment presenta cinco publicaciones entre 2019 y 2020-1. Italia es el país con mayor frecuencia de publicaciones (tres artículos de investigación). De las revistas analizadas cabe destacar que el factor de impacto se encuentra en Q2 (revista Sustainability) y Q1 (Research Policy, Resources, Conservation $\&$ Recycling, Journal of Cleaner Production y Science of the Total Environment), lo que indica publicaciones de gran impacto científico, de acuerdo con las tasas de citación de la comunidad, según se reporta en SJR Scimago Journal $\mathcal{E}$ Country Rank (consultado el 16 de junio de 2020).

\section{Conclusiones}

Posterior a la revisión bibliográfica de los artículos e informes de gestión para todas las categorías descritas, se evidencia que los aportes son significativos puesto que permiten identificar oportunidades investigativas en términos académicos y para el sector productivo.

\section{Oportunidades para la academia}

- En las bases de datos analizadas solo se identificaron cinco artículos con origen en Colombia, tres de ellos de reflexión, uno de investigación y uno de revisión bibliográfica; por tanto, se concluye que la categoría economía circular en Colombia es un campo poco explorado a la fecha de esta revisión, y con bajos niveles de impacto en términos de publicaciones científicas en las bases de datos incluidas en el ejercicio (SCOPUS, Dialnet, Google Académico, Scielo y Redalyc).

- Las nuevas políticas públicas sobre economía circular en Colombia traen consigo grandes retos para la academia, por cuanto se identifican pocas publicaciones con participación del sector productivo y fines de mejoramiento de la productividad. A lo anterior se suma la ausencia de nuevos postulados teóricos, conclusión originada en la revisión de la literatura.

- Los países con mayores políticas de apoyo hacia economías de circularidad presentan mayores aportes tanto para el sector productivo como para la academia, así como la investigación en diseño y desarrollo de productos nuevos o derivados de la cadena de aprovechamiento. 


\section{Oportunidades para el sector productivo}

- La economía circular se ha convertido en una herramienta de planeación estratégica para la generación de valor en las organizaciones. De acuerdo con las publicaciones con origen en Colombia, la industria local presenta grandes oportunidades para la maximización de sus utilidades por esta vía.

- Las innovaciones derivadas de los procesos de economía circular en las organizaciones y en la academia, corresponden a un renglón poco explorado en la economía colombiana.

- El análisis bibliográfico indica que algunas de las ventajas de la incorporación productiva de la economía circular incluyen aportes desde la eficiencia en la generación de energía eólica, hasta el aprovechamiento de lodos en plantas de acueducto, lo que indica no solo beneficios en el sector industrial, sino también el de servicios.

- El origen de las publicaciones presenta bajos niveles de participación en cuanto a transición hacia una economía circular en América con respecto a países de Europa y Asia.

- Los avances en economía circular en el mundo han permitido un cambio de visión en el sector productivo. Los beneficios económicos, mediante prácticas de innovación para la reutilización de materiales, han creado nuevos ingresos y se ha disminuido la percepción de un gasto para las organizaciones.

- La economía circular es, en definitiva, una herramienta estratégica cuyo potencial en América es sustancial, pero en Colombia es inigualable. La política nacional expuesta en el Plan Nacional de Desarrollo 2018-2022 y en la Estrategia Nacional de Economía Circular lo favorecen y esta revisión bibliográfica lo sustentan (Gobierno de la República de Colombia, 2019).

\section{Trabajos futuros}

La revisión de la literatura pertinente, admite una serie de reflexiones para futuras investigaciones en términos de indagar en torno a cómo se está preparando la industria local y nacional para responder ante la nueva legislación existente, cuáles son los niveles de cumplimiento de economía 
circular en los sectores económicos en Colombia, qué tipo de alianzas estrategias se están generando con base en la nueva estrategia nacional para el aprovechamiento, cuáles son los desafíos a los que se enfrentan las industrias dedicadas al aprovechamiento y, finalmente, cuál es el aprovechamiento.

\section{Referencias bibliográficas}

Alreshidi, B. A. (2018). Green business operations for building eco-cities: Identifying the role of business and critical success factors for sustainability. IBIMA Business Review, 2018. https://doi.org/10.5171/2018.592758

Amato, C. N. (2015). Relación entre logística inversa y desempeño. Estudio de casos en Córdoba, Argentina. Cuadernos de Administracion, 31(53), 85-96. http://www.scielo.org. co/scielo.php?script=sci_arttextEpid=S0120-46452015000100008

Ameli, M. et al. (2019). A simulation-optimization model for sustainable product design and efficient end-of-life management based on individual producer responsibility. Resour. Conserv. Recycl. 140, 246e258. https://doi.org/10.1016/j.resconrec.2018.02.031.

Arroyo, A., Eguiluz, J. M., E Cupido, L. S. (2018). Educating T-Shaped professionals to meet substitution challenges and developing business models for substitution and recycling. IOP Conference Series: Materials Science and Engineering, 329(1). https:// doi.org/10.1088/1757-899X/329/1/012008

Arroyo Morocho, F. R. (2018). La economía circular como factor de desarrollo sustentable del sector productivo. INNOVA Research Journal, 3(12), 78-98. https://doi.org/10.33890/ innova.v3.n12.2018.786

Arroyo Morocho, F. R., Bravo Donoso, D. N., y Rivera Valenzuela, M. A. (2018). Economía Circular: Un camino hacia un Quito más sostenible. INNOVA Research Journal, 3(11), 139-158. https://doi.org/10.33890/innova.v3.n11.2018.767

Avraamidou, S., Baratsas, S. G., Tian, Y., \& Pistikopoulos, E. N. (2020). Circular Economy - A challenge and an opportunity for Process Systems Engineering. Computers and Chemical Engineering, 133, 106629. https://doi.org/10.1016/j.compchemeng.2019.106629

Beccarello, M., 8 Di Foggia, G. (2018). Moving towards a circular economy: Economic impacts of higher material recycling targets. Materials Today: Proceedings, 5(1), 531-543. https://doi.org/10.1016/j.matpr.2017.11.115

Bernache Pérez, Gerardo (2015). La gestión de los residuos sólidos: un reto para los gobiernos locales. Sociedad y Ambiente, 1(7),72-98. https://www.redalyc.org/articulo. oa? id $=4557 / 455744912004$

Bernal Figueroa, A. A., Beltrán Parada, C. J., E Márquez Márquez, A. F. (2017). Producción Más Limpia: una revisión de aspectos generales. I3+, 3(2), 66. https://doi. org/10.24267/23462329.219 
Beuchot, Mauricio (1999). Heurística y hermenéutica. Universidad Autónoma de México. Centro de Investigaciones Interdisciplinarias en ciencias y Humanidades. México. http:// computo.ceiich.unam.mx/webceiich/docs/libro/Heuristica_y_hermeneutica.pdf

Bustos, F., $\mathcal{Z}$ Carlos, E. (2015). La logística inversa como fuente de producción sostenible. Actualidad Contable Faces, 18(30), 7-32. https://www.redalyc.org/articulo. oa?id=25739666002

Cainelli, G., D’Amato, A., $\mathcal{E}$ Mazzanti, M. (2020). Resource efficient eco-innovations for a circular economy: Evidence from EU firms. Research Policy, 49(1), 103827. https://doi. org/10.1016/j.respol.2019.103827

Cevallos-Muóz, O., $\mathcal{Z}$ Abreu-Ledón, R. (2017). Evaluación de la sostenibilidad de una cadena de suministro inversa en Ecuador. Ciencias Holguín, 23(3), 1-18. http://www.redalyc. org/articulo.oa?id=181552082006

Chen, X., Tai, C. T., Wu, L., Tsai, F. S., E Srimanus, K. (2018). Business models for social innovation of municipal solid waste recycling companies: Comparison of two business cases in Thailand and Taiwan. Sustainability (Switzerland), 10(4). https://doi.org/10.3390/ su10041009

Cong, L., Zhao, F., Sutherland, J.W., 2019. A design method to improve end-of-use product value recovery for circular economy. J. Mech. Des. 141, 044502. https://doi. org/10.1115/1.4041574.

D’Amato, D., Korhonen, J., $\mathcal{J}$ Toppinen, A. (2019). Circular, green, and bioeconomy: How do companies in land-use intensive sectors align with sustainability concepts? Ecological Economics, 158 (December 2018), 116-133. https://doi.org/10.1016/j.ecolecon.2018.12.026

De Jesús, A., Antunes, P., Santos, R., $\mathcal{Z}$ Mendonça, S. (2018). Eco-innovation in the transition to a circular economy: An analytical literature review. Journal of Cleaner Production, 172, 2999-3018. https://doi.org/10.1016/j.jclepro.2017.11.111

De La Cruz, L. O. V., Marrero Fornaris, C. E., \& Pérez Pravia, M. C. (2017). Contribución a la logística inversa mediante la implantación de la reutilización por medio de las redes de Petri. Ingeniare, 25(1), 154-169. https://doi.org/10.4067/S0718-33052017000100154

Deshpande, P. C., Skaar, C., Brattebø, H., \& Fet, A. M. (2020). Multi-criteria decision analysis (MCDA) method for assessing the sustainability of end-of-life alternatives for waste plastics: A case study of Norway. Science of the Total Environment, 719. https://doi. org/10.1016/j.scitotenv.2020.137353

Dev, N. K., Shankar, R., E Q Qaiser, F. H. (2020). Industry 4.0 and circular economy: Operational excellence for sustainable reverse supply chain performance. Resources, Conservation and Recycling, 153(November 2019), 104583. https://doi.org/10.1016/j. resconrec.2019.104583

Dobrotă, G., Dobrotă, D., \& Petrescu, V. (2017). Circular economy-foundament of challenges for business environment. Balkan Region Conference on Engineering and Business Education, 3(1), 432-439. https://doi.org/10.1515/cplbu-2017-0056 
Donner, M., Gohier, R., $\mathcal{E}$ de Vries, H. (2020). A new circular business model typology for creating value from agro-waste. Science of the Total Environment, 716, 137065. https:// doi.org/10.1016/j.scitotenv.2020.137065

Fan, Y. Van, Klemeš, J. J., Walmsley, T. G., E B Bertók, B. (2020). Implementing circular economy in municipal solid waste treatment system using P-graph. Science of the Total Environment, 701. https://doi.org/10.1016/j.scitotenv.2019.134652

Feitó Cespón, M., Castro, R. C., E Rubio Rodríguez, M. A. (2016). Modelos de optimización para el diseño sostenible de cadenas de suministros de reciclaje de múltiples productos Optimization model to sustainable design of multiple-products recycling supply chain. Revista Chilena de Ingeniería, 24(1), 135-148. http://dx.doi.org/10.4067/S071833052016000100013

Fernández Morilla, M., Fernández-Ramos, M., Raméntol, S., $\mathcal{E}$ Tiana, S. (2019). Objetivo de desarrollo sostenible ${ }^{\circ}$ 12: Consumo y Producción Sostenible. Estudio sobre hábitos de consumo de los estudiantes. Revista De Educación Ambiental Y Sostenibilidad, 1(1), 1201. https://doi.org/10.25267/Rev_educ_ambient_sostenibilidad.2019.v1.i1.1201

Fiallos Tapia, O. A. (2017). Nuevas estrategias administrativas en negocios de gestión ambiental. 4(11), 717-725.

Ghisellini, P., $\mathcal{E}$ Ulgiati, S. (2020). Circular economy transition in Italy. Achievements, perspectives and constraints. Journal of Cleaner Production, 243, 118360. https://doi. org/10.1016/j.jclepro.2019.118360

Gobierno de la República de Colombia. (2019). Estrategia nacional de economía circular. Cierre de ciclos de materiales, innovación tecnológica, colaboración y nuevos modelos de negocio. Bogotá D.C., Colombia. Presidencia de la República; Ministerio de Ambiente y Desarrollo Sostenible; Ministerio de Comercio, Industria y Turismo.

__. (2018). Plan Nacional de Desarrollo 2018-2022 "Pacto por Colombia, pacto por la equidad." https://www.dnp.gov.co/DNPN/Paginas/Plan-Nacional-de-Desarrollo.aspx

Gong, Y., Putnam, E., You, W., $\mathcal{B}$ Zhao, C. (2020). Investigation into circular economy of plastics: The case of the UK fast moving consumer goods industry. Journal of Cleaner Production, 244, 118941. https://doi.org/10.1016/j.jclepro.2019.118941

Guarnieri, P., Cerqueira-Streit, J. A., E Batista, L. C. (2020). Reverse logistics and the sectoral agreement of packaging industry in Brazil towards a transition to circular economy. Resources, Conservation and Recycling, 153(October 2019), 104541. https:// doi.org/10.1016/j.resconrec.2019.104541

Hao, S., Kuah, A. T. H., Rudd, C. D., Wong, K. H., Lai, N. Y. G., Mao, J., E Liu, X. (2020). A circular economy approach to green energy: Wind turbine, waste, and material recovery. Science of the Total Environment, 702, 135054. https://doi.org/10.1016/j. scitotenv.2019.135054

Hernández, R., Fernández C. y Baptista, P. (2015). Metodología de la Investigación. $6^{\circ}$ edición. México: Editorial McGraw Hill 
Hoang, N. H., E Fogarassy, C. (2020). Sustainability evaluation of municipal solid waste management system for hanoi (Vietnam)-why to choose the "waste-to-energy" concept. Sustainability (Switzerland), 12(3), 1-20. https://doi.org/10.3390/su12031085

Holt, D., $\mathcal{E}$ Littlewood, D. (2017). Waste livelihoods amongst the poor - through the lens of bricolage. Business Strategy and the Environment, 26(2), 253-264. https://doi.org/10.1002/ bse.1914

Horsey, C. (2006). No Waste by 2010: Leading the way. WIT Transactions on Ecology and the Environment, 92, 521-536. https://doi.org/10.2495/WM060541

Hsieh, Y. C., Lin, K. Y., Lu, C., E Rong, K. (2017). Governing a sustainable business ecosystem in Taiwan's circular economy: The story of spring pool glass. Sustainability (Switzerland), 9(6). https://doi.org/10.3390/su9061068

Jerez, K. E., Argüelles, V. T., Máynez, A., Teresa, M., $\mathcal{J}$ Portillo, E. (2015). Logística inversa y sustentabilidad: revisión de literatura. Cultura Científica y Tecnológica, 0(55).

Kristensen, H. S., E Mosgaard, M. A. (2020). A review of micro level indicators for a circular economy - moving away from the three dimensions of sustainability? Journal of Cleaner Production, 243, 118531. https://doi.org/10.1016/j.jclepro.2019.118531

Lacovidou, E., Velenturf, A.P.M., Purnell, P., (2019). Quality of resources: a typology for supporting transitions towards resource efficiency using the single-use plastic

bottle as an example. Sci. Total Environ. 647, 441e448. https://doi.org/10.1016/j. scitotenv.2018.07.344.

Lakatos, E. S., Cioca, L. I., Dan, V., Ciomos, A. O., Crisan, O. A., E Barsan, G. (2018). Studies and investigation about the attitude towards sustainable production, consumption and waste generation in line with circular economy in Romania. Sustainability (Switzerland), 10(3), 1-25. https://doi.org/10.3390/su10030865

Lett, L. A. (2014). Las amenazas globales, el reciclaje de residuos y el concepto de economía circular. Revista Argentina de Microbiologia, 46(1), 1-2. https://doi.org/10.1016/S03257541(14)70039-2

Lieder, M., Asif, F. M. A., Rashid, A., Mihelič, A., E Kotnik, S. (2017). Towards circular economy implementation in manufacturing systems using a multi-method simulation approach to link design and business strategy. International Journal of Advanced Manufacturing Technology, 93(5-8), 1953-1970. https://doi.org/10.1007/s00170-017-0610-9

Martínez, A. N., y Porcelli, A. M. (2019). Estudio sobre la economía circular como una alternativa sustentable frente al ocaso de la economía tradicional (segunda parte). Lex, 17(23), 257. https://doi.org/10.21503/lex.v17i23.1679

Martinez, A. N., $\mathcal{J}$ Porcelli, A. M. (2016). Consumo (in) sostenible: nuevos desafíos frente a la obsolescencia programada como compromiso con el ambiente y la sustentabilidad. Ambiente y Sostenibilidad, 2016(6), 105. https://doi.org/10.25100/ays.v0i0.4294

Masi, D., Day, S., E Godsell, J. (2017). Supply chain configurations in the circular economy: A systematic literature review. Sustainability (Switzerland), 9(9). https://doi.org/10.3390/ su9091602 
Merli, R., Preziosi, M., E Acampora, A. (2018). How do scholars approach the circular economy? A systematic literature review. Journal of Cleaner Production, 178, 703-722. https://doi.org/10.1016/j.jclepro.2017.12.112

Misni, F., E Lee, L. S. (2017). A Review on Strategic, Tactical and operational decision planning in reverse logistics of green supply chain network design. Journal of Computer and Communications, 05(08), 83-104. https://doi.org/10.4236/jcc.2017.58007

Morseletto, P. (2020). Targets for a circular economy. Resources, Conservation and Recycling, 153(October 2018), 104553. https://doi.org/10.1016/j.resconrec.2019.104553

Mura, M., Longo, M., $\mathcal{E}$ Zanni, S. (2020). Circular economy in Italian SMEs: A multimethod study. Journal of Cleaner Production, 245, 118821. https://doi.org/10.1016/j. jclepro.2019.118821

Nava, J., E Abreu, Y. (2015). Logística verde y economía circular. International Journal of Good Conscience, 10(3), 80-91.

Nelles, M., Grünes, J., $\mathcal{B}$ Morscheck, G. (2016). Waste management in Germany development to a sustainable circular economy? Procedia Environmental Sciences, 35, 6-14. https://doi.org/10.1016/j.proenv.2016.07.001

Niero, M., $\mathcal{E}$ Hauschild, M. Z. (2017). Closing the loop for packaging: finding a framework to operationalize circular economy strategies. Procedia CIRP, 61, 685-690. https://doi. org/10.1016/j.procir.2016.11.209

Niero, M., Kalbar, P.P., 2019. Coupling material circularity indicators and life cycle based indicators: a proposal to advance the assessment of circular economy strategies at the product level. Resour. Conserv. Recycl. 140, 305e312. https://doi.org/10.1016/j. resconrec.2018.10.002.

ONU. (2014). La agenda para el desarrollo sostenible - Desarrollo Sostenible. https:/www. un.org/sustainabledevelopment/es/development-agenda/

Ovalles Pabón, L., Carvajal, P., Chaustre, D., Espinoza, S., Sepúlveda, Y., \& González, J. (2018). Contribución de la ética ambiental y empresarial a las organizaciones. Mundo FESC, 8(15), 62-72. https://www.fesc.edu.co/Revistas/OJS/index.php/mundofesc/article/ view/253/414

Pauliuk, S. (2018). Critical appraisal of the circular economy standard BS 8001:2017 and a dashboard of quantitative system indicators for its implementation in organizations. Resources, Conservation and Recycling, 129 (October 2017), 81-92. https://doi.org/10.1016/j. resconrec.2017.10.019

Peña Montoya, C. C., Torres Lozada, P., Vidal Holguín, C. J., \& Marmolejo Robellón, L. F. (2017). La logística de reversa y su relación con la gestión integral y sostenible de residuos sólidos en sectores productivos. Entramado, 9(1), 226-238. https://doi.org/10.18041/19003803/entramado.1.3455

Petit-Boix, A., $\mathcal{E}$ Leipold, S. (2018). Circular economy in cities: Reviewing how environmental research aligns with local practices. Journal of Cleaner Production, 195, 1270-1281. https:// doi.org/10.1016/j.jclepro.2018.05.281 
Phu, S. T. P., Fujiwara, T., Dinh, P. V., E Hoa, K. T. (2018). Waste recycling system for a tourism city in Vietnam: situation and sustainable strategy approach - case study in Hoi An City, Vietnam. IOP Conference Series: Earth and Environmental Science, 159(1). https://oi. org/10.1088/1755-1315/159/1/012046

Poponi, S., Colantoni, A., Cividino, S. R. S., E Mosconi, E. M. (2019). The Stakeholders' perspective within the B corp certification for a circular approach. Sustainability (Switzerland), 11(6), 1-15. https://doi.org/10.3390/su11061584

Rojas Conejo, G. (2016). La logística inversa y el cambio climático. Ingeniería: Revista de La Universidad de Costa Rica, 26(1), 55-62. https://doi.org/10.15517/jte.v26i1.24487

Sandhu, G. S., $\mathcal{Z}$ Naeem, M. A. (2017). A case study of innovative businesses involved with efficient municipal solid waste management in Islamabad, Pakistan. WIT Transactions on Ecology and the Environment, 223, 529-538. https://doi.org/10.2495/SC170461

Santos, F., E Eulogio, S. (2010). Aplicación de un modelo para la implementación de logística inversa en la etapa productiva. Industrial Data, 13(1), 32-39. https://www.redalyc.org/ articulo.oa?id=81619989005

Sassanelli, C., Rosa, P., Rocca, R., $\mathcal{E}$ Terzi, S. (2019). Circular economy performance assessment methods: A systematic literature review. Journal of Cleaner Production, 229, 440-453. https://doi.org/10.1016/j.jclepro.2019.05.019

Schüch, A., Morscheck, G., Lemke, A., $\mathcal{Z}$ Nelles, M. (2016). Bio-waste recycling in Germany further challenges. Procedia Environmental Sciences, 35, 308-318. https://doi.org/10.1016/j. proenv.2016.07.011

Seroka-Stolka, O., $\mathcal{E}$ Ociepa-Kubicka, A. (2019). Green logistics and circular economy. Transportation Research Procedia, 39(2018), 471-479. https://doi.org/10.1016/j. trpro.2019.06.049

Silva Rodríguez, J. D. (2017). Gestión de la cadena de suministro: una revisión desde la logística y el medio ambiente. Entre Ciencia e Ingeniería, 11(22), 51. https://doi. org/10.31908/19098367.3549

Sureeyatanapas, P., Poophiukhok, P., E Pathumnakul, S. (2018). Green initiatives for logistics service providers: An investigation of antecedent factors and the contributions to corporate goals. Journal of Cleaner Production, 191, 1-14. https://doi.org/10.1016/j. jclepro.2018.04.206

Tecnalia. (2017). S4_Estudio en la intensidad de utilización de materiales y economía circular en Colombia para la misión de crecimiento verde. Producto 1. Diagnóstico de eficiencia en el uso de materiales y cierre de ciclos en los sectores manufacturero y de construcción. 276. https://bibliotecadigital.ccb.org.co/handle/11520/21034

Ullwer, J., Campos, J. K., $\mathcal{E}$ Straube, F. (2016). Waste and pollution management practices by German companies. IFAC-PapersOnLine, 49(2), 102-107. https://doi.org/10.1016/j. ifacol.2016.03.018

Valdés López, A., López Bastidas, E. J., Alonso Aguilera, A. (2019). Gestión de residuos industriales y sostenibilidad. Necesidad de un enfoque de economía 
ecológica. Universidad y sociedad. 11(4). http://scielo.sld.cu/scielo.php?script=sci arttextËpid=S2218-36202019000400424

Werning, J. P., $\mathcal{Z}$ Spinler, S. (2020). Transition to circular economy on firm level: Barrier identification and prioritization along the value chain. Journal of Cleaner Production, 245, 118609. https://doi.org/10.1016/j.jclepro.2019.118609

Yoon, S. W., E Jeong, S. J. (2016). Implementing coordinative contracts between manufacturer and retailer in a reverse supply chain. Sustainability (Switzerland), 8(9). https://doi.org/10.3390/su8090913

Zulia, U., Urdaneta, G., Joheni, A., $\&$ Zulia, U. (2006). Omnia. Choice Reviews Online, 44(03), 44-1347-44-1347. https://doi.org/10.5860/choice.44-1347

Zuo, L., Wang, C., \& Sun, Q. (2020). Sustaining WEEE collection business in China: The case of online to offline (O2O) development strategies. Waste Management, 101(2020), 222-230. https://doi.org/10.1016/j.wasman.2019.10.008 


\title{
Advertcaring: \\ hibridación publicitaria para el bienestar
}

\author{
Juan-Diego López-Medina ${ }^{1}$ \\ Sofía Rojas Quintero²
}

\section{Introducción}

Este capítulo sugiere un nuevo tipo de hibridación publicitaria (Asquith $\mathcal{E}$ Hearn, 2012) que tácticamente busque mejorar el valor de marca (Brady, 2003; López-Medina, 2017) a través de experiencias que generen bienestar a las personas (BioScripts, n.d.) que se exponen al mensaje, Advertcaring, para fortalecer el vínculo simbólico y emocional entre el consumidor (Ghantous, 2016) y la marca (Ghosh, 2016; Jain, 2017; Orozco Toro $\mathcal{E}$ Ferré Pavia, 2012), planteando una relación innovadora entre las tácticas comerciales de marketing experiencial (Liao, Wu, Lin Ju, $\mathcal{E}$ Rivas, 2010) con la salud, para abrir una perspectiva fresca relacionada con publicidad social (LópezMedina et al., 2019) que redunde en un cambio de estado físico o emocional positivo en la persona.

De manera responsable y respetuosa, se sugiere incorporar como táctica publicitaria una serie de técnicas terapéuticas que atenúen algunos síntomas que afectan la salud pública y el desempeño de las personas (García Ríos, 2009; Vithas Neuro RHB, 2012).

Las piezas publicitarias típicas en las que claramente se nota la diferencia discursiva entre la intención comunicativa del medio, con respecto a la de la marca que pauta, son cada vez menos efectivas (Deutschman, 2005; Vega Amat y León, 2013), pues la hiperinformación (Lipovetsky y Charles, 2016), el descrédito institucional (López-Medina, Ríos Valderrama, Quintero Restrepo,

ORCID: 0000-0002-3105-8980 Dr. Visual Communication - Universidad Católica Luis Amigó Juan.lopezme@amigo.edu.co

2 ORCID: 0000-0002-1006-1136 Profesional en Publicidad - Universidad Católica Luis Amigó sofia.rojasqu@amigo.edu.co 
y Bustamante Osorio, 2019) y la desconfianza hacia quienes promueven ideas y marcas (Klein, 2001), lleva a que el público, de manera consciente o inconsciente, deposite el objetivo y mensaje publicitario en un terreno inerte de su mente. Por ello, la creatividad publicitaria ha procurado, desde hace varias décadas, que la intención comunicativa comercial publicitaria se diluya entre otros formatos narrativos y experienciales.

\section{Hibridaciones publicitarias}

Las hibridaciones son entonces la alternativa para que el alcance, impacto y efectividad del discurso publicitario se optimicen, a pesar de la dificultad que se presenta para controlar y verificar la respuesta efectiva en el público objetivo (Frunză, 2016; Pérez-Latre, 2017; Simmons, 1999).

Previamente, se han hecho investigaciones cuyo objeto de estudio son hibridaciones publicitarias, que en medio de las transformaciones aceleradas de la comunicación (Hauer, 2015; labrujulazul, 2010), resultan ser la mejor táctica para que los diversos públicos sean permeables al discurso publicitario, sobre todo cuando la globalización de las marcas y mercados obliga al diseño de estrategias más agresivas y complejas (Ries y Trout, 1991). El Advertcaring, como hibridación publicitaria, es una propuesta original, dado que no se encontraron evidencias en bases de datos de estudios y procesos publicitarios que relacionen la terapia como táctica publicitaria. A continuación, se presentan referentes de diversas hibridaciones, no figuran en orden cronológico ni hay jerarquía de importancia.

\section{Product Placement [Emplazamiento de producto (marca)]}

Tal vez la primera táctica híbrida. Algunos argumentan que sus rudimentos se evidencian en el mecenazgo renacentista, cuando poderosos pagaban por ser retratados y «publicados» en obras de arte; otros argumentan que se da en tanto se hacen evidentes marcas en piezas artísticas y culturales (a partir del siglo XIX) y que madura como táctica publicitaria en la década de 1920 (Córdoba Arias, 2015).

Para la propuesta que sobre hibridación se realiza en este capítulo, se abordaron los textos de Córdoba Arias (2015) quien relata la historia, tipos y 
casos de emplazamiento; Russell y Rasolofoarison (2017) analizan el asunto desde la perspectiva de las celebridades como legitimadores y emplazadores; Chen y Harley (2014) acercan el emplazamiento de producto al advertainment dentro de juegos en red; Hsu, Matta, Popov y Sogo (2017) comparten su investigación desde una perspectiva estratégica de medios, donde resulta más efectivo el emplazamiento; Noguti y Russell, (2014) se preocupan por aspectos normativos, cuando el emplazamiento induce al consumo de alcohol; Hwang y Jeong, (2019) indagan sobre la pregunta cómo afecta la publicidad nativa lo local, la presencia de emplazamientos foráneos en producciones extranjeras; Karniouchina, Uslay y Erenburg (2011) siembran el interrogante de la efectividad del ciclo de vida de un emplazamiento en el cine, cuando la producción pervive al producto; Hang y Auty (2008) relacionan el emplazamiento en videojuegos, con la respuesta emocional de los niños; finalmente, sobre emplazamiento en el cine, se consideraron los trabajos de Song, Meyer y Ha (2015); Wilson y Till (2011); Galician (2004), y Redondo, Russell y Bernal (2018).

\section{Advertainment. Publicidad + Entretenimiento}

A través de producciones audiovisuales y eventos culturales o deportivos es posible sembrar un nuevo valor de marca en públicos ya cautivos, pero su propósito ulterior es lograr impactar en públicos potenciales que no han tenido la experiencia de marca. Por ejemplo, para acercar a las nuevas generaciones a la experiencia musical y estética de KISS (2020), la banda de rock norteamericana ha participado en varias ocasiones como asunto conector en guiones cinematográficos, como Scooby-Doo! And Kiss: Rock and Roll Mystery (Spike y Tony, 2015), Detroit Rock City (Rifkin, 1999) y Kiss Meets the Phantom of the Park (Hessler, 1978).

Sobre este concepto, Herrmann Lima (2017) explica cómo se logra valor comercial de marca mediante advertainment; por su parte, Asquith y Hearn (2012) tratan el tema como alternativa de optimización comercial de producciones audiovisuales; así mismo, Um y Kim (2014) presentan un análisis prospectivo del contexto normativo de la incorporación de estas estrategias; finalmente, Chitu y Tecău (2010) ilustran sobre esta táctica en el contexto rumano, y Deery (2004) describe los reality TV como espacios óptimos para incorporar marcas. 


\section{Advergaming. Publicidad + Juego}

A principios de la década de 1980 se empieza a incorporar como táctica comercial y publicitaria, la creación de juegos cuyo propósito era generar o fortalecer el vínculo emocional del usuario con una marca determinada. Hoy, con la digitalización, el advergaming se hace más potente porque permite «impulsar el conocimiento de la marca, venta de productos, mayor fidelización, estudios de mercado, captación de nuevos usuarios, formación y educación, distribución de costes de publicidad, reducción de costes de publicidad, creación de comunidades, contacto directo con el cliente, efecto target to target» (Romero Ruiz, 2013 párr. 2).

Cuando en Colombia existía la Corporación Nacional de Ahorro y Vivienda -Conavi- (Pulzo, 2018), se obsequió a los niños, hijos de clientes, una serie de productos relativos a la abejita Conavi, su mascota; uno de ellos era la lotería Conavi, en la que se ilustraba en cada pieza a la abejita desempeñando diferentes roles profesionales (enfermera, bombera, doctora, etc.).

Buenos ejemplos de advergames abundan, unos, con mayor efectividad comercial que otros (Moersen, 2017). No se debe confundir el advergaming con el emplazamiento de producto en juegos, algo que resulta más frecuente de lo imaginado (Sebastián-Morillas et al., 2016).

En el desarrollo de esta investigación se consideraron los trabajos de An, Jin y Park (2014) sobre la efectividad y literacidad de los advergames entre el público infantil; Tuten y Ashley (2016) analizan si la novedad e impacto de esta hibridación, opaca la intención estratégica de marca original; Evans y Grubbs Hoy (2014) revisan la percepción de los padres con respecto a la experiencia de sus hijos con advergames; Thomson (2010) presenta estudio de casos donde el juego publicitario educa en hábitos de consumo alimenticio; Moral y otros (2016) advierten sobre el poder inmersivo de esta hibridación, sobre todo cuando incorpora realidad aumentada; Huang y Dinu (2008) siembran la inquietud sobre cuáles formatos son los más efectivos de acuerdo con los objetivos publicitarios; Sebastián Morillas et al. (2016) presentan conceptual y estratégicamente la diferencia entre advergame e in-game advertising; Ghivru, (2013) propone cómo aplicar el modelo AIDA (NewsMDirector, 2019) a este 
formato híbrido; y Terlutter y Capella (2013) realizan una revisión literaria de este y otros formatos similares.

\section{Tryvertising. Publicidad + Experiencia de producto}

El concepto es relativamente nuevo, pero alude a la entrega de muestras gratis de productos, algo que se hace desde hace varios siglos; sin embargo, se habla de Tryvertising cuando la entrega de muestras gratis es planeada, calculada y controlada, y los usuarios que reciben las pruebas se comprometen a participar de manera crítica en el proceso de mercadeo del producto (López, 2017). Al respecto, se abordó un texto que explica los beneficios de planear promociones de este modo e introduce el término trysumers (Hoback, 2008).

\section{Artvertising. Publicidad + Arte}

Esta hibridación no debería parecer extraña, al menos para Colombia, pues de acuerdo con el Ministerio de Educación (2020), la publicidad como campo técnico-académico está ubicado en el área de bellas artes y afines. Separar el artvertising de la publicidad «corriente» no es fácil, dado que la imagen publicitaria, la ilustración comercial y el discurso publicitario se distancian del contenido informativo o noticioso, en cuanto empiezan a valerse del arte como táctica diferenciadora (Bassat, 1975; Fernández Poyatos, 2013; Ferrándiz, 2008).

Se habla, pues, de artvertising, cuando el aspecto artístico prevalece sobre otros aspectos discursivos, ya sea que la publicidad utilice obras de arte como recurso comunicativo o que la publicidad en sí misma se convierta en pieza artística (Loftninja, 2009). Así como en diseño gráfico, disciplina cercana a la publicidad (Universidad de Palermo, 2019), las vanguardias artísticas marcaron en su momento la línea y concepto comunicativo (Dearstyne, 1986), y en el arte publicitario marcó una línea de aplicación conceptual de dichas vanguardias. Ejemplos de ello se tomaron de Una pausa para la publicidad (2013) y Bauhaus Kooperation (2020). 


\section{Adverteaching. Publicidad + Educación}

Aparece como una hibridación, aunque ya la publicidad social tiene como premisa educar para el bien social (Alvarado López, 2005; Martínez, 1998; París Restrepo y López-Medina, 2015) ${ }^{3}$. Sin embargo, argumentan Rodrigo y Rodrigo (2016) que se refieren al adverteaching, cuando específicamente se diseñan y ejecutan campañas publicitarias con el propósito de transformar los imaginarios y comportamientos de un colectivo determinado, en función de la sana convivencia y el buen vivir; es decir, cuando la publicidad social se desliga del facto marcario y comercial y se dedica al comportamental.

El rastreo de hibridaciones realizado, permite, en coherencia, plantear una hibridación específica, a partir de la publicidad social. De dicha hibridación trata el desarrollo del resto del capítulo.

\section{Metodología}

Para el desarrollo de este capítulo se consideró el enfoque cualitativo (Álvarez-Gayou, 2003; Becerra y Carrillo, 2004), bajo el paradigma criticosocial (Alvarado y García, 2008; Melero Aguilar, 2011), por cuanto pretende intervenir el objeto de estudio y ofrecer un aporte a este.

La recolección de datos se hizo, en principio, mediante investigación documental en bases de datos, que además de fundamentar conceptualmente las hibridaciones descritas con anterioridad, permitió dar cuenta de la ausencia de investigaciones que relacionaran las tácticas publicitarias y de marketing experiencial con actividades de interacción terapéutica y salud pública. Así entonces, el proyecto de investigación se enfoca en conceptualizar respecto a la propuesta de integración de terapias para el bienestar, marketing experiencial y publicidad social.

Se realizaron entrevistas a expertos para identificar la pertinencia de integrar terapias en acciones publicitarias que, además de mejorar el valor de marca, permitan atenuar condiciones de salud pública. Los entrevistados se seleccionaron a conveniencia así: terapeuta especialista

Otros autores: López-Medina, Orozco-Toro, et al. (2019); López-Medina y París-Restrepo (2014); López-Medina, Ríos Valderrama, et al. (2019). 
en salud ocupacional ${ }^{4}$, psicólogo 5 (Díaz et al. 2013) y publicistas ${ }^{6}$ (Hamme y Atkinson, 1994; Pascual, s.f.). Como complemento y en razón al rol de los autores del capítulo, se incorpora como técnica investigativa, la investigación participativa y revisión de algunos casos concretos que pueden catalogarse como advertcaring (Melero Aguilar, 2011).

\section{Advertcaring: Publicidad + Experiencias terapéuticas}

Para contextualizar este concepto novedoso, se abordan ideas acordes con objetos de conocimiento de diferentes ámbitos, que facilitan en el ejercicio publicitario la incorporación de experiencias terapéuticas como tácticas de mejoramiento de valor de marca.

\section{Salud pública}

Hay una idea generalizada de la salud pública como un asunto administrativo, institucionalizado y, por lo tanto, marginal a la experiencia cotidiana del ciudadano, descrita como "la ciencia y el arte de organizar y dirigir los esfuerzos colectivos para proteger, fomentar y reparar la salud. Es sinónimo de administración sanitaria" (Molina, como se citó en Cardona, 1998 p. 286). Sin embargo, el origen del concepto involucra, sobre todo, la interacción humana con su entorno y con los demás. Se refiere, por una parte, a que «salud pública es la aplicación de los conocimientos médicos y científicos para asegurar condiciones sanas de vida al individuo miembro de una comunidad» (Frazer, como se citó en Cardona, 1998 p. 286). A lo anterior se agregan otros aspectos contemplados por la Organización Mundial de la Salud (OMS) como entidad global: «[...] impedir la enfermedad, prolongar la vida y fomentar la salud y eficiencia mediante el esfuerzo organizado de la comunidad para que el individuo en particular y la comunidad en general se encuentren en

\footnotetext{
Juan Fernando Sánchez Caballo, Fisioterapeuta, Especialista en Salud Ocupacional comunicación personal, 18 de octubre de 2019.

Luis Fernando Castaño Pamplona, Psicólogo comunicación personal, 26 de octubre de 2019.

- Rafael Vargas Cano Magíster en Educación. Publicista y. Andrés Ignacio Montoya, Especialista en Mercado Estratégico. Publicista comunicación personal, viernes 13 de Septiembre del 2019.
} 
condiciones de gozar de su derecho natural a la salud y longevidad» (citado en Cardona, 1998, p. 286-287).

La OMS no restringe el concepto a un asunto de organizaciones públicas o estatales; sin lugar a dudas habla de esfuerzo de la comunidad, lo que involucra a cada persona y ente activo en un territorio, ecosistema o ambiente. En este sentido, la publicidad como un esfuerzo organizado de comunicación estratégica, puede incorporarse como actor en las dinámicas de sostenimiento y mejoramiento de salud pública. Pero «la falta de una definición precisa en nuestro medio hace que la brecha entre la gente y el equipo de salud se sigue agrandando» (López, 2005 p. 109 (337)). Actualmente, como apuntan Frenk y Gómez-Dantés (2007), la salud pública integra todo tipo de organizaciones, no solo de la salud, sino comerciales, industriales y de servicios, porque la globalización e integración de sistemas en el contexto mundial lleva a que la salud pública supere las barreras autoimpuestas de ser un asunto que le atañe a las organizaciones públicas y de salud, y pasa de ser un asunto menor de corte local y particular, a convertirse en tema de agenda global (Pacto Global - Red Colombia, 2018).

En 2020 se hace más evidente que la salud pública no depende de decisiones político-administrativas, sino de la educación, la disciplina y el autocontrol de la ciudadanía. El caso ineludible de contagio pandémico sufrido por el COVID-19 evidencia que a pesar del control del Estado, si no hay acato ciudadano, comercial, económico, religioso y cultural, no se logra el objetivo macro: "Cada país debe adaptar la respuesta según las capacidades de sus sistemas de salud, sus recursos económicos e infraestructura, y el grado de responsabilidad colectiva e individual» (Chaccour, 2020 párr. 14).

Por lo anterior, resulta entonces más pertinente el concepto de que la salud pública es un encuentro individuo-sociedad y técnico-político que resulta de la relación entre concepto (pensamiento) y acción, para mejorar la calidad de vida en tres fases: generación (producción), reproducción (enseñanza) y traducción (materialización para soluciones, que incluye vacunas, procedimientos clínicos, protocolos, aplicaciones móviles para usabilidad de ciudadanos, etc.). La salud pública bajo esos criterios es, de este modo, un sistema social rural o urbano que se interconecta con los demás sistemas (Frenk Mora, 2013), por ello, esta última concepción resulta más 
pertinente para la idea de advertcaring, pues la acción social-ciudadana es la que dinamiza y hace efectiva la salud pública, no son solo disposiciones administrativas o control estadístico; se trata de tácticas de experiencias vívidas para las personas.

Para poder hablar de salud pública, es necesario, primero, entender el concepto de salud; sin embargo, esto es altamente subjetivo, pues considerar saludable o no a una persona es un juicio que requiere de diagnósticos múltiples, y es posible que esa persona se considere saludable, mientras que las evidencias clínicas, fisiológicas o psicológicas digan lo contrario. De igual manera, una persona puede sentir que su salud flaquea, pero clínicamente estar bien (López, 2005); por eso se alude mejor a la idea de bienestar.

López (2005) hace un paralelo entre varias definiciones, dando un horizonte más claro cuando plantea que se trata de «una actividad multiprofesional» (p. 109 (337)) que mediante la articulación interinstitucional de acciones educativas, preventivas, correctivas y normativas, busca el mayor bienestar físico, mental y emocional de las comunidades.

Para explorar este nuevo terreno es importante analizar las tres tendencias que están influyendo de manera determinante en la salud global a principios del siglo XXI: a) la creciente transferencia internacional de riesgos y oportunidades para la salud; b) el mayor pluralismo en la arena de la salud internacional, con una acelerada multiplicación del número de actores, y c) el papel cada vez más crítico de la salud dentro de la agenda del desarrollo económico, la seguridad global y la democracia. (Frenk y Gómez-Dantés, 2007 p. 157)

Frenk y Gómez-Dantés (2007) sostienen que en los últimos doscientos años, la concepción de salud pública, cada vez ha ido incorporando más entidades e instituciones públicas y privadas, y dado el desarrollo del mundo actual, «el gran reto en este escenario de enorme pluralismo es desarrollar un verdadero sistema global de salud que permita generar acciones concertadas en materia de definición de prioridades, movilización de recursos, diseño e implantación de estrategias, y monitoreo y evaluación de resultados» (Frenk E Gómez-Dantés, 2007 p. 160). 
Así, la publicidad como campo de conocimiento dedicado a estrategias comunicativas con propósitos concretos y, propiamente, la publicidad social desde su intención educativa en el bien social, favorece la salud pública, cuando se incorpora en su ejercicio, logrando que los intereses colectivos de bienestar, puedan lograrse de maneras más atractivas y efectivas en los diversos grupos de interés.

Desde otro punto de vista, no se puede desconocer la relación entre la salud pública y el desarrollo económico, la «paradoja inaceptable», según Frenk (2007 p. 161), que obliga a que el bienestar colectivo dependa del fortalecimiento económico del sistema social, de nuevo, la publicidad como herramienta estratégica cumple un papel importante como articuladora estratégica entre áreas de conocimiento. De manera atrevida, la preocupación por definir de manera concreta la salud pública, se habla también de «medicina social» o sociomedicina (Frenk Mora, 2013 p. 7)

Como síntesis de este punto, se presenta la figura 1 con la cual se busca realizar una tímida taxonomía de las concepciones de la salud pública, en la que Frenk propone un esquema ecologista (es decir, la relación del sujeto con su hábitat). Cabe considerar que el advertcaring que planteamos en este capítulo reviste un papel relevante.

\section{Figura 1.}

Principales modelos conceptuales sobre la salud pública

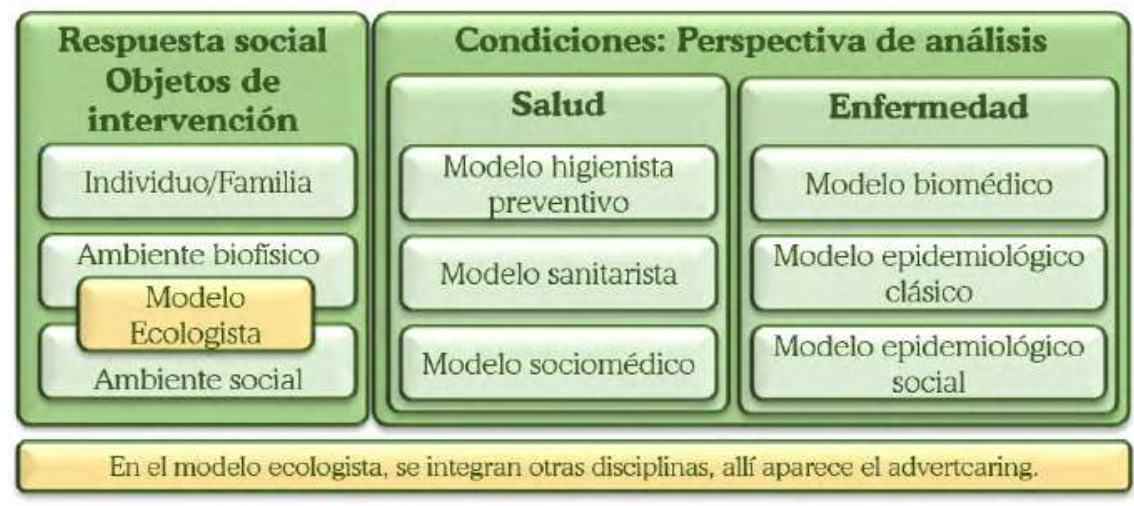

Nota: En el modelo ecologista se integran otras disciplinas. Allí aparece el advertcaring. Fuente: Elaboración propia, adaptada de Frenk Mora (2013 p. 10). 


\section{Terapias}

El término terapia ha sido usado de modo abusivo con fines comerciales y experienciales, pues muchas interacciones sujeto/objeto son contempladas como terapéuticas, inclusive, sin un bagaje científico, metodológico o técnico. Hoy se convierte en un nicho de mercado, altamente lucrativo, la oferta de servicios terapéuticos que, tal vez, carecen de soporte científico; sin embargo, a los mercados a los que obedece la oferta, cuentan con alta demanda que busca un beneficio más sensual-sensorial, que clínico: la sensación de sentir bienestar. El nuevo universo terapéutico comercial abarca terapias con gemas, piedras, frutas, olores, colores, melodías, chocolate, masajes, corrientes de agua, animales domésticos, baile, chistes, aceites, actividades sexuales y una amplia gama de propuestas creativas que suplen necesidades más simbólicas y emocionales, que fisiológicas.

En este capítulo aludimos a tres tipos de terapia que tradicionalmente tienen su rigor, su método y, sobre todo, su protocolo, para medir, verificar, controlar y mejorar la condición de la persona o paciente que acude a terapia.

\section{Terapia ocupacional}

Respetando el rigor que representa la OMS (citada por Vithas Neuro RHB, 2012), terapia ocupacional es:

El conjunto de técnicas, métodos y actuaciones que, a través de actividades aplicadas con fines terapéuticos, previene y mantiene la salud, favorece la restauración de la función, suple los déficit invalidantes y valora los supuestos comportamentales y su significación profunda para conseguir la mayor independencia y reinserción posible del individuo en todos sus aspectos: laboral, mental, físico y social. (párr. 1)

Esta definición suaviza, de alguna manera, la intención productiva que hay detrás de ese acompañamiento al sujeto para «conseguir la mayor independencia y reinserción posible del individuo» (párr. 1); sin embargo, en muchos países es obligatorio un marco legislativo que obliga a contar con políticas de salud y seguridad en el trabajo, que a su vez presentan programas 
de salud ocupacional (López-Medina, Orozco y Postigo, 2012; Organización Internacional de Normalización-ISO, 2007).

La terapia ocupacional supera el ámbito laboral o contractual, pues se hace más importante cuando la persona entra en inactividad laboral; su bienestar físico y emocional requieren de un acompañamiento terapéutico para la adaptación a su nueva vida.

Es este tipo de terapia una táctica pertinente para el advertcaring, debido a que los procedimientos que se emplean para mantener activa y saludable la mente y el cuerpo pueden ser aplicados y asociados a estrategias de marca. El acompañamiento terapéutico, en contextos específicos de experiencia de marca, puede favorecer el valor de marca (Em, Agroquímicas y Cortázar, 2013; Financiera, n.d.; López-Medina, 2017; Oliveira y Furlani, n.d.) y hacer de esta un elemento más significativo para la persona (Havas Media, 2016).

\section{Terapia psicológica}

Debe advertirse que el advertcaring no pretende sustituir el ejercicio profesional de la psicología, sino valerse de algunos elementos experienciales para el bienestar:

Un tratamiento psicológico bien planteado, bien pensado y dirigido por un especialista en salud mental, es muy eficaz para aliviar los síntomas y eliminar tanto el sufrimiento derivado de los problemas psicológicos, como el trastorno en sí mismo. En la mayoría de los problemas psicológicos, por ejemplo, la ansiedad y todas sus manifestaciones como; la angustia, la inseguridad, los miedos y las fobias, las intervenciones psicológicas han demostrado ser muy satisfactorios para su curación, eliminando el enorme sufrimiento.

Asimismo, los tratamientos psicológicos han demostrado su eficacia en la eliminación de problemas obsesivos, ciertos trastornos de la personalidad, conflictos emocionales, en el tratamiento de enfermedades como la depresión y muchos otros trastornos. (Centro Manuel Escudero, 2020) 
Desde la psicología clínica, se tiene especial respeto y cuidado con la interacción con los pacientes, en virtud a que la intervención del profesional afecta sustancialmente la calidad de vida de las personas; por ello, cada vez se le otorga mayor rigor al protocolo de acompañamiento y seguimiento de la condición de las personas que acuden a tratamiento psicológico: «Los puntos de convergencia entre la investigación y la psicoterapia [...] están alcanzando cada vez más relevancia» (Mustaca, 2004 p. 18).

En concreto, la incorporación de psicoterapia como táctica para el advertcaring, deberá ser altamente cuidadosa y fruto de un proceso exhaustivo de investigación, para no incurrir en afectaciones irresponsables. Ahora bien, resulta más prudente acudir a la terapia humanista existencial fenomenológica (Rosso y Lebl, 2006) que alude al:

Respeto a la capacidad e independencia del ser humano, es un rechazo hacia todo aquello que coarta la independencia del sujeto como ser libre (...) De acuerdo a este nuevo modo de hacer psicoterapia, el ser humano siempre va a elegir la dirección de su libertad y va a seleccionar para él mismo los caminos constructivos. (Rosso y Lebl, 2006 p. 93)

Con esta perspectiva, las tácticas de psicoterapia para la publicidad encaminadas al bienestar son respetuosas de la persona y no hurgan en ella más allá de lo que ella misma quiera compartir. Se recomiendan tres posturas o condiciones para que la experiencia entre paciente y terapeuta ${ }^{7}$ sea efectiva: congruencia, entre lo que se expresa y cómo se actúa; aceptación positiva incondicional, respeto mutuo y apertura a conocer al otro; y comprensión empática, disposición para el diálogo emocional entre actores de la experiencia (Rosso y Lebl, 2006 pp. 94-96).

La experiencia terapéutica no intenta resolver el problema de fondo en la persona; busca, eso sí, que la persona tenga una motivación para que ella misma experimente un cambio actitudinal: "otorga una importancia mayor a la situación inmediata que al pasado de un sujeto, los modelos de comportamiento emocional de una persona, se manifiestan, igualmente, en su adaptación presente e, incluso, durante el tiempo de la entrevista" (Rosso

Para el caso del advertcaring, sería adoptante objetivo-o público objetivo-y marca. Nota de los autores. 
y Lebl, 2006 p. 101). Entendiendo la entrevista, en el caso del advertcaring, como la táctica experiencial que acerca la marca a las personas.

\section{Publicidad social}

Se trata de un ejercicio proyectual y estratégico con fines educativos y de promoción del bien social. La publicidad social se ha convertido en los últimos cuarenta años en un aspecto relevante para cultivar la reputación corporativa y el valor de marca, creadora de marcas significativas y de acciones sociales que mueven a diversos grupos de interés y comunidades a cambiar comportamientos de consumo e interacción (Alvarado López, 2005; LópezMedina y París-Restrepo, 2017; Martínez, 1998) ${ }^{8}$.

En este capítulo no se detalla en definir el concepto, dado que previamente se insinuó al respecto con las descripciones de otras hibridaciones publicitarias. Lo que se busca es dar a entender que el advertcaring, como propuesta de nueva hibridación, es un enfoque táctico muy específico de la publicidad social.

Aunque dentro de la publicidad social hay un espacio relevante para las campañas educativas en salud y la donación de sangre o de órganos, el advertcaring no se propone ejecutar este tipo de campañas, que como se advirtió anteriormente en el tema de salud pública, a veces parecen marginales y no son aprehendidas por las comunidades; el propósito del advertcaring, desde la publicidad social, es incorporar la mezcla de prosumidores o las $4 \mathrm{E}^{9}$ para que la sociedad sea parte dinámica de la experiencia de marca, a través de actividades que favorezcan la salud pública.

De los enfoques de la publicidad (propagandístico, comercial, institucional y social), es posible que se apliquen tácticas de advertcaring, por cuanto dichos enfoques coinciden con los de la salud, que con el uso de un lenguaje más técnico, son leídos como elementos proyectuales para publicidad; la salud

\footnotetext{
Otros autores: Havas Media (2016); Codeluppi, (2007); Financiera (n.d.); Jain, (2017); Liu, Liu, y Lin (2015); López-Medina, Orozco-Toro, et al. (2019); Orozco Toro y Ferré Pavia (2012)

$97 \mathrm{E}$ en la práctica, «Unos autores hablan de Exchange, Engagement, Emotion, Exclusivity; otros de Exchange, Experience, Evangelism, Everyplace. Dado que el autor del presente capítulo no considera las dos concepciones excluyentes, se contemplan 7 E» (López-Medina en Lopera Quiroz $\mathcal{E}$ (Comp.), 2020 p. 138).
} 
pública es considerada la oportunidad de acción (o problema); la percepción de bienestar, es el objetivo que busca la marca; y las terapias, son las tácticas de las interacciones entre sujeto y marca.

Para que el advertcaring sea una experiencia de usuario efectiva, es necesario el contacto directo entre el adoptante objetivo y la experiencia terapéutica que ofrece la marca, de manera que mediante acciones no convencionales de impacto, alcance y frecuencia de marca (Bassat, 1975; De Durán, 2014; López-Medina, Orozco-Toro et al., 2019), sea posible permear a las personas de una experiencia positiva que resulte responsable socialmente y que atenúe alguna afectación de salud pública experimentada por dicho adoptante.

La figura 2 que aparece más adelante, ilustra la relación entre los enfoques de publicidad y mercadeo, y de la salud. Se incorporan en los enfoques de publicidad y mercadeo, elementos que permiten plantear ciertos tipos de tácticas publicitarias, como los conceptos relacionados con la mezcla dirigida al prosumidor (Quain, 2012; Wuebben, 2017) o adoptante objetivo (Alvarado López, 2005; Orozco Toro $\mathcal{E}$ Ferré Pavia, 2012) y los modos de ejecución de tácticas publicitarias, donde básicamente las acciones de advertcaring se evidencian como acciones Below The Line; sin embargo, la recursividad está dispuesta para aplicarse en cualquier modo.

\section{ATL. Above the line}

Traducido al castellano como (sobre la línea), es todo el ejercicio publicitario tradicional que implica el pago de una comisión por mediación de las agencias publicitarias entre el anunciante y el medio publicitario; sigue siendo el recurso que más presupuesto mueve y regularmente se emplea para campañas de alcance masivo, esto insinúa que el menaje se dispersa homogéneamente a todos. (Escamilla, 2019; Tenesaca Fajardo, 2017)

\section{BTL. Below the line}

Traducido (bajo la línea), contempla las tácticas publicitarias cuya mediación no es convencional, no se paga comisión a agencias de publicidad; no obstante, el concepto fue llevado más allá y ahora hace referencia a tácticas 
alternativas no tradicionales, que pretenden impactar en públicos más segmentados y a menores costos, muchas veces buscando la interacción con el público mediante experiencias de marca de alto impacto creativo (Tenesaca Fajardo, 2017). Como acciones BTL, pueden considerarse patrocinios, relaciones públicas, emplazamiento de productos, advertgaming y experiencias en punto de venta (Escamilla, 2019).

\section{OTL. On the line}

Hace referencia a lo relativo al internet y a la red. Se usa con estrategias que van dirigidas a un público amplio a través de las herramientas que ofrece el internet desde la social media, el SEO, el SEM, banners, mail, hasta advertgaming (Fajardo, 2017). Cada vez se aplican más, por asunto de bajos costos, medición precisa en tiempo real y recolección de datos, focalización por regiones y públicos (usuarios de apps y plataformas) e instantaneidad (Letra Mágica, 2017).

\section{TTL. Through the line}

Traducido (a través de la línea), conjuga las tácticas ATL y BTL, para optimizar resultados (Tenesaca Fajardo, 2017). Esta estrategia potencia las acciones realizadas con un enfoque integrado de $360^{\circ}$, uniendo la creatividad publicitaria con el desarrollo de una comunicación más tradicional, y ofrece un alto alcance, pero generando buenos resultados (Planimedia, 2015).

\section{FTL. Fuck the line}

Puede traducirse como (al carajo la línea). Creada por Martín Bueno y Joe Wisem, es más un recurso mixto de los anteriores que pretende valerse de circunstancias no planeadas del ambiente físico y digital para la promoción de marcas (Tenesaca Fajardo, 2017). Se incorporan elementos preexistentes en el entorno, a piezas publicitarias, por ejemplo, postes, líneas de energía, huecos en las vías, cuerpos verdes o de agua en las ciudades, etc. (Katecontre, 2012) y busca derribar las barreras entre comunicación, mercadeo, publicidad, 
diseño urbano y demás disciplinas relativas a la interacción comunicativa con las marcas y entidades (Smith, 2013).

La publicidad, adoptando elementos de otras áreas de intervención social, resulta en hibridaciones diferentes que pueden hacer que los objetivos publicitarios se logren de manera más efectiva. La figura 2 muestra estas hibridaciones resultantes, detallando en los conceptos que permiten proponer el advertcaring como una de ellas. Además, las hibridaciones existentes, y a las que se suma el advertcaring, no son ejercicios exclusivos o aislados. Una propuesta publicitaria puede valerse de varias hibridaciones de manera simultánea o transversal, pues esto toca además con el asunto de la transmediación (Hidalgo Casas, 2012; Sepúlveda, 2017) que lleva el mensaje publicitario a espacios diversos en los estilos de vida de públicos y adoptantes objetivo.

\section{Figura 2.}

Hibridaciones publicitarias. Enfoques para el advertcaring

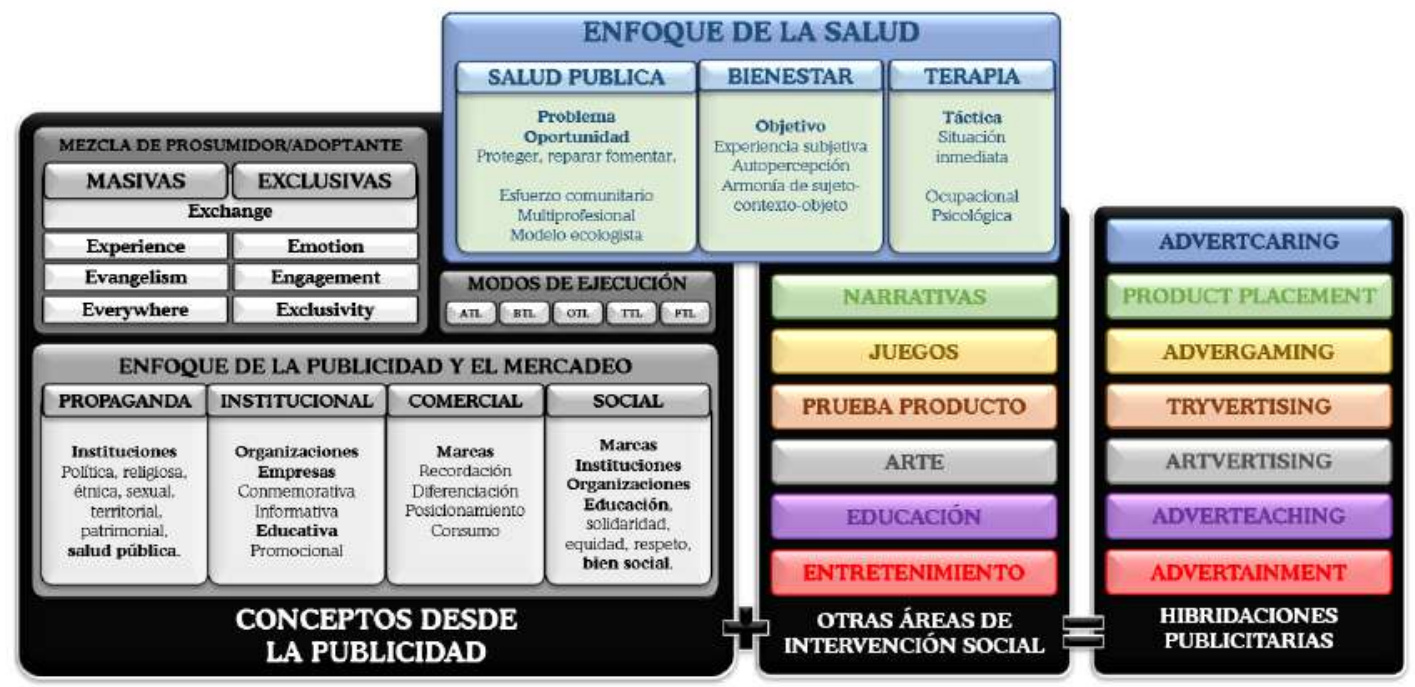

Nota: relación entre conceptos de publicidad, mercadeo y salud pública, como tácticas para proponer una nueva hibridación publicitaria. Fuente: Elaboración propia 


\section{Consideraciones finales}

El propósito fundamental del advertcaring, o publicidad para el bienestar, es buscar que las marcas, comerciales o no, realicen campañas que promocionen sus productos o servicios, pero adicionalmente generen un bienestar a las personas desde la salud pública con métodos terapéuticos, como tácticas de marca que permitan experiencias significativas en el adoptante objetivo, quien luego del contacto con la marca sentirá bienestar.

Para que se efectúen tácticas de advertcaring, se recurre a publicidad sensorial y experiencial, estimulando los sentidos y produciendo emociones, interviniendo la salud del adoptante o público objetivo desde lo físico, lo emocional y lo mental, de una manera no clínica, por ejemplo, utilizando en BTL recursos terapéuticos no invasivos ni que comprometan a la persona en un proceso de acompañamiento de varias sesiones: olores y sonidos relajantes, actividades para bajar los niveles de estrés, elementos interactivos para ayudar con los dolores musculares, o generando momentos donde las personas se sientan particularmente asistidas en favorecimiento de su autopercepción de bienestar.

La dinámica del advertcaring es cuidar y mimar a las personas, considerando siempre la responsabilidad y conciencia social; si no hay un interés genuino por generar valor de marca desde la aprehensión social del bienestar que se ofrece, no hay objeto en incorporar esta hibridación a una estrategia publicitaria.

Si bien antes se dijo que el BTL es el mejor recurso para ejecutar advertcaring, no quiere decir que sea la única manera. Es importante que estas tácticas de advertcaring BTL se articulen como ejercicios trasmediados a experiencias y tácticas tradicionales, pues no pueden percibirse como acciones marginales de una campaña.

En el presente capítulo se hace la propuesta de implementar el advertcaring como táctica para mejorar el bienestar ciudadano y el valor de marca. La insinuación puede llevarse a contextos diferentes al enfoque comercial, por ejemplo, aplicar el advertcaring al público interno de una organización, en entidades educativas y de administración pública y todo tipo de espacios de interacción social, como ejercicio permanente de bienestar laboral, social, emocional y físico. La hibridación que se propone, puede 
institucionalizarse con el apoyo de marcas aliadas y así desarrollar sinergias interinstitucionales de interés.

Las hibridaciones publicitarias tratadas en este capítulo se abordaron como marco referencial. Por las condiciones técnicas de espacio y límite de contenido, no se profundiza en cada una ni se hace una comparación crítica entre ellas. Se invita a los interesados en profundizar el asunto a comparar aplicaciones híbridas en contextos institucionales, propagandísticos, comerciales y sociales, que además están en permanente evolución y adaptación a diversos factores mercadológicos. Existen muchas probabilidades de que las descripciones de este texto no sean precisas con respecto a ejemplos reales, dado que las hibridaciones no funcionan de manera purista; es decir, entre ellas hay sincretismo y, por lo tanto, una táctica puede ser al mismo tiempo advergaming y adverteaching, o artvertisement y advertainemt, como los casos cinematográficos.

El ejercicio juicioso y permanente de investigación en salud pública, sumado a la investigación publicitaria, podrá permitir la gestación de advertcaring efectivo, que en el mediano y largo plazo impacte de tal modo en los adoptantes objetivo para que genere verdaderos cambios en los hábitos por un mayor bienestar. La idea no es planear tácticas sueltas o esporádicas, sino generar en el mediano y largo plazo, experiencias positivas que mitiguen afectaciones de salud pública, claro está, ajustadas a los contextos; no es prudente copiar para Colombia una táctica realizada con éxito en Dubai -no solo en el advertcaring- en términos generales en salud pública y publicidad, no es conveniente importar estrategias, sí se pueden estudiar y adaptar luego de un prudente pilotaje.

El advertcaring no es una táctica caprichosa de una marca; debe ser el concurso ecosistémico de diversas organizaciones que confluyen en el interés del bienestar social y que a través de tácticas de marca, como alianzas y cobranding, planean experiencias favorecedoras para la reputación corporativa mediante el contacto directo con las personas que a través de ejercicios terapéuticos, reciben un estímulo positivo a la mente y cuerpo, que deberá tener alguna relación funcional o conceptual con las marcas involucradas, pues el propósito de ejecución de la táctica publicitaria para el bienestar, deberá lograr, después de todo, alguna de las premisas publicitarias: recordación, posicionamiento, diferenciación o consumo. 


\section{Referencias bibliográficas}

Actualidad Sanitaria. (2020). El estrés. La enfermedad del siglo XXI. https://actualidadsanitaria. com/vida-saludable/el-estres-la-enfermedad-del-siglo-xxi/

Alvarado, L. y García, M. (Diciembre, 2008). Características más relevantes del paradigma socio-crítico: su aplicación en investigaciones de educación ambiental y de enseñanza de las ciencias realizadas en el Doctorado de Educación del Instituto Pedagógico de Caracas. Sapiens. Revista Universitaria de Investigación, Año 9, 187(2), 187-202.

Alvarado López, M. (2005). La publicidad social: concepto, objeto y objetivos. Redes.Com: Revista de Estudios Para El Desarrollo Social de La Comunicación, (2), 265-284.

Álvarez-Gayou, J. L. (2003). Como hacer investigacion cualitativa: fundamentos y metodología. Paidós Educador. http://sapp.uv.mx/univirtual/especialidadesmedicas/mi2/modulo2/ docs/InvestCualitativa.pdf

An, S., Jin, H. S., E Park, E. H. (2014). Children's Advertising Literacy for Advergames: Perception of the Game as Advertising. Journal of Advertising, 43(1), 63-72. https://doi. org/10.1080/00913367.2013.795123

Asquith, K., E Hearn, A. (2012). Promotional Prime Time: "Advertainment" Internal Network Promotion, and the Future of Canadian Television. Canadian Journal of Communication, 37, 241-257.

Bassat, L. (1975). El libro rojo de la publicidad. Debolsillo. https:/www.pqs.pe/sites/default/ files/2016/03/aprende-mas/libro_rojo_de_la_publicidad1.pdf

Bauhaus Kooperation. (2020). Printing and Advertising. Recuperado en Abril 3, 2020, de https:/www.bauhaus100.com/the-bauhaus/works/printing-and-advertising/

Becerra, A. J., E Carrillo, A. T. (2004). La práctica investigativa en Ciencias Sociales. La práctica investigativa en ciencias sociales. http://bibliotecavirtual.clacso.org.ar/ar/libros/colombia/ dcsupn/practica.pdfMemoria+individual,+memoria+colectiva+y+memoria+histórica . + Eots=DqAoQyBz-LEsig=d9TvlcVDNqiwtftZafIBGQPBlkw

Bernardin, T., Kemp-Robertson, P., Stewart, D. W., Cheng, Y., Wan, H., Rossiter, J. R., ... Fukawa, N. (2009). Envisioning the Future of Advertising Creativity Research: Alternative Perspectives. Journal of Advertising, 37(4), 131-150. https://doi.org/10.2753/joa00913367370411

BioScripts. (n.d.). Bienestar. Recuperado en Marzo 31, 2020, de https://www.biodic.net/ palabra/bienestar/\#.XoNFKOpMSwV

Brady, A. (2003). How to generate sustainable brand value from responsibility. Journal of Brand Management, 10(4), 279-289. https://doi.org/10.1057/palgrave.bm.2540124

Cardona, J. (1998). La salud pública en período de crisis. Revista Cubana de Medicina General Integral, 14(3), 286-294.

Centro Manuel Escudero. (2020). ¿Las intervenciones psicológicas son eficaces? Recuperado en Abril 14, 2020, de https://www.manuelescudero.com/texto-de-videos-psicologia/ tratamientos-psicologicos-y-su-eficacia/ 
Chaccour, C. (2020). COVID-19: Cinco respuestas de salud pública diferentes ante la epidemia. https://www.isglobal.org/healthisglobal//custom-blog-portlet/covid-19-cinco-respuestasde-salud-publica-diferentes-ante-la-epidemia/2877257/0

Chen, H., $\mathcal{E}$ Harley, E. (2014). Product Placement in Social Games: Consumer Experiences in China.: EBSCOhost. Journal of Advertising, 43(3), 286-295. Recuperado de http:// web.a.ebscohost.com/ehost/pdfviewer/pdfviewer?vid=0Essid=1a9b6dd0-01dc-4bbcb858-e91434f8d76f\%40sdc-v-sessmgr03

Chitu, I. B., छ Tecău, A. S. (2010). PRODUCT PLACEMENT AS A FORM OF ADVERTAINMENT. Bulletin of the Transiluania University of Braşov, 3(52), 23-26.

Codeluppi, V. (2007). El papel social de la publicidad. Pensar La Publicidad. Revista Internacional de Investigaciones Publicitarias, 1(1), 149-155. https://doi.org/-

Córdoba Arias, S. (2015). Product Placement: Historia, modalidades y casos. Universidad de Valladolid. Recuperado de https://uvadoc.uva.es/bitstream/10324/14124/1/ TFG-N.333.pdf

De Durán, A. (2014). Estrategias Creativas En Publicidad. Universidad Rey Juan Carlos. Recuperado de http://www.albertodeduran.es/wp-content/uploads/2014/08/2x08Estrategias-creativas-en-publicidad.pdf\%5Cnhttp://www.ub.edu/sentipensar/pdf/ saturnino/estrategias_creativas_universitaria.pdf

Dearstyne, H. (1986). Inside the Bauhaus. New York: The Architectural Press. Recuperado de https://books.google.com.co/books?hl=esElr=EZid=hdN3BgAAQBAJËoi=fndËpg=PP1Edq $=$ bauhaus + and + advertisingEots $=$ MOZCFsTRK7Esig $=$ JvhLkNPyVGz29mxpP2rJKJkavzg\# $\mathrm{v}=$ onepage $\mathcal{E} \mathrm{q}=$ bauhaus and advertising $\mathcal{E} \mathrm{f}=$ false

Deery, J. (2004). Reality TV as Advertainment.pdf. Popular Communication, 2(1), 1-20.

Deutschman, A. (2005). La TV ha muerto, iviva la Web! Gestión, 8(3), 24-29.

Díaz, L., Torruco, U., Martínez, M., $\mathcal{Z}$ Varela, M. (2013). La Entrevista, Recurso Flexible y Dinámico. Investigación En Educación Médica, 2(7), 162-167. Recuperado de http://www. scielo.org.mx/scielo.php?pid=S2007-50572013000300009Esscript=sci_arttext

Em, A., Agroquímicas, C., E Cortázar, L. O. (2013). Relación entre valor de marca y las ventas . Un estudio aplicado en compañías agroquímicas, 21(29), 105-124.

Escamilla, O. (2019). ¿QUÉ SIGNIFICA ATL? ¿QUÉ SIGNIFICA BTL? Recuperado en Abril 29, 2020, de https://www.merca20.com/que-significa-atl-que-significa-btl/

Evans, N., E Grubbs Hoy, M. (2014). GOT GAME? AN INVESTIGATION OF PARENTS ' UNDERSTANDING OF AND ATTITUDES TOWARD ADVERGAMES, 115-119.

Fernández Poyatos, M. D. (2013). Propuestas cronológicas para la Historia de la publicidad. Ilu, 18, 267-277. https://doi.org/10.5209/rev_HICS.2013.v18.43965

Ferrándiz, R. R. (2008). La publicidad como industria cultural. Pensar La Publicidad Revista Internacional de Investigaciones Publicitarias, 2(June 2008), 19-36.

Financiera, E. (n.d.). El efecto de la marca y la reputación en el valor de la empresa.

Franco G., Á. (2006). Tendencias y teorías en salud pública. Revista Facultan Nacional de Salud Pública, 24(2), 119-130. Recuperado de http://www.scielo.org.co/pdf/rfnsp/v24n2/ v24n2a12.pdf 
Frenk, J., E Gómez-Dantés, O. (2007). La globalización y la nueva salud pública. Salud Publica de Mexico, 49(2), 156-164. Recuperado de https://www.scielosp.org/pdf/spm/2007. v49n2/156-164

Frenk Mora, J. (2013). La salud de la pobllacion. Hacia una nueva salud pública. Revista Cubana de Salud Pública. Madrid: Fondo de cultura económica. Recuperado de https:// biblioceop.files.wordpress.com/2011/02/la_nueva_salud_p25fablica.pdf

Frunză, S. (2016). Advertising constructs reality (). Journal of Media Research, 9(1), 121-125.

Galician, M. (2004). Introduction: Product Placements in the Mass Media: Unholy Marketing Marriages or Realistic Story-Telling Portrayals, Unethical Advertising Messages or Useful Communication Practices? Journal of Promotion Management, 10(1-2), 1-8. https://doi. org/10.1300/J057v10n01_01

García Ríos, M. del C. (2009). El paradigma de la fisioterapia a través de un estudio cienciométrico. Universidad de Granada. Recuperado de https://digibug.ugr.es/handle/10481/3495

Ghantous, N. (2016). The Impact of Services Brand Personality on Consumer - Brand Relationship Quality. Services Marketing Quarterly, 37(3), 185-199. https://doi.org/10.1 080/15332969.2016.1184544

Ghivru, A. I. (2013). The aida model for advergames. The USV Annals of Economics and Public Administration, 13(1), 90-99.

Ghosh, S. (2016). Modeling the Personality Construct of Brands: A Study on Apparel Brands in India.

Hamme, M., E Atkinson, P. (1994). Etnografía. Métodos de investigación. Etnografía Métodos de Investigación, 1-19. https://doi.org/10.1017/CBO9781107415324.004

Hang, H., \& Auty, S. (2008). Investigating Product Placement in Video Games : The Effect of Mood on Children' s Choice. European Advances in Consumer Research, 8, 39-41.

Hauer, T. (2015). Virilio, dromology and visual culture. International Multidisciplinary Scientific Conference on Social Sciences and Arts, 795-803. Recuperado de http:// web.b.ebscohost.com/ehost/pdfviewer/pdfviewer?vid=1Esid=2e90f95a-9ea8-499e8c13-735bb0700ac5\%40sessionmgr102

Havas Media. (2016). Meaningful Brands powered by Havas. Recuperado en Enero 20, 2020, de https://www.meaningful-brands.com/en

Herrmann Lima, L. S. (2017). O valor econômico do endosso social nas práticas comunicacionais: adoção da estratégia de advertainment na El valor económico de endoso social en las prácticas de comunicación: la adopción de la estrategia de advertainment en la campaña “ Oscar Selfie ." Revista Eptic, 19, 136-155.

Hessler, G. (1978). Kiss Meets the Phantom of the Park (p. En línea). Estados Unidos: NBC. Recuperado de https://www.imdb.com/title/tt0077788/?ref_=nm_flmg_act_80

Hidalgo Casas, F. J. (2012). Las narrativas transmedia en la educación. Madrid. Recuperado de https://issuu.com/javierhidalgocasas/docs/usos_de_las_narrativas_transmedia_en_ la_educaci_n

Hoback, J. (2008, November). Psst ... viral marketing not a bad disease to have. Business $\mathcal{E}$ Merchandising, (November), 12-14. 
Hsu, C. L., Matta, R., Popov, S. V., E Sogo, T. (2017). Optimal Product Placement. Review of Industrial Organization, 51(1), 127-145. https://doi.org/10.1007/s11151-017-9575-y

Huang, S., E Dinu, L. F. (2008). More than an Advergame: Effects of Advergame Type and Presence of Spokes- Characters on Advergame Effectiveness. In American Academy of Advertising Conference Proceedings (pp. 65-67). Los Angeles: American Academy of Advertising.

Hwang, Y., E Jeong, S. H. (2019). Editorial content in native advertising: How do brand placement and content quality affect native-advertising effectiveness? Journal of Advertising Research, 59(2), 208-218. https://doi.org/10.2501/JAR-2018-019

Jain, R. (2017). Brand Personality and Brand Loyalty. International Journal of Research in Commerce 8 Management, 8(06), 43-46. Recuperado en from http://0212u6u77.y.http.eds.b.ebscohost.com.proxy.uludag.deep-knowledge.net/eds/ detail/detail?vid=0Essid $=5 \mathrm{~d} 6 \mathrm{c} 5670-37 \mathrm{cf}-467 \mathrm{e}-\mathrm{a} 56 \mathrm{c}-0050 \mathrm{c0c6af53} \% 40 \mathrm{sessionmgr} 102 \mathcal{E}$ bdata=Jmxhbmc9dHImc2loZT11ZHMtbGl2ZQ\%3D\%3D\%0Ahttp://ijrcm.org.in/

Jeong, J. (2015). Advertising vs . R E D: Relative effectiveness on brand equity, 46(3), 31-43. Karniouchina, E., Uslay, C., EJ Erenburg, G. (2011). Of Product Placement In Movies Cycles? The Case of Product. Journal of Marketing, 75(3), 27-48.

Katecontre. (2012). "Fuck the Line" Lo Nuevo del Marketing. Recuperado en Abril 29, 2020, de https://www.conexioncentral.com/blog/fuck-the-line-lo-nuevo-del-marketing/

KISS. (2020). KISS World. Recuperado en Abril 1, 2020, de https://www.kissonline.com/

Klein, N. (2001). No logo, el poder de las marcas. No Logo. https://doi.org/10.9774/ GLEAF.978-1-907643-44-6_31

labrujulazul. (2010). DROMOLOGǴA. Recuperado en Junio 19, 2019, de https:/labrujulazul. wordpress.com/2010/11/20/835/

Letra Mágica. (2017). ¿De qué se trata la publicidad OTL? Recuperado en Abril 29, 2020, de http://blog.letramagica.com/index.php/menu-principal/de-que-se-trata-la-publicidad-otl/

Liao, Y.-K., Wu, W.-Y., Lin Ju, T., E Rivas, A. A. A. (2010). Cognitive, Experiential, and Marketing Factors Mediate the Effect of Brand Personality on Brand Equity. Social Behavior and Personality, 45(1), 1-18. https://doi.org/10.2224/sbp.5621

Lipovetsky, G., $\mathcal{E}$ Charles, S. (2016). Los tiempos hipermodernos (2nd ed.). Barcelona: Anagrama S. A.

Liu, C., Liu, H., E Lin, W. (2015). Constructing Customer-based Museums Brand Equity Model : The Mediating Role of Brand Value, 238(November 2013), 229-238. https://doi. org/10.1002/jtr

Loftninja. (2009). ARTvertising. Recuperado en Abril 3, 2020, de https://www.urbandictionary. com/define.php?term=ARTvertising

Lopera Quiroz, C., E (Comp.), A. (2020). Sosteniblidad, culturay sociedad. Comunidades (Vol. 6). Medellín: Fondo Editorial Pascual Bravo. Recuperado de https://pascualbravo.edu. co/wp-content/uploads/2020/03/libro-sostenibilidad-cultura-sociedad.pdf

López-Medina, J.-D. (2017). Mejoramiento del valor de marca en el marco del posacuerdo Farc-Estado. XX Encuentro Nacional de Investigación Funlam, 143-149. 
López-Medina, J.-D., Orozco-Toro, J. A., Muñoz-Sánchez, O., Restrepo Díaz, D. A., Doria Gómez, D. A., Vélez Ochoa, C. I., ... Granda Viveros, M. L. (2019). Estrategias de publicidad social. Coyunturas sociales como oportunidad de mejoramiento de valor responsable. Medellín: Fondo Editorial Luis Amigó. Recuperado de https://www.funlam.edu.co/ modules/fondoeditorial/item.php?itemid $=514$

López-Medina, J.-D., Orozco, H., $\mathcal{E}$ Postigo, C. (2012). Diseño de un sistema integrado de gestión bajo las normas ISO 9001 y RUC en la empresa Soporte S.A. Viña del Mar.

López-Medina, J.-D., $\mathcal{E}$ París-Restrepo, R. (2014). Línea de investigación en PublicidadSocial. Medellín. Recuperado de https:/www.academia.edu/18586920/Línea_de_ investigación_Publicidad-Social_PROGRAMA_DE_PUBLICIDAD_FACULTAD_DE_COMUNICACIÓN_SOCIAL_Y_PÜBLICIDAD_FÜNLAM

López-Medina, J.-D., E París-Restrepo, R. (2017). Pertinencia de la investigación publicitaria (1st ed.). Dusseldorf: Editorial Académica Española. Recuperado de https://www.morebooks. de/bookprice_offer_ff296086a4f053730cc74dibidcccd0dbf7b0a4c?auth_token=d3d3LmVhZS1wdWJsaXNoaW5nLmNvbTo2OGRIODY1MWJiYjZhMWIxZjBjMjM4NTgxODZmNzY2Mg\%3D\%3DElocale=gbEcurrency=EUR

López-Medina, J.-D., Ríos Valderrama, J. C., Quintero Restrepo, J. M., $\mathcal{B}$ Bustamante Osorio, N. (2019). POPaganda. El fracaso institucional y el triunfo de nadie. Medellín: Fondo Editorial Universidad Católica Luis Amigó. Recuperado de https://www.funlam.edu.co/ modules/fondoeditorial/item.php?itemid=538

López, E. A. (2005). Hacia una nueva salud pública en Latinoamérica. Atención Primaria, 36(6), 336-338. https://doi.org/10.1157/13079870

López, G. (2017). El tryvertising, una forma de muestreo controlado. Recuperado en Abril 4, 2020, de https://www.informabtl.com/el-tryvertising-una-forma-de-muestreo-controlado/

Martínez, J. L. (1998). Publicidad para causas sociales: argumentos racionales vs argumentos emocionales. Comunicación y Sociedad, XI(1), 69-90.

Ministerio de Educación Nacional. (2020). Área de conocimiento. Recuperado de https:// www.mineducacion.gov.co/1621/article-136452.html

Moersen, A. (2017). The 5 Best Advergames of All Time. Recuperado en Abril 4, 2020, de https://innotechtoday.com/advergames/

Moral, D., Pérez, E., Villalustre, Martínez, L., E Neira-Piñeiro, M. R. (2016). MINORS TRAPPED IN THE MAGICAL WORLD OF AUGMENTED REALITY, ADVERGAMING AND SOCIAL NETWORKS. Prisma Social, (Especial 1), 0-28.

Mustaca, A. E. (2004). Tratamientos psicológicos eficaces y ciencia básica. Revista Latinoamericana de Psicología, 36(1), 11-20. Recuperado de https://www.redalyc.org/ pdf/805/80536102.pdf

Nazar Beutelspacher, A., E Z Zapata Martelo, E. (2000). Desarrollo, bienestar y género: consideraciones teóricas. La Ventana, (11), 73-118. Recuperado de http://148.202.18.157/ sitios/publicacionesite/pperiod/laventan/Ventana11/ventana11-3.pdf

NewsMDirector. (2019). Todo lo que necesitas saber sobre el método AIDA. Recuperado en Abril 4, 2020, de https:/www.mdirector.com/mdirector/metodo-aida.html 
Noelia Melero Aguilar. (2011). El paradigma crítico y los aportes de la investigación acción participativa en la transformación de la realdiad social: Un análisis desde las ciencias sociales. Cuestiones Pedagógicas, 21, 339-355. Recuperado de https:/institucional.us.es/ revistas/cuestiones/21/art 14.pdf

Noguti, V., $\mathcal{E}$ Russell, C. A. (2014). Normative influences on product placement effects: Alcohol brands in television series and the influence of presumed influence. Journal of Advertising, 43(1), 46-62. https://doi.org/10.1080/00913367.2013.810557

Oliveira, E. R. De, E Furlani, R. M. (n.d.). O Papel da Comunicação Integrada de Marketing na Construçãodo Valor da Marca: O Caso Bunge Fertilizantes The Role of Integrated Marketing Communication in Construction of Brand Value: The Case Bunge Fertilizers, 127-160.

Organización Internacional de Normalización-ISO. (2007). Sistema De Gestión En Seguridad Y Salud Ocupacional. OHSAS Project groupSistema de Gestión en Seguridad y Salud Ocupacional - Requisitos. Alicante. https://doi.org/ISBN 9780580508028

Orozco Toro, J. A., $\mathcal{Z}$ Ferré Pavia, C. (2012). El ADN de la marca. La concepción de sus valores intangibles en un contexto dialogado. Signo y Pensamiento, XXXI(jul-dic 2012), 56-71. https://doi.org/10.11144/4418

Pacto Global - Red Colombia. (2018). Objetivos de Desarrollo Sostenible. Recuperado en Mayo 31, 2019, de https://www.pactoglobal-colombia.org/ods/los-objetivos-de-desarrollosostenible-ods.html

París Restrepo, R., E López-Medina, J.-D. (2015). Publicidad Social: educar para vivir de manera ética y estética. In Encuentro nacional de Investigación Funlam 2015. Medelln, CO: Universidad Católica Luis Amigó.

Pascual, A. S. (n.d.). Estrategias y prácticas cualitativas de investigación social.

Pérez-Latre, F. J. (2017). Marcas Humanas. Fundamentos de la publicidad en el siglo XXI. Catalunya: Editorial UOC. Recuperado de http://ebookcentral.proquest.com/lib/ utnortesp/detail.action?docID $=5214304$

Planimedia. (2015). ¿Qué aporta el Marketing TTL? Recuperado en Abril 29, 2020, de https:// blog.planimedia.es/que-aporta-el-marketing-ttl/

Pulzo. (2018). Los 8 bancos que desaparecieron, pero que los colombianos siempre recordarán. Recuperado en Abril 4, 2020, de https://www.pulzo.com/economia/bancosdesaparecidos-recordados-colombia-PP557601

Quain, B. (2012). Pro-sumer power! (Revisited). New Delhi: Thomson Press.

Redondo, I., Russell, C. A., E Bernal, J. (2018). To brand or not to brand a product placement ? Evidence from a fi eld study of two in fl uence mechanisms of positive portrayals of alcohol in fi lm. Drug and Alcohol Review, 37(5), 366-375. https://doi.org/10.1111/dar.12671

Ries, A., $\mathcal{E}$ Trout, J. (1991). Marketing de guerra (Edición Re). Barcelona: Mcgraw Hill.

Rifkin, A. (1999). Detroit Rock City (p. En línea). Estados Unidos: New Line Cinema. Recuperado en from https://www.imdb.com/title/tt0165710/?ref_=nm_flmg_act_44

Rodrigo, L., $\mathcal{E}$ Rodrigo, I. (2016). Advertising, children, family and education. Advertising as a cultural homologator. Prisma Social, (Especial 1), 338-377. 
Romero Ruiz, E. (2013). ¿Qué es el advergaming? Recuperado en Abril 4, 2020, de https:// br.escueladenegociosydireccion.com/business/marketing-ventas/que-es-el-advergaming/

Rosso, A., $\mathcal{G}$ Lebl, B. M. (2006). Terapia humanista existencial fenomenológica: estudio de caso. Ajayu, IV(1), 90-117. https://doi.org/http://www.scielo.org.bo/scielo.php?script=sci_ arttextEpid=S2077-21612006000100005Elang=es

Russell, C. A., \& Rasolofoarison, D. (2017). Uncovering the power of natural endorsements: A comparison with celebrity-endorsed advertising and product placements. International Journal of Advertising, 36(5), 761-778. https://doi.org/10.1080/02650487.2017.1348033

Sebastián Morillas, A., Núñez Cansado, M., E 3 Muñoz Sastre, D. (2016). New business models for advertisers: The video games sector in Spain. Advergaming Vs Ingame Advertising. Revista ICONO14. Revista Científica de Comunicación y Tecnologías Emergentes, 14(2), 256. https://doi.org/10.7195/ri14.v14i2.964

Sepúlveda, E. (2017). Transmedia e intertextualidades: apuntes para la formación de competencias narrativas. Revista Internacional de Cultura Visual, 4(1), 17-24. Recuperado de http://journals.epistemopolis.org/index.php/imagen/article/view/237

Simmons, S. (1999). Advertising Seizes Control of Life: Berlin Dada and the Power of Advertising. Oxford Art Journal, 22(1), 119-146. https://doi.org/10.1093/oxartj/22.1.119

Smith, S. (2013). FTL "fuck the line" La mercadotecnia sin barreras. Recuperado en Abril 29, 2020, de https://marketiin.wordpress.com/2013/04/18/ftl-fuck-the-line-la-mercadotecniasin-barreras-por-shardey-smith/

Song, R., Meyer, J., \& Ha, K. (2015). The Relationship Between Product Placement And the Performance of Movies. Journal of Advertising Research, 55(3), 322-338. https://doi. org/10.2501/JAR-2015-012

Spike, B., E Tony, C. (2015). Scooby-Doo! And Kiss: Rock and Roll Mystery (p. En línea). Estados Unidos: Warner Bros. Animation. Recuperado de https://www.imdb.com/title/ tt4717798/?ref_=nm_flmg_act_12

Tenesaca Fajardo, M. A. (2017). Medios de comunicación publicitaria y sus implicaciones en las empresas de la ciudad de Machala. Universidad Técnica de Machala. Recuperado de http:// repositorio.utmachala.edu.ec/bitstream/48000/10911/4/ECUACE-2017-MKT-DE00084.pdf

Terlutter, R., E Capella, M. L. (2013). The Gamification of Advertising: Analysis and research directions of in-game advertising, advrgames, and advertising in social networks. Journal of Advertising, 42(2-3), 95-112. https://doi.org/10.1080/00913367.2013.774310

Thomson, D. M. (2010). Marshmallow Power and Frooty Treasures: Disciplining the Child Consumer through Online Cereal Advergaming. Critical Studies in Media Communication, 27(5), 438-454. https://doi.org/10.1080/15295030903583648

Tuten, T. L., $\mathcal{Z}$ Ashley, C. (2016). Do social advergames affect brand attitudes and advocacy? Journal of Marketing Communications, 22(3), 236-255. https://doi.org/10.1080/1352726 6.2013.848821

Um, N.-H., E Kim, S. (2014). Practitioners' Perspectives on Branded Entertainment in The United States. Journal of Promotion Management, 20(2), 164-180. https://doi.org/10.1080 /10496491.2014.885477 
Una pausa para la publicidad. (2013). 20 ejemplos de artvertising. Recuperado en Abril 3, 2020, de https://unapausaparalapublicidad.com/2013/09/25/20-ejemplos-de-artvertising/

Universidad de Palermo. (2019). Epistemología del Diseño. Recuperado en Junio 18, 2019, de https://www.palermo.edu/dyc/cat/024688.html

Vega Amat y León, X. (2013). La publicidad (como la conocemos) ha muerto. Perspectiva de marcas desde una visión adolescente. Lima: Mayo Draft FCB.

Vegheş, C., E Popescu, I. C. (2016). The Proust Questionaire as a tool of studying the brand personality: an exploratory approach. Romanian Journal Of Marketing, 2, 77-84. Recuperado en from http://journals.ama.org/doi/abs/10.1509/jmkg.75.4.35

Vithas Neuro RHB. (2012). ¿Qué es la Terapia Ocupacional? Recuperado en Marzo 3, 2020, de https://neurorhb.com/blog-dano-cerebral/que-es-la-terapia-ocupacional/

Wilson, R. T., \& Till, B. D. (2011). Product placements in movies and on Broadway A field study, 30(3), 373-398. https://doi.org/10.2501/IJA-30-3-373-398

Wuebben, J. (2017). Future marketing. Winning in the prosumer age. San Diego: Content Launch Press.

Yao, Q., Chen, R., $\mathcal{E}$ Xu, X. (2015). Consistency Between Consumer Personality and Brand Personality Influences Brand Attachment. Social Behavior and Personality, 43(9), 14191428. https://doi.org/10.2224/sbp.2015.43.9.1419 


\title{
El traje: valores poéticos de la creación en un performance de ciudad
}

\author{
Juan Sebastián Hernández Olave ${ }^{1}$ \\ Andrés Mauricio López Galeano ${ }^{2}$
}

\section{Introducción}

En los últimos diez años el desarrollo de procesos de investigación-creación en Colombia ha generado reflexiones oportunas en las disciplinas del diseño frente a los aportes potenciales que formas de investigar no estructuradas en las dinámicas científicas tradicionales pueden construir. El programa de diseño de modas CUN ha venido analizando el impacto de dichos procesos no solo en la construcción reflexiva, sino en torno a futuros aportes que deriven de múltiples disciplinas o contextos. Por tanto, el ejercicio de analizar el vestido más allá de sus concepciones tradicionales, establece aprendizajes y rutas de desarrollo académico que expanden las líneas de comprensión epistémica de la disciplina.

En la primera parte del capítulo se hace un recorrido sobre las posturas y visiones que desde la investigación-creación estructuran el desarrollo de la obra en análisis, y las deliberaciones que a la postre se construyen; en la segunda parte se explica la forma como se constituyó la obra-creación y su relación con la ciudad, como parte de un ejercicio performático planificado; y en la tercera parte se concluye tratando de dar luces sobre la forma como una obra creación en diseño de modas puede constituirse en un resultado de investigación.

Diseñador Industrial, magíster en Administración. Líder de grupo de investigación CODIM de la Escuela de Comunicación y Bellas Artes de la Corporación Unificada Nacional de Educación Superior (CUN), juan_hernandezo@cun.edu.co

2 Diseñador de Modas, Magíster en Comunicación, Desarrollo y Cambio Social. Docente Diseño Gráfico / Universidad Santo Tomás, andres.lopezg@usantotomas.edu.co 


\section{Metodología}

Esta reflexión disciplinar, anclada no al objeto o a la obra como principal protagonista, sino al papel e importancia de nuevos métodos y prácticas, se da en dos momentos: el primero tiene que ver con el ejercicio de observación de la obra creación: en este caso, dicha contemplación requirió la comprensión de las prácticas de creación y de la obra creación como parte del ejercicio de investigación, encontrando allí conocimientos construidos colectivamente y significados poéticos que transcurrieron en el proceso que tuvieron como fundamento las miradas heurísticas provenientes de las artes.

El segundo se vincula al soporte teórico que a partir de la revisión sistemática de la literatura (RSL) asociada se desarrolla para analizar de manera crítica el soporte proveniente de los registros obtenidos en los procesos de creación colectiva y la fundamentación epistémica que estos tenían en su desarrollo y posterior análisis.

\section{Resultados de la investigación: sobre la creación como valor poético para la investigación en los campos del diseño}

Jorge Drexler (2017) plantea en su charla TED, Poetry, music and identity, un discurso narrativo al cual se pueden asociar los sucesos y hallazgos de los proyectos de investigación creación que se vinculan a la escritura de este capítulo. Drexler arma un guion exquisito que explora la riqueza de la décima ${ }^{3}$ como recurso literario, pero también explica su complejidad y valor como canal para el tejido de conexiones históricas, socioculturales y políticas; esto implica que, de manera no explícita, en dicha charla se le asignan valores poéticos e identitarios ${ }^{4}$ a los procesos de creación musical en los que la décima define diversos ritmos y conexiones armónicas conectados entre sí.

\footnotetext{
3 En literatura y poesía es una estrofa constituida por diez versos octosílabos; un verso octosílabo es aquel que posee ocho sílabas métricas.

Canciones como La masa, de Mercedes Sosa; Latinoamérica, de Calle 13 e, incluso, El baile de los que sobran, de Los Prisioneros, son canciones consideradas únicas, cargadas de valores poéticos y simbólicos anclados a la historia de Latinoamérica; puntualmente, a la represión, las dictaduras, necesidades sociales y culturales aún por resolver.
} 
Esta introducción parece desconectada del diseño o la moda; sin embargo, hemos establecido que la intención en este escrito es narrar otras experiencias que armonicen con esta disciplina y qué mejor para los procesos de creación que usar analogías y referencias de otros campos y de otra realidad. Así, entonces, la propuesta de Drexler es el detonante para aprovechar su discurso y usarlo como un modelo narrativo del proceso de investigación que se resume en este capítulo.

Ejemplificando desde la moda, con referencia al proceso de creación del como analogía de la décima, las dos configuran diversos conceptos y conexiones que al igual que los ritmos musicales tejen redes socioculturales. Dentro del marco de esta obra creación, se desarrollaron exploraciones sobre las relaciones del vestido con la creación, el arte, y la sostenibilidad, haciendo una alusión a la interacción de saberes propuestas por Aguiló Bonet (2011) y relacionadas con la ecología de saberes que analiza las formas en que el conocimiento reconoce la pluralidad de otros pensamientos y enfatiza en las interconexiones y cruces existentes entre ellos.

Era necesario, entonces, estructurar un proceso metódico desligado de las lógicas de creación tradicionalmente usadas en el diseño, que corresponden a fundamentos provistos por el pensamiento científico, y alimentados por métodos, herramientas e instrumentos de las humanidades y las ingenierías que fueron desarrollados desde la Bauhaus y se establecieron como formas institucionalizadas del diseño. Por tanto, la décima como elemento rector (articulador) en la estructura musical, con la suficiencia, flexibilidad y capacidad de mutación tal que se instala en diversos ritmos musicales y asume sus características sociales, culturales, espaciales e, incluso, sus condiciones políticas, fue la analogía apropiada para representar la forma como el proceso de creación asociado a la obra creación «El traje: una construcción de la mano del grafiti» (López Galeano y Escobar, 2019) desarrollada desde métodos exploratorios constituidos desde las artes, específicamente el del andar como práctica estética (Careri et al., 2002), dando a entender que la deriva es un suceso natural en la creación, y el artista diseñador tiene que convertirse en caminante, en observador de los paisajes que lo rodean y es interconector entre los significados que se construyen al reconocer un lugar y la atribución de los valores estéticos y simbólicos que de estos procesos de exploración se despliegan. 
Este planteamiento buscó cuestionar y redefinir marcos epistemológicos que han reproducido estructuras de poder dominantes desde otras visiones científicas válidas, pero sujetas a poca reflexión teórica desde el diseño; por tanto, el reconocimiento de la pluralidad de saberes provenientes de las artes, contrarresta una única forma de ver, entender o estudiar los procesos de creación y su incidencia en los espacios socioculturales y académicos inmersos en el desarrollo de herramientas metodológicas del estudio del diseño y la moda, fomentando la transculturalidad, los vínculos epistemológicos y los procesos de transformación y circulación del conocimiento.

Los valores poéticos de los procesos de creación son necesarios, fundamentales y dotan de espíritu o aura ${ }^{5}$ a los objetos. A pesar de esto, en el diseño no están implícitos, porque al estar inscrito en un escenario discursivo que vincula el uso de metodologías, métodos, herramientas e instrumentos en algunos proyectos de las ciencias sociales, en otros de las ciencias exactas, en otros más de las ciencias naturales, se han desarrollado confusiones epistémicas históricamente adquiridas sobre lo que verdaderamente es el diseño en los entornos de generación de conocimiento, y no son menores las preocupaciones que, por ejemplo, Buchanan (1990) y Cross, (2018) y (Krippendorff, 2016) plantean al respecto, que no se desarrollarán en este capítulo, pero que se considera son relevantes para comprender la propuesta que desde las reflexiones adscritas al mismo se presentan.

Por su parte, la moda ha generado dentro de su lógica productiva e industrial, nuevas acepciones del vestido a través de acciones performáticas dentro de pasarelas ${ }^{6}$ o de creaciones que dotan de otros significados al vestido y los materiales que lo componen; a través de la producción de obras asociadas al reúso de textiles e insumos, abogando por la sostenibilidad y propiciando cuestionamientos sobre los límites de la corporeidad, el vestido es sujeto y agente de debate académico. Este debate es visible en papers que narran

\footnotetext{
Aura, desde lo estipulado por Walter Benjamin (1936) en su ensayo «La obra de arte en su época de reproductibilidad técnica», quien considera que toda obra posee un valor intrínseco que la dota de una superioridad, lo que hace que trascienda la noción de objeto a obra.

Acerca de esto, diseñadores de moda como Jean Paul Gaultier usaron el concepto de burlesque al de performance para las puestas en escena de sus pasarelas; otros diseñadores como Alexander Mc Queen han incorporado fuego, máquinas autómatas y otras corporeidades como insumos que afianzan y cuentan la historia de sus procesos de investigación y conceptualización.
} 
las creaciones de diseñadores como Yamamoto o Kawakubo a finales de los años 80. En este sentido, se considera que en Colombia la relación entre arte, moda y creación requiere de un mayor mapeo, revisión e indagación, dado que en esta se construyen nuevas experiencias o procesos que enriquecen el estudio de esta disciplina y el planteamiento de nuevos métodos, necesidades o relaciones disciplinares. Tomando como caso a la diseñadora Manuela Álvarez, que durante el BCapital de 2019 introdujo una sinfónica a su experiencia de marca como se visualiza en la figura 1, es posible evocar las interacciones disciplinares como insumo articulador en los procesos creativos, tal y como se entiende la analogía de la décima en este proyecto.

\section{Figura 1}

Montaje marca Manuela Álvarez

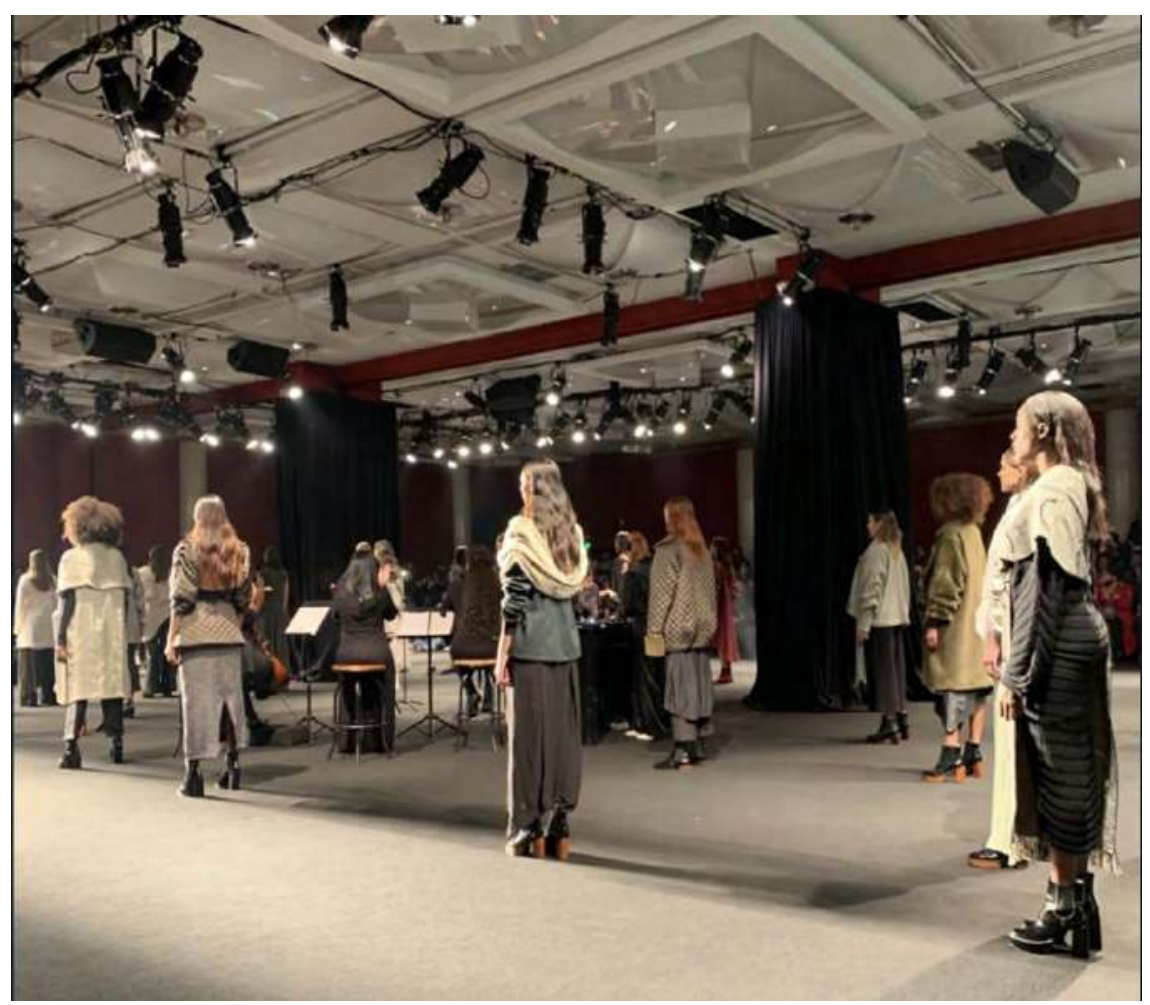

Nota. Performance de la marca en BCapital. Fuente: Fotografía archivo personal. Bogotá, 18 de octubre de 2019. 
La décima es la raíz de muchos ritmos musicales alrededor del mundo; la pregunta instaurada con respecto a la relación entre la analogía y el desarrollo reflexivo de la obra-creación y de este texto es: ¿la creación en diseño de modas como proceso podría usar la décima como analogía, teniendo en cuenta las interacciones socioculturales, históricas y políticas que su estructura plantea? A partir de esta inquietud y otras asociadas a los valores estéticos de la creación artística, la propuesta de la investigación-creación, en el programa de Diseño de Modas de la CUN, migró a los procesos de investigación artística (Borgdorff, 2010; Busch, 2009; Frayling, 1993; Klein, 2010), centralizando así las reflexiones investigativas y curriculares hacia la poética de la creación y su relación con las interacciones humanas, que desde la perspectiva de los autores de este capítulo le imprimen identidad al diseño y a la creación del vestido como campo de reflexión, más que los enfoques técnicos o productivos en los que tradicionalmente se ha inscrito.

Esta propuesta no busca ser excluyente, porque, de inicio, la creación no tiene ruta ni receta; por el contrario, así como la décima en la música y la literatura, la existencia de rigor y conciencia sobre los procesos de creación asociados genera diversidad de resultados y de saberes, que en el caso de la investigación artística pueden terminar en posturas teóricas reflexivas, en objetos de diversos usos, instalaciones conceptuales que expresan los fundamentos de composición plástica o en productos de obra-creación; así entonces, no hay una sola forma posible de aproximarse a la creación en arte y diseño, si bien existen modelos que intentan medir los productos de la creación (Colciencias, 2018), estos no miden los prácticas per se; por tanto, es fundamental retomar la idea sobre los procesos de creación y situar las reflexiones sobre la investigación artística en los planteamientos que mencionan autores relevantes sobre el particular: «[...] no cualquier práctica creativa conduce a la producción de un conocimiento que se podría calificar de «nuevo». Este tipo de procesos de creación se puede entender como formas de generación de conocimiento cuando se estructuran a través de una práctica creativa constante, rigurosa y estructurada, que permite evolucionar ideas y conceptos a través del contacto con el material (Bonilla et al., 2018, p.286).

En el proceso creativo «El traje: una construcción de la mano del grafiti» (López Galeano y Escobar, 2019) la construcción conceptual colectiva se 
desarrolló en función de romper las estructuras de investigación tradicionales; por tanto, el énfasis en los sistemas de registro conceptual y visual de las dinámicas de creación son fundamentales y se presentan en la figura 2.

\section{Figura 2}

Conceptualización y primeras ideas

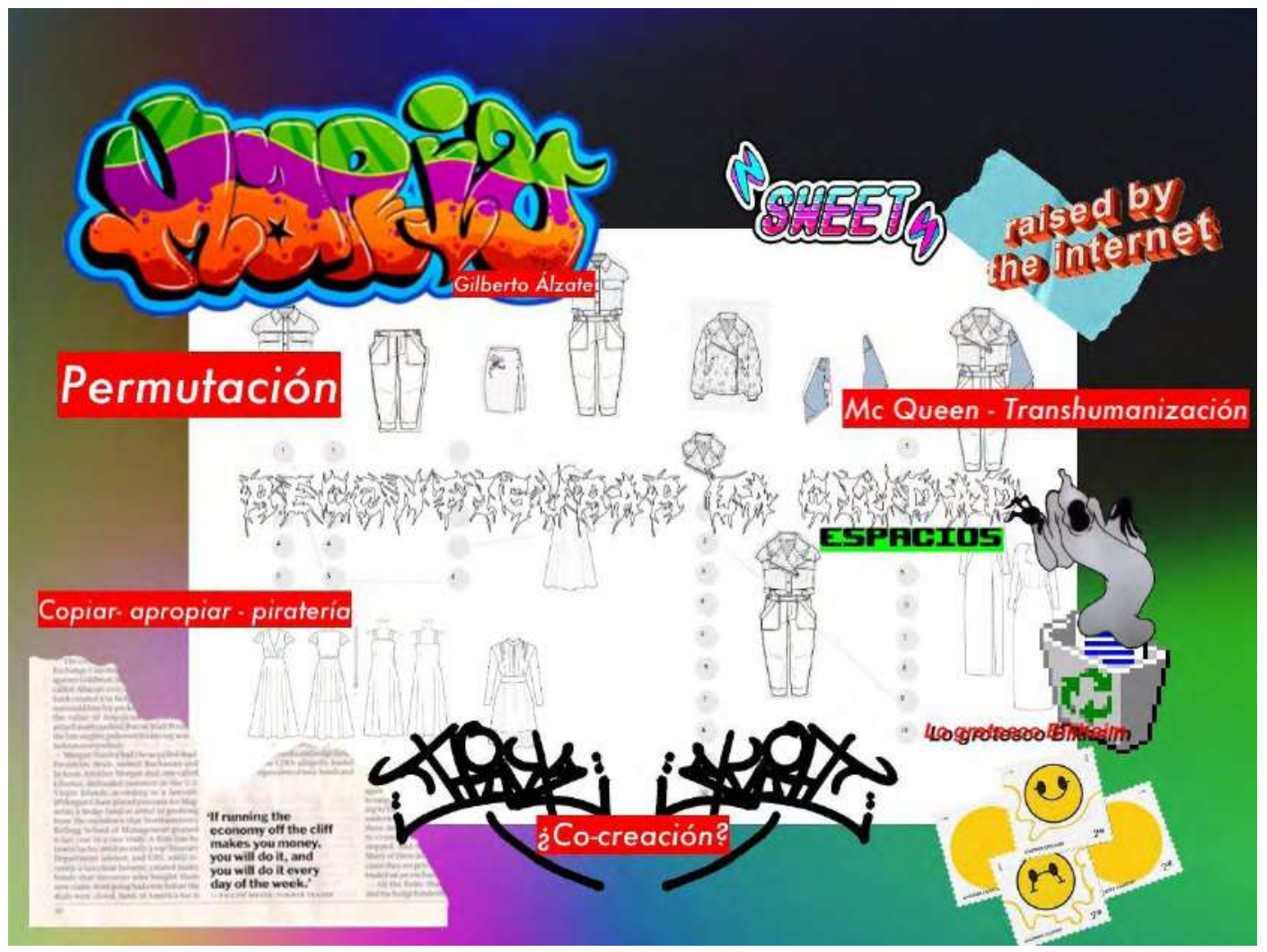

Nota. Mapa mental Kitsch. Fuente: López Galeano (2019).

La complejidad de los procesos artísticos replantea las estructuras de investigación tradicionales, invitando a creativos y diseñadores a comprender de manera diversa las formas de generación y registro del conocimiento artístico, dada la multiplicidad de usos que pueden derivar de estos espacios; esto, a su vez, permite entender y darle valor a distintos sistemas de registro no tradicionales o ajenos a otras prácticas, y a reflexionar sobre las conexiones 
existentes entre disciplinas; también sobre los productos de creación y los entornos en que se desenvuelven. Esta secuencia de análisis detona la existencia de la obra-creación que se menciona y analiza como caso de estudio en este capítulo. Parte de estos análisis se basa en la construcción colectiva del traje como lienzo en blanco y el resultado de las conceptualizaciones previas que permiten estructurar la propuesta de dicho lienzo se presentan en la Figura 3.

\section{Figura 3}

Estudiantes en taller - exploración de volumen para creación de obra
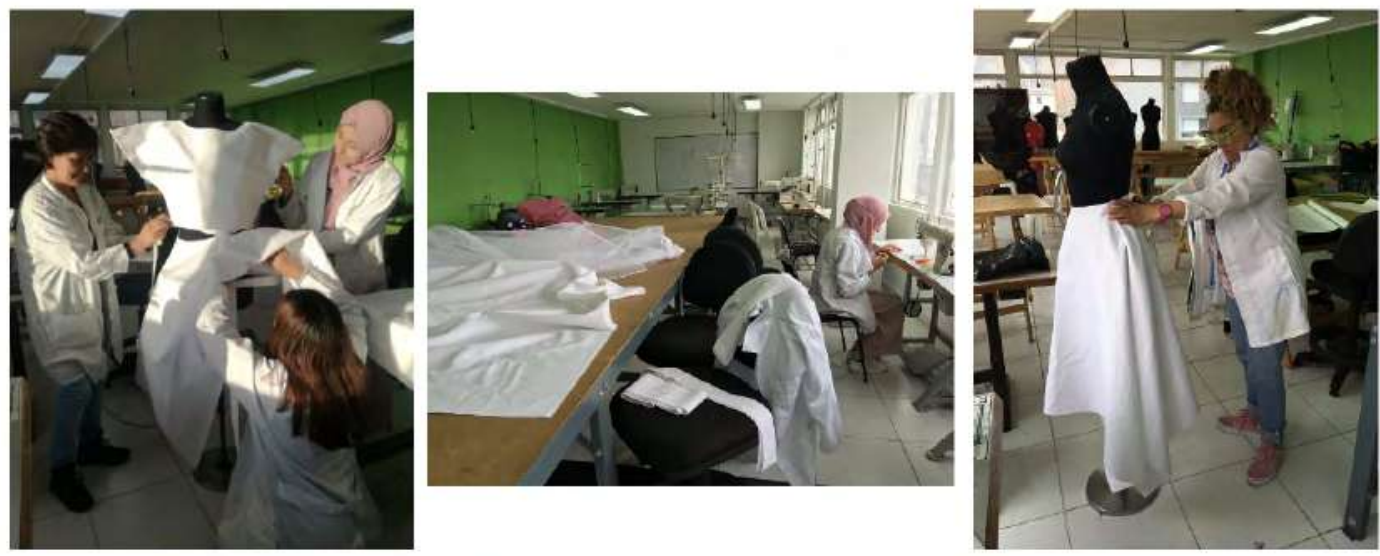

Nota. Mosaico fotográfico de proceso de conceptualización. Archivo personal. (2019)

Lo anterior implica que esta creación de nuevo conocimiento y articulación de saberes tiene potentes implicaciones, tanto poéticas como académicas, sobre todo si hablamos de la descentralización o descolonización del conocimiento de los espacios convencionales o tradicionales. Esto es particularmente importante en el campo del diseño de modas, que en algunas instancias apropia nociones occidentales, como el estudio de la moda desde ciclos de temporadas que, para el caso de Colombia, no debería ser prioritario dentro de los procesos de enseñanza. Esa otra mirada, esa nueva forma de entender o, más bien, de reaprender la moda, ha sido incorporada en su discurso académico a través del concepto de otredad, relacionado ampliamente con los estudios de género y lo queer. 
La categoría de otredad ${ }^{7}$ ha ganado un amplio campo e importancia dentro de los debates humanísticos de la última década del siglo XX. En primera instancia, fue tratado por Jacques Derrida en la filosofía de la diferencia; así mismo, en las reflexiones críticas de Michel Foucault, las cuales evidencian que además de los discursos dominantes existen otras formas de pensar; se trata de discursos con potencial subversivo que han sido marginalizados y excluidos (por ende, no reconocidos). Esta construcción epistémica de la otredad no se presenta en este análisis como una acción subversiva, desde las reflexiones sobre las relaciones entre diseño, moda e investigación-creación, pero sí es relevante manifestar la existencia de relaciones de otredad dentro de estas disciplinas, que dan cuenta de su coexistencia y, por tanto, de la posibilidad de generar procesos de creación que involucren estos aspectos.

\section{Procesos de creación en «El traje: una construcción de la mano del grafiti» y su relación con la ciudad}

Teniendo como punto de partida las reflexiones mencionadas en el aparte anterior, se hace necesario presentar la obra y la forma como se construyeron los valores poéticos que le fueron asignados. Estos constituyen no solo una forma de expresión simbólica, desde el vestido-obra, sino que también hacen parte de una forma de interacción entre ciudad, espacio y público, y es solo en el marco de este espacio donde se puede observar el carácter propio, único e irrepetible de la obra, que al ser performática vincula estructuras socioculturales, históricas y políticas las cuales Drexler (2017) menciona en su discurso y por la importancia que se le asigna a la décima es fundamental para comprender la analogía.

Vale recalcar el escenario en que esta obra fue presentada, en el marco de lo que era conocido como El Bronx, en la ciudad de Bogotá. Lo anterior, en la medida que existe, desde la mirada cultural y social, una carga simbólica que hacía parte de este espacio concebido como una zona violenta con todo

En su libro Experimental Fashion, Francesca Granatta explica con mayor profundidad la concepción de la otredad dentro de la moda y fija esta noción a lo grotesco y a la reconfiguración constante de estándares de lo anormal en torno a la corporeidad. 
tipo de problemáticas de índole social. En la figura 4 se presenta el escenario donde se desarrolló el proceso de creación performático de la obra.

\section{Figura 4}

Montaje y escenografia creada por la Fundación Gilberto Alzate Avendaño
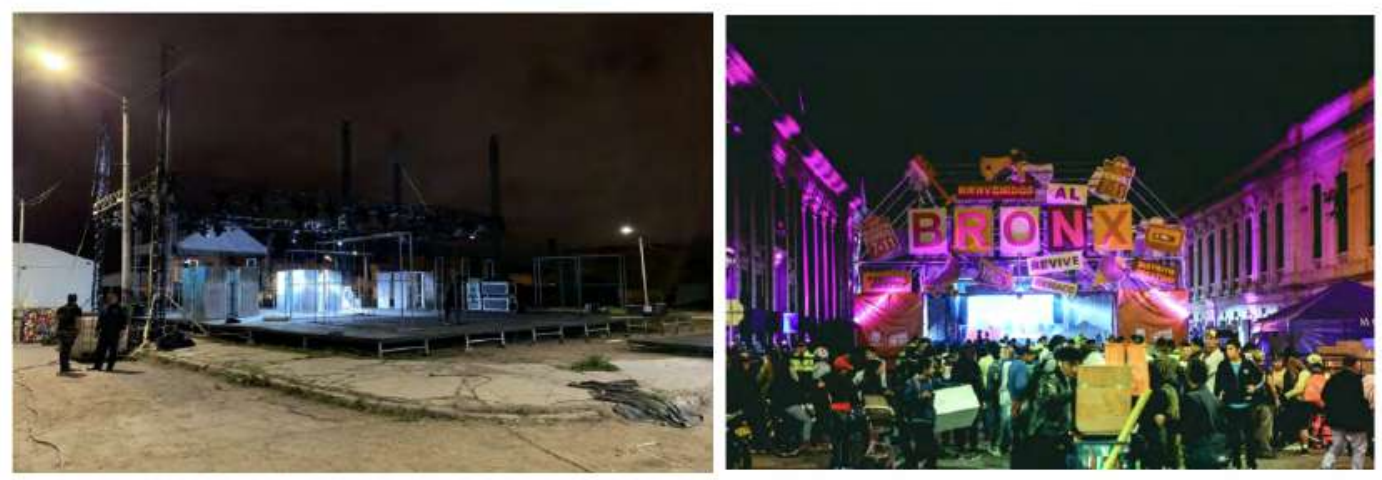

Nota. Mosaico Antes y después. Fuente: Archivo personal, (2019).

«El traje - una construcción de la mano del grafiti», de López Galeano y Escobar (2019), es una obra que se construye desde el performance. Su existencia primaria depende de las interacciones entre creadores, artistas y diseñadores que participan en su desarrollo, y el público, teniendo como escenario el Distrito Creativo del Bronx en el marco de Tributo en $2019^{8}$.

La obra es una propuesta construida en colectivo por estudiantes y dirigida creativamente desde la investigación de los profesores del programa de Diseño de Modas de la CUN, Andrés López Galeano y Mildred Escobar. $\mathrm{Su}$ intención fue desarrollar entornos de construcción abierta y colectiva, en los que la comunidad académica se relacionara con públicos externos, con el propósito de generar procesos y resultados de creación orgánicos que involucraran espacios de ciudad. Adicionalmente, fue considerado como un lugar de evaluación de principios de gamificación en los cuales el programa incursionó para comprender el potencial que el concepto tiene para motivar

\footnotetext{
8 Evento de cierre académico semestral del programa de Diseño de Modas de la CUN, también se está consolidando como evento de investigación, de acuerdo con el modelo de medición propuesto por Colciencias (2018).
} 
a estudiantes y generar dentro de la enseñanza espacios de carácter más atractivo y entretenido (Hammer $\mathcal{E}$ Lee, 2011).

El vestido, entonces, se configuró, en primera instancia como lienzo de construcción sobre el cuerpo, fundamentado en conceptos de gamificación que partieron de exploraciones basadas en el juego, el azar y el entretenimiento. El Bronx, como espacio, no solo fue entorno de circulación de la obra, sino también de su configuración poética, en un esfuerzo por vincular actividades y procesos de creación considerados urbanos (como el grafiti o el street dance) los investigadores gestionan la participación de artistas urbanos del grafiti; estos, a través de la narración visual generada mediante la técnica del spray painting, conectan la corporalidad con la visualidad gráfica y obtienen así un traje intervenido desde la acción performática. En una entrevista personal el autor de la obra, López Galeano (2020) menciona que

[...] la obra está basada en un proceso muy interesante, que tomó como referentes pasarelas interactivas, por ejemplo, la de los brazos robóticos de Alexander McQueen. Nosotros pensando en la lúdica y en la práctica de creación al azar, lo que buscábamos era hacer que tanto los artistas del grafiti como los espectadores sin ningún tipo de planeación entraran en un ejercicio de juego con la obra, unos haciendo intervención y otros visualizando la acción performática. (Min 12. Sp.)

Es de este modo como se comprende que el performance como acción se desarrolló bajo los conceptos de lúdica y gamificación, buscando los resultados de la acción transformadora sobre el traje y con el traje que finalmente se desarrollaron. Aunque se planeó de forma tácita sobre métodos heurísticos de creación, es fundamental ubicar esta concepción investigativa para así apreciar nuevamente los valores poéticos que se generan en un proceso de creación de este tipo, teniendo en cuenta que, argumentalmente, la heurística fomenta el descubrimiento en la medida que como lo propone Mandolini (2013): «[...] si los diversos componentes que sirven de punto de partida a un proyecto se legitiman en todo o en parte a posteriori, por el simple hecho mismo [sic] de la realización del susodicho proyecto, y no a priori, a través 
de la verificación experimental independiente de la realización, el método utilizado es heurístico» (p. 66).

En este sentido, la participación de la comunidad no creadora, es decir, los públicos que validan la acción performática, también influye en que la obra evolucione a una dimensión distinta a la que habitualmente se desarrollan las creaciones generadas desde el diseño de moda, porque propone que además de la configuración de aspectos técnicos, se definan interacciones socioculturales que dotan de carácter al vestido como artefacto. En la figura 5 se muestra la forma como los estudiantes comprendieron el mensaje y el significado de la intervención urbana asociada a los lenguajes plásticos y visuales que con el concepto se relacionan.

\section{Figura 5}

\section{Estudiantes modas CUN}
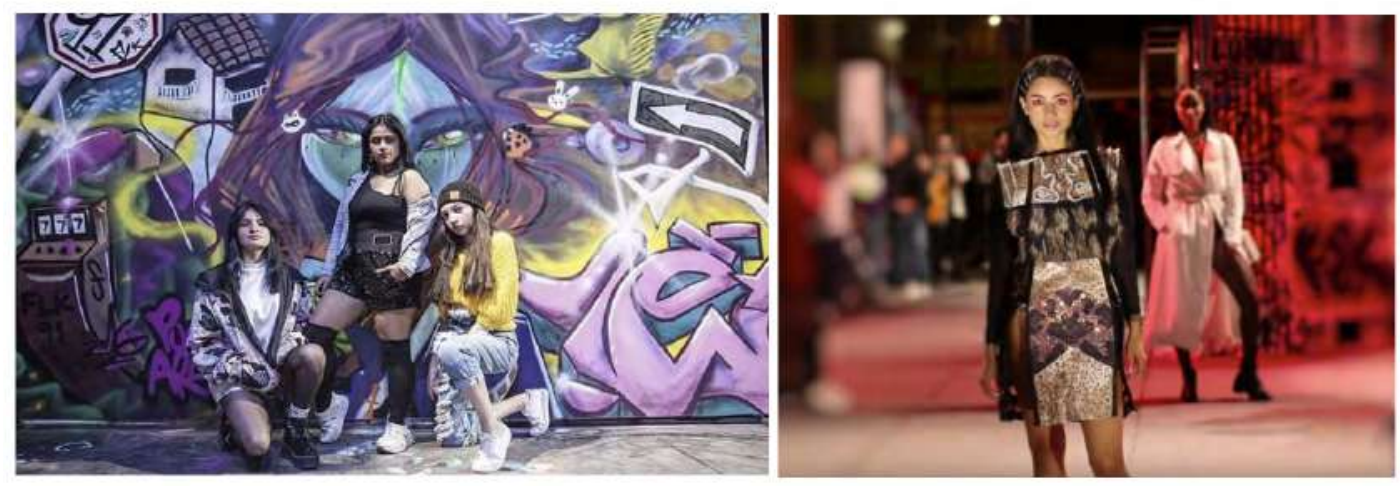

Nota. Mosaico experiencia de creación en el BRONX. Fuente: archivo personal, (2019)

Por tanto, las expectativas que se generaban en la acción performática se enfocaron en la interacción que en el contexto seleccionado tendrían los diseñadores del traje y los artistas del grafiti, la razón fundamental de esta sospecha se relaciona con los aspectos sociales y culturales que rodeaban la creación. La creación colectiva de la obra sobre el lienzo conectaba los estudios sobre la corporalidad y los procesos de desarrollo desde la gráfica y la visualidad, adicionalmente la existencia de público y la ubicación espacial del performance configuraban aquello que desde el inicio del texto se ha 
venido mencionando como la poética de la creación. Así entonces, tanto la interpretación que los públicos dieron a la obra, como el carácter que le impregnaban al vestido los artistas del grafiti situaban a la obra en una dimensión más avanzada que la de ropa en su concepto más tradicional, sino que la establecían como un agente de cambio desde las consideraciones que al arte callejero le corresponden, en ese sentido Hansen $\mathcal{J}$ Danny (2015) explican que el grafiti se conecta con el entorno urbano en la medida en que tiene intenciones sociales y políticas usando la calle como medio de difusión.

Es aquí donde la creación como proceso, como práctica y como obra, en el caso concreto de «El traje: una construcción de la mano del grafiti», se vuelve transformador y asume un sentido conceptual crítico, teniendo en cuenta que, si bien desde la planificación inicial no se esperaba un resultado en donde la ciudad también se estableciera como agente configurador y transformador de la obra, en el performance la lógica de la acción creadora estableció los puentes heurísticos que la definieron como arte urbano, asumiendo como criterio base de análisis que el proceso de creación se aleja del aula, de la sala de exhibición y usa la ciudad como entorno de creación, circulación y difusión. Esta premisa se puede, así mismo, comprender, en la medida en que Baudrillard (1981), por ejemplo, define la calle como esa manera transgresora y alterna de luchar contra los medios masivos, a través de unas formas de interacción inmediatas que rompen los esquemas jerárquicos entre emisores y receptores.

La calle es un espacio dotado de valores simbólicos e imaginarios; es un lugar impactado por distintas relaciones sociales, económicas y culturales. Para la obra, esta relación entre creación y lugar fue fundamental para vincular nuevas perspectivas debatidas dentro del programa de diseño de modas en torno al desarrollo sostenible, que adicional a las referencias exclusivas a la problemática ambiental y como ha sido ampliamente debatido desde el concepto de moda sostenible, refiere a otras nociones asociadas a la sostenibilidad, como el desarrollo social y cultural, por ejemplo, que de acuerdo con López Galeano (2020),

es un concepto anclado a la sostenibilidad, donde se entiende que la cultura es también un motor de desarrollo para ciertas comunidades; y dentro de los contextos, esto es muy interesante, dado que convierte al desarrollo en un 
proceso social, donde múltiples actores, objetos y espacios interactúan para configurar las vivencias y subjetividades dentro de esos contextos, entonces más allá de referirse a indicadores o factores económicos, habla de la vida misma y como se forjan conexiones y relaciones dentro de espacios en la calle, y claro dentro del espacio del Bronx aportan nuevos significados... (min. 18)

Desde perspectivas culturales, este espacio anteriormente denominado Bronx, ahora Distrito Creativo, con historias, contextos violentos, problemáticas sociales y otras implicaciones, incluso políticas, fue por una noche, en el marco de Tributo, un espacio en busca de la resignificación, ajeno a violencias. Desde la misma marginalidad de la calle como entorno dinámico, adquirió valor poético a través de la creación artística mediada por las expresiones visuales del grafiti; la plasticidad, que desde la corporalidad provee el vestido, y la improvisación musical proveniente de la creación sonora a tiempo de décimas. En la figura 6 se muestra parte de la experiencia del performance en el Bronx Distrito Creativo.

\section{Figura 6}

Experiencia de moda Bronx distrito creativo
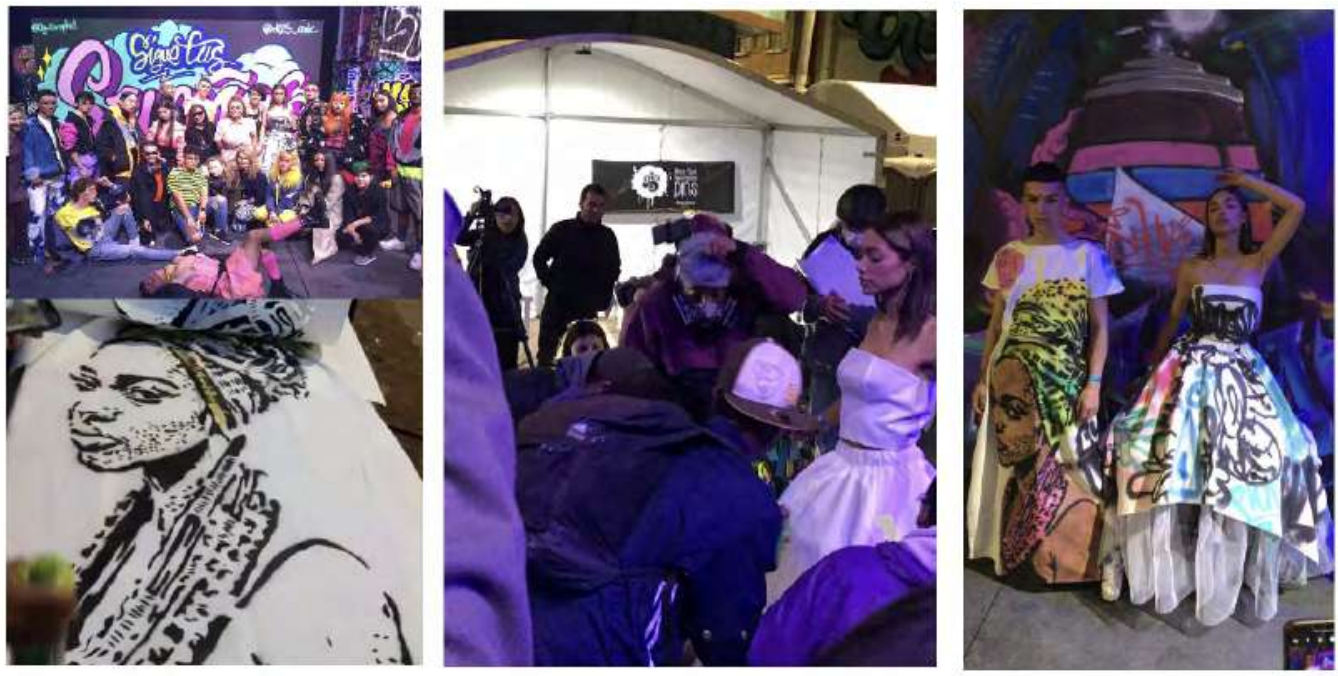

Nota. Mosaico acción performática. Fuente: Archivo personal, (2019) 
El desarrollo impulsado por la cultura promueve beneficios no generadores de capital económico, como la inclusión social, el despliegue de la creatividad y la innovación social, basadas en modelos de resiliencia dirigidos hacia personas y comunidades. La cultura, en este sentido, debe ser estudiada desligándose de lo que convencionalmente es entendido por cultura, dado que su indagación académica no constituye una disciplina, sino como lo menciona Reguillo (2004), «[...] una forma de enfrentar los desafíos de una sociedad en continua transformación que no se deja "leer" desde los marcos disciplinarios» (p. 2).

A través de este tipo de acciones de creación reflexionan, igualmente, acerca de los aportes que las visiones sobre el desarrollo cultural establecen en los contextos urbanos o rurales, desde la comprensión de las particularidades del lugar, como agente de cambio, o de las diversas dimensiones que a través de las comunidades actúan, en este caso, desde acciones de creación planeadas en los entornos académicos e investigativos del arte y el diseño. De acuerdo con el documento La Cultura como base del desarrollo contemporáneo (Sen, 1998),

La cultura ha comenzado a redefinir paulatinamente su papel frente a la economía y el desarrollo. Poco se duda ya acerca de su importancia como inductora de desarrollo y cohesión social, de su relevante papel ante la cuestión de la diversidad cultural, la integración de comunidades minoritarias, los procesos de igualdad de género y la problemática de las comunidades urbanas y rurales marginadas. (p.1)

En suma, la cuestión en la obra es también indagar desde la creación por maneras a través de las cuales los hábitos y las formas de habitar la ciudad pueden ser insumos para la reflexión artística y, por tanto, para la generación de obras de creación.

\section{¿Esta obra de creación es investigación?}

Se podría abrir acá el debate en el que el lector cuestione si, entonces, la creación que se menciona en este capítulo se sitúa en la obra como resultado o en la obra como proceso. Como autores, tenemos la responsabilidad de situarnos y asumir postura sobre el particular, no sin antes reafirmar que lo que en este proceso de creación es, para otros no puede serlo. 
Teniendo en cuenta esta introducción, se plantea, en consecuencia, que la obra en sí no es investigación: es el resultado, así como la reflexión que se consigna en este capítulo que desde la escritura discurre sobre los procesos de creación. Sin embargo, la intención de acompañar la obra con un texto que lo fundamente también propicia que desde la obra misma y la lectura de este capítulo haya otros procesos de investigación; por tanto, el registro escrito es fundamental para su réplica y estudio posterior. Para fortalecer dicho planteamiento y dar luces de algunas referencias sobre cómo construir investigación desde la creación, se usa como referencia a Kathryn Busch (2009), quien en su texto Artistic research and the poetics of knowledge propone diversas formas de hacer investigación artística que toman sentido en este aparte y son presentadas en la tabla:

\section{Tabla 1}

Formas de investigación artística

\begin{tabular}{|c|c|}
\hline Forma de investigación artística & Descripción \\
\hline Arte con investigación & $\begin{array}{l}\text { El arte recurre a la investigación científica usando referencias } \\
\text { teóricas que los artistas reflejan en sus obras }\end{array}$ \\
\hline Arte sobre investigación & $\begin{array}{l}\text { La investigación científica tradicional se convierte en objeto } \\
\text { de una práctica artística que no se limita a funcionar como } \\
\text { un objeto de la ciencia en sí mismo }\end{array}$ \\
\hline $\begin{array}{l}\text { Arte en sí mismo como } \\
\text { investigación }\end{array}$ & $\begin{array}{l}\text { Paradigma que sitúa al arte como forma de conocimiento que } \\
\text { no solo integra conceptos y teorías, sino que la analiza y la } \\
\text { aglutina con la práctica. }\end{array}$ \\
\hline Arte como ciencia & $\begin{array}{l}\text { La práctica artística asume posturas teóricas y usa métodos } \\
\text { científicos para sus discusiones y resultados. }\end{array}$ \\
\hline Arte sobre ciencia & $\begin{array}{l}\text { El arte se valida a sí mismo como forma independiente para } \\
\text { la generación de conocimiento. }\end{array}$ \\
\hline $\begin{array}{l}\text { Arte como una forma diferente de } \\
\text { conocimiento }\end{array}$ & $\begin{array}{l}\text { El arte es no solo independiente, sino diferente, en } \\
\text { concordancia con su interés constante de cuestionar las } \\
\text { estructuras racionales de la modernidad. }\end{array}$ \\
\hline Arte o poética del conocimiento & $\begin{array}{l}\text { El conocimiento se construye en las diversas estructuras de } \\
\text { representación que provienen de las prácticas de creación. }\end{array}$ \\
\hline Hibridación de arte e investigación & $\begin{array}{l}\text { La investigación artística se sitúa de forma cercana a la ciencia } \\
\text { tradicional, generando procesos de hibridación. }\end{array}$ \\
\hline
\end{tabular}

Nota: Tabla comparativa de formas de investigación artística. Elaboración propia (2020) a partir de Busch, K (2009) 
Uno de los factores más distintivos del arte, más que otros campos, es la atribución de valores estéticos y simbólicos sobre los funcionales o utilitarios que este adquiere o posee, y vale la pena mencionar que una de las razones por las cuales ha existido una exclusión dentro del contexto de la moda hacia el arte, ha sido principalmente por su amplia relación con distintas instancias y su uso utilitario, donde el vestido siempre ha tenido alguna función, ya sea protectora, ritual, comunicativa o representativa, fomentando estructuras de posicionamiento social o de pertenencia a grupos sociales (Craik, 2003). Si a esto se adiciona su lógica de acción desde la producción masiva, el vestido es considerado como objeto utilitario que posee cierto grado de simbolismo y no una obra artística en sí misma.

La obra, no solo como expresión de creación, sino como objeto mismo, cumple con las formas utilitarias del vestido en relación con su cuerpo; sin embargo, posee un carácter crítico y simbólico que define su existencia y la dualidad de ser vestido desde sus concepciones primitivas y, a su vez, pieza de crítica y reflexión investigativa. Zuidervaart (1990), que estudia el concepto de autonomía del arte planteado por Adorno, explica que a través de los estudios del autor referenciado se proclamó que el arte se caracteriza por esa dualidad y que siendo un fenómeno autónomo al mismo tiempo posee unas implicaciones sociales que lo definen o lo pueden constituir como un agente crítico solo por su existencia. Por tanto, quedan abiertas inquietudes que dirigen la mirada hacia la posibilidad que tienen las dinámicas de creación artística y simbólica para aportar a la configuración de nuevos contextos culturales sostenibles bajo los modelos anteriormente planteados.

Un proyecto de investigación-creación o investigación artística9 debería situarse en una postura que abarque alguna comprensión o crítica del contexto donde se desenvuelve y, claro, dentro de las formas de investigación descritas por Kathryn Busch, la investigación- creación es una apuesta amplia, donde el investigador podría migrar de una a otra metodología en el desarrollo de su vida investigativa. Esta descripción y el contenido mismo de esta tabla buscan situar los referentes que desde la reflexión sobre la creación empiezan a gestarse dentro del programa de Diseño de Modas.

Su uso no pretende ser indistinto, entendiendo sus complejidades conceptuales, pero se equiparan con el fin de clarificar su uso en los marcos institucionales de investigación en Colombia. 
Es relevante mencionar que para efectos de establecer una postura teórica que fundamente el desarrollo de la obra creación, usada como caso de estudio en este capítulo, los autores hemos definido que en este análisis concreto la forma de investigación propuesta por Busch (2009), que se relaciona con «El traje: una construcción de la mano del grafiti (López Galeano y Escobar, 2019) es la de arte o poética del conocimiento, porque desde el inicio de este ejercicio de análisis se ha fomentado la potencia que tienen los métodos heurísticos en los procesos de creación; por tanto, estas nuevas formas de representación que provienen de la práctica artística, en la obra presentada se sitúan en las maneras alternativas de comprender la relación entre ciudad, corporalidad y visualidad, a través de la acción performática que se presenta en la figura 7 y, adicionalmente, busca que las formas de circulación y visibilización del conocimiento artístico se desarrollen en escenarios abiertos, colectivos y no necesariamente institucionalizados, donde la ecología de saberes fundamente estos cruces epistémicos.

\section{Figura 7}

Experiencia de moda Bronx distrito creativo
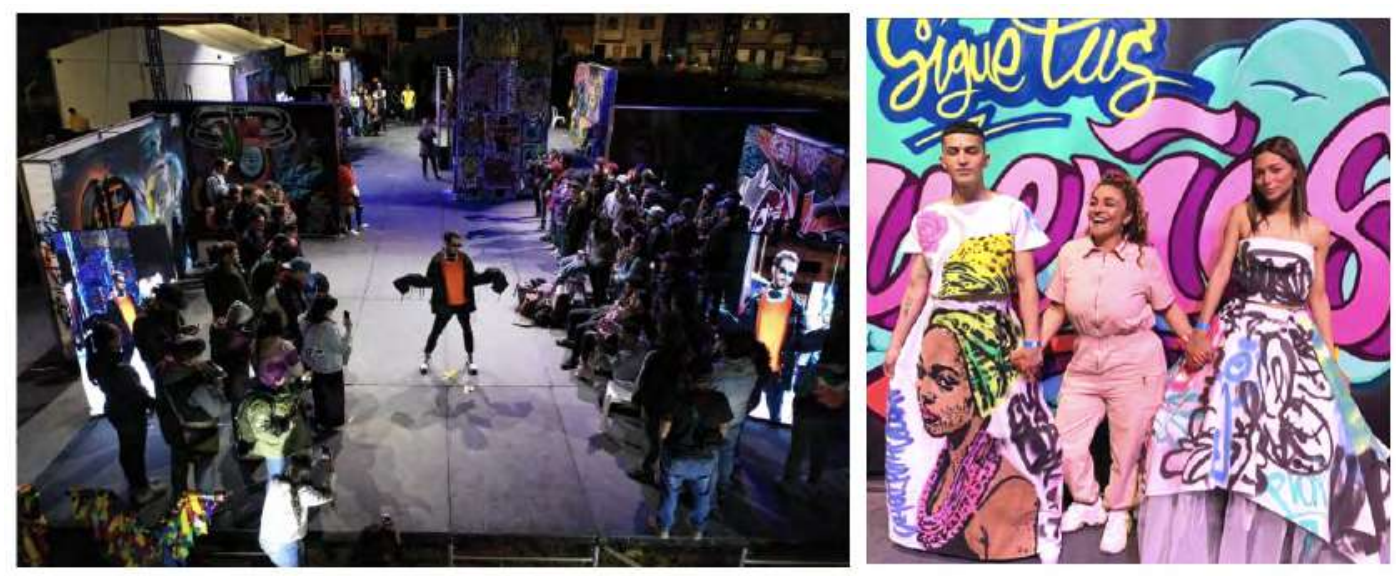

Nota: Mosaico Cierre experiencia Bronx. Fuente: Archivo personal, (2019)

"El traje: una construcción de la mano del grafiti" (López Galeano $\mathcal{E}$ Escobar, 2019) es, en coherencia, una de las tantas décimas que desde la creación constituyen procesos de construcción diversa, que se establecen 
desde la investigación que, en este caso, al igual que en la referencia que con tanta maestría narra Drexler (2017):

... Pero este patrón rítmico característico viene desde África. Ya en el siglo IX se lo encuentra en los burdeles de Persia, en el XIII, en España, desde donde cinco siglos después cruzan a América con los esclavos africanos. Mientras en los Balcanes se junta con una escala gitana y da en parte, origen al klezmer, que los inmigrantes judíos ucranianos llevan a Brooklyn, Nueva York.

Lo cantan en su salón de fiestas. Y su vecino, un niño argentino de origen italiano llamado Astor Piazzolla, lo escucha, lo incorpora y transforma el tango de la segunda mitad del siglo XX con su... Un dos tres, un dos tres, un dos.

Tocado además en su bandoneón, un instrumento alemán del siglo XIX creado para las iglesias que no se podían permitir comprar un órgano y que increíblemente termina en el Río de la Plata constituyendo la esencia misma del tango y de la milonga, al igual que otro instrumento igual de importante que el bandoneón: la guitarra española. (Min 8:14 a 9:25)

La interconexión de las ideas de otros es lo que permite generar nuevo conocimiento; esta acción poética, basada en el poder que tiene el descubrimiento para los seres humanos, fundamenta, en gran medida, el reconocimiento que, desde la corporalidad, la visualidad, la oralidad y otras formas de representación estructuran un programa de Diseño de Modas que no solo le apunta a la ropa, sino que despliega sus acciones de pensamiento hacia la configuración de una cultura investigativa. Lo dicho, con el horizonte puesto en la recuperación de los valores artísticos que, históricamente, el diseño se debe a sí mismo como disciplina y que aportan a la construcción de nuevas formas de desarrollo cultural y de procesos de sostenibilidad para que desde la producción artística resignifiquen espacios, contextos y comprensiones sobre el valor del vestido, sus conexiones históricas, políticas y socioculturales; todo ello, al ritmo de décimas que armonicen y definan avances significativos sobre los entornos reflexivos que se deben generar en el campo disciplinar del diseño de modas. 


\section{Referencias bibliográficas}

Aguiló Bonet, A. J. (2011). Boaventura de Sousa Santos, Descolonizar el saber, reinventar el poder. Utopía y Praxis Latinoamericana, 16(54), 145-147.

Baudrillard, J. (1981). Requiem for the Media. For a Critique of the Political Economy of the Sign, 164-184.

Bonilla, H. et al. (2018). Apuntes sobre el debate académico en Colombia en el proceso de reconocimiento gubernamental de la creación como práctica de generación de nuevo conocimiento, desarrollo tecnológico e innovación. Cuadernos de Música, Artes Visuales y Artes Escénicas, 13(1), 281-294.

Borgdorff, H. (2010). El debate sobre la investigación en las artes. Cairon: revista deficiencias de la danza, 13, 25-46.

Buchanan, R. (1990). Problemas perversos en el Pensamiento del Diseño. In Colloque Recherche sur le Design: Incitations, Implications, Interactions. Compiégne, Francia.

Busch, K. (2009). Artistic research and the poetics of knowledge. Art 8 Research: A Journal of Ideas, Contexts and Methods, 2(2), 1-7.

Careri, F. et al. (2002). Walkscapes: el andar como práctica estética. Barcelona: Editorial Gustavo Gili.

Colciencias, G. D. C. (2018). Modelo de Medición de Grupos de Investigación, Desarrollo Tecnológico o de Innovación y de Reconocimiento de Investigadores del Sistema Nacional de Ciencia, Tecnología e Innovación, Año 2018. Bogotá: Departamento Administrativo de Ciencia, Tecnología e Innovación, Colciencias. Dirección de Fomento a La Investigación. https://minciencias.gov.co/sites/defauLt/files/uplıad/convocatoria/4. Anexo, 1.

Craik, Jennifer. (2003). The face of fashion: Cultural studies in fashion. The Face of Fashion: Cultural Studies in Fashion

Cross, N. (2018). Developing design as a discipline. Journal of Engineering Design, 29(12), 691-708.

Drexler, J. (Abril de 2017). Poetry, music and identity [Video file]. Recuperado de https:// www.ted.com/talks/jorge_drexler_poetry_music_and_identity/transcript

Frayling, C. (1993). Research in Art and Design, Royal College of Art Research Papers 1.1. S. 1-5

Hammer, J., $\mathcal{Z}$ Lee, J. (2011). Gamification in Education: What, How, Why Bother. Academic Exchange Quarterly, 15(2).

Hansen, S., $\mathcal{E}$ Danny, F. (2015). 'This is not a Banksy!': Street art as aesthetic protest. Continuum, 29(6), 898-912.

Klein, J. (2010). What is artistic research. Journal for Artistic Research. Retrieved from https:// www. jar-online. net/what-artistic-research.

Krippendorff, K. (2016). Design, an undisciplinable profession.

LEE, J. E HAMMER, J. (2011). Gamification in education: What, how, why bother?, Academic Exchange Quarterly, 15(2), (2011), 146-1151.

López Galeano, A., Y Escobar, M. (2019). El traje: una construcción de la mano del grafiti. Bogotá: Bronx Distrito Creativo / Casa Museo Gaitán. 
Mandolini, R. (2013). Heurística y Arte: una contribución para la comprensión de los procesos artísticos creativos. Revista de Humanidades de Valparaíso, (1), 63-92.

Reguillo, R. (2004). Los estudios culturales. El mapa incómodo de un relato inconcluso. Aula Abierta. Lecciones Básicas. Barcelona: Instituto de la Comunicación, Universidad Autónoma de Barcelona www.portalcomunicacion.com/download/16.pdf.

Sen, A. (1998). La cultura como base del desarrollo contemporáneo. Diálogos Unesco. Documentos y encuentros Internacionales sobre Cultura y Desarrollo.

Zuidervaart, L. (1990). The social significance of autonomous art: Adorno and Bürger. Journal of Aesthetics and Art Criticism, 61-77. 


\title{
Industria 4.0 para la competitividad en el sector textil, confección, diseño y moda de Medellín: aplicación del escaneo 3D para estudios antropométricos
}

\author{
Juan Fernando Arenas Betancur ${ }^{1}$ \\ Iván Darío Rojas Arenas ${ }^{2}$ \\ Jairo Alonso Palacio Morales ${ }^{3}$ \\ Elizabeth Jiménez Medina ${ }^{4}$ \\ César Augusto Rodríguez Ledesma ${ }^{5}$ \\ Jim Giraldo-Builes ${ }^{6}$
}

\begin{abstract}
1 Magister en Educación Universidad de San Buenaventura, diseñador industrial Universidad Pontificia Bolivariana. Docente Institución Universitaria Pascual Bravo, Facultad de Producción y Diseño. j.arenasbe@pascualbravo.edu.co

2 Ingeniero Industrial Universidad Nacional Sede Medellín, especialista en Logística Integral ITM, Especialista en Gerencia Educativa UCM, Magíster en Gestión de la Innovación Tecnológica, Cooperación y Desarrollo Regional, ITM. Docente Institución Universitaria Pascual Bravo, Facultad de Producción y Diseño. ivan.rojasar@pascualbravo.edu.co

3 Magíster Automatización y Control Instituto Tecnológico Metropolitano (ITM), Ingeniero en Instrumentación y Control Politécnico Colombiano Jaime Isaza Cadavid. Docente ITM Departamento de Calidad - Producción. jairopalacio@itm.edu.co

4 Magíster en Gestión Tecnológica Universidad Pontificia Bolivariana, especialista en Formulación y Evaluación de Proyectos Instituto Tecnológico Metropolitano, ingeniera administradora Universidad Nacional de Colombia. Docente Institución Universitaria Pascual Bravo, Facultad de Producción y Diseño.e.jimenezme@pascualbravo.edu.co.

5 Tecnólogo en Instrumentación Industrial IU Politécnico Jaime Isaza Cadavid, ingeniero de sistemas Universidad de San Buenaventura Sede Medellín, especialista en Informática y Telemática Fundación Universitaria del Área Andina, magíster en Automatización de Procesos Industriales Instituto Tecnológico Metropolitano (ITM). Docente ITM Departamento de Calidad - Producción. cesarrodriguez@itm.edu.co 6 Administrador en Salud - Gestión Sanitaria y Ambiental Universidad de Antioquia, especialista en Gerencia de la Salud Ocupacional Universidad CES y magíster en Gestión de Ciencia, Tecnología e Innovación Universidad de Antioquia. Docente Institución Universitaria Pascual Bravo, Facultad de Producción y Diseño. jim.giraldo@pascualbravo.edu.co
\end{abstract}


El mundo está pasando por un momento importante. El acelerado ritmo de cambio tecnológico impone nuevas formas de entender los sistemas productivos; las estrategias de negocios de las organizaciones deben adaptarse a las exigencias de un mercado interconectado con una competencia global, en un entorno económico complejo y cambiante. En este contexto surge el concepto de Industria 4.0 como una manera de explicar la creciente utilización de distintas herramientas tecnológicas digitales y de interconectividad en distintas industrias, constituyendo sistemas ciber físicos en donde interactúan personas, máquinas e información (Cho, May y Kiritsis, 2019), lo cual ha generado un cambio de paradigma en la manera de pensar los procesos productivos y los entornos laborales, particularmente, el sector TCDM que representa un renglón económico importante a nivel mundial y local (Statista, 2018), susceptible del impacto de la incorporación de nuevas tecnologías en los procesos (Hasanbeigi y Price, 2015). En este sentido, es pertinente la aplicación de tecnologías -como el escaneo 3D para estudios antropométricos- que permitan generar un valor agregado al sector, a partir de su implementación a lo largo de la cadena productiva (Xia, Guo, Li y Istook, 2018). Lo dicho, significa entender cómo el trabajo colaborativo entre distintos agentes económicos y sociales, como son las universidades y las empresas, consienten el desarrollo de propuestas creativas e innovadoras a problemáticas reales que, a su vez, redundan en mayores beneficios para las empresas y la sociedad en general.

En este estudio se muestran resultados acordes con la ejecución del escaneo 3D en estudios antropométricos. Para tal efecto, se procedió a elaborar un estado del arte tomando como categorías de análisis los conceptos de competitividad, Industria 4.0, competitividad en el sector TCDM y perspectivas del mismo, así como la medida del cuerpo y sus métodos de medición. La metodología empleada se dividió en tres etapas: identificar tecnologías 4.0, realizar el diagnóstico de aplicación de tecnologías en el sector, desarrollar la prueba piloto y el establecimiento de principios orientadores que permitan mejorar la competitividad. Así mismo, se presentan los resultados concernientes a la revisión de literatura en torno a los conceptos mencionados y sobre la aplicación actual de algunas herramientas tecnológicas. También se presentan conclusiones y discusiones en torno a la temática de estudio, 
haciendo énfasis en la importancia del uso de tecnologías, como la propuesta en el sector TCDM para aumentar su competitividad, y el reto que entraña para este poder adaptarse al contexto cambiante actual.

\section{Marco conceptual}

\section{La competitividad}

La competitividad se asocia generalmente con la capacidad que tienen las empresas o los países de tener éxito en un mercado específico, en el cual se transan bienes y servicios con los que se generan ventajas respecto a los demás, lo cual deriva en menores costos, mayor calidad y aumento de los ingresos. Está determinada por el tipo de estrategia implementada, la cual puede ser de tres tipos: de costos, de diferenciación, y de enfoque (Calle y Tamayo, 2005). En este sentido, Porter (1990) establece una serie de elementos que se relacionan y permiten a las organizaciones ser competitivas, a través de su diamante de la competitividad.

El concepto de competitividad goza de muchas definiciones, y no existe un consenso por cuanto son disímiles los enfoques desde los cuales se aborda. Uno de ellos es la relación costo/participación de mercado, el cual la considera como el costo unitario de una ubicación. El enfoque en la productividad, por su parte, la considera como el nivel de productividad de una ubicación, lo que permite mantener el nivel de vida de las personas. Mirada desde el enfoque de productividad, comprende tres dimensiones: la microeconómica que incluye la sofisticación de las empresas, los clústeres que agrupan industrias relacionadas y la calidad del ambiente de las empresas; lo macroeconómico, dimensión en la cual se ubican las instituciones políticas, la infraestructura social y las políticas macroeconómicas; en los soportes, están los recursos naturales, la localización geográfica y el tamaño de la economía (Ketels, 2016).

A lo anterior se agrega el hecho de que existen nuevos enfoques que definen la competitividad como la capacidad de un país para cumplir los objetivos para sus ciudadanos, más allá del producto interno bruto (PIB). De esta manera, se amplían las concepciones iniciales y se añade valor al incluir elementos como los sistemas sociales y ambientales (Aiginger, BärenthalerSieber y Vogel, 2013). Por otro lado, Carmona y Gil (2008) expresan la 
importancia de la vocación económica de una región para ser competitiva, en la medida en que se puedan aprovechar ventajas comparativas, convirtiéndolas, a partir de procesos de innovación y generación de valor agregado, en ventajas competitivas, y enfocando la producción de bienes y servicios hacia las necesidades de mercados, tanto nacionales como internacionales.

\section{Industria 4.0}

La constante búsqueda del fortalecimiento del sector productivo y la revolución tecnológica han impactado la industria al punto de fomentar una reconversión de los sistemas productivos, las relaciones laborales y los modelos de negocio. Es así como Navarro y Sabalza (2016) definen la Industria 4.0 como una referencia a la cuarta revolución industrial, en la cual la digitalización e interconexión de la actividad productiva en sistemas ciberfísicos transforma el modo como las empresas agregan valor a sus productos y servicios. Para los autores, lo anterior conlleva al mejoramiento de procesos, la reducción de costos, el mejoramiento de calidad de bienes y servicios, el incremento de la flexibilidad y una mayor agregación de valor.

López y Escudero (2016) hablan de internet industrial, conectividad, big data, sistemas ciber-fisicos, inteligencia artificial, cloud computing, ciberseguridad, realidad aumentada y realidad virtual, robótica colaborativa y fabricación aditiva como los diez pilares fundamentales de la Industria 4.0 y ven la misma como un universo de posibilidades para la transformación de las organizaciones, lo cual conlleva a otras concepciones de los modelos de negocio, fundamentados en nuevas formas de relacionarse con los clientes y proveedores, un uso masivo de datos, la creación de valor a partir de redes, la flexibilidad, la necesidad de nuevos talentos e intraemprendimiento.

Ynzunza et al. (2017) hacen referencia al surgimiento, en Alemania, del concepto de Industria 4.0 como una política estatal para el uso intensivo de la tecnología, la personalización de los sistemas productivos, la prestación de servicios y el desarrollo de negocios con alto valor agregado, con alta interacción entre personas y sistemas tecnológicos. Visto así, la innovación en productos y procesos posibilitará la creación de fábricas inteligentes y de nuevas formas de colaboración, a partir de la digitalización de la producción, 
la automatización y el desarrollo de sistemas ciberfísicos. Los autores argumentan que la Industria 4.0, como disrupción industrial, hará que las empresas cambien sus formas de producir y relacionarse con el mercado, si quieren ser competitivas. Pedroni y Pérez (2019) entienden que las nuevas formas de producción que se están gestando a partir de la cuarta revolución industrial, tienen un capítulo importante en el uso, cada vez más intensivo, de las redes sociales como formas de comunicación masiva, lo cual suscita nuevos discursos en torno a las tendencias de consumo. De su lado, Castresana (2016) presenta objetivos, retos y desafíos enfocados en las necesidades del cliente, la sostenibilidad, la colaboración y la seguridad; todo ello, con la mediación de un marco de acción institucional, facilitará la implementación de fábricas inteligentes por medio de unas tecnologías habilitadoras a la Industria 4.0.

Frente a las tecnologías existentes para la medición del cuerpo humano, Xia et al. (2018) presentan un comparativo de tres diferentes tecnologías: cinta métrica, escáner 3D comercial estacionario, y escáner de mano. Entre los resultados se encuentra que el escáner estacionario tiene un mejor desempeño, frente al escáner de mano. Frente a la cinta métrica el escáner de mano presentó un mejor desempeño en la validez de los datos tomados, al realizar una mayor cantidad de medidas; sin embargo, la cinta métrica presenta mayor confiabilidad.

Entre las diferentes tecnologías disponibles para el escaneo 3D se encuentran el sistema de línea de láser, cuya principal ventaja es el cálculo de precisión de la deformación de una línea 2D proyectada en una superficie 3D. El sistema de luz estructurado tiene como principal ventaja la velocidad; es Sistema de cámara de múltiples vistas presenta el uso de la óptica, lo que hace que frente a las tecnologías anteriores no se genere interferencia con la luz solar; sin embargo, los sistemas anteriores presentan mayor precisión. Finalmente, se tiene el sistema de ondas milimétricas, cuya ventaja es poder atravesar la ropa, pero no la piel; sin embargo, ello supone dilemas éticos al invadir la privacidad corporal de los sujetos de prueba (Daanen y Ter Haar 2013; Braganca et al., 2015).

Otra tecnología disponible es el kinect (Shotton et al., 2013) cuya desventaja es su baja precisión (Bragança et al., 2014). Por su parte, Zeraatkar y Khalili (2020) presentan un comparativo de diferentes tecnologías disponibles 
para el escaneo corporal frente a un dispositivo propio equipado con cien cámaras. Este escáner es presentado como único y con un costo de desarrollo de \$USD6000; comparado con otras tecnologías disponibles comercialmente, supone un bajo costo. La principal ventaja de este dispositivo es la velocidad en la captura de las imágenes (0.001 s).

Frente a la aplicación de escaneo corporal 3D, en relación con las tecnologías de la Industria 4.0, autores como Grazioso et al. (2019) desarrollaron un dispositivo de reconstrucción del cuerpo, a partir del uso de la fotogrametría, para aplicaciones relacionadas con el sector salud. En este sentido, entre otras, las ventajas del dispositivo son: la adquisición instantánea de la medidas y formas del cuerpo, precisión similar a los sistemas láser, sin errores por balanceo del cuerpo; adicionalmente, se resalta que es un sistema no invasivo, lo cual genera mayor comodidad y satisfacción en los pacientes tratados al no necesitar marcadores para la captura de imágenes. El uso y desarrollo de este dispositivo es posible a través del uso de tecnología de fabricación aditiva con impresoras 3D y técnicas de fabricación sustractiva por medio del uso de la robótica las cuales son parte de la industria 4.0. Lorenz et. al, (2015)

Otro ejemplo del uso de las tecnologías de la industria 4.0 es la tecnología de Hernández $\mathcal{E}$ Lemaire (2016), quienes a través del uso de celulares inteligentes desarrollaron un método de fotogrametría y servicio de software en la nube para digitalizar encajes prostéticos, por cuanto presentan como dificultad el escaneo en su interior. Si bien el resultado de este desarrollo es menos preciso que otras tecnologías, este método se plantea como accesible al presentar suficiente precisión para esta aplicación y su bajo costo.

\section{Marco contextual}

\section{Competitividad en el sector TCDM}

El sector TCDM en Colombia, particularmente en la ciudad de Medellín, viene pasando por una crisis que, según Restrepo (2015), se debe a la pérdida de mercados - como el venezolano- al incremento de las importaciones de productos de bajo costo provenientes de países como China y Vietnam, y a la poca innovación en las empresas del sector; lo anterior se ve reflejado en las cifras negativas presentadas por distintos subsectores, con una disminución 
del $2.3 \%$ en la parte de hilatura, tejeduría y acabado, y de un 5.9\% en confección de prendas, con variaciones de $-15.3 \%$ y-19,1\%, respectivamente (Superintendencia de Sociedades, 2017).

Para Minian et al. (2017), la alta participación de algunas economías emergentes en las exportaciones mundiales se debe a una relocalización de la actividad productiva del sector, dadas las ventajas comparativas derivadas de un costo de mano de obra más bajo; además, sostienen que, aunque se han hecho avances en temas tecnológicos, aún no se puede competir con el trabajo barato de estos países; explican por qué aún la tasa de adopción tecnológica no es muy alta en los mismos.

Teniendo en cuenta la necesidad de mejorar la competitividad del país, tanto en el mediano como en el largo plazo, se han planteado diversas estrategias, como promover el desarrollo de sectores claves para la economía, con una visión al año 2032; dentro de dichos sectores TCDM (Zuluaga et al., 2011). En este sector se hace necesaria la integración de los distintos eslabones de la cadena productiva, a través de un mecanismo como el clúster, de manera que se puedan aprovechar las ventajas comparativas y fomentar economías de escala.

El modelo clúster puede aportar para la creación de valor agregado, a través del mejoramiento de procesos, el establecimiento de nuevos esquemas de comercialización y distribución, y el incremento de las capacidades tecnológicas y de innovación de las empresas. Aspectos como el autoabastecimiento, el aumento en inversión en I $\mathcal{G}$ D, el apoyo a productores locales, la comercialización de marcas propias, el mejoramiento en procesos logísticos y la apertura de nuevos mercados son vitales al momento de pensar en un clúster TCDM con competitividad global (Carmona y Gil, 2008).

Marulanda y Montoya (2015) opinan al respecto que la innovación tecnológica es fundamental para las empresas textileras y de confección, la cual debe sumarse a la generación de nuevas estrategias de comercialización y distribución, al tiempo que debe ajustarse a las necesidades cambiantes de un mercado dinámico. Para Fábregas (2013) es vital que las empresas del sector tengan modelos de negociación para la gestión comercial de los negocios internacionales, aprovechando las oportunidades que se presentan en mercados externos. 
Por su parte, Barajas y Oliveros (2014) manifiestan el notable rezago del sector TCDM en el país, debido, entre otros factores, a la producción de algodón subsidiada en otros países, al contrabando, a la entrada al país de prendas de vestir a muy bajos costos, y las condiciones desiguales de los TLC, sumado a las problemáticas fronterizas, lo cual ha afectado los ingresos de los productores nacionales. Esto obliga a una reorientación de la cadena de suministros y a pensar en nuevos modelos de producción, basados en las tendencias actuales, como la ecoinnovación (Barsoumian et al.; citados por Baraja y Oliveros, 2014), la llamada «moda rápida» o «fast fashion» (Barnes $\mathcal{E}$ Lea Greenwood; citados por Baraja y Oliveros, 2014), los «textiles inteligentes» y la «textrónica» (Muñoz et al., 2016) y la «moda lenta» (Gardetti y Torres, 2011).

El estudio Cierre de brechas de Innovación y Tecnología, realizado por Innpulsa y la ANDI (2017), muestra la evolución y tendencias del sector a nivel mundial, tomando en cuenta aspectos como las materias primas, los procesos, la eficiencia, el modelo de negocio, la sostenibilidad, el mercado y el consumidor. El estudio pone de manifiesto la importancia del sector a nivel mundial, dado su crecimiento entre los años 2000 a 2015, con más de cien billones de unidades de prendas vendidas (Ellen MacArthur Foundation 2017), impulsado por el uso de nuevas tecnologías y la producción de nuevas tendencias de consumo y nuevos modelos de negocio.

De esta forma, los sistemas productivos se deben ajustar a los requerimientos del mercado mundial y local, tales como el fast fashion (Trujillo, 2015), en el cual se producen prendas más económicas, de forma rápida y con menor calidad, lo cual conlleva a una menor duración, mayor rotación de las colecciones y el acceso a un mercado enorme constituido principalmente por consumidores de clase media. El impacto de las nuevas tecnologías en el sector se evidencia en tres frentes - nuevos modelos de negocio, digitalización de productos y sostenibilidad y circularidad-y a través del desarrollo de cuatro estrategias de innovación -eficiencia de recursos y economía circular; materiales inteligentes de alto rendimiento, manufactura digital avanzada, y cadenas de valor - y modelos de negocio; soluciones de alto valor agregado para mercados en crecimiento (Innpulsa y ANDI, 2017).

Dichas estrategias de innovación se fundamentan, a su vez, en los pilares de la Industria 4.0. El Internet de las cosas (IoT) ofrece múltiples posibilidades 
de crecimiento a partir del uso de la red para producir y analizar información; el big data y la inteligencia artificial permiten la obtención de datos del mercado para la toma de decisiones, el pronóstico de ventas y tendencias y, en general, toda aquella información que se considere útil de un mercado. La realidad virtual y la realidad aumentada plantean la necesidad de inserción en nuevos mercados, en donde las estrategias de mercadeo han cambiado y cada vez más los consumidores recurren a aplicaciones y simuladores para espacios de intercambio comercial.

Desde la biotecnología y la nanotecnología se están desarrollando fibras con nuevas propiedades, amigables con el planeta, las cuales irán reemplazando gradualmente las fibras tradicionales; adicionalmente, a través de la manufactura 3D se plantea el reto de imprimir prendas de vestir a la medida, las cuales pueden ser diseñadas de forma remota; aquí, el escaneo 3D es de mucha utilidad. Por último, la eficiencia energética se ha convertido en un factor determinante para la industria, en razón a la escasez de recursos y el alto impacto ambiental que tiene el sector TCDM en el mundo (Innpulsa y ANDI, 2017).

Las nuevas tendencias, marcadas por el acelerado avance tecnológico, presuponen retos interesantes para el sector TCDM; de manera que, si se busca ser competitivo en el mercado actual, la industria debe migrar hacia el uso estratégico de las nuevas tecnologías de la información y las comunicaciones e, igualmente, entender que la llegada de la Industria 4.0 es un hecho innegable. En este sentido, algunas tendencias actuales en las que se tendrá que poner especial cuidado son (Innpulsa y ANDI, 2017):

- Textiles inteligentes.

- Plataformas IoT para el análisis de datos en tiempo real.

- Implementación del big data y técnicas de análisis avanzadas.

- Uso de la robótica en el proceso de fabricación de ropa.

- Fábricas inteligentes.

- Mercadeo virtual.

- Mejoramiento de experiencia de compra: realidad virtual y realidad aumentada. 
- Uso de aplicaciones para el proceso de compra y la trazabilidad del producto.

- Nuevos materiales, amigables con el medio ambiente y que mejoran la eficiencia energética.

- Escaneo e impresión 3D.

- Reducción de la cadena de suministro.

- Desarrollo de fibras con nanotecnología para usos médicos.

- Uso de enzimas para reemplazar ácidos y agentes oxidantes en la extracción de fibras naturales, el blanqueamiento de textiles y desarrollo de colorantes.

\section{La medida y unidades de medición}

Desde la antigüedad el hombre necesitó la medición tanto para la construcción arquitectónica como de toda clase de objetos. Los egipcios, en el año 3000 a. C. realizaron mediciones para la construcción de pirámides; es comprensible que desde entonces el hombre haya tomado partes de su cuerpo como instrumentos de medición, como la braza obtenida con los dos brazos extendidos, la pulgada con el ancho del dedo pulgar, el codo correspondiente a la longitud del antebrazo o, el pie, entre otros. Así mismo, se desarrollaron instrumentos como el pie de rey a partir del pie del faraón, o la escuadra. Sin embargo, debido a intereses comerciales, diferentes pueblos adoptaron distintas unidades de medida, hasta que surgió la necesidad de establecer un sistema internacional, creado por The International Bureau of Weights and Measures (BIPM) en París 1875.

Surge así la metrología como la ciencia encargada de todo aquello relacionado con las mediciones y sus instrumentos, lo que permite determinar que dicha ciencia es transversal a muchas disciplinas, influenciando directamente campos como la investigación, la producción industrial y el comercio (Llamosa y Villarreal, 2011; Gutiérrez et al., 2008).

El progreso de nuestras sociedades está fuertemente relacionado con la metrología, debido a que en los comienzos de la civilización se hizo necesario el intercambio y pago de productos, que involucraban inicialmente magnitudes e instrumentos de pesos y medidas, razón por la cual el sector comercial se presenta como pionero e impulsor de la metrología. Buscando en 
todo momento un mejoramiento continuo a través de la calidad del producto o servicio ha permitido la generación de elementos para la productividad y la competitividad, aplicados a los diversos sectores económicos.

La estandarización de unidades y medidas condujo a la estandarización de procesos y a la especialización de campos de la medición como la antropometría, que surge como parte de la antropología física. Varea y Cardoso (2014) afirman que la antropología fundamenta su rigor metodológico sobre la práctica empírica de la medición y cuantificación de su objeto de investigación; para esto se desarrollaron técnicas biométricas como la antropometría y la craneometría. Antropometría proviene del griego anthropos que significa hombre, metron que significa medida, e ía que significa cualidad; actualmente se entiende como el tratado de las proporciones y medidas del cuerpo humano (Bustamante, 2008). Los teóricos han establecido que el concepto técnico pertinente para el estudio de las dimensiones corporales es el percentil. El Anthropometric Source Book, editado por la NASA define el percentil de la siguiente manera:

Para cualquier serie de datos -por ejemplo, los pesos de un grupo de pilotos- el primer percentil es un valor que, por un lado, es mayor que los pesos del $1 \%$ de los pilotos menos pesados y, por otro, menor que el $99 \%$ de los de mayor peso. Según esto, el segundo percentil es mayor que el $2 \%$ menos pesado y menor que el $99 \%$ de mayor peso Para cualquier valor de $\mathrm{K}$-desde 1 a 99- el percentil K será un valor mayor que el menor K\% de los pesos y menor que el más elevado (100K) \%. El percentil $50^{\circ}$, localizado en los promedios, es el valor que se obtiene de dividir un conjunto de datos en dos grupos que contengan el $50 \%$ de estos valores mayores y menores. (NASA, 1978, p.9-14)

Es decir, el primer percentil en estatura o altura, por ejemplo, indica que el $99 \%$ de la población estudiada superaría esta dimensión. De igual manera, un percentil con magnitud del $95 \%$ en estatura diría que solo el $5 \%$ de la población en observación la sobrepasaría, mientras que el $95 \%$ restante tendría alturas iguales o menores. Es importante señalar que los percentiles se refieren de manera exclusiva a una dimensión corporal, sea la estatura o altura en posición sedente. Dicha noción solo aplica a una medida en 
particular, de modo que un sujeto puede tener un percentil $50^{\circ}$ de estatura y un percentil $40^{\circ}$ de altura de rodillas. Panero y Zelnik (1997) es decir, no existe una persona en un percentil determinado; solo podría decirse que una persona puede tener, por ejemplo, percentil $50^{\circ}$ de altura.

La metrología, por su parte, es la ciencia de la medición y abarca todos los aspectos teóricos y prácticos de las mediciones en sus diferentes aplicaciones y niveles de exactitud ISO/IEC (2006). La ISO clasifica los métodos de medición según su origen (ISO/IEC 17025): métodos normalizados, métodos internos, desarrollados por el laboratorio y métodos no normalizados.

Para el caso analizado en este proyecto, se asume que los métodos de medición antropométricos pueden ser directos e indirectos (Alonso, 2006). El método directo se basa en la obtención de las dimensiones antropométricas de la persona a partir de los puntos antropométricos, haciendo uso de equipos e instrumentos. Con el paso de los años el desarrollo de las tecnologías ha permitido la creación de sistemas de captación de las dimensiones antropométricas, sin necesidad de entrar en contacto con el sujeto a medir a partir de un método indirecto, (Alonso, 2006). El método de medición directa consiste en la toma de medidas de manera manual directa sobre el cuerpo del sujeto de estudio, a través de instrumentos como el calibrador, la cinta métrica, el antropómetro, entre otros. Valga indicar que se van registrando los datos obtenidos uno a uno.

Tanto el BIPM, la ISO, la NASA y, en general, las empresas y gobiernos apoyan a la denominada Infraestructura de Calidad (IC), que se constituye en un sistema integrado de organizaciones públicas y privadas que parte del aseguramiento de mediciones confiables hasta llegar a la certificación de bienes y servicios por parte de organizaciones competentes para este fin, con base en normas adoptadas (normalización), y como resultado de dicho proceso. En un momento dado se da la trazabilidad, que es la propiedad de un resultado de medida por la cual el resultado puede relacionarse con una referencia mediante una cadena ininterrumpida y documentada de calibraciones, cada una de las cuales contribuye a la incertidumbre de medida ISO/IEC GUIDE 99 (2006).

Paralelo a estos conceptos surge también la ergonomía, que la International Ergonomics Association define como el conjunto de conocimientos científicos 
aplicados para que el trabajo, los sistemas, los productos y ambientes se adapten a las capacidades y limitaciones físicas y mentales de la persona. La ergonomía se define, además, como una disciplina que busca adaptar el medio habitable al habitante (Bustamante, 2008), punto donde llega a participar activamente el diseño industrial definido por la Industrial Designers Society of America (IDSA), como el servicio profesional para la creación de productos y sistemas que optimizan la función, el valor y la apariencia para el beneficio mutuo del usuario y el fabricante. El diseño se preocupa por los productos, servicios y sistemas concebidos con las herramientas, organizaciones y la lógica introducida por la industrialización.

\section{Métodos de medición fotográficos}

La fotometría o método de medición fotográfica por escalado disminuye sustancialmente el tiempo que debe permanecer el sujeto de estudio en la toma de las fotografías; además, no se requiere contacto por parte del antropometrista con el sujeto de medición. Con este sistema el sujeto solo debe ubicarse frente a un sinfín, al lado de una regla métrica que servirá de escala en posteriores mediciones; seguidamente, se toman las fotografías frontal y lateral teniendo en cuenta que la cámara debe estar ubicada a mitad de la altura para evitar distorsiones. Este proceso toma segundos de duración, requiere condiciones de luz apropiadas y una cámara; posteriormente, con las imágenes $2 \mathrm{D}$ se procede a calcular las dimensiones comparando con la escala que deberá aparecer en la fotografía de manera clara y alineada.

El método de medición por fotografía moiré o estereofotogrametría raster o bioestereometría es más utilizado en medicina y arquitectura. Se trata de una técnica muy compleja y costosa que requiere mayor tecnología aumentando los costos, igual que con el método de medición por láser o el método de medición por ultrasonido.

Un instrumento con aplicación relativamente nuevo en antropometría es el escáner tridimensional. Los escáneres 3D generan una nube tridimensional de puntos de la parte exterior del cuerpo humano que puede ser usada para diseño de ropa, diseño automotriz, ingeniería y aplicaciones médicas ISO 20685 (2015). En concordancia con este nuevo sistema, la ISO 20685 intenta asegurar la comparabilidad de las medidas del cuerpo según lo especificado 
por la ISO 7250-1, tomando medidas con la ayuda de un escáner corporal $3 \mathrm{D}$, en lugar de los instrumentos antropométricos tradicionales - como las cintas métricas y los calibradores-. Conforme con esta norma internacional se intenta que cualquier dato obtenido con el escáner sea adecuado para incluirse en bases de datos internacionales, como los que se describen en la ISO 15535 (2012).

\section{Solución a la problemática}

\section{Metodología}

En la primera etapa del estudio se realizó una revisión, por medio de fuentes secundarias, sobre las tecnologías de la Industria 4.0 con aplicación en el sector a estudiar, y a nivel mundial, y que tengan alto potencial para aumentar la competitividad en la ciudad. En la segunda etapa se realizó un diagnóstico para identificar las acciones relacionadas en la ciudad de Medellín, con el objetivo de conocer el estado actual del sector con respecto a la aplicación de las tecnologías de la industria aludida.

En la tercera etapa se realizó una prueba piloto con una de las tecnologías disponibles para el sector, como es el escaneo 3D. Se realizaron pruebas doble ciego para el levantamiento de información, las cuales consistieron en la obtención de un determinado número de dimensiones antropométricas por parte de dos grupos diferentes, uno de ellos con el método de medición directa con cinta métrica y calibrador; el otro por medio de captura con escáner 3D; luego se compararon ambos resultados para establecer si las medidas obtenidas con el escáner se mantenían o no dentro de las tolerancias establecidas por la norma ISO 20685. En caso de que las medidas coincidieran, se dio por sentado que con ellas se podría elaborar la respectiva prenda. Por último, se realizó un análisis de todos los hallazgos encontrados para proponer principios orientadores que ayudaran a la competitividad del sector.

\section{Prueba piloto}

En la etapa 3 para la prueba piloto doble ciego, a partir de la norma ISO 20685, se tomaron los datos obtenidos dentro del proyecto Diseño de un sistema de medición antropométrica con dispositivo semiautomático de captura de 
modelos corporales digitales con escáner 3D. Si bien la norma establece que todo equipo utilizado en un estudio antropométrico con escáner 3D debe pasar por una prueba de calibración. Para efectos de este estudio, la misma prueba se adaptó como procedimiento para determinar la posibilidad de producción de una prenda de vestir a partir de las mediciones obtenidas con un escáner 3D de bajo costo.

El siguiente es el desglose de las actividades comprendidas en la etapa 3. Para la realización de la prueba de Medición directa" es necesario invocar la norma NTC-ISO 10012 (2003), Sistemas de Gestión de la medición. Requisitos para los procesos de medición y los equipos de medición, la cual determina la ruta y da garantía al realizar cualquier proceso de medición, particularmente en la figura 1, en el numeral 7, confirmación metrológica y realización de los procesos de medición:

\section{Figura 1}

Actividades prueba medición directa

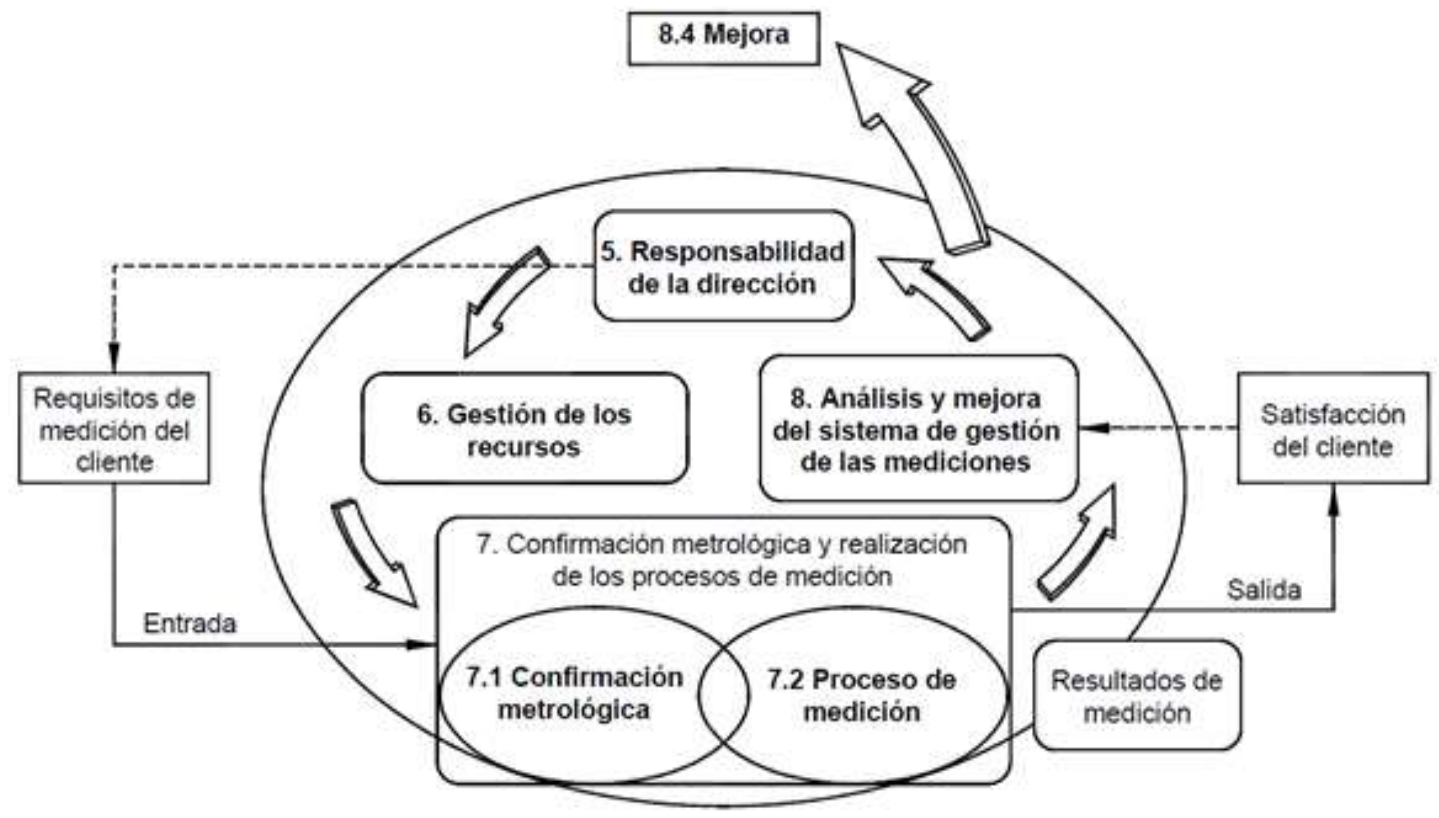

Nota: Sistema de gestión de la medición. Fuente: Tomado de la NTC-ISO 10012 (2003). 
La fase 7.1, confirmación metrológica, consiste en la calibración y verificación de los equipos de medición. Para el proceso de medición en la magnitud longitud se utilizaron dos instrumentos calibrados con trazabilidad (tienen certificado de calibración vigente realizado por un laboratorio acreditado por la Organización Nacional de Acreditación [ONAC]), los cuales garantizan que la incertidumbre en la medición esté dentro de los límites permisibles para los instrumentos utilizados (pie de rey análogo y cinta antropométrica).

El pie de rey utilizado debe tener características especiales, es decir, un rango de medición mínimo de $750 \mathrm{~mm}$, para que pueda medir diferentes personas o un gabarit ${ }^{7}$; por lo tanto, su exactitud permite conservar la tolerancia que necesita el proceso de medición, aunque sean medidas grandes. La cinta utilizada debe tener una función especial para hacer mediciones antropométricas, es decir, que viabiliza de manera directa realizar mediciones al torso de un cuerpo humano, o gabarit, con exactitud, cumpliendo con la tolerancia y la forma anatómica del proceso de medición.

La fase 7.2, Proceso de medición, con los instrumentos anteriormente descritos, consiste en medir las distancias establecidas por los marcadores esféricos en los puntos anatómicos de medición en el gabarit.

Otro factor importante a tener en cuenta, según la NTC-ISO 10012 (2003) es verificar que las personas que hacen las mediciones sean personas idóneas, esto es, que hayan realizado la pasantía en la magnitud longitud, la cual enseña los fundamentos teóricos y prácticos que se deben tener en cuenta al manipular instrumentos de longitud. En conclusión, al haber seguido lo establecido en la NTC-ISO 10012, en el proceso de medición con los instrumentos, se garantiza que las mediciones son trazables; quiere decir que en todo momento se puede saber la incertidumbre en la medición realizada.

Para la realización de la prueba de medición antropométrica con escáner 3D, se tomó como base la norma ISO 20685, 3D scanning methodologies for internationally compatible anthropometric databases. La prueba se llevó a cabo con un gabarit que consiste en un torso de cuerpo humano con unas dimensiones obtenidas en estudios antropométricos previos, de donde resultan las tallas promedio de una población determinada. Para ello se utilizó un objeto

Traducción: modelo. 
con forma y tamaño similar al de un ser humano adulto, cuya superficie se encuentra abullonada por lo que toma la apariencia de piel. Se sometió a evaluación un Scanner SENSE en versión 1, de la marca 3DSYSTEMS con una resolución de $0,9 \mathrm{~mm}$; luego, con instrumentos análogos, el grupo 1 , siguiendo el método de medición directa, se tomaron tres dimensiones: un perímetro de cintura, una distancia entre dos puntos, una sección de arco (sección perímetro cintura); para cada medición individual se realizaron tres repeticiones, de donde se obtuvieron las estadísticas que arrojaron la diferencia mínima, máxima y media.

\section{Figura 2}

Medición captura software 3D

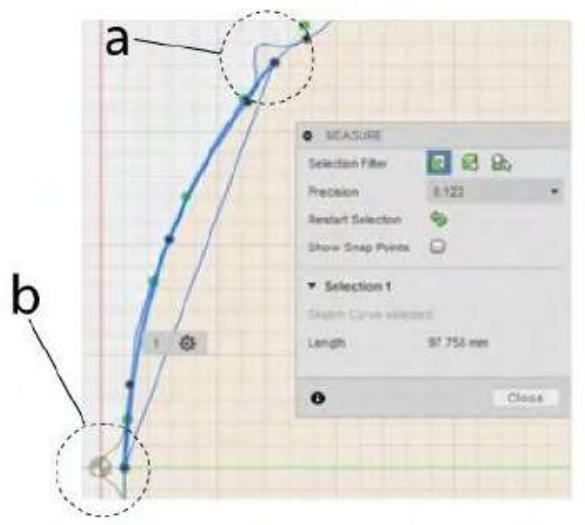

Nota: Visualización de la medición en el software del escáner 3D. Fuente: Elaboración propia.

Para facilitar la extracción de medidas (figura 2), teniendo en cuenta el método para la reducción del error en la captura de modelos corporales con escáner 3D (ISO 20685 anexo A), se fijaron como elementos de referencia, marcadores esféricos en los puntos anatómicos de medición (puntos: a y b). Posteriormente, el grupo 2, siguiendo el método de medición indirecta realizó tres capturas con escáner 3D y extrajeron digitalmente el mismo tipo y cantidad de medidas obtenidas con los instrumentos análogos; se procedió, entonces, a cruzar los resultados (ver ejemplo en tabla 1). Cabe aclarar que los grupos 1 y 2 realizaron las mediciones en momentos diferentes, a modo de prueba doble ciego. 


\section{Figura 3}

Marcadores puntos anatómicos de medición

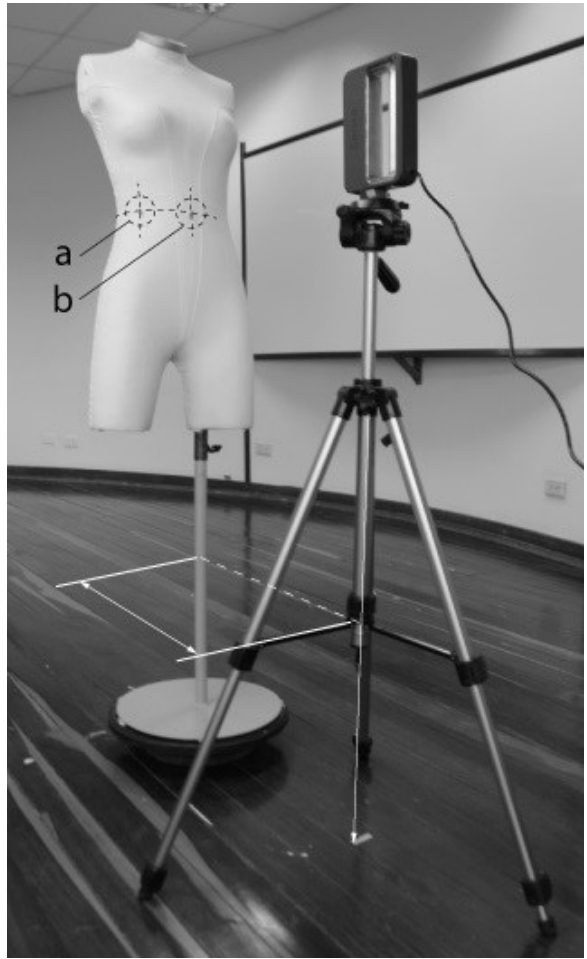

Nota: Marcación puntos anatómicos para que los reconozca el escáner 3D. Fuente: Elaboración propia.

Para la verificación de los resultados se consideraron las tolerancias permitidas por la norma (ISO 20685, tabla 4$)^{8}$ que para el ejemplo de la tabla 1 corresponde al $1 \%$ del valor de la dimensión obtenida por medición manual, puesto que está siendo tomado con instrumentos convencionales, como lo es el calibrador o pie de rey; según la norma, será el valor de referencia. $\mathrm{Su}$ incertidumbre en la medición se obtuvo a partir de sus respectivos certificados vigentes. Según los datos obtenidos, se consiguió un error de cero del Scanner 3D con respecto al pie de rey y a la cinta antropométrica; al ser conocido se corrigió.

8 Máximo permitido entre el valor extraído y el valor de la medición tradicional, tabla 4, ISO 206885. 


\section{Tabla 1}

Error de cero

\begin{tabular}{cc}
\hline Distancia entre el escáner y el gabarit & Error de cero-mm \\
\hline $500 \mathrm{~mm}$ & +3 \\
$1000 \mathrm{~mm}$ & $-0,5$ \\
$1500 \mathrm{~mm}$ & +5 \\
\hline
\end{tabular}

Nota: Error de cero del escáner 3D dependiendo de la distancia a medir. Fuente: Elaboración propia

\section{Tabla 2}

Distancia entre dos puntos

\begin{tabular}{ccccc}
\hline $\begin{array}{c}\text { Distancia entre el escáner } \\
\text { 3D y el gabarit }\end{array}$ & T1-mm & T2-mm & T3-mm & Ref (pie de rey) mm \\
\hline $500 \mathrm{~mm}$ & 93,09 & 93,47 & 92,82 & 93,1 \\
$1000 \mathrm{~mm}$ & 93,35 & 93,25 & 93,66 & 93,05 \\
$1500 \mathrm{~mm}$ & 93,94 & 92,74 & 93,43 & 93,05 \\
\hline
\end{tabular}

Nota: Medición de la distancia entre dos puntos con el escáner 3D vs pie de rey. Fuente: Elaboración propia

A partir de la tabla 2, es posible realizar el siguiente análisis:

- Para una distancia entre el escáner 3D y el gabarit de $500 \mathrm{~mm}$ :

- Error en la medición de $\mathrm{T} 1=93,09 \mathrm{~mm}-93,1 \mathrm{~mm}=0,01 \mathrm{~mm}$

- $\quad$ Error en la medición de T2 $=93,47 \mathrm{~mm}-93,1 \mathrm{~mm}=0,37 \mathrm{~mm}$

- Error en la medición de T3=92,82 mm - 93,1 mm =0,28 mm

- Máximo error en la medición: 0,37 mm

- Máximo permitido norma: $93,1 \times 1 \%=0,931 \mathrm{~mm}$

- $\quad 0,37 \mathrm{~mm}>0,931 \mathrm{~mm}$ (menor que el máximo permitido por la norma, cumple).

- Para una distancia entre el escáner 3D y el gabarit de $1000 \mathrm{~mm}$ :

- $\quad$ Error en la medición de T1 $=93,35 \mathrm{~mm}-93,05 \mathrm{~mm}=-0,3 \mathrm{~mm}$

- Error en la medición de T2 $=93,25 \mathrm{~mm}-93,05 \mathrm{~mm}=-0,2 \mathrm{~mm}$

- Error en la medición de T3=93,66 mm - 93,05 mm $=-0,61 \mathrm{~mm}$

- Máximo error en la medición: - 0,61 mm 
- Máximo permitido norma: $93,05 \times 1 \%=0,9305 \mathrm{~mm}$

- $\quad 0,61 \mathrm{~mm}>0,93 \mathrm{~mm}$ (menor que el máximo permitido por la norma, cumple).

- Para una distancia entre el escáner 3D y el gabarit de $1500 \mathrm{~mm}$ :

- $\quad$ Error en la medición de T1 = 93,94 mm-93,05 mm =0,89 mm

- $\quad$ Error en la medición de T2 $=92,74 \mathrm{~mm}-93,05 \mathrm{~mm}=0,31 \mathrm{~mm}$

- $\quad$ Error en la medición de T3=93,43 mm - 93,05 mm =0,38 mm

- Máximo error en la medición: 0,89 mm

- Máximo permitido norma: 93,05 x 1\% $=0,9305 \mathrm{~mm}$

- $\quad 0,89 \mathrm{~mm}<0,9305 \mathrm{~mm}$ (menor que el máximo permitido por la norma, cumple)

La incertidumbre expandida en la medición de este proceso con un

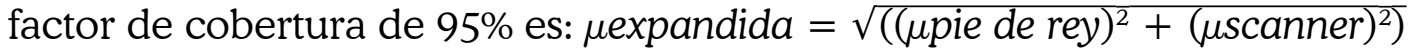
uexpandida $=\sqrt{\left((0,2 \mathrm{~mm})^{2}+(1,0 \mathrm{~mm})^{2}\right)}$

$\mu$ expandida $= \pm 1 \mathrm{~mm}$ Cuando se mide con el Pie de rey y el Escáner 3D $\mu$ expandida $= \pm 1,1 \mathrm{~mm}$ Cuando se mide con la Cinta antropométrica y el Escáner 3D

\section{Resultados}

\section{Aplicación actual de las tecnologías del sector en Medellín}

En general, el sector tiene claro que los textiles serán inteligentes a través del uso de componentes activos de nanotecnología. Las prendas de vestir no solo leerán o percibirán el ambiente, sino que reaccionarán ante diferentes estímulos generando cambio en su estructura, transformando su resistencia, densidad, color y demás propiedades físicas de las telas. En las fibras de los tejidos de las prendas de vestir se incorporará un tipo de tecnología que permitirá absorber, cargar, almacenar y crear zona de capacitancia entre los hilos de los tejidos; lo que posibilitará recargar dispositivos portátiles - como celulares, manillas inteligentes, dispositivos usables, entre otros- (Ren et al., 2014; citados por Innpulsa, 2017). Por ejemplo, en Fabricato tienen acabados 
especiales en textiles, aplicando nanotecnología para tener prendas anti manchas (Ruta N, 2015).

En general, en Medellín se identificaron cuatro oportunidades para el sector: generación de un centro de excelencia en textiles inteligentes que permita articular, de manera efectiva, la investigación científica, el desarrollo tecnológico y la innovación en el sector; desarrollo de modelos de negocio a partir de la funcionalización de textiles implementando productos biotecnológicos y la nanotecnología; diseño y desarrollo de sistemas producto/ servicio a partir de la aplicación de textiles inteligentes; diseño y desarrollo de productos a partir de la aplicación de textiles inteligentes para nichos de mercado de alto crecimiento. Realizando una exploración con expertos de Inexmoda sobre la aplicación de tecnologías de la Industria 4.0 en el sector textil, diseño, confección y moda, se concluyó que, aunque en Medellín se están aplicando algunas tecnologías, aún falta mayor difusión de las mismas (Inexmoda, 2018).

Actualmente, desde el diseño del producto se aplican varias tecnologías de la Industria 4.0, como el patronaje 3D. Esta tecnología busca eliminar el desarrollo de los prototipos, ya que normalmente una empresa necesita un prototipo por cada referencia, lo que tiene una implicación en el costo. Por el contrario, lo que se hace con el prototipado 3D es montar las medidas y tipos de telas, luego, por medio de un visualizador 3D se observan los errores que puede tener la prenda; además, se lee la caída y cómo se mueve. En Medellín existen algunas empresas que lo están implementando.

De la mano de la impresión 3D, en el mundo se ha desarrollado la tecnología de escaneo 3D con láser. Esta tecnología, normalmente acompañada de software de diseño 3D, presenta una enorme ventaja a la hora de capturar modelos corporales digitales, que superan los métodos tradicionales de medición manual con instrumentos análogos. Un caso importante lo presenta el SENA con un escáner que ligado a un software de diseño de patronaje que permite capturar una exploración de alta precisión y en 17 segundos en procesar todos los datos que incluyen todas las medidas y dimensiones necesarias para la producción de una prenda personalizada o para alimentar bases de datos antropométricas (Inexmoda, 2016). En el área de diseño se está utilizando inteligencia artificial, por medio del análisis 
de las referencias más vendidas en los puntos de venta. Estos datos se llevan a algoritmos que ayudan a analizar las tendencias de consumo, para luego definir si se repone o no en tienda esa referencia. Esta información también ayuda a entender mejor el consumidor, cuáles son los gustos actuales y los colores de temporada.

Otro mecanismo que se está utilizando en Medellín es el corte láser digital. Esta tecnología tiene una extendedora digital, la cual escanea la tela con sus respectivas capas y empieza a cortar de una manera precisa. Es un proceso totalmente robotizado, pero aún no se ha llegado hasta el proceso de ensamble. En Medellín varias empresas están usando esta tecnología, en especial las más grandes. De igual forma, las empresas en el mundo están implementando la tecnología del blockchain para analizar la trazabilidad y sostenibilidad de las prendas, buscando conocer el tipo de acabado, los químicos que tiene, sus componentes, si tiene algodón orgánico, entre otras características que dan valor agregado a la prenda.

La impresión 3D a nivel de manufactura se está utilizando en Medellín, sobre todo para reemplazar partes de máquinas. Muchas veces las máquinas se dañan y los repuestos son costosos, por lo que estos repuestos se imprimen; empresas de marroquinería y calzado también usan impresoras 3D para crear partes ya sea para accesorios, suelas de zapatos e incluso piezas para las prendas.

Con respecto a la economía circular, Inexmoda trajo un nano-filtro que utiliza nanotecnología. Este filtro ayuda a la recirculación de agua. Esto permite a las empresas tener mayor control del uso de este recurso. Igualmente, los materiales inteligentes con tecnología nano usan aditivos especiales para las telas. Por el lado de la realidad aumentada, aunque se está trabajando en Medellín, su aplicación es muy pobre. En países como Corea y Estados Unidos se usa esta tecnología para ayudar a tener una mejor experiencia a sus clientes. Otra tecnología interesante es la robotización de toda la cadena, como lo hacen marcas como Nike y Adidas, pero como la manufactura es de detalle, todavía no se aceptan estos métodos. 


\section{Conclusiones y análisis}

El sector textil, diseño y moda de Medellín es consciente de que la aplicación de tecnologías relacionadas con la Industria 4.0 le ayudará al aumento de la competitividad y la productividad del sector. Es por esto que ya varias empresas han aplicado algunas tecnologías; no obstante, lo anterior, falta mayor difusión y aplicación de las mismas.

Según los estudios analizados en el desarrollo del proyecto, se concluye que el sector tiene mucho potencial de activarse aún más usando tecnologías de la Industria 4.0, como lo es la impresión 3D, blockchain, IoT, inteligencia artificial, Big Data, realidad virtual, realidad aumentada, drones y automatización a través de robots.

La aplicación de dichas tecnologías ayudará a que el sector pueda usar mejor los recursos naturales, tener trazabilidad de todo el proceso, mejorar la atención al cliente actual, el cual es cada vez más exigente, tener modelos de negocio innovadores, aumentar su productividad debido a la automatización de procesos, entre otros. Para lograr lo anterior, se quiere estudiar y potencializar las oportunidades que ofrece la aplicación de estas tecnologías y aumentar la difusión de las mismas en Medellín.

El reto que tienen las empresas en Medellín es observar el producto desde la funcionalidad aplicando las tecnologías para facilitar la vida de las personas. Esta aplicación ayudará a que el sector sea más sostenible, rentable y eficiente; por ejemplo, los sistemas de escaneo e impresión 3D apuntan al diseño personalizado y a la generación de bases de datos antropométrica alimentadas permanentemente por los mismos usuarios a través de apps. El almacenamiento en la nube y la transmisión de datos a través de la red rompe barreras espaciales, temporales, de almacenamiento y de procesamiento de datos para los procesos industriales, permitiendo, incluso, la conformación de equipos de diseño internacionales.

En principio, el proceso de medición a través del método directo con instrumentos análogos parece ser más económico, mientras que los sistemas de escáner 3D tienen costos muy altos; no obstante, luego de las pruebas se concluye que ya existen en el mercado equipos láser 3D a costos accesibles que, aunque no poseen altas resoluciones, sí pueden ser utilizados en la 
industria de la confección, por cuanto llegan a tener márgenes de error aceptables para sus productos. Para el caso particular de este estudio se utilizó un escáner marca SENSE, cuyo costo aproximado es de US \$1300 y su margen de error en la medición, comparado con el instrumento análogo, resultó entre 1 y $2 \mathrm{~mm}$.

Es claro que Medellín es un hub de la Industria 4.0 en el país, por lo que existen grandes oportunidades para aquellos sectores que deseen trabajar en pro del desarrollo de las tecnologías que ofrece dicha industria. El sector textil, diseño y moda no puede ser la excepción, máxime cuando es uno de los sectores más relevantes en la industria antioqueña. Para que este sector pueda implementar de manera exitosa las tecnologías de la industria 4.0, debe ser apoyado de forma especial. Este apoyo debe ser liderado por el gobierno y demás instituciones que gestionan la innovación en la ciudad, pero, además las empresas medianas y pequeñas también deben dar un paso adelante para que sean referentes en la aplicación de las tecnologías. Para lograr esto, las grandes empresas también deben apoyar a las medianas y pequeñas.

En general, se deben romper muchos paradigmas que han sido creados en tantos años en la industria de la moda; adicionalmente, se deben formar personas con las competencias adecuadas para suplir las necesidades del sector. Esta formación va de la mano de las Instituciones de Educación Superior, las cuales deben flexibilizar su currículo para que los estudiantes puedan obtener esas competencias que ayudarán a implementar de forma exitosa las tecnologías de la Industria 4.0 en el sector textil, diseño y moda.

Con respecto a las tecnología de escaneo 3D, se encuentran disponibles en el mercado local hace más de 10 años, pero las asimilación ha sido lenta, se sabe por ejemplo de empresas que han adquirido software para el procesamiento 3D y no lo utilizan, sub utilizando su capacidad instalada, una razón puede ser la falta de capacitación en el uso de estas nuevas tecnologías, y el dominio en los sistemas tradicionales, otra puede ser que las instituciones educativas apenas están asimilando dichas tecnologías, y estas mismas aún se encuentran en la primera etapa de su curva de aprendizaje, por tal motivo se debe aguardar aún más tiempo para producir la transferencia. En el mismo sentido el Estado, a través de las instituciones públicas de educación, debe actualizar sus tecnologías para estar a la vanguardia del desarrollo, apoyando 
así los clústeres como el de diseño, confección y moda que son un sector importante de la economía local y nacional.

Finalmente de acuerdo con la prueba de medición realizada, al comparar las dimensiones obtenidas manualmente vs. las obtenidas con un escáner 3D de bajo costo con una resolución de $0,9 \mathrm{~mm}$, se pudo concluir que efectivamente este agiliza el proceso de medición, evitando contacto con el sujeto a medir, disminuyendo tiempos de captura, aumentando significativamente la cantidad de dimensiones obtenidas, y por ende disminuyendo los costos del proceso de medición; además al realizar la captura en los diferentes rangos de 500 $\mathrm{mm}, 1.000 \mathrm{~mm}$ y $1.500 \mathrm{~mm}$ se encontró que las dimensiones obtenidas con el escáner evaluado no superan el máximo error permitido entre el valor extraído y el valor de la medición tradicional, de allí que acorde a lo establecido por la norma ISO 20685 puede afirmarse que cualquier dato obtenido con dicho equipo, es adecuado para incluirse en bases de datos internacionales como los que se describen en la ISO 15535.

\section{Referencias bibliográficas}

Aiginger, K., Bärenthaler-Sieber, S., E Vogel, J. (2013). Competitiveness under new perspectives (No. 44). Working Paper. http://www.oecd.org/economy/Competitiveness-under-NewPerspectives.pdf

Alonso, A. (2006). Ergonomía, La Habana, Cuba. Editorial Félix Varela.

Barajas, L. y Oliveros, D. (2014). El clúster como modelo factible para el desarrollo del sector de confecciones-diseño de moda: un estudio en Bucaramanga (Colombia). Universidad E Empresa, 16(27), 267-288. DOI: https://doi.org/10.12804/rev.univ.empresa.27.2014.09

Braganca, S. et al. (2015). An overview of the current three-dimensional body scanners for anthropometric data collection. Occupational Safety and Hygiene III, 149-153. doi:10.1201/ b18042-32

Bragança, S. et al., (2014). A Validation Study of a Kinect Based Body Imaging (KBI) Device System Based on ISO 20685:2010, Proceedings of the fifth International Conference on 3D Body Scanning Technologies, Lugano, Switzerland. http://dx.doi.org/10.15221/14.372

Bustamante, A. (2008). Ergonomía para diseñadores. Fundación Mapfre, Instituto de Prevención, Salud y Medio Ambiente. Calle, A., Tamayo, V., (2005). Estrategia e internacionalización en las pymes: caso Antioquia. Cuadernos de Administración, 18(30), 137-164. http://www.scielo.org.co/scielo.php?script=sci_arttextËpid=S0120$35922005000200007 \mathcal{E} \operatorname{lng}=$ enĖtlng $=$ es. 
Carmona, R. y Gil, J. (2008). Competitividad y retos en la productividad del clúster textilconfección, diseño y moda en Antioquia. Revista Ciencias Estratégicas, 16(20), 247-263. https://www.redalyc.org/pdf/1513/151312829003.pdf

Castresana, C. (2016). Industria 4.0. Grado en Administración y Dirección de Empresas Universidad de La Rioja. https://biblioteca.unirioja.es/tfe_e/TFE002004.pdf

Cho, S., May, G., $\mathcal{J}$ Kiritsis, D. (2019, May). A semantic-driven approach for industry 4.0. In 2019 15th International Conference on Distributed Computing in Sensor Systems (DCOSS) (pp. 347-354). IEEE. https://doi.org/10.1109/DCOSS.2019.00076

Daanen, H. A. M., E Ter Haar, F. B. (2013). 3D whole body scanners revisited. Displays, 34(4), 270-275. doi: 10.1016/j.displa.2013.08.011

Ellen MacArthur Foundation. (2017). A new textiles economy: Redesigning fashion's future. http://www.ellenmacarthurfoundation.org/publications.

Fábregas, C. (2013). Identificación de factores no monetarios asociados a las pymes del sector confecciones que afectan su ingreso a mercados internacionales. Desarrollo Gerencial. Universidad Simón Bolívar. Revista Universidad Simón Bolívar, 5(2), 127-159. http://revistas. unisimon.edu.co/index.php/desarrollogerencial/article/view/492

Gardetti, M. Á. y Torres, A. L. (2011). Moda y diseño lentos. CINTEX, 16(9), https://revistas. pascualbravo.edu.co/index.php/cintex/article/view/76

Grazioso, S. et al. (2019, June). Using photogrammetric 3D body reconstruction for the design of patient-tailored assistive devices. In 2019 II Workshop on Metrology for Industry 4.0 and IoT (MetroInd4. 0EIOT) (pp. 240-242). IEEE. DOI: 10.1109/METROI4.2019.8792894

Hasanbeigi, A., E Price, L. (2015). A technical review of emerging technologies for energy and water efficiency and pollution reduction in the textile industry. Journal of Cleaner Production, 95, 30-44. DOI: 10.1016/j.jclepro.2015.02.079

Hernández, A. E Lemaire, E. (2016). A smartphone photogrammetry method for digitizing prosthetic socket interiors. Prosthetics and Orthotics International, 41(2), 210-214. DOI: 10.1177/0309364616664150

Inexmoda (2016) En Colombiatex, SENA lanza nuevo servicio tecnológico: Body Scanner 3D para estudios antropométricos. http://www.saladeprensainexmoda.com/sobreinexmoda/

Inexmoda (2018). Un 2018 para abrir los ojos. http:/www.saladeprensainexmoda.com/ sobre-inexmoda/

Innpulsa y ANDI (2017). Cierre de brechas de Innovación y Tecnología. http://www.andi.com. co/Uploads/Estudio\%20Cierre\%20de\%20Brechas\%20Innovacion\%20y\%20Tecnologiailovepdf-compressed.pdf

ISO/IEC GUIDE 99:2007. Guide 99 International vocabulary of metrology - Basic and general concepts and associated terms (VIM), 3a ed.

ISO 15535:2012. (Ratificada) Requisitos generales para el establecimiento de bases de datos antropométricos (3a ed.).

ISO 20685:2010, 3-D scanning methodologies for internationally compatible anthropometric databases. Second edition. 
ISO/IEC 17025:2017. General requirements for the competence of testing and calibration laboratories.

ISO 10012:2003. Sistemas de gestión de las mediciones - Requisitos para los procesos de medición y los equipos de medición.

Ketels, C. (2016). Review of competitiveness frameworks: An analysis conducted for the Irish National Competitiveness Council. https://www.hbs.edu/faculty/pages/item. aspx?num $=50988$

López, J., $\mathcal{E}$ Escudero, V. (2016). Industria 4.0, la gran oportunidad. Economía Aragonesa, número 59. Ibercaja Banco S.A. Zaragoza. https://dialnet.unirioja.es/servlet/ articulo?codigo $=5657067$

Lorenz, M., Rüßmann, M., Waldner, M., Engel, P., Harnisch, M., Gerbert, P. E Justus, J. (2015) Industry 4.0: The Future of Productivity and Growth in Manufacturing Industries. Boston Consulting Group. https://www.bcg.com/publications/2015/engineered_products_ project_business_industry_4_future_productivity_growth_manufacturing_industries

Llamosa R., L. E. y Villarreal C, M. F. (2011) La metrología como tema transversal en la formación en ciencias básicas. Scientia et technica, 1(47). DOI: https://doi. org/10.22517/23447214.503

Marulanda, N. y Montoya, I. (julio-diciembre, 2015). Modelo para gestionar el conocimiento en el sector textil de Medellín, empleando dinámica de sistemas. Semestre Económico, Revista Universidad de Medellín, 18((38) pp. 161-190. Universidad de Medellín. DOI: https:// doi.org/10.22395/seec.v18n38a6

Minian, I. et al. (2017). Cambio tecnológico y relocalización de la industria del vestido. Revista Problemas del Desarrollo, 188(48). PP 139-164. México. Universidad Nacional Autónoma de México. DOI: https://doi.org/10.1016/j.rpd.2017.01.007

Muñoz. L., Meza. L. y Torres, M. (2016). La capacidad de absorción y su impacto sobre la innovación: un análisis en el sector textil y confecciones. DOI: 10.13140/RG.2.1.1501.8480.

NASA. (1978). National Aeronautics and Space Administration, Anthropometric Source Book, 3 vols., Scientific and Technical Information Office, N.A.S.A. Reference Pub. 1024. https://ntrs.nasa.gov/citations/19790005541

Navarro, M., E Sabalza, X. (2016). Reflexiones sobre la Industria 4.0 desde el caso vasco. Ekonomiaz: Revista vasca de economía, (89), 142-173.

Panero, J. y Zelnik, M. (1997). Las dimensiones humanas en los espacios interiores. G.G. https:// dialnet.unirioja.es/servlet/libro?codigo $=305560$

Porter, M. E. (1990) La ventaja competitiva de las naciones. Buenos Aires: Vergara.

Pedroni, M. y Pérez, C. (2019). Investigación en moda: cambió, comunicación e industria. Revista Prisma Social, (24), pp. 1-9. http://isdfundacion.org/wp-content/uploads/2019/01/ N24_editorial.pdf

Restrepo M, J. A. (2015). Aplicación de un método multicriterio, basado en lógica difusa, para evaluar la capacidad exportadora de las Pymes: validación en el clúster del sector textil-confecciones de la ciudad de Medellín (Doctoral dissertation, Universidad CEU San Pablo). https://dialnet.unirioja.es/servlet/tesis?codigo=120359 
Ruta N. (2015). Avance de mercado textil, confección y moda. Observatorio Ct+i. https:// www.rutanmedellin.org/es/observatorio-todos/item/textiles-inteligentes

Statista, 2018. Global Apparel Market Size Projections from 2012 to 2025, by Region (In Billion U.S. Dollars). https://www.statista.com/statistics/279757/

Shotton, J. et al. (2013). Real-time human pose recognition in parts from single depth images. Communications of the ACM, 56(1), 116. doi:10.1145/2398356.2398381

Superintendencia de Sociedades. (2017). Desempeño del sector textil-confección informe. Recuperado de: http://incp.org.co/Site/publicaciones/info/archivos/Textiles.pdf

Trujillo, C. (2015). El sinsentido del 'fast fashion' en Colombia. Semana. http://sostenibilidad. semana.com/opinion/articulo/el-fastfashion-no-tiene-sentido-en-colombia/38738).

Ynzunza, C., Izar, J., Bocarando, J., Aguilar, F., $\mathcal{Z}$ Larios, M. (2017). El Entorno de la Industria 4.0: Implicaciones y Perspectivas Futuras. Conciencia Tecnológica No. 54. PP 33-45. https://www.redalyc.org/jatsRepo/944/94454631006/94454631006.pdf

Zuluaga, A. y otros (2011). La evaluación de proveedores en la gestión del abastecimiento en las empresas del sector textil, confección, diseño y moda en Colombia. Revista Politécnica, (13), 79-89. https://revistas.elpoli.edu.co/index.php/pol/article/view/196

Varea, C., y Cardoso, T. (2014). Antropología física: aportaciones fundamentales y proyecciones como ciencia interdisciplinar. Encuentros Multidisciplinares. 1-13. http:// hdl.handle.net/10486/678654

Xia, S. et al. (2018). Comparison of different body measurement techniques: 3D stationary scanner, 3D handheld scanner, and tape measurement. The Journal of The Textile Institute, 1-11. DOI: 10.1080/00405000.2018.1541437

Zeraatkar, M., E Khalili, K. (2020). A Fast and Low-Cost Human Body 3D Scanner Using 100 Cameras. Journal of Imaging, 6(4). DOI: 10.3390/jimaging6040021 
En Ecociudades: una experiencia urbana se considera la importancia de los aportes que se pueden realizar desde el diseño para el equilibrio de las urbes con la naturaleza, gracias a la calidad del diseño de espacios públicos que incorporan zonas verdes y elementos de patrimonio cultural para conseguir entornos Ilenos de diversidad. Una ecociudad es un lugar atractivo para vivir y trabajar, que maximiza el bienestar humano y el respeto por el entorno natural. Es aquella que minimiza el costo total del ciclo de vida de los productos y la demanda de transporte contaminante y que se caracteriza por estimular el uso de materia prima ecológica y responsable en la industria, por incentivar el consumo de productos y servicios amigables con el medio ambiente, y por brindar a la sociedad movilidad sostenible. Todo ello con el fin de contribuir e impactar la consecución de los Objetivos de Desarrollo Sostenible.

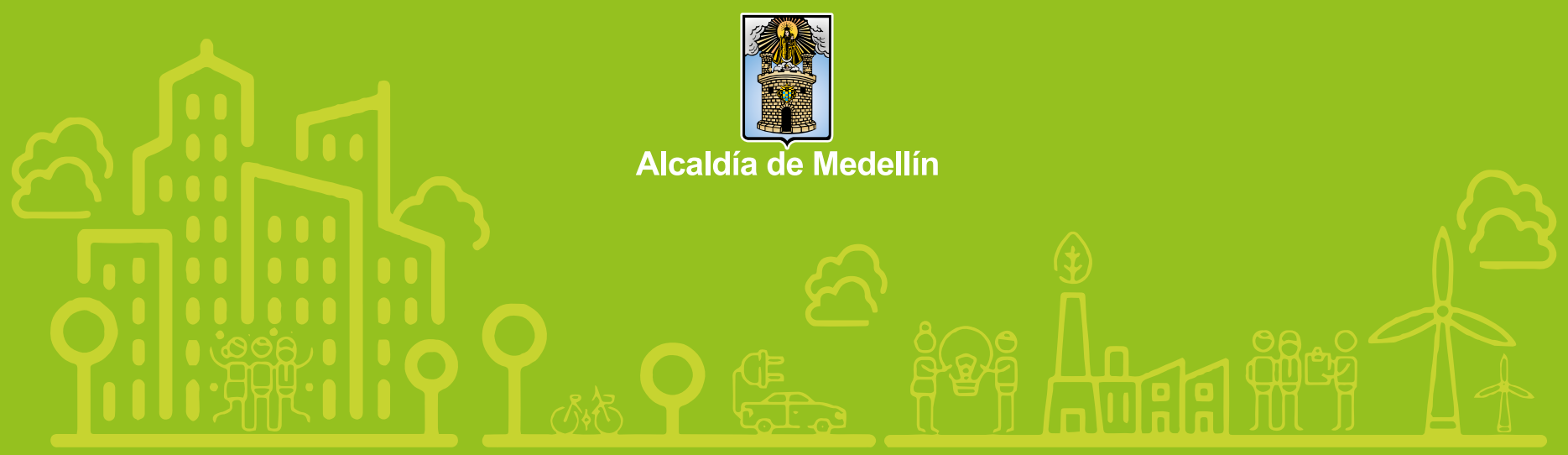

$\overline{\text { VIGILADA }}$ Mineducación

\section{Más información}

Teléfono: (+57 4) 4480520

Calle 73 \# 73a - 226 Robledo, Vía El Volador

Medellín - Colombia

$\oplus \odot \odot \odot$

www.pascualbravo.edu.co 